\title{
Transcranial magnetic stimulation (TMS) for schizophrenia (Review)
}

\author{
Dougall N, Maayan N, Soares-Weiser K, McDermott LM, McIntosh A
}

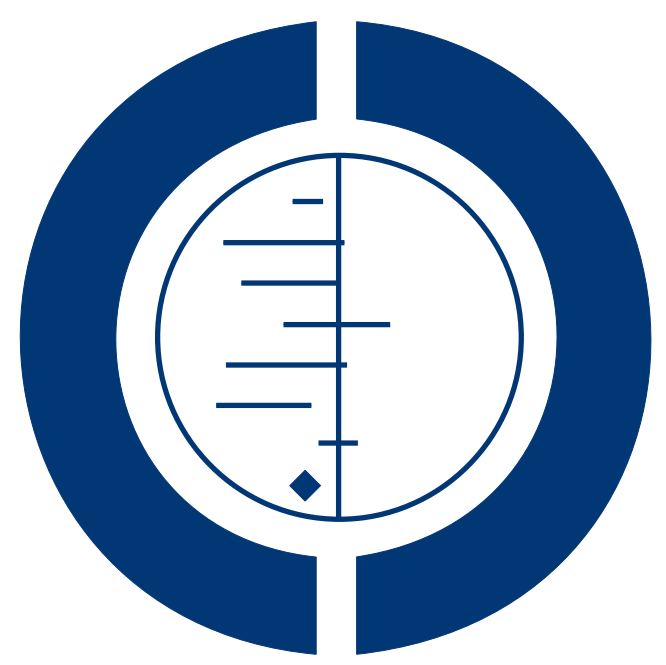

\section{THE COCHRANE COLLABORATION $^{\circledR}$}

This is a reprint of a Cochrane review, prepared and maintained by The Cochrane Collaboration and published in The Cochrane Library 2015, Issue 8

http://www.thecochranelibrary.com

\section{WILEY}

Transcranial magnetic stimulation (TMS) for schizophrenia (Review)

Copyright @ 2015 The Cochrane Collaboration. Published by John Wiley \& Sons, Ltd. 
TABLE OF CONTENTS

HEADER . . . . . . . . . . . . . . . . . . . . . . . . . . . . . . . . . . . . . . . . . . . . .

ABSTRACT . . . . . . . . . . . . . . . . . . . . . . . . . . . . . . . . . . . . . . . . . . . . . . 1

PLAIN LANGUAGE SUMMARY . . . . . . . . . . . . . . . . . . . . . . . . . . . . . . . . . . . . . . . . . . . . .

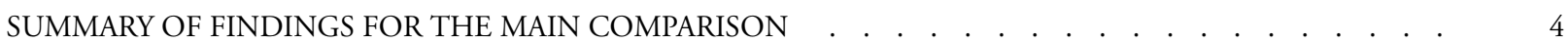

BACKGROUND . . . . . . . . . . . . . . . . . . . . . . . . . . . . . . . . . . . . . . . . . . . . . . .

OBJECTIVES . . . . . . . . . . . . . . . . . . . . . . . . . . . . . . . . . . . . . . . . . . . . . . . . .

METHODS . . . . . . . . . . . . . . . . . . . . . . . . . . . . . . . . . . . . . . . .

RESULTS . . . . . . . . . . . . . . . . . . . . . . . . . . . . . . . . . . . . . . . . . . . .

Figure 1. . . . . . . . . . . . . . . . . . . . . . . . . . . . . . . . . . . . . . 14

Figure 2. . . . . . . . . . . . . . . . . . . . . . . . . . . . . . . . . . . . . .

Figure 3. . . . . . . . . . . . . . . . . . . . . . . . . . . . . . . . . . . . . . 19

ADDITIONAL SUMMARY OF FINDINGS . . . . . . . . . . . . . . . . . . . . . . . . . . . . . . . . . .

DISCUSSION . . . . . . . . . . . . . . . . . . . . . . . . . . . . . . . . . . . . . . . . . . .

AUTHORS' CONCLUSIONS . . . . . . . . . . . . . . . . . . . . . . . . . . . . . . . . . . . . . . . .

ACKNOWLEDGEMENTS . . . . . . . . . . . . . . . . . . . . . . . . . . . . . . . . . . . . . . .

REFERENCES . . . . . . . . . . . . . . . . . . . . . . . . . . . . . . . . . . . . . . . . . . . .

CHARACTERISTICS OF STUDIES . . . . . . . . . . . . . . . . . . . . . . . . . . . . . . . . . . . . . . 46

DATA AND ANALYSES . . . . . . . . . . . . . . . . . . . . . . . . . . . . . . . . . . . . . . . . . . . . . 122

Analysis 1.1. Comparison 1 TEMPOROPARIETAL TMS vs SHAM TMS, Outcome 1 Global state: 1. Clinical

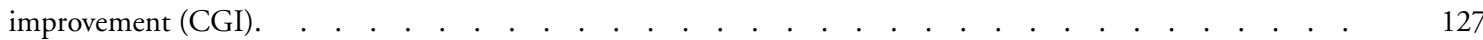

Analysis 1.2. Comparison 1 TEMPOROPARIETAL TMS vs SHAM TMS, Outcome 2 Global state: 2. Average score for clinical improvement $($ CGI, high = poor). $\quad . \quad$. . . . . . . . . . . . . . . . . . . . . . . . . . . . . . . . $\quad 128$

Analysis 1.3. Comparison 1 TEMPOROPARIETAL TMS vs SHAM TMS, Outcome 3 Mental state: 1. General: a. Clinical improvement $($ PANSS $>30 \%$ reduction). . . . . . . . . . . . . . . . . . . . . . . . . . . .

Analysis 1.4. Comparison 1 TEMPOROPARIETAL TMS vs SHAM TMS, Outcome 4 Mental state: 1. General: b. Average total score (various scales). . . . . . . . . . . . . . . . . . . . . . . . . . . . . 130

Analysis 1.5. Comparison 1 TEMPOROPARIETAL TMS vs SHAM TMS, Outcome 5 Mental state: 1. General: c. Average general psychopathology score (PANSS general, high = poor). . . . . . . . . . . . . . . . . . . . . . . . 131

Analysis 1.6. Comparison 1 TEMPOROPARIETAL TMS vs SHAM TMS, Outcome 6 Mental state: 2. Specific: a. Average depression score (various scales).

Analysis 1.7. Comparison 1 TEMPOROPARIETAL TMS vs SHAM TMS, Outcome 7 Mental state: 2. Specific: b.i. Hallucinations - clinical improvement (various scales). . . . . . . . . . . . . . . . . . . . . . . . . . . . .

Analysis 1.8. Comparison 1 TEMPOROPARIETAL TMS vs SHAM TMS, Outcome 8 Mental state: 2. Specific: b.ii. Average hallucinations score (various scales). $\quad . \quad$. . . . . . . . . . . . . . . . . . . . . . . . . . . . . . . . . $\quad . \quad 134$

Analysis 1.9. Comparison 1 TEMPOROPARIETAL TMS vs SHAM TMS, Outcome 9 Mental state: 2. Specific: c. Average negative symptom score (various scales). . . . . . . . . . . . . . . . . . . . . . . . . . . . . . . . 136

Analysis 1.10. Comparison 1 TEMPOROPARIETAL TMS vs SHAM TMS, Outcome 10 Mental state: 2. Specific: d.i. Positive symptoms - clinical improvement (PANSS $>30 \%$ reduction).

Analysis 1.11. Comparison 1 TEMPOROPARIETAL TMS vs SHAM TMS, Outcome 11 Mental state: 2. Specific: d.ii.

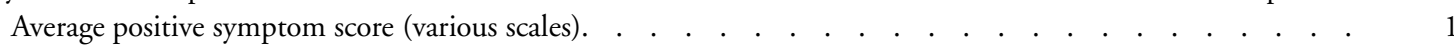

Analysis 1.12. Comparison 1 TEMPOROPARIETAL TMS vs SHAM TMS, Outcome 12 Adverse effects: 1 . General: a. Serious. . . . . . . . . . . . . . . . . . . . . . . . . . . . . . . . . . . . . . . . . . . . .

Analysis 1.13. Comparison 1 TEMPOROPARIETAL TMS vs SHAM TMS, Outcome 13 Adverse effects: 1. General: b. Leaving the study early. . . . . . . . . . . . . . . . . . . . . . . . . . . . . . . . $\quad$. 140

Analysis 1.14. Comparison 1 TEMPOROPARIETAL TMS vs SHAM TMS, Outcome 14 Adverse effects: 2. Specific. 141

Analysis 1.15. Comparison 1 TEMPOROPARIETAL TMS vs SHAM TMS, Outcome 15 Quality of life: Average score (Q-LES-Q, low = poor). . . . . . . . . . . . . . . . . . . . . . . . . . . . . . . . . . . . . . . . . . . . . .

Analysis 2.1. Comparison 2 TEMPOROPARIETAL TMS vs STANDARD TREATMENT, Outcome 1 Global state:

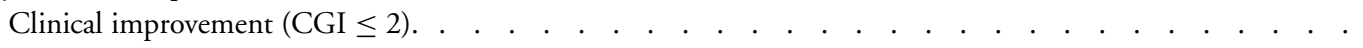

Analysis 2.2. Comparison 2 TEMPOROPARIETAL TMS vs STANDARD TREATMENT, Outcome 2 Adverse effects: Leaving the study early. 
Analysis 3.1. Comparison 3 PREFRONTAL TMS vs SHAM TMS, Outcome 1 Global state: Average score (various scales).

Analysis 3.2. Comparison 3 PREFRONTAL TMS vs SHAM TMS, Outcome 2 Mental state: 1. General: a. Clinical

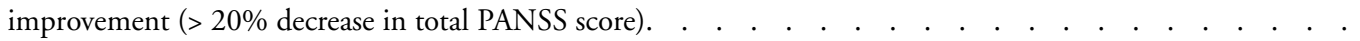

Analysis 3.3. Comparison 3 PREFRONTAL TMS vs SHAM TMS, Outcome 3 Mental state: 1. General: b. Average total score (various scales).

Analysis 3.4. Comparison 3 PREFRONTAL TMS vs SHAM TMS, Outcome 4 Mental state: 1. General: c. Average general psychopathology score $($ PANSS, high = poor) . . . . . . . . . . . . . . . . . . . . . . . . . . . . . . . . . .

Analysis 3.5. Comparison 3 PREFRONTAL TMS vs SHAM TMS, Outcome 5 Mental state: 2. Specific: a. Average depression score (various scales).

Analysis 3.6. Comparison 3 PREFRONTAL TMS vs SHAM TMS, Outcome 6 Mental state: 2. Specific: b. Average hallucinations score $($ PANSS, high = poor). . . . . . . . . . . . . . . . . . . . . . . . . .

Analysis 3.7. Comparison 3 PREFRONTAL TMS vs SHAM TMS, Outcome 7 Mental state: 2. Specific: c. i. Negative symptoms - clinical improvement $(>20 \%$ decrease in PANSS negative)..$\quad$. . . . . . . . . . . . . . . . . .

Analysis 3.8. Comparison 3 PREFRONTAL TMS vs SHAM TMS, Outcome 8 Mental state: 2. Specific: c. ii. Average negative symptom score (various scales).

Analysis 3.9. Comparison 3 PREFRONTAL TMS vs SHAM TMS, Outcome 9 Mental state: 2. Specific: d. Average positive symptom score (various scales).

Analysis 3.10. Comparison 3 PREFRONTAL TMS vs SHAM TMS, Outcome 10 Mental state: 2. Specific: e. Average psychotism score (SCL-90 PSY, high = poor).

Analysis 3.11. Comparison 3 PREFRONTAL TMS vs SHAM TMS, Outcome 11 Adverse effects: 1. General: a. Adverse events (UKU).

Analysis 3.12. Comparison 3 PREFRONTAL TMS vs SHAM TMS, Outcome 12 Adverse effects: 1. General: b. Leaving the study early.

Analysis 3.13. Comparison 3 PREFRONTAL TMS vs SHAM TMS, Outcome 13 Adverse effects: 2. Specific: a. Various.

Analysis 3.14. Comparison 3 PREFRONTAL TMS vs SHAM TMS, Outcome 14 Adverse effects: 2. Specific: b. Average score $(\mathrm{CSSES}$, high = poor). . . . . . . . . . . . . . . . . . . . . . . . . . . . . . . . . . . . . . . .

Analysis 4.1. Comparison 4 PREFRONTAL THETA BURST STIMULATION TMS vs SHAM TMS, Outcome 1 Global state: Clinical improvement. . . . . . . . . . . . . . . . . . . . . . . . . . . . . .

Analysis 4.2. Comparison 4 PREFRONTAL THETA BURST STIMULATION TMS vs SHAM TMS, Outcome 2 Mental state: 1. General: a. Average overall mental state score (PANSS total, high = poor).

Analysis 4.3. Comparison 4 PREFRONTAL THETA BURST STIMULATION TMS vs SHAM TMS, Outcome 3 Mental state: 1. General: b. Average general psychopathology score (PANSS, high = poor).

Analysis 4.4. Comparison 4 PREFRONTAL THETA BURST STIMULATION TMS vs SHAM TMS, Outcome 4 Mental state: 2. Specific: a. Average negative symptom score (various scales).

Analysis 4.5. Comparison 4 PREFRONTAL THETA BURST STIMULATION TMS vs SHAM TMS, Outcome 5 Mental state: 2. Specific: b. Average positive symptom score (PANSS, high = poor) . . . . . . . . . . . . . . .

Analysis 4.6. Comparison 4 PREFRONTAL THETA BURST STIMULATION TMS vs SHAM TMS, Outcome 6 Cognitive state: Average score (various measures).

Analysis 4.7. Comparison 4 PREFRONTAL THETA BURST STIMULATION TMS vs SHAM TMS, Outcome 7 Adverse effects: 1 . Leaving the study early. . . . . . . . . . . . . . . . . . . . . . . . . . . . . . . . . .

Analysis 4.8. Comparison 4 PREFRONTAL THETA BURST STIMULATION TMS vs SHAM TMS, Outcome 8 Adverse effects: 2 . Specific.

Analysis 5.1. Comparison 5 SENSITIVITY ANALYSIS: PREFRONTAL THETA BURST STIMULATION TMS vs SHAM TMS, Outcome 1 Global state: Clinical improvement. . . . . . . . . . . . . . . . . . 166 ADDITIONAL TABLES . . . . . . . . . . . . . . . . . . . . . . . . . . . . . . . . . . . 166 APPENDICES . . . . . . . . . . . . . . . . . . . . . . . . . . . . . . . . . . . . . . 174 CONTRIBUTIONS OF AUTHORS . . . . . . . . . . . . . . . . . . . . . . . . . . . . . . . . . . . . 176

DECLARATIONS OF INTEREST . . . . . . . . . . . . . . . . . . . . . . . . . . . . . . . . . . . . . . .

SOURCES OF SUPPORT . . . . . . . . . . . . . . . . . . . . . . . . . . . . . . . . . . . 176 DIFFERENCES BETWEEN PROTOCOL AND REVIEW . . . . . . . . . . . . . . . . . . . . . . . . . . . . . . 176

Transcranial magnetic stimulation (TMS) for schizophrenia (Review) 


\title{
[Intervention Review]
}

\section{Transcranial magnetic stimulation (TMS) for schizophrenia}

\author{
Nadine Dougall $^{1}$, Nicola Maayan ${ }^{2}$, Karla Soares-Weiser ${ }^{2}$, Lisa M McDermott ${ }^{3}$, Andrew McIntosh $^{4}$ \\ ${ }^{1}$ NMAHP Research Unit, University of Stirling, Stirling, UK. ${ }^{2}$ Enhance Reviews Ltd, Wantage, UK. ${ }^{3}$ Primary Care and Public Health \\ Sciences, King's College London, London, UK. ${ }^{4}$ University of Edinburgh, Royal Edinburgh Hospital, Edinburgh, UK \\ Contact address: Nadine Dougall, NMAHP Research Unit, University of Stirling, Unit 13 Scion House, Stirling University Innovation \\ Park, Stirling, FK9 4NF, UK. Nadine.dougall@stir.ac.uk.
}

Editorial group: Cochrane Schizophrenia Group.

Publication status and date: New, published in Issue 8, 2015.

Review content assessed as up-to-date: 15 April 2013.

Citation: Dougall N, Maayan N, Soares-Weiser K, McDermott LM, McIntosh A. Transcranial magnetic stimulation (TMS) for schizophrenia. Cochrane Database of Systematic Reviews 2015, Issue 8. Art. No.: CD006081. DOI: 10.1002/14651858.CD006081.pub2.

Copyright (C) 2015 The Cochrane Collaboration. Published by John Wiley \& Sons, Ltd.

\begin{abstract}
A B S T R A C T

\section{Background}

People with schizophrenia often experience symptoms which fail to fully respond to antipsychotic medication. Transcranial magnetic stimulation (TMS) has been proposed as a new treatment for people with schizophrenia, especially those who experience persistent auditory hallucinations.
\end{abstract}

\section{Objectives}

To estimate the effects of TMS alone, compared with sham TMS or with 'standard management' and any other comparison interventions in reducing psychotic symptoms associated with schizophrenia.

\section{Search methods}

We searched the Cochrane Schizophrenia Group Trials Register (June 2006, June 2008, April 2013). This register is compiled by methodical searches of MEDLINE, EMBASE, BIOSIS, CINAHL, Dissertation abstracts, LILACS, PSYNDEX, PsycINFO, RUSSMED, and Sociofile, and is supplemented with handsearching of relevant journals and numerous conference proceedings.

\section{Selection criteria}

We included all randomised controlled trials recruiting at least five participants and comparing TMS with sham TMS or any other treatment for people with schizophrenia.

\section{Data collection and analysis}

We extracted data independently. For dichotomous data we calculated relative risks (RRs) and their 95\% confidence intervals (CIs). For continuous data, we calculated mean differences (MD) and 95\% CI. We used a fixed-effect model. We assessed overall quality of the evidence using the GRADE approach.

\section{Main results}

We included 41 studies with 1473 participants in the review. We found significant differences in favour of temporoparietal TMS compared to sham TMS for global state measured on the CGI scale (7 RCTs, $\mathrm{n}=224$, MD $-0.5,95 \%$ CI -0.76 to -0.23 , very lowquality evidence) and positive symptoms measured on the PANSS scale (5 RCTs, $\mathrm{n}=127, \mathrm{MD}-6.09$, 95\% CI -10.95 to -1.22 , very low-quality evidence). Participants experienced significantly more headaches in the temporoparietal TMS group $(10 \mathrm{RCTs}, \mathrm{n}=392, \mathrm{RR}$

Transcranial magnetic stimulation (TMS) for schizophrenia (Review)

Copyright () 2015 The Cochrane Collaboration. Published by John Wiley \& Sons, Ltd. 
2.65, 95\% CI 1.56 to 4.50, very low-quality evidence). However, no more participants left the study early from the TMS group than from the sham group (very low-quality evidence). Cognitive state was assessed using 39 different measures, and all were equivocal (very low-quality evidence).

We included only two trials which compared temporoparietal TMS with standard treatment. In both trials the participants received first- and second-generation antipsychotic medication in both treatment groups, therefore TMS was used an adjunctive therapy to medication. We found no significant differences in the number of participants that showed clinical improvement in global state (1 RCT, $\mathrm{n}=100$, RR $1.19,95 \%$ CI 0.91 to 1.57 ) or left the study early (2 RCTs, $\mathrm{n}=140$, RR 0.33 , 95\% CI 0.08 to 1.46 ) (both very low-quality evidence). No studies reported on global state score, mental state, cognitive state and adverse effects.

For prefrontal TMS compared to sham TMS, global state was measured on three different scales, all of which presented equivocal results (very low quality evidence). We could not pool data for mental state on the PANSS scale due to high heterogeneity. Cognitive state was assessed using 19 different measures, with 15/19 being equivocal (very low-quality evidence). Prefrontal TMS caused more headaches (6 RCTs, $\mathrm{n}=164$, RR 2.77, $95 \%$ CI 1.22 to 6.26, very low-quality evidence) but there was no difference in the number of participants leaving the study early (very low-quality evidence). No studies reported data for clinical improvement.

We found a significant difference in favour of prefrontal theta burst stimulation TMS compared to sham TMS for mental state on the PANNS scale (3 RCTs, $\mathrm{n}=108$, MD $-5.71,95 \%$ CI -9.32 to -2.10 , very low evidence). We found no difference for clinical improvement, cognitive state, number of headaches, and leaving the study early (very low-quality evidence).

None of the included studies reported satisfaction with care.

\section{Authors' conclusions}

Based on this review, there is insufficient evidence to support or refute the use of TMS to treat symptoms of schizophrenia. Although some evidence suggests that TMS, and in particular temporoparietal TMS, may improve certain symptoms (such as auditory hallucinations and positive symptoms of schizophrenia) compared to sham TMS, the results were not robust enough to be unequivocal across the assessment measures used. There was insufficient evidence to suggest any added benefit with TMS used as an adjunctive therapy to antipsychotic medication.

The overall quality of evidence was graded as very low due to risk of bias, and this was accompanied by an imprecision in estimates due to the relatively small number of participants in the studies. Thus, consideration is required in improving the quality of trial processes, as well as the quality of reporting of ongoing and future TMS trials, so as to facilitate accurate future judgements in assessing risk of bias. Differences in TMS techniques in relation to stimulation intensity, stimulation length, brain areas stimulated and variations in the design of sham TMS all contributed to the heterogeneity of study findings and limited the interpretation and applicability of the results. In addition, the trials assessed their outcomes with a variety of scales, and usable data were limited. Therefore, to better evaluate the treatment effects of TMS in people with schizophrenia, we favour the use of standardised treatment protocols and outcome measures.

\section{PLAIN LANGUAGESUMMARY}

Transcranial magnetic stimulation (TMS) for the treatment of schizophrenia

\section{Review Question}

Is transcranial magnetic stimulation (TMS) useful in treating people with schizophrenia?

\section{Background}

Transcranial magnetic stimulation is a relatively new and sophisticated device-based therapy. TMS involves the skilful application of a strong magnetic field close to the surface of the scalp. The TMS device delivers strong and very brief magnetic pulses that stimulate the brain and its network of neurons. TMS is a relatively painless and non-invasive technique that stimulates parts of the brain (the cerebral cortex). Brain activity has been shown to differ in people with schizophrenia compared to other people.

People with schizophrenia often experience symptoms, such as hearing voices or seeing things (hallucinations), which fail to fully respond to medication. TMS has been proposed as a new treatment for people with schizophrenia, especially those who experience persistent auditory hallucinations. Antipsychotic medication also often has debilitating side effects, such as weight gain, apathy or lack or drive, and shaking. TMS could be an alternative treatment for people who do not cope well with standard medication.

\section{Description of Studies}

Transcranial magnetic stimulation (TMS) for schizophrenia (Review)

Copyright () 2015 The Cochrane Collaboration. Published by John Wiley \& Sons, Ltd. 
A search for trials was run in 2013 and 41 randomised controlled studies are now included in this review. The studies included people diagnosed with schizophrenia and randomised participants to receive either temporoparietal TMS, prefrontal TMS, sham TMS or standard care.

\section{Results}

At this time, there is not strong evidence to support the use of TMS to treat schizophrenia. Some very low-quality evidence appears to tentatively indicate that TMS may improve global state and certain symptoms such as hearing voices, compared to sham TMS. However, the research at present is not robust, consistent and standardised enough to support any firm conclusions about using TMS for schizophrenia.

There was no evidence to indicate TMS may improve symptoms of schizophrenia when used alongside the standard treatment of antipsychotic medication. There were also limitations related to differing TMS techniques. It was difficult to compare the results of studies in this review, as there were various different TMS procedures used, different symptom measures of schizophrenia, and data were limited. More robust and consistent research is therefore required. The authors of the review suggest that in the future, with more research, there is the possibility that TMS may be useful for treating some of the symptoms of schizophrenia. 


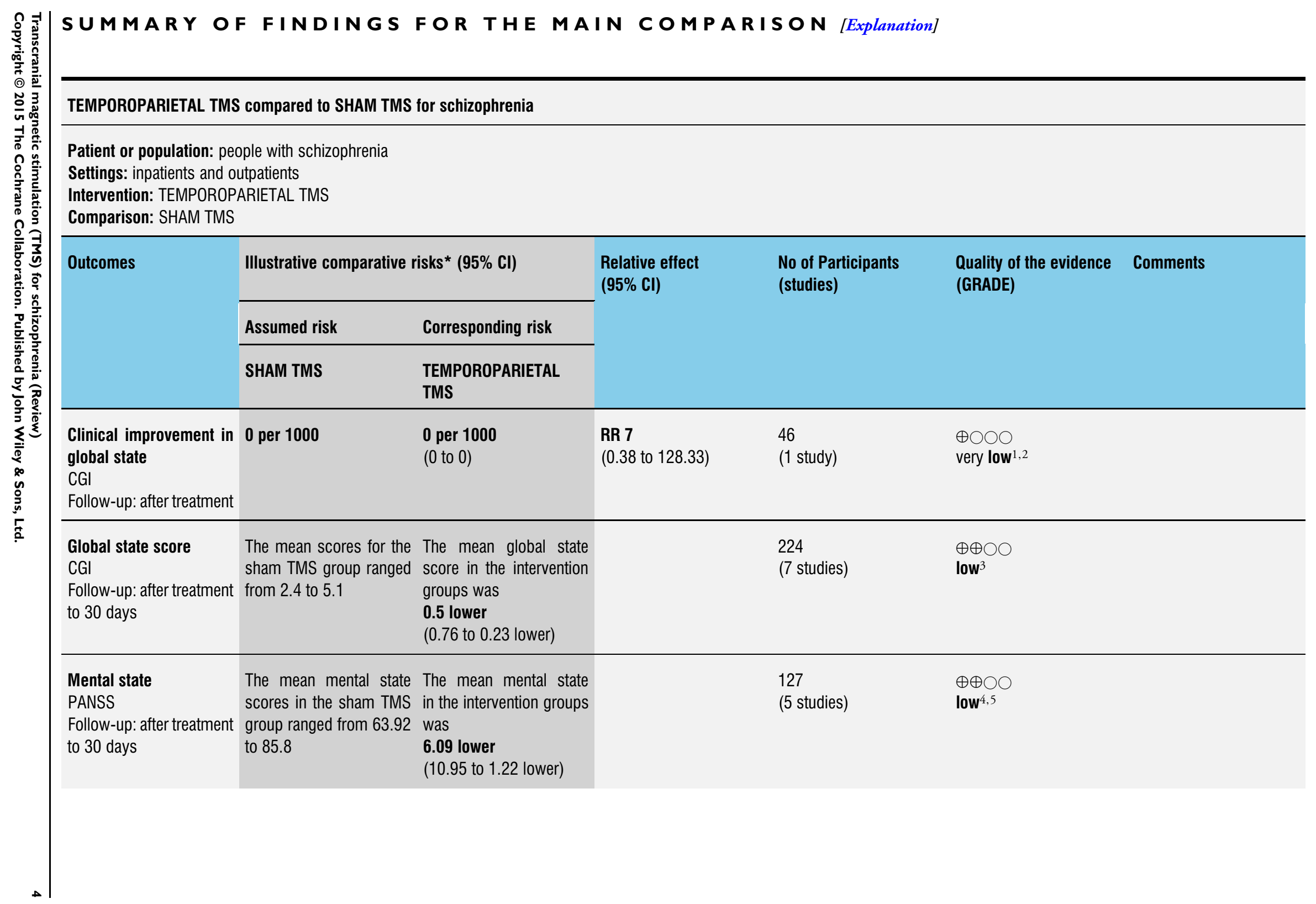




\begin{tabular}{|c|c|c|c|c|c|c|}
\hline $\begin{array}{l}\text { Cognitive state } \\
\text { Various measures } \\
\text { Follow-up: after treatment }\end{array}$ & See comment & See comment & Not estimable & $\begin{array}{l}82 \\
\text { (3 studies) }\end{array}$ & $\begin{array}{l}\oplus \oplus \bigcirc \bigcirc \\
\text { low }^{6}\end{array}$ & $\begin{array}{l}\text { Cognitive state was re- } \\
\text { ported in } 3 \text { studies using } \\
39 \text { different measures. } \\
\text { Results were equivocal } \\
\text { for all measures }\end{array}$ \\
\hline $\begin{array}{l}\text { Adverse effects: general } \\
\text { or specific } \\
\text { Follow-up: after treatment } \\
\text { to } 30 \text { days }\end{array}$ & See comment & See comment & Not estimable & $\begin{array}{l}442 \\
\text { (11 studies) }\end{array}$ & $\begin{array}{l}\oplus \oplus \bigcirc \bigcirc \\
\text { low }^{5,7}\end{array}$ & $\begin{array}{l}\text { There } \\
\text { were more headaches } \\
\text { and jaw and facial con- } \\
\text { traction in the TMS group. } \\
\text { Results for other adverse } \\
\text { events - concentration } \\
\text { problems, earache, light- } \\
\text { headedness, mild amne- } \\
\text { sia, restless legs, somatic } \\
\text { discomfort, tingling sen- } \\
\text { sation in the arm, worsen- } \\
\text { ing hallucinations - were } \\
\text { equivocal }\end{array}$ \\
\hline $\begin{array}{l}\text { Adverse effects: Leaving } \\
\text { the study early }\end{array}$ & 152 per 1000 & $\begin{array}{l}118 \text { per } 1000 \\
(70 \text { to } 200)\end{array}$ & $\begin{array}{l}\text { RR } \mathbf{0 . 7 8} \\
(0.46 \text { to } 1.32)\end{array}$ & $\begin{array}{l}320 \\
\text { (8 studies) }\end{array}$ & $\begin{array}{l}\oplus \bigcirc \bigcirc \bigcirc \\
\text { low }^{5,8}\end{array}$ & \\
\hline $\begin{array}{l}\text { Satisfaction with care - } \\
\text { not reported }\end{array}$ & See comment & See comment & Not estimable & - & See comment & $\begin{array}{l}\text { No studies reported on } \\
\text { this outcome }\end{array}$ \\
\hline
\end{tabular}

*The basis for the assumed risk is the median control group risk across studies for pooled data and the control group risk for single studies. The corresponding risk (and its $95 \%$ confidence interval) is based on the assumed risk in the comparison group and the relative effect of the intervention (and its $95 \% \mathrm{Cl}$ ).

Cl: Confidence interval; RR: Risk ratio;

GRADE Working Group grades of evidence

High quality: Further research is very unlikely to change our confidence in the estimate of effect.

Moderate quality: Further research is likely to have an important impact on our confidence in the estimate of effect and may change the estimate.

Low quality: Further research is very likely to have an important impact on our confidence in the estimate of effect and is likely to change the estimate.

Very low quality: We are very uncertain about the estimate. 
욜 ${ }^{1}$ Risk of bias: serious - this study had an unclear risk of bias for randomisation, allocation concealment, blinding and incomplete outcome data. Downgraded one level.

${ }^{2}$ Imprecision: very serious - there were very few participants and very few events; there are wide confidence intervals that include both appreciable benefit and appreciable harm. Downgraded two levels

${ }^{3}$ Risk of bias: very serious - five studies had an unclear risk of bias for randomisation, six for allocation concealment, four studies for blinding of participants and four blinding of outcome assessors. One study had a high risk of bias for incomplete outcome data.

Downgraded two levels.

${ }^{4}$ Risk of bias: serious - four studies had an unclear risk of bias for randomisation, five for allocation concealment, four for blinding of participants and two for blinding of outcome assessors. Three studies also had an unclear risk for incomplete outcome data. Downgraded one level.

Imprecision: serious - there are wide confidence intervals for this outcome that include appreciable and non-appreciable benefit. Downgraded one level.

${ }^{6}$ Imprecision: very serious - different scales were used to measure this outcome, all had wide confidence intervals. Downgraded two levels.

${ }^{7}$ Risk of bias: serious - six studies had an unclear risk of bias for randomisation and nine for allocation concealment. All studies had an unclear risk of bias for blinding of participants and three for blinding of outcome assessors. Six studies also had an unclear risk for incomplete outcome data. Downgraded one level.

${ }^{8}$ Risk of bias: serious - six studies had an unclear risk of bias for randomisation, five for allocation concealment, five studies for blinding of participants and four for blinding of outcome assessment. One study had a high risk of bias for incomplete outcome data. Downgraded one level.

Imprecision: very serious - there are wide confidence intervals for this outcome that include appreciable benefit and appreciable harm. Downgraded two levels. 


\section{B A C K G R O U N D}

\section{Description of the condition}

People with schizophrenia typically experience auditory hallucinations (hearing voices) or delusions (false beliefs) during acute episodes. Although several effective treatments are available, many patients have intractable symptoms that do not recover between acute episodes. In addition, motivation and social behaviour may also be adversely affected (negative symptoms). Relatively high numbers of people with schizophrenia have persistent symptoms in spite of apparently adequate drug treatment. In some cases treatment failure is associated with non-adherence, although it is understood that many people have enduring symptoms in spite of adequate treatment. Transcranial magnetic stimulation (TMS) could prove an alternative treatment for patients who do not cope well with standard medication.

\section{Description of the intervention}

Transcranial magnetic stimulation is a relatively new sophisticated device-based therapy which involves the skilful application of a strong magnetic field close to the surface of the scalp. The procedure is a non-invasive and relatively painless technique for stimulating the cerebral cortex and altering neuronal function (Chouinard 2003). The device uses specifically-designed insulated wire coils which deliver strong and very brief magnetic pulses, passing from carefully chosen surface landmarks without hindrance into underlying brain regions. The magnetic field then induces small transient electrical currents in the neural circuitry of treated individuals. By varying the intensity, duration and frequency of the magnetic field, the neuronal systems may be excited or inhibited for as long as the current pulses in the coil (Barker 2002).

\section{How the intervention might work}

Brain activity has been shown to differ in people with schizophrenia compared to the brain activity of people who do not have this condition. Whereas activity in the temporoparietal cortex (TPC) appears to increase in people with schizophrenia experiencing auditory hallucinations (Shergill 2000), activity in the dorsolateral prefrontal cortex (DLPFC) appears to be reduced in people with schizophrenia (Weinberger 1996). Reduced activity also appears to be correlated with negative symptoms (e.g. decreased motivation and social function) experienced by the patient. It is possible that by normalising activity in these brain regions, auditory hallucinations and negative symptoms would also improve.

Transcranial magnetic stimulation has been applied in several trials in two main paradigms: high-frequency TMS and low-frequency TMS. Low-frequency TMS $(1 \mathrm{~Hz})$ is typically applied to the left TPC of patients, aiming to decrease brain activity and reduce auditory hallucinations. High-frequency TMS is applied to left DLPFC in an attempt to increase activity and reduce negative symptoms. Low-frequency TMS is considered to inhibit cortical activity (Chen 1997) and high-frequency TMS generally increases cortical activity in stimulated areas (Pascual-Leone 1998). Positive (Hoffman 2005) and negative (McIntosh 2004) controlled studies have been published using both treatment approaches, and it is unclear whether TMS represents a significant treatment advance. In schizophrenia, there is evidence of both decreased and increased cortical activity compared to unaffected controls, and in some cases the altered activity correlates with the presence of a known symptom of cognitive deficit. Studies have demonstrated an association between temporal lobe activity and auditory hallucinations in people with schizophrenia (D'Alfonso 2002; Hoffman 2000; Lee 2005; Poulet 2005). Active stimulation has been found to significantly reduce hallucinations in comparison to sham stimulation (Hoffman 2000). Not all attempts at replication have unequivocally supported Hoffman's findings (McIntosh 2004; Saba 2006b).

\section{Why it is important to do this review}

Placebo arms of TMS trials often use sham treatments. There are limitations to this approach; no satisfactory placebo condition has been established and individuals may not have identical expectations of real or sham TMS. Placebo or sham TMS should result in scalp and noise sensation identical to active TMS, without the cortical stimulation. Although noise sensation can be mimicked, generating the scalp sensation may also produce a therapeutic cortical stimulation. Avoiding the confounding of cortical stimulation with sham TMS yields a control arm of the trial which typically controls for noise sensation but not for scalp sensation. In trials which implement sham TMS, double-blinding of observer and participant is not guaranteed and estimated efficacy rates of TMS will possibly be confounded if participants are aware which treatment arm they are in.

Bearing in mind the limitations of the trial methodology and in the absence of an entirely inactive sham condition that mimics real TMS, this systematic review aims to evaluate the current evidence base of TMS in the treatment for schizophrenia. We wish to ascertain the efficacy and safety of TMS, explore sources of heterogeneity that might explain contradictory positive and negative effects, investigate whether pooled effect sizes can be derived and whether they are statistically robust, and lastly, provide recommendations where possible for future research.

\section{O B J E C T I V E S}

To estimate the effects of TMS alone compared with sham TMS or with 'standard management' and any other comparison interven- 
tions in reducing psychotic symptoms associated with schizophrenia.

\section{METHODS}

\section{Criteria for considering studies for this review}

\section{Types of studies}

All relevant randomised controlled trials with group sizes of at least five. Where a trial was described as 'double-blind' but it implied that the study is randomised and the demographic details of each group are similar, we included it. We excluded quasi-randomised studies, such as those allocated by using alternate days of the week.

\section{Types of participants}

People with schizophrenia and related affective psychoses, diagnosed according to standardised operational criteria, irrespective of age and sex.

\section{Types of interventions}

1. Transcranial magnetic stimulation: at any stimulus voltage, frequency or charge, administered to the head at any location

2. Sham TMS: TMS administered using fake instruments or with the coil applied at an oblique angle, greater than or equal to 45 degrees, to the skull

3. Standard treatment: any treatment (including antipsychotic medication) provided as part of routine care, however defined

\section{Any other pharmacological or non-pharmacological treatments given as part of an experimental intervention. Examples might include electroconvulsive therapy (ECT) and cognitive behaviour therapy (CBT).}

\section{Types of outcome measures}

We classified outcomes in the eight categories detailed below:

\section{Primary outcomes}

\section{Global state}

1.1 Clinical improvement in global state (as defined by individual studies)

1.2 Mean endpoint global state score

1.3 Mean change in global state scores

\section{Secondary outcomes}

\section{Mental state}

2.1 Clinical improvement in general mental state (as defined by individual studies)

2.2 Mean endpoint general mental state score

2.3 Mean change in general mental state scores

2.4 No clinically important change in specific symptoms

2.5 Mean endpoint-specific symptom score

2.6 Mean change in specific symptom scores

\section{Cognitive state}

3.1 Clinical improvement in cognitive state (as defined by individual studies)

3.2 Mean endpoint cognitive state score

3.3 Mean change in cognitive state scores

3.4 Mean endpoint-specific cognitive state score

3.5 Mean change in specific cognitive state scores

\section{Adverse effects}

4.1 Incidence of adverse effects, general or specific

4.2 Leaving the study early

4.3 Measured acceptance of treatment

4.4 Use of antiparkinsonian treatment

4.5 Sudden and unexpected death

\section{Hospital and service outcomes}

5.1 Hospitalisation of people in the community

5.2 Duration of hospital stay

5.3 Severity of symptoms when discharged from hospital

5.4 Changes in hospital status (for example, changes from informal care to formal detention in care, changes of level of observation by ward staff and use of secluded nursing environment) 5.5 Changes in services provided by community teams

\section{Satisfaction with care}

6.1 Recipient of care

6.2 Informal care givers

6.3 Professional carers 


\section{Economic outcomes}

\section{Quality of Life}

8.1 Clinical improvement in quality of life (as defined by individual studies)

8.2 Mean endpoint quality of life score

8.3 Mean change in quality of life scores

\section{'Summary of findings' table}

We used the GRADE approach to interpret findings (Schünemann 2008) and used GRADE profiler to import data from Review Manager 5 (RevMan) to create 'Summary of findings' tables. These tables provide outcome-specific information concerning the overall quality of evidence from each included study in the comparison, the magnitude of effect of the interventions examined, and the sum of available data on all outcomes we rated as important to participant care and decision making. We included the following short- or medium-term outcomes in 'Summary of findings' tables:

\section{Global state}

1.1 Clinical improvement in global state

1.2 Mean endpoint score

\section{Mental state}

2.1 Mean endpoint score

\section{Cognitive state}

3.1 Mean change score

\section{Adverse effects}

4.1 Incidence of adverse effects, general or specific 4.2 Leaving the study early

\section{Satisfaction with care}

5.1 Recipient of care

\section{Search methods for identification of studies}

\section{Electronic searches}

\section{The Cochrane Schizophrenia Group's Trials Register}

We searched this in June 2006, June 2008 and April 2013 using the phrase:
[((*TMS* OR * ${ }^{*}$ transcranial* ${ }^{*}$ OR * ${ }^{*}$ trans-cranial ${ }^{*} \mathrm{OR}^{*}$ magnetic $\left.{ }^{*}\right)$ in REFERENCE) and (magn* in STUDY)]

This register is compiled by systematic searches of major databases, handsearches and conference proceedings (see Group Module).

We applied no language restriction for the searching.

\section{Requests for additional data}

We contacted Magstim Company Ltd., the company who markets TMS machines in the UK, for published and unpublished data on the treatment (Table 1).

\section{Searching other resources}

\section{Reference lists}

We retrospectively searched reference lists of included and excluded studies for additional relevant studies, and contacted authors of relevant studies to enquire about other sources of relevant information. We prospectively searched for studies which cited included relevant studies up to April 2013

\section{Data collection and analysis}

\section{Selection of studies}

Two review authors (ND, AM for the 2006 and 2008 searches, and two members of the Enhance Reviews team (NM and KSW) for the 2013 update search) independently inspected all abstracts of studies identified as above and identified potentially relevant reports. Where disagreement occurred we resolved it by discussion, or where there was still doubt, we acquired the full article for further inspection. Jun Xia screened Chinese language studies. We acquired the full articles of relevant reports for reassessment and carefully inspected them for a final decision on inclusion (see Criteria for considering studies for this review). The review authors were not blinded to the names of the authors, institutions or journal of publication. Where difficulties or disputes arose, we added these studies to those awaiting assessment and contacted the authors of the papers for clarification.

\section{Data extraction and management}

\section{Data extraction}

Review authors ND and AM extracted data independently from included studies resulting from the 2006 and 2008 searches, and two members of the Enhance Reviews team (NM and KSW) extracted data independently for the included studies from the 2013

Transcranial magnetic stimulation (TMS) for schizophrenia (Review)

Copyright $\odot 2015$ The Cochrane Collaboration. Published by John Wiley \& Sons, Ltd. 
search. Again, we discussed any disagreement, documented decisions and, if necessary, contacted authors of studies for clarification. JX extracted data for all Chinese studies. We extracted data presented only in graphs and figures whenever possible, but only included them if two review authors independently had the same result. Where possible, we extracted data relevant to each component centre of multicentre studies separately.

\section{Management}

\subsection{Forms}

We extracted data onto standard, simple forms.

\subsection{Scale-derived data}

We included continuous data from rating scales only if: a) the psychometric properties of the measuring instrument have been described in a peer-reviewed journal (Marshall 2000); and b) the measuring instrument is not written or modified by one of the trialists for that particular trial. Ideally the measuring instrument should either be a self report or completed by an independent rater or relative (not the therapist).

\subsection{Endpoint versus change data}

There are advantages of both endpoint and change data. Change data can remove a component of between-person variability from the analysis. On the other hand, calculation of change needs two assessments (baseline and endpoint) which can be difficult in unstable and difficult-to-measure conditions such as schizophrenia. We decided to primarily use endpoint data and only use change data if the former were not available. We combined endpoint and change data in the analysis as we used weighted mean differences rather than standardised mean differences throughout (Higgins 2011 b, chapter 9.4.5.2). All data in the analyses are endpoint data unless specifically noted as change data in the footnote of the analysis.

\subsection{Skewed data}

Continuous data on clinical and social outcomes are often not normally distributed. To avoid the pitfall of applying parametric tests to non-parametric data, we applied the following standards to all data before inclusion: a) standard deviations (SDs) and means were reported in the paper or obtainable from the authors; $b$ ) when a scale starts from the finite number zero, the standard deviation, when multiplied by two, was less than the mean (as otherwise the mean is unlikely to be an appropriate measure of the centre of the distribution, (Altman 1996); c) if a scale started from a positive value (such as the positive and negative syndrome scale (PANSS) which can have values from 30 to 210) we modified the calculation described above to take the scale starting point into account. In these cases skew is present if $2 S D>(S-S$ min $)$, where $S$ is the mean score and $S$ min is the minimum score. Endpoint scores on scales often have a finite start and endpoint and these rules can be applied. When continuous data were presented on a scale that includes a possibility of negative values (such as change data), it is difficult to tell whether data were skewed or not. We entered skewed data from studies of fewer than 200 participants in additional tables rather than into an analysis. Skewed data pose less of a problem when looking at means if the sample size is large, and we entered them into syntheses.

\subsection{Common measure}

To facilitate comparison between trials, we intended to convert variables that can be reported in different metrics, such as days in hospital (mean days per year, per week or per month) to a common metric (e.g. mean days per month).

\subsection{Conversion of continuous to binary}

Where possible, we tried to convert outcome measures to dichotomous data. This could be done by identifying cut-off points on rating scales and dividing participants accordingly into 'clinically improved' or 'not clinically improved'. We generally assumed that if there had been a 50\% reduction in a scale-derived score such as the Brief Psychiatric Rating Scale (BPRS, Overall 1962) or the Positive and Negative Syndrome Scale (PANSS, Kay 1986), we could consider this as a clinically significant response (Leucht 2005a; Leucht 2005b). Data based on these thresholds were not available, so we used the primary cut-off presented by the original authors.

\subsection{Direction of graphs}

We extracted and entered data into RevMan in such a way that the area to the left of the line of no effect indicated a 'favourable' outcome for TMS. For some outcomes this was not possible, and we reported data where the left of the line indicates an unfavourable outcome. We have noted this in the relevant graphs.

\section{Assessment of risk of bias in included studies}

ND and AM independently allocated trials from the 2006 and 2008 searches to Categories A or B in the review. When upgraded criteria for risk of bias became available, $\mathrm{LMcD}$ correspondingly upgraded the trial quality assessments using criteria described in the Cochrane Handbook (Higgins 2011b). Two members of the Enhance Reviews team assessed the risk of bias of studies included from the 2013 search, also using the upgraded criteria. This set of criteria is based on evidence of associations between overestimate of effect and high risk of bias of the article, such as sequence generation, allocation concealment, blinding, incomplete outcome data and selective reporting. When the raters disagreed, they made the final rating by consensus, with the involvement of another member of the review team. When there were inadequate details 
of randomisation and other characteristics of trials, we contacted authors of the studies in order to obtain further information. We reported non-concurrence in quality assessment, but if disputes arose as to the appropriate category to which a trial should be allocated, we resolved the matter by discussion. We noted the level of risk of bias in both the text of the review and in the 'Summary of findings' tables.

\section{Measures of treatment effect}

\section{Binary data}

For binary outcomes we calculated a standard estimation of the risk ratio (RR) and its $95 \%$ confidence interval (CI). It has been shown that the RR is more intuitive (Boissel 1999) than the odds ratios and that odds ratios tend to be interpreted as RRs by clinicians (Deeks 2000).

\section{Continuous data}

For continuous outcomes we estimated the mean difference (MD) between groups with $95 \%$ CIs.

\section{Unit of analysis issues}

\section{Cluster trials}

Studies increasingly employ 'cluster randomisation' (such as randomisation by clinician or practice) but analysis and pooling of clustered data pose problems. Firstly, authors often fail to account for intra-class correlation in clustered studies, leading to a 'unit of analysis' error (Divine 1992) whereby P values are spuriously low, confidence intervals unduly narrow and statistical significance overestimated. This causes type I errors (Bland 1997; Gulliford 1999).

None of the included studies was cluster-randomised. Measures to deal with cluster RCTs that we would have employed, and that we shall use for updates of this review for such designs, are described in the section Differences between protocol and review.

\section{Cross-over trials}

A major concern of cross-over trials is the carry-over effect. It occurs if an effect (e.g. physiological or pharmacological) of the treatment in the first phase is carried over to the second phase. As a consequence, on entry to the second phase the participants can differ systematically from their initial state, despite a wash-out phase. For the same reason cross-over trials are not appropriate if the condition of interest is unstable (Elbourne 2002). As both effects are very likely in schizophrenia, we only used data from the first phase of cross-over studies.

\section{Studies with multiple treatment groups}

When a study involved more than two treatment arms, if relevant, we presented the additional treatment arms in comparisons. If data were binary these were simply added and combined within the two-by-two table. If data were continuous, we combined data using the RevMan calculator. Where the additional treatment arms were not relevant, we did not reproduce these data.

\section{Dealing with missing data}

\section{Overall loss of credibility}

To some degree, loss of follow-up data must lose credibility (Xia 2009). We choose that, for any particular outcome, if more than $50 \%$ of data were unaccounted for, we did not reproduce these data or use them within analyses. If more than $50 \%$ of those in one arm of a study were lost, but the total loss was less than $50 \%$, we would have flagged such data with an asterisk $(*)$ to indicate that such a result may well be prone to bias.

\section{Binary}

All analyses have been conducted per number analysed in the studies. For the primary outcome 'clinical improvement in global state', if there was attrition, we compared in sensitivity analyses the results per number analysed with results of all the participants randomised (an intention-to-treat analysis). For the intention-totreat analysis, we assumed that those leaving the study early all have the same rates of negative outcome as those who completed the trial.

\section{Continuous}

\subsection{Attrition}

In the case where attrition for a continuous outcome is between 0 and $50 \%$ and completer-only data were reported, we have reproduced these.

\subsection{Standard deviations}

We first tried to obtain the missing values from the authors. When these were not available, we did not add the data to the analysis. Measures to deal with missing SDs that we shall use for updates of this review are described in the section Differences between protocol and review. 


\subsection{Last observation carried forward}

We anticipated that in some studies the method of last observation carried forward (LOCF) would be employed within the study report. As with all methods of imputation to deal with missing data, LOCF introduces uncertainty about the reliability of the results (Leucht 2007). Therefore, where LOCF data had been used in the trial, if less than $50 \%$ of the data had been assumed, we reproduced these data and indicated that they are the product of LOCF assumptions.

\section{Assessment of heterogeneity}

\section{Clinical heterogeneity}

We considered all included studies initially, without seeing comparison data, to judge clinical heterogeneity. We simply inspected all studies for clearly outlying situations or people which we had not predicted would arise. When such situations or participant groups arose, we discussed them fully.

\section{Methodological heterogeneity}

We considered all included studies initially, without seeing comparison data, to judge methodological heterogeneity. We simply inspected all studies for clearly outlying methods which we had not predicted would arise. When such methodological outliers arose, we discussed them fully.

\section{Statistical heterogeneity}

\subsection{Visual inspection}

We visually inspected graphs to investigate the possibility of statistical heterogeneity.

\subsection{Employing the $I^{2}$ statistic}

We investigated heterogeneity between studies by considering the $\mathrm{I}^{2}$ method alongside the $\mathrm{Chi}^{2} \mathrm{P}$ value. The $\mathrm{I}^{2}$ provides an estimate of the percentage of inconsistency thought to be due to chance (Higgins 2003). The importance of the observed value of $I^{2}$ depends on: a) magnitude and direction of effects, and b) strength of evidence for heterogeneity (e.g. P value from $\mathrm{Chi}^{2}$ test, or a confidence interval for $\mathrm{I}^{2}$ ). An $\mathrm{I}^{2}$ estimate greater than or equal to $50 \%$ accompanied by a statistically significant $\mathrm{Chi}^{2}$ statistic, we interpreted as possibly evidence of substantial levels of heterogeneity (Section 9.5.2 - Deeks 2011). When we found substantial levels of heterogeneity in the primary outcome measure, we cautiously explored reasons for heterogeneity (Subgroup analysis and investigation of heterogeneity).

\section{Assessment of reporting biases}

Reporting biases arise when the dissemination of research findings is influenced by the nature and direction of results (Egger 1997). These are described in Chapter 8 of the Cochrane Handbook (Higgins 2011a). We are aware that funnel plots may be useful in investigating reporting biases, but are of limited power to detect small-study effects. We did not use funnel plots for any outcomes as there were 10 or fewer studies, or where all studies were of similar sizes; in the case of the adverse effect headache, we did not produce a funnel plot, as this outcome was not systematically reported by all studies. Had we used funnel plots, we would have sought statistical advice in their interpretation.

\section{Data synthesis}

We understand that there is no closed argument for preference use of fixed-effect or random-effects models. The fixed-effect model assumes each trial makes an estimate of a common effect size of the same population. The random-effects method incorporates an assumption that the different studies are estimating different, yet related, intervention effects. The random-effects model takes into account differences between studies even if there is no statistically significant heterogeneity. There is, however, a disadvantage to the random-effects model. It puts added weight onto small studies, which are often the most biased ones. Depending on the direction of effect, these studies can either inflate or deflate the effect size. For this reason we favoured using fixed-effect models, employing random-effects only when investigating heterogeneity.

\section{Subgroup analysis and investigation of heterogeneity}

\section{Subgroup analysis}

We planned no subgroup analyses for this review. We knew the literature would yield sparse amounts of data and that any subgroup analysis would most likely be inadequately powered for us to draw any conclusions.

\section{Investigation of heterogeneity}

If inconsistency was high, we reported it. First we investigated whether data had been entered correctly. Second, where data were correct, we visually inspected the graph, and successively removed outlying studies, to see if heterogeneity remained. For this review, we decided that should this occur with data contributing to the summary finding no more than around $10 \%$ of the total weighting, we would present the data. If not, we did not pool data, but discussed the issues. We know of no supporting research for this $10 \%$ cut-off but are investigating the use of prediction intervals as an alternative to this unsatisfactory state. When unanticipated clinical or methodological heterogeneity was obvious, we simply stated hypotheses regarding these for future reviews or versions of this review. We did not undertake analyses relating to these. 


\section{Sensitivity analysis}

\section{Implication of randomisation}

We planned to include trials in a sensitivity analysis if they were described in some way as to imply randomisation. All studies were reported as randomised, so we did not undertake any sensitivity analysis related to implication of randomisation.

\section{High attrition rates}

We planned a sensitivity analysis to test how prone results were to change when we compared 'completer' data only to the imputed data, using the above assumption. If there had been a substantial difference, we would have reported results and discussed them but continued to employ our assumption. However, we did not make any assumptions about lost binary data and undertook no sensitivity analysis.

\section{R E S U L T S}

\section{Description of studies}

For a full description of studies please see: Characteristics of included studies and Characteristics of excluded studies.

\section{Results of the search}

The search strategy identified 99 reports that were potentially relevant. Agreement about which reports may have been randomised was $100 \%$. In total, we included 41 studies in the review and in the analysis (see Figure 1). One study (Jin 2012) met the inclusion criteria but did not report data in a usable way, and is in the excluded studies table. 
Figure I. Study flow diagram.

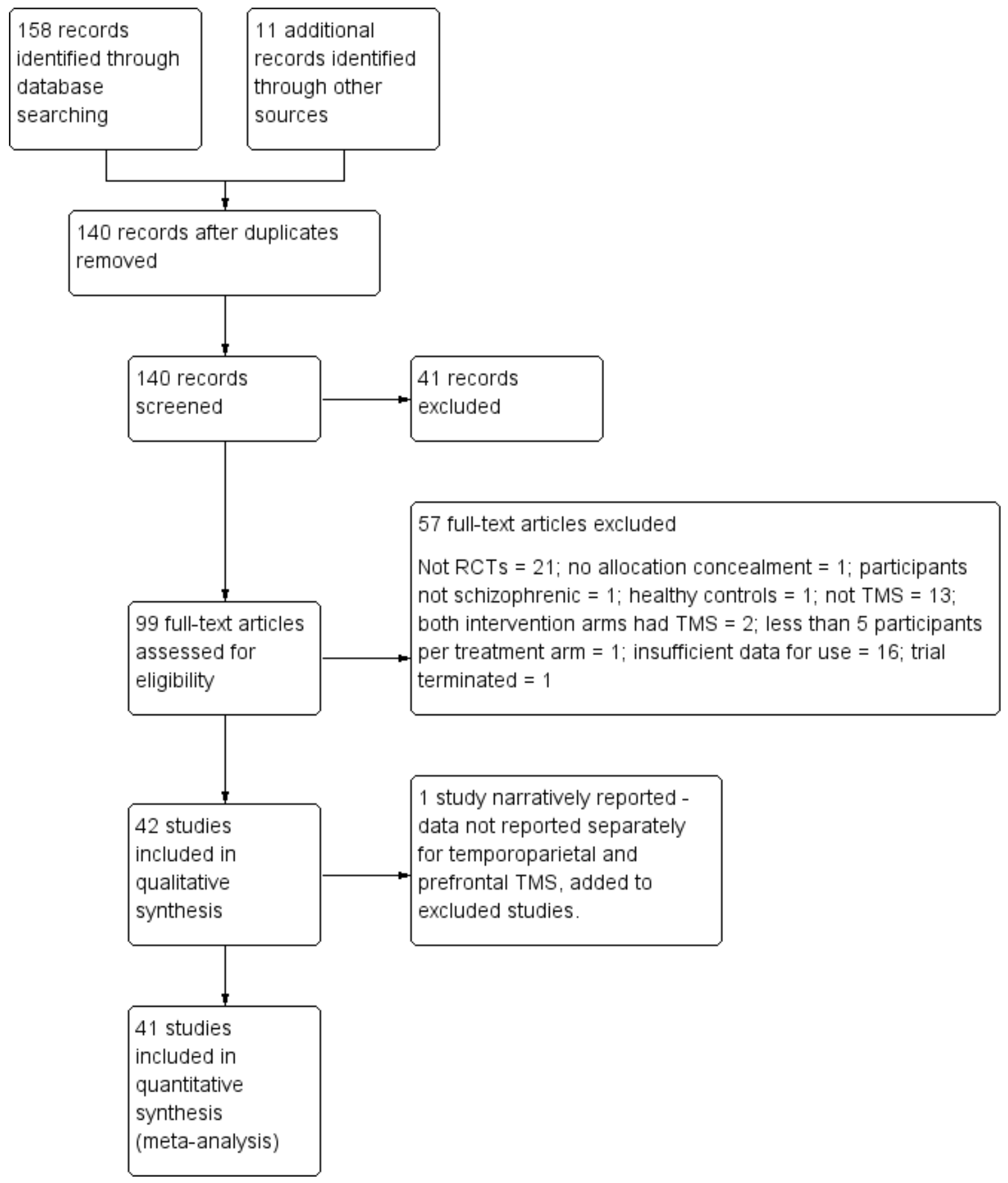




\section{Included studies}

\section{Length of studies}

The duration of trials ranged from four days (McIntosh 2004) to 10 weeks (Wing 2012); 26 trials were short (from five days to two weeks), 12 were medium length (three to six weeks) and four trials were long (eight weeks or longer).

\section{Design}

All but two included studies presented a parallel longitudinal design and two studies had a cross-over design (McIntosh 2004; Poulet 2005).

\section{Participants}

Most studies included participants with schizophrenia or schizoaffective disorder according to the DSM-IV. Of those that did not use DSM-IV, seven studies diagnosed schizophrenia according to the CCMD-3 (Gao 2009a; Gao 2009b; Gao 2010; Hao 2008; Liu 2008; Xu 2011; Zheng 2012). Rosenberg 2012 diagnosed according to DSM-IV-TR. Bagati 2009, Guse 2013, and Prikryl 2007 used ICD-10, and De Jesus 2011 OPCRIT 4.0.

In total, 1473 participants are included in the review, and the number of people included in individual studies ranged from 10 (Poulet 2005) to 100 (Liu 2011).

\section{Settings}

Eleven studies included inpatients (Chen 2011; Cordes 2010; Gao 2009a; Hao 2008; Holi 2004; Klein 1999; Liu 2008; Poulet 2005; Prikryl 2007; Saba 2006a; Zheng 2012), five studies included outpatients (Fitzgerald 2005; Fitzgerald 2008; Mogg 2005; Schneider 2008; Wing 2012) and five studies included both inpatients and outpatients (Bagati 2009; Guse 2013; Novak 2006; Rosenberg 2012; Vercammen 2009a). In 22 studies the setting was either unclear or not reported.

Fourteen studies were carried out in China (Chen 2011; Gao 2009a; Gao 2009b; Gao 2009c; Gao 2010; Hao 2008; Liu 2008; Liu 2011; Ren 2010; Ren 2011; Xu 2011; Yu 2010; Zhang 2010; Zheng 2012), 13 in Europe, including three in the Czech Republic (Klirova 2010; Novak 2006; Prikryl 2007), three in France (Brunelin 2006; Poulet 2005; Saba 2006a), two in Germany (Cordes 2010; Guse 2013), two in the Netherlands (Slotema 2011; Vercammen 2009a), two in the UK (McIntosh 2004; Mogg 2005), and one in Finland (Holi 2004). Of the remainder, six were conducted in the USA (Hoffman 2005; NCT00308997; Schneider 2008) or Canada (Barr 2013; Blumberger 2012; Wing 2012), two in Australia (Fitzgerald 2005; Fitzgerald 2008), two in Brazil (De Jesus 2011; Rosa 2007), two in Israel (Klein 1999; Rosenberg 2012), one in India (Bagati 2009), and one in Korea (Lee 2005).

\section{Interventions}

\subsection{Temporoparietal TMS}

Twenty-two studies used temporoparietal TMS, most using the left temporoparietal region, Lee 2005 also using right temporoparietal TMS, and NCT00308997 using Wernicke's area and right homologous area. Most studies used low-frequency TMS with 1 $\mathrm{Hz}$ at 80 to $110 \%$ motor threshold; Hao 2008 and Liu 2008 both used $10 \mathrm{~Hz}$ at $110 \%$ motor threshold, Saba 2006a used $1 \mathrm{~Hz}$ at $20 \%$ of motor threshold and Klirova 2010 used $0.9 \mathrm{~Hz}$ at $100 \%$ motor threshold. Blumberger 2012 included two TMS groups, one with priming TMS of $6 \mathrm{~Hz}$ at $90 \%$ motor threshold.

In regards to length of TMS stimulations, a wide variety were reported across studies, ranging from five sessions of one minute, with one minute gaps (Saba 2006a) to 12 sessions of 20 minutes each a day (Vercammen 2009a). Blumberger 2012 used MRItargeted TMS, and Klirova 2010 and Slotema 2011 both included an MRI-targeted TMS arm and a non-targeted TMS arm. De Jesus 2011, Hoffman 2005, and McIntosh 2004 reported using the 10 - 20 EEG electrode position system. Rosenberg 2012 used deep H1 coil TMS with single pulse stimulation, which allows stimulation of deeper brain areas.

\subsection{Prefrontal TMS}

Nineteen studies used prefrontal TMS, with most using left prefrontal TMS or left dorsolateral prefrontal cortex TMS. Klein 1999 reported using right prefrontal TMS and Barr 2013; Fitzgerald 2008; Ren 2010; Ren 2011 and Wing 2012 reported using bilateral prefrontal TMS. Various stimulations of TMS were administered. Seven studies reported using $10 \mathrm{~Hz}$ at 90 to $110 \%$ motor threshold, Gao 2009c used $15 \mathrm{~Hz}$ at $90 \%$ motor threshold, three studies used $20 \mathrm{~Hz}$ at $90 \%$ motor threshold (Barr 2013; Novak 2006; Wing 2012). Klein used low-frequency TMS with $1 \mathrm{~Hz}$ at $10 \%$ above threshold. Two studies (Chen 2011; Zhang 2010) used theta burst stimulation (TBS) TMS, in which $50 \mathrm{~Hz}$ are applied in bursts, and Zheng 2012 used three arms of TMS $10 \mathrm{~Hz}, 20 \mathrm{~Hz}$ and TBS $(50 \mathrm{~Hz})$.

In terms of stimulation length for each session of TMS, there was much variation reported across the studies. TMS ranged from two trains of one minute with a three-minute gap (Klein 1999), to 40 trains of 2.5 seconds with a 30-second gap (Novak 2006). Barr 2013 used MRI-targeted TMS and Guse 2013 and Poulet 2005 reported using the 10 - 20 EEG electrode position system. 


\subsection{Sham TMS}

For the sham TMS condition a variety of techniques were used. Seventeen studies described using the same stimulation as for active TMS but with the edge resting at a 90 degree angle to the scalp, six studies used a 45 degree angle (De Jesus 2011; Fitzgerald 2005; Gao 2009b; Guse 2013; Hoffman 2005; McIntosh 2004) and two at 180 degrees (Hao 2008, Liu 2008). Zhang 2010 and Zheng 2012 used the reverse side of the coil plane to the scalp. NCT00308997 used placebo stimulation, which feels similar to real rTMS but does not produce direct brain effects, Vercammen 2009a used sham designed to produce an identical sound, Wing 2012 administered sham in the single-wing tilt position. Additionally, some studies described further sham methods which included using the same stimulation as for active TMS but with a sham coil designed to produce identical sound (Brunelin 2006; Chen 2011; Cordes 2010; Mogg 2005; Poulet 2005; Rosa 2007; Rosenberg 2012; Saba 2006a), and a sham treatment which used a magnetically non-translucent headpiece (Schneider 2008). Bagati 2009 and Liu 2008 did not use sham but compared TMS to antipsychotics only.

\subsection{Standard treatment}

Two studies (Bagati 2009; Liu 2011) compared temporoparietal TMS to standard treatment, which was treatment with antipsychotics. In both trials, participants in the TMS group also received antipsychotics. We found no studies that compared prefrontal TMS to standard treatment.

\section{Use of antipsychotics}

In 10 studies participants in both treatment groups received firstgeneration and second-generation antipsychotics (Bagati 2009; Barr 2013; Blumberger 2012; Chen 2011; Cordes 2010; Liu 2011; McIntosh 2004; Mogg 2005; Ren 2011; Slotema 2011), although in McIntosh 2004 participants on clozapine were excluded from the trial. In 12 studies participants used second-generation antipsychotics: in De Jesus 2011 and Rosa 2007 all participants took clozapine; in Fitzgerald 2005 a significant number in each treatment group used clozapine; in Gao 2009b and Yu 2010 participants received risperidone; and in three studies all participants used second-generation antipsychotics apart from one participant in the TMS group who used first-generation antipsychotics (Holi 2004; Novak 2006; Fitzgerald 2008). Six studies did not report whether antipsychotics were used in the study (Brunelin 2006; Lee 2005; NCT00308997; Wing 2012; Xu 2011; Zhang 2010) and in the remaining studies all participants received antipsychotics, but the type was not reported.

\section{Outcomes}

A variety of scales, used to assess clinical response and cognitive performance, are described in Appendix 1. They assessed global state, mental state, cognitive state, adverse events and quality of life.

\section{Missing outcomes}

No usable data were available for a number of outcomes, including adverse events, hospital and service outcomes, satisfaction with care, and economic outcomes.

\section{Excluded studies}

We excluded 58 studies. Reasons for exclusion were that 20 studies were not randomised controlled trials; one study was not randomised and the number of participants was less than five (Hoffman 1999); one study used no allocation concealment (Jandl 2006); one study included participants with depression and not schizophrenia (Hasey 2000); one study used healthy controls (NCT01620086); for 12 studies the intervention was transcranial direct current stimulation and not TMS (ACTRN12611000731998; ACTRN12612000217808; ACTRN12612001112853; Brunelin 2012; Mattai 2011; NCT00757497; NCT00870909; NCT01378078; NCT01607840; NCT01623726; Rushby 2010; Weickert 2010); for one study the intervention was an antidepressant plus fMRI and not TMS (NCT01041274); for two studies both intervention and comparison arms included TMS (NCT01595503; Slotema 2012); for one study the number of participants in each arm of the trial was less than five (Schonfeldt-Lecuona 2004); 16 studies provided insufficient data for use (Alva 2001; Arends 2005; Benitez 2005; Cordes 2008; Daskalakis 2007; Grenier 2008; Hajak 2004; Hasan 2010; Hoffman 2000; Hoffman 2003; Jin 2003; Jin 2006; Loo 2010; Mobascher 2005; Potkin 2000; Rollnik 2000; Schneider 2001); and one study was terminated as they were unable to recruit participants (NCT00517075). We excluded Jin 2012 as data were not reported separately for temporoparietal and prefrontal TMS

\section{Awaiting assessment}

There is one study, Mohr 2006, awaiting assessment because we could not find the full article. See Characteristics of studies awaiting classification for more details.

\section{Ongoing studies}

We identified 18 ongoing studies, with 790 planned participants. One trial out of the 18 ongoing trials compares TMS with treatment as usual, and the remaining studies compare TMS with sham TMS, although one trial (NCT01370291) plans to compare both treatments with and without the use of risperidone. Three studies use high-frequency prefrontal TMS, five use low-frequency temporoparietal TMS, but a further nine studies use other TMS procedures (deep-coil TMS in one study, high-frequency temporopari- 
etal TMS in another, and theta burst stimulation TBS in seven).

See Characteristics of ongoing studies for details of each study.

\section{Risk of bias in included studies}

See Characteristics of included studies for our judgements and motivation for risk of bias for each study, Figure 2 for an overview of our judgements of risk of bias for each study and Figure 3 for an overview of percentages of low, unclear and high risk of bias for each category. 
Figure 2. Risk of bias summary: review authors' judgements about each risk of bias item for each included study.

\begin{tabular}{|c|c|c|c|c|c|c|c|}
\hline & 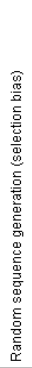 & 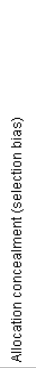 & 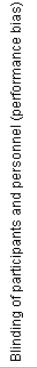 & 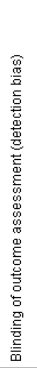 & 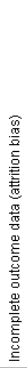 & 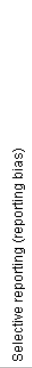 & 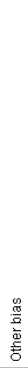 \\
\hline Bagati 2009 & 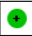 & $?$ & ? & + & $?$ & ? & $?$ \\
\hline Barr 2013 & $?$ & $?$ & $?$ & $\odot$ & + & $\odot$ & + \\
\hline Blumberger 2012 & $?$ & $?$ & $?$ & + & $\odot$ & + & + \\
\hline Brunelin 2006 & $?$ & $?$ & 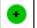 & 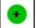 & $?$ & † & $?$ \\
\hline Chen 2011 & $\odot$ & $?$ & $?$ & (†) & † & $\odot$ & $\odot$ \\
\hline Cordes 2010 & $?$ & $?$ & $?$ & $\odot$ & $\odot$ & (†) & $\oplus$ \\
\hline De Jesus 2011 & 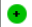 & $\odot$ & $?$ & 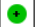 & $?$ & $?$ & $\oplus$ \\
\hline Fittgerald 2005 & $?$ & $\odot$ & $?$ & $\odot$ & $?$ & $\theta$ & $\oplus$ \\
\hline Fitzgerald 2008 & ๑) & (†) & $?$ & ๑ & $?$ & ○ & $?$ \\
\hline Gao 2009a & (†) & $?$ & $?$ & $?$ & $?$ & ○ & $?$ \\
\hline Gao 2009b & + & $?$ & $?$ & $\odot$ & $\odot$ & † & $?$ \\
\hline Gao 2009c & $?$ & $?$ & $?$ & $?$ & ๑ & (2) & $?$ \\
\hline Gao 2010 & $?$ & $?$ & $?$ & $?$ & ? & † & $?$ \\
\hline Guse 2013 & $\odot$ & $?$ & $?$ & † & $?$ & ○ & $\odot$ \\
\hline HaO 2008 & (†) & $?$ & $?$ & $?$ & $?$ & (†) & $?$ \\
\hline Hoffiman 2005 & ๑ & $?$ & + & $\odot$ & † & † & + \\
\hline Holi 2004 & $?$ & ๑) & $?$ & 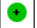 & $?$ & 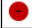 & $?$ \\
\hline Klein 1999 & $?$ & ? & $?$ & 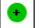 & $?$ & ○ & $\odot$ \\
\hline Klirova 2010 & $?$ & $?$ & $?$ & $?$ & $?$ & $?$ & $?$ \\
\hline Lee 2005 & $?$ & $?$ & $?$ & 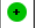 & $?$ & 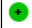 & 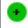 \\
\hline Liu 2008 & $\odot$ & $?$ & $?$ & $?$ & $\odot$ & $\oplus$ & $?$ \\
\hline Liu 2011 & $\odot$ & $?$ & $?$ & ? & ๑ & (2) & $?$ \\
\hline McIntosh 2004 & $\odot$ & (-) & $?$ & (†) & ๑ & 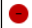 & $\odot$ \\
\hline Mogg 2005 & $?$ & † & $?$ & (†) & † & († & ๑ \\
\hline NCT00308997 & $?$ & $?$ & $?$ & 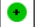 & $\odot$ & † & $?$ \\
\hline Novak 2006 & $?$ & $?$ & $?$ & $\odot$ & $?$ & (2) & $\oplus$ \\
\hline Poulet 2005 & $?$ & ? & ๑) & 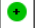 & $\odot$ & $?$ & $\odot$ \\
\hline Prikryl 2007 & 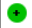 & ? & ๑ & 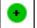 & $?$ & $?$ & († \\
\hline Ren 2010 & $?$ & $?$ & $?$ & $?$ & † & (†) & $?$ \\
\hline Ren 2011 & $?$ & $?$ & $?$ & ? & $\odot$ & † & $\odot$ \\
\hline Rosa 2007 & $?$ & $?$ & $?$ & ๑) & $?$ & ๑ & $\odot$ \\
\hline Rosenberg 2012 & $?$ & $?$ & (†) & (†) & ○ & (†) & $?$ \\
\hline Saba 2006a & $?$ & $?$ & (†) & $\odot$ & $?$ & († & $?$ \\
\hline Schneider 2008 & $?$ & ? & $\odot$ & 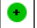 & $?$ & ○ & + \\
\hline Slotema 2011 & $\odot$ & $\odot$ & $?$ & + & ? & $\odot$ & † \\
\hline Vercammen 2009a & $?$ & $?$ & $?$ & 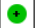 & $?$ & $\odot$ & $\odot$ \\
\hline Wing 2012 & $?$ & $?$ & $?$ & $?$ & ○ & $?$ & $\odot$ \\
\hline Хu 2011 & $?$ & $?$ & $?$ & $?$ & (†) & (†) & $?$ \\
\hline Үи 2010 & 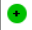 & $?$ & $?$ & $?$ & † & $\odot$ & $?$ \\
\hline Zhang 2010 & $\odot$ & $?$ & $?$ & $?$ & † & ○ & $?$ \\
\hline Zheng 2012 & + & $?$ & $?$ & ๑ & † & $\odot$ & († \\
\hline
\end{tabular}


Figure 3. Risk of bias graph: review authors' judgements about each risk of bias item presented as percentages across all included studies.

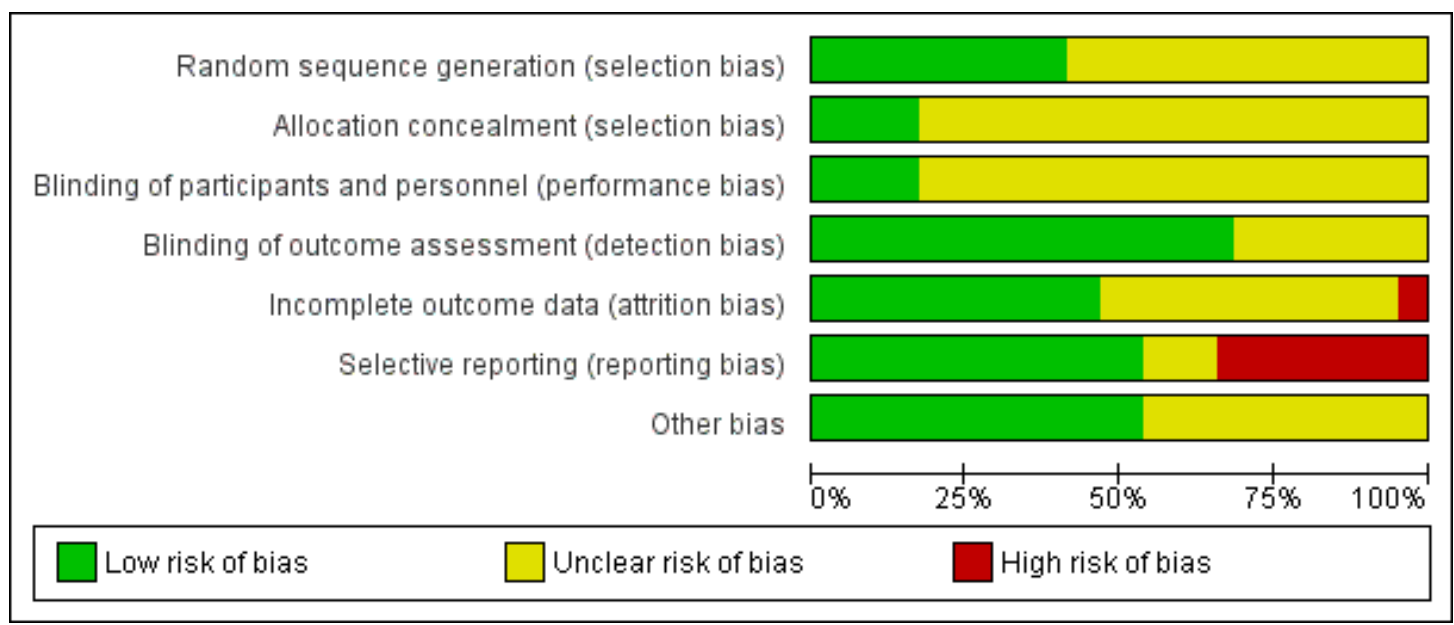

\section{Allocation}

All included studies were reported as randomised. Seventeen studies adequately described the method of sequence generation (Bagati 2009; Chen 2011; De Jesus 2011; Fitzgerald 2008; Gao 2009a; Gao 2009b; Guse 2013; Hao 2008; Hoffman 2005; Liu 2008; Liu 2011; McIntosh 2004; Prikryl 2007; Slotema 2011; Yu 2010; Zhang 2010; Zheng 2012) and thus had a low risk of selection bias; the remaining studies did not provide details and were at unclear risk of selection bias. Seven studies were rated at low risk of bias as they had adequate allocation concealment (De Jesus 2011; Fitzgerald 2005; Fitzgerald 2008; Holi 2004; McIntosh 2004; Mogg 2005; Slotema 2011). However, most studies had unclear allocation concealment.

\section{Blinding}

Only seven studies adequately described the blinding of participants and personnel (Brunelin 2006; Hoffman 2005; Poulet 2005; Prikryl 2007; Rosenberg 2012; Saba 2006a; Schneider 2008) and had a low risk of performance bias, and 34 studies had unclear risk of performance bias as the method of blinding participants and personnel was not adequately described. Most studies had a low risk of detection bias as the raters were adequately blinded, but with 13 studies at unclear risk of detection bias as they did not adequately describe blinding of outcome assessment (Gao 2009a; Gao 2009c; Gao 2010; Hao 2008; Klirova 2010; Liu 2008; Liu 2011;
Ren 2010; Ren 2011; Wing 2012; Xu 2011; Yu 2010; Zhang 2010).

\section{Incomplete outcome data}

Most studies had an unclear risk of attrition bias because reasons for loss to follow-up were not consistently indicated or were unreported. Nineteen studies had a low risk of attrition bias: three studies were analysed on an intention-to-treat basis (Blumberger 2012; Hoffman 2005; Mogg 2005), seven studies adequately reported and dealt with attrition (Barr 2013; Chen 2011; Cordes 2010; Liu 2008; NCT00308997; Zhang 2010; Zheng 2012) and nine studies reported no losses to follow-up (Gao 2009b; Gao 2009c; Liu 2011; McIntosh 2004; Poulet 2005; Ren 2010; Ren 2011; Xu 2011; Yu 2010). Two studies had a high risk of attrition bias. For Wing 2012, losses to follow-up were not balanced between treatment groups, and Rosenberg 2012 had a very high (44\%) attrition rate.

\section{Selective reporting}

Most studies had a low risk of reporting bias as they fully reported all stated outcomes. In five studies we considered the risk of reporting bias to be unclear (De Jesus 2011; Klirova 2010; Poulet 2005; Prikryl 2007; Wing 2012). In 14 studies we considered the risk of reporting bias to be high, as some stated outcomes were not adequately reported (Bagati 2009; Fitzgerald 2005; Fitzgerald 2008; 
Gao 2009a; Gao 2009c; Guse 2013; Holi 2004; Klein 1999; Liu 2011; McIntosh 2004; Novak 2006; Schneider 2008; Yu 2010; Zhang 2010). We attempted to obtain any data which were not reported in published literature by contacting the authors.

\section{Other potential sources of bias}

We rated 22 studies at low risk of bias, as we detected no other potential sources of bias. The remaining 19 had an unclear risk of bias as there was insufficient information to make a judgement.

\section{Effects of interventions}

See:

Summary

of findings for the main comparison TEMPOROPARIETAL TMS compared to SHAM TMS for schizophrenia; Summary of findings 2 TEMPOROPARIETAL TMS compared to STANDARD TREATMENT for schizophrenia; Summary of findings 3 PREFRONTAL TMS compared to SHAM TMS for schizophrenia; Summary of findings 4 PREFRONTAL TBS TMS compared to SHAM TMS for schizophrenia

\section{COMPARISON I: TEMPOROPARIETAL TMS vS SHAM TMS}

Twenty trials randomised 692 participants and compared TEMPOROPARIETAL TMS ( $\mathrm{n}=399)$ vs SHAM TMS $(\mathrm{n}=293$ ) (Blumberger 2012; Brunelin 2006; De Jesus 2011; Fitzgerald 2005; Gao 2009a; Gao 2010; Hao 2008; Hoffman 2005; Klirova 2010; Lee 2005; Liu 2008; McIntosh 2004; NCT00308997; Rosa 2007; Rosenberg 2012; Saba 2006a; Slotema 2011; Vercammen 2009a; Xu 2011; Yu 2010).

\section{I.I Global state}

\section{a. Clinical improvement (CGI)}

One study (Gao 2009a) found that the number of participants with a clinical improvement in global state did not differ between temporoparietal TMS and sham TMS when measured on the CGI scale; however they did not report the response criteria used to define clinical improvement (Analysis 1.1; 46 participants).

\section{b. Average scores for clinical improvement (CGI, high = poor)}

Seven studies reported global state measured on the CGI scale and found a clear difference in favour of temporoparietal TMS (7 RCTs, $\mathrm{n}=224, \mathrm{MD}-0.50,95 \% \mathrm{CI}-0.76$ to -0.23 , Analysis 1.2 ).

\section{I.2 Mental state}

\section{a. General}

\section{i. Clinical improvement (PANSS $>30 \%$ reduction)}

Blumberger 2012 reported clinical improvement in mental state, defined as more than a $30 \%$ reduction in total PANSS score; the proportion of participants that had a clinical improvement in mental state did not differ between the treatment groups (Analysis 1.3; 51 participants).

\section{ii. Average total score (various scales)}

Mental state was measured on the BPRS by De Jesus 2011 (17 participants), which found no clear difference in scores between treatment groups. In contrast, total PANSS scores were clearly lower in the temporoparietal TMS group than the sham TMS group (5 RCTs, $\mathrm{n}=127$, MD -6.09 , 95\% CI -10.95 to -1.22 , Analysis 1.4).

\section{iii. Average general psychopathology score (PANSS general)}

Four studies provided data regarding general psychopathology measured on the PANSS general subscale. There was no significant difference in scores between temporoparietal TMS and sham TMS (Analysis 1.5; 87 participants).

\section{b. Specific}

\section{i. Average depression score (various scales)}

Hao 2008 found that participants showed significantly less depression when measured on the SDS (1 RCT, $\mathrm{n}=25, \mathrm{MD}-5.59$, $95 \%$ CI -11.57 to 0.39 , Analysis 1.6), but results were equivocal when measured on the HAMD by the same small study. De Jesus 2011 also reported data for depression and excitement factor on the BPRS, but these data were skewed so we have not presented them in analyses (see Table 2).

\section{ii. Hallucinations - clinical improvement (various scales)}

Significantly more participants that received temporoparietal TMS showed a clinical improvement in hallucinations when defined as an HCS score of 5 or less (3 RCTs, $n=133$, RR 2.26, $95 \%$ CI 1.18 to 4.35 ) or more than a $30 \%$ decrease on the AHRS 
(3 RCTs, $\mathrm{n}=120$, RR 2.99, 95\% CI 1.12 to 7.98, Analysis 1.7 ). However, AHRS pooled data showed moderate heterogeneity ( ${ }^{2}$ $=55 \%)$ and when we applied the random-effects model the results became non-significant. Rosa 2007 reported "Reality" and "Attentional Salience" scores from the AHRS in figures, which showed a significant group effect $(\mathrm{P}=0.0493$ and $\mathrm{P}=0.0360$, respectively). We found no clear difference for clinical improvement in hallucinations when defined as improvement of one or more points on the PANSS hallucination item score, or more than a $30 \%$ reduction on the PSYRATS score.

\section{iii. Average hallucinations score (various scales)}

Hallucinations scores were significantly lower in the temporoparietal TMS when measured on the HCS ( 3 RCTs, $n=162$, MD $-1.64,95 \%$ CI -2.80 to -0.48$)$ and by the PANSS hallucination item (4 RCTs, $\mathrm{n}=125$, MD -1.01, 95\% CI - 1.97 to -0.04, Analysis 1.8). However, the PANSS hallucination item data were highly heterogenous ( $\mathrm{I}^{2}=81 \%$ ), with no obvious clinical or methodological reason for the heterogeneity. Removal of the outlying study, Gao 2010, reduced the heterogeneity $\left(\mathrm{I}^{2}=30 \%\right)$.

In contrast, when hallucinations were measured using AVH-related items from the PSYRATS and the AHRS, there was no significant difference in hallucination scores between treatment groups. However, the latter showed high levels of heterogeneity $\left(\mathrm{I}^{2}=62 \%\right)$, which we could not explain by differences in the treatment as all used low frequency $(1 \mathrm{~Hz})$. Furthermore, when we removed Rosenberg 2012, which used deep temporoparietal TMS, the heterogeneity was unchanged. However, when we removed change data from the analysis (NCT00308997; Poulet 2005) the heterogeneity was reduced $\left(\mathrm{I}^{2}=20 \%\right)$.

Poulet 2005 also reported endpoint data for hallucinations on the AHRS, but these data were skewed so we have not presented them in analyses (see Table 2).

\section{iv. Average negative symptom scores (various scales)}

Negative symptoms were measured using the BPRS, PANSS negative and SANS scales. We found no significant difference in scores on the BPRS and PANSS; however one small study, Hao 2008, which used high-frequency temporoparietal TMS $(10 \mathrm{~Hz})$ showed a significant difference favouring temporoparietal TMS (1 RCT, $\mathrm{n}=25, \mathrm{MD}-23.58,95 \% \mathrm{CI}-37.06$ to -10.1 , Analysis 1.9). Rosenberg 2012 also reported data for negative symptoms on the SANS, but these data were skewed so we have not presented them in analyses (see Table 2). v. Positive symptoms - clinical improvement (PANSS > 30\% reduction)

Blumberger 2012 found no difference in clinical improvement of positive symptoms, which was defined as more than a $30 \%$ reduction in PANSS positive subscale score (Analysis 1.10; 51 participants).

\section{vi. Average positive symptom score (various scales)}

Positive symptom scores were significantly lower in the temporoparietal TMS group than in the sham TMS group when measured on the PANSS positive subscale (11 RCTs, $\mathrm{n}=333$, MD $2.14,95 \%$ CI -3.15 to -1.14 , Analysis 1.11 ), but not significantly different when measured on the BPRS in one study (De Jesus 2011; 17 participants) or the SAPS used by Brunelin 2006 and Hao 2008. Poulet 2005 and Rosenberg 2012 also reported data for positive symptoms on the SAPS, but these data were skewed so we have not presented them in analyses (see Table 2).

\section{I.3 Cognitive state}

Cognitive state was reported in three studies (Hoffman 2005; Liu 2008; Xu 2011) using 39 different measures. These data are reported in Table 3. Results were equivocal for all measures. $\mathrm{Xu}$ 2011 also reported cognitive data on the CPT, but these data were skewed so we did not present them in Table 3 (see Table 2).

\section{I.4 Adverse effects}

\section{a. General}

\section{i. Serious}

NCT00308997 and Vercammen 2009a reported that there were no serious adverse events in either treatment group (Analysis 1.12; 130 participants).

\section{ii. Leaving the study early}

The number of participants leaving the study early did not differ significantly between treatment groups (Analysis 1.13; 8 studies, 320 participants).

Transcranial magnetic stimulation (TMS) for schizophrenia (Review) 


\section{b. Specific}

Participants receiving temporoparietal TMS clearly experienced more headaches (10 RCTs, $\mathrm{n}=392$, RR 2.65, 95\% CI 1.56 to 4.50 ) and jaw and facial contraction (2 RCTs, $\mathrm{n}=70$, RR 8.32, 95\% CI 1.13 to 61.17 , Analysis 1.14) than those receiving sham TMS. Other adverse events - concentration problems, earache, lightheadedness/dizziness, mild memory impairment/amnesia, restless legs, somatic discomfort, tingling sensation in the arm, worsening hallucinations/audible thoughts - were not clearly different between treatment groups.

\section{I.5 Quality of life}

\section{a. Average score (Q-LES-Q, low = poor)}

Rosenberg 2012 measured quality of life on the Q-LES-Q and found no clear difference between deep temporoparietal TMS and sham TMS (Analysis 1.15; 20 participants).

\section{COMPARISON 2: TEMPOROPARIETAL TMS vS STANDARD TREATMENT}

Two trials randomised 140 participants and compared TEMPOROPARIETAL TMS $(\mathrm{n}=70)$ versus STANDARD TREATMENT ( $\mathrm{n}=70$ ) (Bagati 2009; Liu 2011). In both studies the participants received first- and second-generation antipsychotics in both treatment groups.

\section{I Global state}

\section{a. Clinical improvement $($ CGI $\leq 2)$}

Liu 2011 found that there was no clear difference in the number of participants experiencing clinical improvement when temporoparietal TMS and antipsychotics were compared to antipsychotic treatment alone (Analysis 2.1; 100 participants).

\subsection{Mental state}

\section{a. Average hallucinations score (AHRS)}

Bagati 2009 reported data for hallucinations on the AHRS, but these data were skewed so we have not presented them in analyses (see Table 4).

\subsection{Adverse effects}

\section{a. General - leaving the study early}

The number of participants leaving the study early was not clearly different between temporoparietal TMS and antipsychotics alone (Analysis 2.2; 140 participants).

\section{COMPARISON 3: PREFRONTAL TMS vS SHAM TMS}

Seventeen trials randomised 502 participants and compared PREFRONTAL TMS ( $\mathrm{n}=266$ ) versus SHAM TMS $(\mathrm{n}=236)$ (Barr 2013; Cordes 2010; Fitzgerald 2008; Gao 2009b; Gao 2009c; Guse 2013; Holi 2004; Klein 1999; Mogg 2005; Novak 2006; Poulet 2005; Prikryl 2007; Ren 2010; Ren 2011; Schneider 2008; Wing 2012; Zheng 2012).

\section{I Global state}

\section{a. Average scores (various scales)}

Three small studies (Guse 2013; Holi 2004; Klein 1999) measured global state on the CGI, CGI-S, GAF and SCL-90, none of which showed a significant effect between prefrontal TMS and sham TMS (Analysis 3.1; 85 participants).

\subsection{Mental state}

\section{a. General}

\section{i. Clinical improvement (> 20\% decrease in total PANSS score)}

Results from one small trial (Holi 2004) show that more participants in the prefrontal TMS group had a clinical improvement in mental state than those that received sham TMS ( 1 RCT, $\mathrm{n}=22$, RR 0.14, 95\% CI 0.02 to 0.98 , Analysis 3.2).

\section{ii. Average total score (various scales)}

Mental state was measured using the BPRS and PANSS scales. We found no clear difference in participants' mental state between treatment groups on either scale (Analysis 3.3; 219 participants). However, the pooled data for the PANSS scale were heterogeneous $\left(I^{2}=68 \%\right)$. When we removed the low-frequency trial (Ren 2010), the heterogeneity remained. Removing outlying trials, Fitzgerald 2008 and Gao 2009b, eliminated the heterogeneity, but the studies account for more than $40 \%$ of the weight for this outcome and we therefore did not pool the data. 


\section{iii. Average general psychopathology score (PANSS, high=poor)}

Six studies reported data on general psychopathology of participants, measured on the PANSS scale. The pooled data were highly heterogenous $\left(\mathrm{I}^{2}=81 \%\right)$ and removal of the two low-frequency trials (Klein 1999; Ren 2010) did not reduce the heterogeneity. Removal of the outlying trials, Gao 2009b and Klein 1999, eliminated the heterogeneity, but as these trials accounted for $36 \%$ of the weighting, we did not pool the data (Analysis 3.4; 199 participants).

\section{b. Specific}

\section{i. Average depression score (various scales)}

Depression was reported on four scales by four different studies. There were no significant differences on the HDRS and SCL90 DEP subscale, whereas, when measured on the HAMD-17 (1 RCT, $\mathrm{n}=43, \mathrm{MD}-2.40,95 \% \mathrm{CI}-3.88$ to -0.92$)$ and MADRS (1 RCT, $\mathrm{n}=22$, MD $-4.3695 \%$ CI -7.05 to -1.67 ), prefrontal TMS was efficacious when compared to sham TMS (Analysis 3.5). Barr 2013 and Fitzgerald 2008 also reported data for depression on the Calgary depression scale (CDS) and Calgary depression rating scale (CDRS) respectively, but as these data are skewed we have not presented them in analyses (see Table 5).

CDRS - Calgary depression rating scale

CDS - Calgary depression scale

\section{ii. Average hallucinations score (PANSS)}

Ren 2010 found no difference in hallucinations between treatment groups (1 RCT, $\mathrm{n}=25, \mathrm{MD}-0.68,95 \% \mathrm{CI}-1.68$ to 0.32 , Analysis 3.6).

\section{iii. Negative symptoms - clinical improvement (> 20\% decrease in PANSS negative)}

One small study (Novak 2006) found no difference in the number of participants that experienced a clinical improvement in negative symptoms (Analysis 3.7; 16 participants).

\section{iv. Average negative symptom score (various scales)}

Pooled data for 10 studies that reported negative symptoms on the PANSS positive subscale were highly heterogeneous. Removing the low-frequency studies (Fitzgerald 2008; Klein 1999) did not reduce the heterogeneity. Removal of the outlying trials (Gao 2009b; Gao 2009c) reduced the heterogeneity $\left(\mathrm{I}^{2}=16 \%\right)$, and results show no significant difference between treatment groups. When measured on the SANS, three small studies found that participants receiving prefrontal TMS had a significant improvement compared to sham TMS (3 RCTs, $\mathrm{n}=71$, MD $-12.68,95 \% \mathrm{CI}$ -18.60 to -6.77 , Analysis 3.8). Barr 2013 also reported data for negative symptoms on the PANSS, but these data were skewed so we have not presented them in analyses (see Table 5).

\section{v. Average positive symptom score (various scales)}

Positive symptoms were not significantly different between treatment groups for 10 studies (279 participants) that used the PANSS positive subscale and one small study (Prikryl 2007; 22 participants) on the SAPS (Analysis 3.9). Fitzgerald 2008 also reported data for positive symptoms on the PANSS, but these data were skewed so we have not presented them in analyses (see Table 5).

\section{vi. Average psychotism score (SCL-90 PSY)}

Holi 2004 also found no difference in psychotism measured on the SCL-90 PSY subscale between prefrontal TMS and sham TMS (Analysis 3.10; 22 participants).

\subsection{Cognitive state}

Cognitive effects were reported in four studies (Guse 2013; Mogg 2005; Novak 2006; Zheng 2012), using 19 different measures. These data are reported in Table 6. Results were equivocal for most of the outcome measures, with limited evidence to suggest a beneficial effect of TMS for five cognitive test scores. One study (Mogg 2005) reported significantly increased cognitive test scores on average in the TMS arm compared with the control arm for four outcomes: Hopkins verbal learning test (HVLT)-delayed recall (after two weeks follow-up), controlled oral word association test (COWAT) (two weeks after TMS), and the Stroop test (within 24 hours of treatment and at two weeks follow-up). A second study (Guse 2013) reported significantly increased scores for Wisconsin card sorting test (WCST) categories (for people with WCST categories pre-treatment median $\leq 4$ ). More trials are needed to confirm or refute the beneficial effects of these cognitive test outcomes.

\subsection{Adverse effects}

\section{a. General}

\section{i. Leaving the study early}


The number of participants leaving the study was reported in eight studies and did not differ significantly between treatment groups (8 RCTs, $\mathrm{n}=174$, RR 1.19, 95\% CI 0.56 to 2.50, Analysis 3.12).

\section{b. Specific}

\section{i. Various}

Participants in the prefrontal TMS group experienced more headaches than those in the sham TMS group (6 RCTs, $\mathrm{n}=164$, RR 2.77, 95\% CI 1.22 to 6.26), and more TMS-related site discomfort or pain (2 RCTs, $\mathrm{n}=42$, RR 8.33, 95\% CI 1.68 to 41.27, Analysis 3.13). Cordes 2010 reported no adverse events measured on the UKU side effect rating scale and Klein 1999 reported no cognitive difficulties in either treatment group. Klein 1999 also found no significant difference in facial twitching and worsening of pre-existing akathisia and OCD.

\section{ii. Average scores (CSSES)}

Mogg 2005 measured subjective side effects and cognitive complaints on the CSSES and found no significant differences between prefrontal TMS and sham TMS (Analysis 3.14; 17 participants).

\section{COMPARISON 4: PREFRONTAL TBS TMS vs SHAM TMS}

Three trials randomised 115 participants and compared PREFRONTALTBS TMS $(\mathrm{n}=59)$ versus SHAM TMS $(\mathrm{n}=56)$ (Chen 2011; Zhang 2010; Zheng 2012).

\section{I Global state}

\section{a. Clinical improvement}

Zhang 2010 found no difference in the number of participants showing a clinical improvement in global state between prefrontal TBS TMS and sham TMS (Analysis 4.1; 27 participants).

\subsection{Mental state}

\section{a. General}

\section{i. Average total score (PANSS, high = poor)}

Three studies (Chen 2011; Zhang 2010; Zheng 2012) reported data for mental state on the PANSS scale and found that prefrontal
TBS TMS was efficacious when compared to sham TMS (3 RCTs, $\mathrm{n}=108, \mathrm{MD}-5.71,95 \%$ CI -9.32 to -2.10 , Analysis 4.2).

\section{ii. Average general psychopathology score (PANSS, high = poor)}

General psychopathology was also significantly better in the prefrontal TBS TMS group (3 RCTs, $\mathrm{n}=108, \mathrm{MD}-2.47$, 95\% CI 4.21 to -0.73 , Analysis 4.3).

\section{b. Specific}

\section{i. Average negative symptom score (PANSS, high = poor)}

Negative symptoms were significantly lower in the prefrontal TBS TMS group than in the sham TMS group when measured on the PANSS (3 RCTs, $\mathrm{n}=108$, MD -2.67, 95\% CI -4.25 to -1.09) and the SANS (1 RCT, $\mathrm{n}=27, \mathrm{MD}-11.55,95 \% \mathrm{CI}-21.90$ to 1.2, Analysis 4.4).

\section{ii. Average positive symptom score (PANSS, high = poor)}

Positive symptoms were not significantly different between treatment groups (Analysis 4.5; 108 participants).

\subsection{Cognitive state}

\section{a. Average scores on various measures}

We found no difference in cognitive state between treatment groups when measured using the digit span test and the verbal fluency test in one small study (Zheng 2012) (Analysis 4.6; 39 participants).

\subsection{Adverse effects}

\section{a. General - Leaving the study early}

The number of participants leaving the study early did not differ between the treatment groups (Analysis 4.7; 2 RCTs, 76 participants).

\section{b. Specific}

Participants did not experience significantly different numbers of adverse events (headaches or sleep disorder) between prefrontal TBS TMS and sham TMS (Analysis 4.8; 1 RCT, 27 participants). 


\section{Unusable data}

Jin 2012 reported data for clinical improvement combined for the two TMS groups (frontal and parietal) in the study, and so could not be added to any of the comparisons on the analyses. Clinical improvement was defined as at least a 30\% improvement in PANSS score; 17 of 41 patients responded to the TMS (42\%), whereas three of 24 responded to sham TMS (12\%).

\section{Sensitivity analysis}

There were no losses to follow-up for the outcome 'clinical improvement in global state' for temporoparietal TMS compared to sham TMS or standard treatment, and no studies reported on this outcome when prefrontal TMS was compared with sham TMS. For prefrontal TBS TMS versus sham TMS there were no differences when completer-only data were compared with all randomised in an intention-to-treat analysis. 


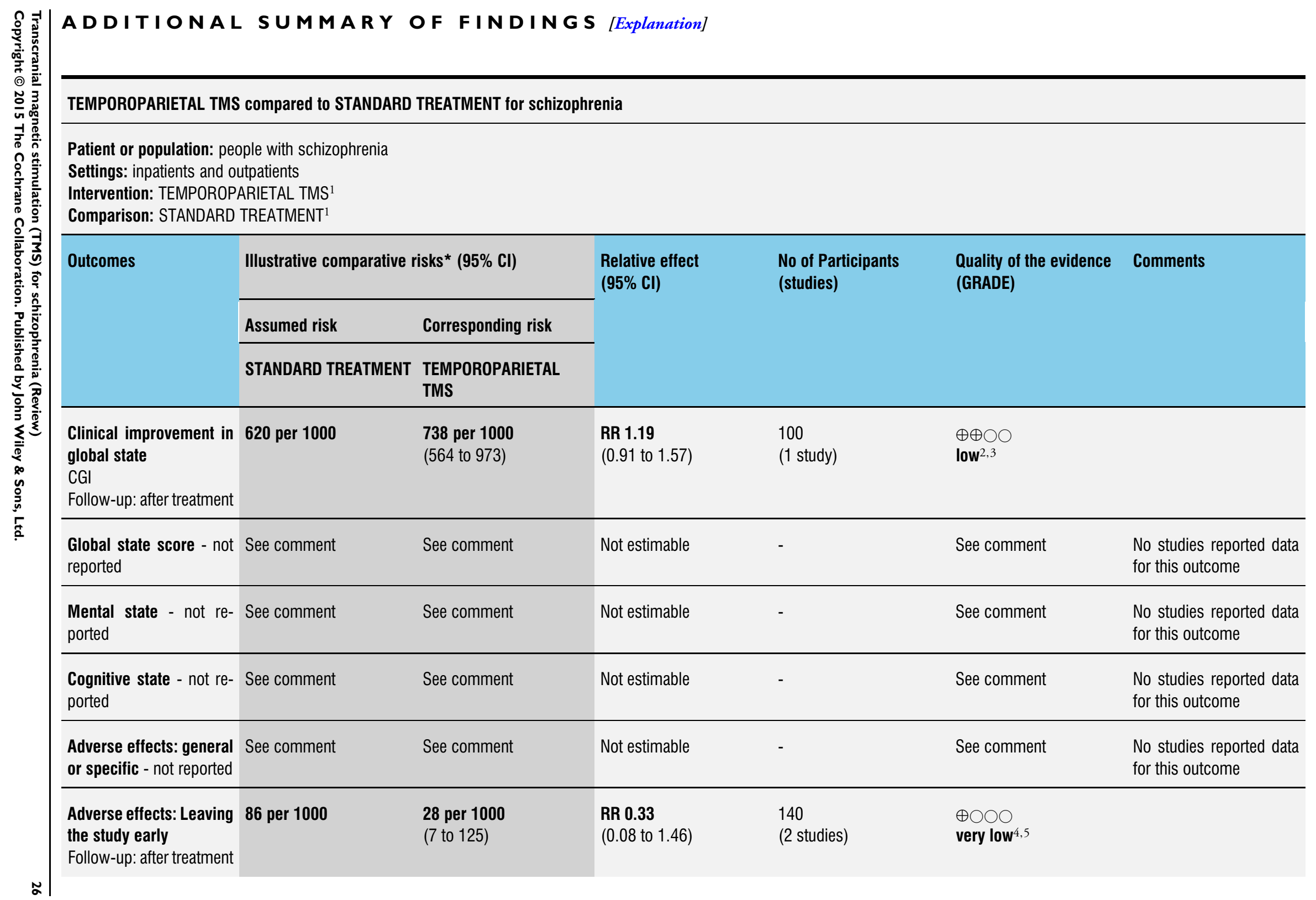




\begin{tabular}{|c|c|c|c|c|c|c|}
\hline $\begin{array}{l}\text { Satisfaction with care - } \\
\text { not reported }\end{array}$ & See comment & See comment & Not estimable & - & See comment & $\begin{array}{l}\text { No studies reported data } \\
\text { for this outcome }\end{array}$ \\
\hline
\end{tabular}

*The basis for the assumed risk is the median control group risk across studies) is provided in footnotes. The corresponding risk (and its $95 \%$ confidence interval) is based on the assumed risk in the comparison group and the relative effect of the intervention (and its $95 \% \mathrm{Cl}$ ).

CI: Confidence interval; RR: Risk ratio;

\section{GRADE Working Group grades of evidence}

High quality: Further research is very unlikely to change our confidence in the estimate of effect.

Moderate quality: Further research is likely to have an important impact on our confidence in the estimate of effect and may change the estimate.

Low quality: Further research is very likely to have an important impact on our confidence in the estimate of effect and is likely to change the estimate.

Very low quality: We are very uncertain about the estimate.

${ }^{1}$ Participants received first and second generation antipsychotics in both treatment groups

${ }^{2}$ Risk of bias: serious - this study had an unclear risk of bias for allocation concealment and blinding of participants and outcome

assessors

${ }^{3}$ Imprecision: serious - the confidence intervals are wide and include both benefit and harm

${ }^{4}$ Risk of bias: serious - one study had an unclear risk of bias for randomisation and both studies for allocation concealment. One study

had a unclear risk of bias for blinding of participants

${ }^{5}$ Imprecision: very serious - there were few participants and very few events; there are wide confidence intervals. 


\begin{tabular}{|c|c|c|c|c|c|c|}
\hline \multicolumn{7}{|c|}{ PREFRONTAL TMS compared to SHAM TMS for schizophrenia } \\
\hline \multicolumn{7}{|c|}{$\begin{array}{l}\text { Patient or population: people with schizophrenia } \\
\text { Settings: inpatients and outpatients } \\
\text { Intervention: PREFRONTAL TMS } \\
\text { Comparison: SHAM TMS }\end{array}$} \\
\hline \multirow[t]{3}{*}{ Outcomes } & \multicolumn{2}{|c|}{ Illustrative comparative risks* $(95 \%$ Cl) } & \multirow{3}{*}{$\begin{array}{l}\text { Relative effect } \\
(95 \% \mathrm{Cl})\end{array}$} & \multirow{3}{*}{$\begin{array}{l}\text { No of Participants } \\
\text { (studies) }\end{array}$} & \multirow{3}{*}{$\begin{array}{l}\text { Quality of the evidence } \\
\text { (GRADE) }\end{array}$} & \multirow[t]{3}{*}{ Comments } \\
\hline & Assumed risk & Corresponding risk & & & & \\
\hline & SHAM TMS & PREFRONTAL TMS & & & & \\
\hline $\begin{array}{l}\text { Clinical improvement in } \\
\text { global state - not re- } \\
\text { ported }\end{array}$ & See comment & See comment & Not estimable & - & See comment & $\begin{array}{l}\text { No studies reported data } \\
\text { for this outcome }\end{array}$ \\
\hline $\begin{array}{l}\text { Global state score } \\
\text { Various scales } \\
\text { Follow-up: after treatment }\end{array}$ & See comment & See comment & Not estimable & $\begin{array}{l}85 \\
(3)\end{array}$ & See comment & $\begin{array}{l}3 \text { small studies measured } \\
\text { global state on the CGI, } \\
\text { CGI-S, GAF and SCL- } 90 \text {, } \\
\text { none of which showed a } \\
\text { significant treatment ef- } \\
\text { fect }\end{array}$ \\
\hline $\begin{array}{l}\text { Mental state } \\
\text { PANSS } \\
\text { Follow-up: after treatment }\end{array}$ & See comment & See comment & Not estimable & $\begin{array}{l}188 \\
\text { (6 studies) }\end{array}$ & $\begin{array}{l}\oplus \bigcirc \bigcirc \bigcirc \\
\text { very low }\end{array}$ & $\begin{array}{l}\text { There was very high het- } \\
\text { erogeneity for this out- } \\
\text { come, so we did not pool } \\
\text { the data }\end{array}$ \\
\hline $\begin{array}{l}\text { Cognitive state } \\
\text { Various measures } \\
\text { Follow-up: after treatment } \\
\text { to } 6 \text { weeks }\end{array}$ & See comment & See comment & Not estimable & $\begin{array}{l}138 \\
\text { (4 studies) }\end{array}$ & $\begin{array}{l}\oplus \oplus \bigcirc \bigcirc \\
\text { low }^{3,4}\end{array}$ & $\begin{array}{l}\text { Cognitive state was re- } \\
\text { ported in } 4 \text { studies using } \\
19 \text { different measures. } \\
\text { Results were equivocal } \\
\text { for all measures apart } \\
\text { from } 4\end{array}$ \\
\hline
\end{tabular}




\begin{tabular}{|c|c|c|c|c|c|c|}
\hline $\begin{array}{l}\text { Adverse effects: general } \\
\text { or specific } \\
\text { Follow-up: after treatment }\end{array}$ & See comment & See comment & Not estimable & $\begin{array}{l}199 \\
\text { (7 studies) }\end{array}$ & $\begin{array}{l}\oplus \oplus \bigcirc \bigcirc \\
\text { low }^{5}\end{array}$ & $\begin{array}{l}\text { There were more } \\
\text { headaches and TMS-re- } \\
\text { lated site discomfort or } \\
\text { pain in the TMS group. } \\
\text { Results for other adverse } \\
\text { effects - cognitive diffi- } \\
\text { culties, facial twitching, } \\
\text { worsening of pre-existing } \\
\text { akathisia and OCD - were } \\
\text { equivocal }\end{array}$ \\
\hline $\begin{array}{l}\text { Adverse effects: Leaving } \\
\text { the study early } \\
\text { Follow-up: after treatment } \\
\text { to } 2 \text { weeks }\end{array}$ & 106 per 1000 & $\begin{array}{l}126 \text { per } 1000 \\
\text { (59 to } 265)\end{array}$ & $\begin{array}{l}\text { RR } 1.19 \\
\text { (0.56 to } 2.5)\end{array}$ & $\begin{array}{l}174 \\
\text { (8 studies) }\end{array}$ & $\begin{array}{l}\oplus \oplus \bigcirc \bigcirc \\
\text { low }^{6,7}\end{array}$ & \\
\hline $\begin{array}{l}\text { Satisfaction with care - } \\
\text { not reported }\end{array}$ & See comment & See comment & Not estimable & - & See comment & $\begin{array}{l}\text { No studies reported data } \\
\text { for this outcome }\end{array}$ \\
\hline
\end{tabular}

*The basis for the assumed risk (e.g. the median control group risk across studies) is provided in footnotes. The corresponding risk (and its $95 \%$ confidence interval) is based on the assumed risk in the comparison group and the relative effect of the intervention (and its $95 \% \mathrm{Cl}$ ).

Cl: Confidence interval; RR: Risk ratio;

GRADE Working Group grades of evidence

High quality: Further research is very unlikely to change our confidence in the estimate of effect.

Moderate quality: Further research is likely to have an important impact on our confidence in the estimate of effect and may change the estimate.

Low quality: Further research is very likely to have an important impact on our confidence in the estimate of effect and is likely to change the estimate.

Very low quality: We are very uncertain about the estimate.

${ }^{1}$ Risk of bias: serious - two studies had an unclear risk of bias for randomisation and five for allocation concealment. Five studies had

an unclear risk for blinding of participants and two for blinding of outcome assessors and incomplete outcome data.

${ }^{2}$ Incosistency: very serious - there was a very high heterogeneity for this outcome and we did not pool results

${ }^{3}$ Risk of bias: serious - two studies had an unclear risk of bias for randomisation and three for allocation concealment. All studies had

an unclear risk for blinding of participants and two studies had an unclear risk for incomplete outcome data

${ }^{4}$ Imprecision: serious - different scales were used to measure this outcome, the majority had wide confidence intervals

${ }^{5}$ Risk of bias: very serious - five studies had an unclear risk of bias for randomisation and allocation concealment. All had an unclear risk

for blinding of participants, and two for blinding of outcome assessors. Four had an unclear risk for incomplete outcome data

ก ${ }^{6}$ Imprecision: serious: there are wide confidence intervals 


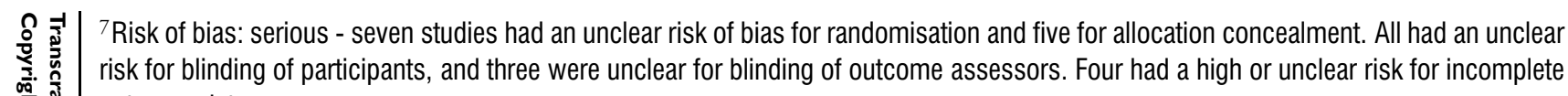
outcome data 


\section{PREFRONTAL TBS TMS compared to SHAM TMS for schizophrenia}

Patient or population: people with schizophrenia

Settings: inpatients and outpatients

Intervention: PREFRONTAL TBS TMS

Comparison: SHAM TMS

\begin{tabular}{|c|c|c|c|c|c|c|}
\hline \multirow[t]{3}{*}{ Outcomes } & \multicolumn{2}{|c|}{ Illustrative comparative risks* $(95 \%$ Cl) } & \multirow{3}{*}{$\begin{array}{l}\text { Relative effect } \\
(95 \% \text { Cl) }\end{array}$} & \multirow{3}{*}{$\begin{array}{l}\text { No of Participants } \\
\text { (studies) }\end{array}$} & \multirow{3}{*}{$\begin{array}{l}\text { Quality of the evidence } \\
\text { (GRADE) }\end{array}$} & \multirow[t]{3}{*}{ Comments } \\
\hline & Assumed risk & Corresponding risk & & & & \\
\hline & SHAM TMS & PREFRONTAL TBS TMS & & & & \\
\hline $\begin{array}{l}\text { Clinical improvement in } \\
\text { global state } \\
\text { Follow-up: after treatment }\end{array}$ & 0 per 1000 & $\begin{array}{l}\mathbf{0} \text { per } 1000 \\
(0 \text { to } 0)\end{array}$ & $\begin{array}{l}\text { RR } 4.06 \\
\text { (0.21 to } 77.37)\end{array}$ & $\begin{array}{l}27 \\
\text { (1 study) }\end{array}$ & $\begin{array}{l}\oplus \bigcirc \bigcirc \bigcirc \\
\text { very low }\end{array}$ & \\
\hline $\begin{array}{l}\text { Global state score - not } \\
\text { reported }\end{array}$ & See comment & See comment & Not estimable & - & See comment & $\begin{array}{l}\text { No studies reported data } \\
\text { for this outcome }\end{array}$ \\
\hline $\begin{array}{l}\text { Mental state } \\
\text { PANSS } \\
\text { Follow-up: after treatment }\end{array}$ & $\begin{array}{l}\text { The mean scores for the } \\
\text { sham TMS group ranged } \\
\text { from } 67.6 \text { to } 68.4\end{array}$ & $\begin{array}{l}\text { The mean mental state } \\
\text { in the intervention groups } \\
\text { was } \\
\mathbf{5 . 7 1} \text { lower } \\
\text { (9.32 to } 2.1 \text { lower) }\end{array}$ & & $\begin{array}{l}108 \\
\text { (3 studies) }\end{array}$ & $\begin{array}{l}\oplus \oplus \bigcirc \bigcirc \\
\text { low }^{1,3}\end{array}$ & \\
\hline $\begin{array}{l}\text { Cognitive state } \\
\text { Various measures } \\
\text { Follow-up: after treatment }\end{array}$ & See comment & See comment & Not estimable & $\begin{array}{l}39 \\
\text { (1 study) }\end{array}$ & $\begin{array}{l}\oplus \oplus \bigcirc \bigcirc \\
\text { low }^{1,4}\end{array}$ & $\begin{array}{l}\text { This was measured on } \\
2 \text { scale, both showed } \\
\text { equivocal results }\end{array}$ \\
\hline $\begin{array}{l}\text { Adverse effects: general } \\
\text { or specific } \\
\text { Follow-up: after treatment }\end{array}$ & See comment & See comment & Not estimable & $\begin{array}{l}27 \\
\text { (1 study) }\end{array}$ & $\begin{array}{l}\oplus \oplus \bigcirc \bigcirc \\
\text { low }^{1,3}\end{array}$ & $\begin{array}{l}\text { No } \\
\text { differences in headaches } \\
\text { and sleep disorders }\end{array}$ \\
\hline
\end{tabular}




\begin{tabular}{|c|c|c|c|c|c|c|}
\hline $\begin{array}{l}\text { Adverse effects: Leaving } \\
\text { the study early }\end{array}$ & 139 per 1000 & $\begin{array}{l}50 \text { per } 1000 \\
\text { (10 to } 242)\end{array}$ & $\begin{array}{l}\text { RR } \mathbf{0 . 3 6} \\
(0.07 \text { to } 1.74)\end{array}$ & $\begin{array}{l}76 \\
\text { (2 studies) }\end{array}$ & $\begin{array}{l}\oplus \oplus \bigcirc \bigcirc \\
\mathbf{l o w}^{1,2}\end{array}$ & \\
\hline $\begin{array}{l}\text { Satisfaction with care - } \\
\text { not reported }\end{array}$ & See comment & See comment & Not estimable & - & See comment & $\begin{array}{l}\text { No studies reported data } \\
\text { for this outcome }\end{array}$ \\
\hline
\end{tabular}

*The basis for the assumed risk (e.g. the median control group risk across studies) is provided in footnotes. The corresponding risk (and its $95 \%$ confidence interval) is based on the assumed risk in the comparison group and the relative effect of the intervention (and its $95 \% \mathrm{Cl}$ ).

Cl: Confidence interval; RR: Risk ratio;

GRADE Working Group grades of evidence

High quality: Further research is very unlikely to change our confidence in the estimate of effect.

Moderate quality: Further research is likely to have an important impact on our confidence in the estimate of effect and may change the estimate.

Low quality: Further research is very likely to have an important impact on our confidence in the estimate of effect and is likely to change the estimate.

Very low quality: We are very uncertain about the estimate.

${ }^{1}$ Risk of bias: serious - there was an unclear risk of bias for allocation concealment and blinding

Imprecision: serious - there were very few participants and very few events; the confidence intervals are wide

${ }^{3}$ Imprecision: serious - there are wide confidence intervals

${ }^{4}$ Imprecision: serious - this was measured on two scales by one study, both of which had wide confidence intervals 


\section{DISCUSSION}

Overall the quality of the evidence was rated as very low based on the 'Summary of findings' tables (Summary of findings for the main comparison; Summary of findings 2; Summary of findings 3; Summary of findings 4).

\section{Summary of main results}

\section{COMPARISON I: TEMPOROPARIETAL TMS VERSUS SHAM}

Very low-quality evidence from one small trial showed no evidence of effect of temporoparietal TMS compared to sham TMS for clinically improving global state. However, there is some very lowquality evidence to show that global state scores on the CGI scale are superior with temporoparietal TMS. There is also very lowquality evidence from the PANSS scale that temporoparietal TMS is superior to sham TMS in improving mental state. While there may be some benefits with TMS over sham TMS, the clinical significance of some of the scale-driven data is unclear. Very low-quality evidence shows that temporoparietal TMS does not affect cognitive state; however, participants receiving temporoparietal TMS experienced more headaches than those in the sham TMS group. No more participants left the study early in the temporoparietal TMS than the sham TMS group, but again, this is very low-quality evidence. No studies reported whether participants were satisfied with their care.

\section{COMPARISON 2: TEMPOROPARIETAL TMS VERSUS STANDARD CARE}

Limited low-quality evidence shows that temporoparietal TMS is not superior to standard treatment (first- and second-generation antipsychotic medication) in clinically improving global state, and the number of participants leaving the study early does not differ between temporoparietal TMS and standard treatment. No studies reported on participants' mental state and cognitive state, experience of adverse effects and whether they were satisfied with their care.

\section{COMPARISON 3: PREFRONTAL TMS VERSUS SHAM}

We found no evidence that prefrontal TMS is superior to sham TMS in improving global state, mental state and cognitive state, although the quality of the evidence is very low. Prefrontal TMS does not cause more headaches than sham TMS, and the number of participants leaving the study early did not differ between treatment groups, but again the evidence is of very low quality. No studies reported whether participants were satisfied with their care.

\section{COMPARISON 4: PREFRONTAL TBS TMS VERSUS SHAM}

Prefrontal TBS TMS is not superior to sham TMS in improving global state and cognitive state, but there is some evidence that it improves mental state, although the evidence is of very low quality. Prefrontal TBS TMS does not cause participants to experience more headaches or to leave the study earlier than sham TMS, but again this is from very low-quality evidence. No studies reported whether participants were satisfied with their care.

\section{Overall completeness and applicability of evidence}

\section{Duration}

Studies reported substantial differences in the length of trials, which ranged from four days (McIntosh 2004) to 10 weeks (Wing 2012). This issue is therefore potentially problematic for comparison, and caution should be considered in relation to any conclusions. Difference in study length may arise from the nature of the population samples in terms of the associated high attrition rates. The lack of consistency across studies in relation to study length may also reflect the novel aspect of the intervention and the lack of a standardised procedure. We did not stratify the data by the different time periods specified in Types of outcome measures in the protocol, as there were not enough data (see Differences between protocol and review).

\section{Participants}

Participants were consistently classified with schizophrenia or schizoaffective disorder, with most studies using a diagnosis according to the DMS-IV. Prikryl 2007 reported the ICD-10, and Schneider 2008 reported the use of both a diagnosis of schizophrenia with at least one year prior hospitalisation. The sample groups included for review were therefore well matched.

\section{Control condition}

A wide variety of sham TMS techniques were reported across the included studies. Although most studies reported use of the same stimulation as for active TMS, additional descriptions of this procedure varied from the edge of the coil resting at a 45 degree angle, a 90 degree angle, with one wing touching or with both wings touching. In addition further descriptions included a sham coil which produced identical sounds to the active TMS, and a sham coil which had a magnetically non-translucent headpiece. Drawing a comparison across results and the interpretation of findings is therefore hindered.

Surprisingly, there is very little information on TMS compared to other treatments for schizophrenia. No studies compared TMS 
with other physical methods of treatment such as electroconvulsive therapy (ECT), and two (out of 41 included) studies compared TMS with standard treatment. The standard treatment in these studies (Bagati 2009; Liu 2011) was antipsychotics, although those given TMS also received them.

One trial out of the 18 ongoing trials compares TMS with treatment as usual, and the remaining studies compare TMS with sham TMS, although one trial (NCT01370291) plans to compare both treatments with and without the use of risperidone. This indicates that the evidence base for TMS is still being studied against sham TMS, before comparisons with active treatments can be envisaged.

\section{Intervention}

The active TMS intervention in both the prefrontal and temporoparietal conditions varied substantially across studies in terms of stimulation intensity, length of stimulation, and location of TMS. Studies which conducted prefrontal TMS reported the greatest variations. Stimulation intensity included ranges of $1 \mathrm{~Hz}$, $10 \%$ above threshold to $20 \mathrm{~Hz}$ at $80 \%$ motor threshold, and three studies used TBS of $50 \mathrm{~Hz}$. Length of stimulation for prefrontal TMS studies ranged from two trains of one minute with a threeminute gap (Klein 1999), to 40 trains of 2.5 seconds with a 30second gap (Novak 2006) with a number of different variations across studies. Location of prefrontal TMS stimulation also differed, with reports of left prefrontal TMS, left dorsolateral prefrontal cortex TMS, right prefrontal TMS, and bilateral prefrontal TMS. For studies which used temporoparietal TMS, there was some consistency in that all but two studies reported using TMS stimulations of $1 \mathrm{~Hz}$. However the level of motor threshold did vary, with reports of $20 \%$ below motor threshold to $100 \%$ motor threshold. As with the prefrontal TMS studies, in the case of temporoparietal TMS a wide variety of stimulation length was reported, which ranged from five sessions of one minute with oneminute gaps (Saba 2006a) to two session of 20 minutes each a day (Vercammen 2009a). There was also more consistency with studies of temporoparietal TMS in regards to location, as all but one study reported left temporoparietal TMS, with the exception of Lee 2005 which reported also using right temporoparietal TMS. Comparing data within each intervention is therefore problematic, particularly for the prefrontal TMS for which the procedure varied more widely.

\section{Outcomes}

Of the seven categories of predefined outcomes, six were addressed in both the prefrontal TMS and temporoparietal TMS interventions. No data were available for analysis in the categories of hospital and service outcomes, satisfaction with care, and economic outcomes. There was a lack of data for quality of life, with only one study reporting this outcome for temporoparietal TMS. Future trials should consider including mechanisms for collecting these additional data; however, the authors acknowledge the tension between doing limited good-quality data collection at the expense of quantity.

\section{Quality of the evidence}

This review includes 41 studies with 1473 participants. Although all studies were reported as randomised, most studies reported unclear allocation concealment (Figure 2 and Figure 3). There is therefore a risk of selection bias due to a possible lack of good methods to conceal the allocation. Overall, only seven papers reported adequate allocation concealment. Most studies included in the review were described as double-blind. However, only seven studies reported an adequate blinding procedure. This can influence both performance and attrition bias, and is of particular importance in such study designs, due to the use of subjective measures. In many studies data were not fully reported and we had to contact authors in order to obtain both means and standard deviations for individual measures.

Overall, we judged the quality of the evidence to be low to very low. In general, the results were consistent, although scale data results for mental state showed some heterogeneity. We downgraded the evidence in the 'Summary of findings' tables mostly because of the risks of bias in the studies mentioned above, and the imprecision of the results due to wide confidence intervals.

\section{Potential biases in the review process}

We tried to identify all relevant trials in our search strategy. It is, however, possible that we may not have identified all studies. We are also aware the search date is old at time of publication and there may be new studies available.

The extraction of data and the risk of bias assessments for the Chinese language studies were completed by only one review author. There is the possibility that this may have introduced some bias into the results, as it was not possible to cross-check these data.

\section{Agreements and disagreements with other studies or reviews}

Previous research has found that TMS can significantly reduce symptoms of schizophrenia. However, not all studies have subsequently replicated these findings. This was also reflected in the findings of the current review, as although there was some evidence to support the benefit of TMS in schizophrenia, findings were inconsistent across measures.

This review concluded that there was limited evidence for temporoparietal TMS as superior to sham TMS in improving auditory hallucinations; two meta-analyses of sham-controlled studies are in agreement with this finding, both concluding that there was 
a large and significant effect size for improving auditory hallucinations (Freitas 2009; Matheson 2010a). This review found limited evidence that temporoparietal TMS is superior to sham TMS for improving positive symptoms when measured on the PANSS scale; a meta-analysis of sham-controlled studies was in agreement, finding a large and significant effect size (Freitas 2009).

Limited evidence that prefrontal TMS is superior to sham in improving negative symptoms has also been reported elsewhere in two meta-analyses (Dlabac-de Lange 2010; Freitas 2009), the former finding a statistically significant improvement in an analysis of both PANSS and SANS, and the latter finding a non-significant small effect size for negative symptoms. Further agreement that prefrontal TMS can be effective in improving negative symptoms has been reached in a follow-up communication to a review (Matheson 2010b).

\section{AUTHORS' CONCLUSIONS}

\section{Implications for practice}

\section{For people with schizophrenia}

At present there is not strong evidence to support the use of TMS (temporoparietal or prefrontal) to treat or manage symptoms of schizophrenia. There was some evidence that TMS may help reduce some symptoms (such as auditory hallucinations and negative symptoms, which include apathy), compared to sham TMS, although the results were unclear and the findings were not the same across all of the small studies identified in the review. Moreover, very few studies compared TMS with standard treatments, including antipsychotic drugs such as clozapine that are often used when troublesome symptoms persist. However, in the future once more high-quality studies have been conducted, there is a possibility that TMS may be useful for treating and managing some symptoms of schizophrenia in addition to usual care.

\section{For clinicians}

Based on this review, we can make no recommendations for the use of TMS to treat symptoms of schizophrenia. The review found that temporoparietal TMS may help reduce auditory hallucinations and positive symptoms of schizophrenia, and that prefrontal TMS helps to reduce some negative symptoms of schizophrenia. However, any significant results were not consistent across various symptom measures, and there were a limited number of studies for each finding. Although the evidence does not support the use of TMS as a treatment option at present, further research with consistent protocols may lead to the development of an effective procedure for its use in future practice.

\section{For managers/policy makers}

Findings from this review do not provide robust data to support the use of TMS in clinical practice for schizophrenia. However there was a suggestion that TMS may improve some symptoms of schizophrenia, although this was equivocal. Future research that uses routine protocols for both TMS and sham treatment procedures should therefore be supported where possible.

\section{Implications for research}

\section{General}

There are 18 studies currently ongoing, which plan to include 790 participants, and all but one compare TMS to sham TMS. Future studies should aim to adhere to more standardised procedures for both TMS and sham protocols. However, given the range of procedures in the included and ongoing studies, it appears that we are still at an exploratory stage and no clear evidence-based protocol has emerged. Research should aim for the use of standardised outcomes and measures with which to analyse findings, with publication of analysis protocols before completion of the study itself. This would improve comparability of results across studies and provide a clearer insight into the potential benefits of TMS.

\section{Specific}

\section{I More studies}

In order to clarify some of the findings presented in this review, we require further research to investigate the possibility of TMS as a viable treatment option for schizophrenia. Research should specifically aim to identify which symptoms would benefit from the technique and which methods could be most effective. This will need both more high-quality studies and the recruitment of samples with sufficient statistical power to address the primary questions posed by the research teams.

\subsection{Duration}

There should be standardised procedures in terms of study duration in order to improve compatibility of findings. Although we acknowledge that there are difficulties about adherence for the participant group, research should aim to be more consistent to allow a greater basis for comparison and to extend the clinical data collection period beyond the duration of the treatment phase itself, so as to assess the sustainability of any observed effect.

\subsection{Sham protocol}

The protocol for sham treatment should be standardised to reduce variation and ensure that the control condition refers to a similar procedure across research. Efforts should be made to ensure that 
the experience of the treatment procedure using the sham protocol is indistinguishable from the active intervention, to improve blinding of participants and their carers.

\subsection{Intervention protocol}

For both temporoparietal and prefrontal TMS, a consistent protocol in relation to stimulation intensity, length of stimulation, and location of treatment should be developed. This would reduce the large variation in procedures and greatly improve the comparability of findings.

\subsection{Randomisation}

There should be clear reporting of study design, in particular the methods to guarantee allocation concealment and double-blinding, to provide comprehensive information on study procedures which can be compared. There should be good-quality blinding at allocation, to reduce any risk of selection bias.

\subsection{Outcome measures}

Research should aim to provide consistency of outcome measures for both the type of measure (e.g. endpoint or change score) and the scales used. Comparison of findings is greatly hindered by differences in outcome measures, and consistency in this area would provide a stronger basis for informed conclusions.

\section{ACKNOW LEDGEMENTS}

We would like to thank the editorial base of the Cochrane Schizophrenia Group for their support, and Enhance Reviews for helping us with the final push with screening the 2013 search results. We gratefully acknowledge the financial support of the Gordon Small charitable trust. ND would like to thank the support of the Chief Scientist Office of the Scottish Government-funded NMAHP Research Unit, University of Stirling.

We thank Prathap Tharyan for his feedback and recommendations as editor of this review and Dr Sudheer Lankappa for peer reviewing it.

Thank you to Jun Xia for screening and data extraction of Chinese papers.

Thank you to Prof Klaus Ebmeier for his help. Klaus was involved in the review up until 2010; resolved conflicts between authors; performed data extraction and helped draft the review.

\section{R E F E R E N C E S}

\section{References to studies included in this review}

Bagati 2009 \{published data only\}

Bagati D, Nizamie SH, Prakash R. Effect of augmentatory repetitive transcranial magnetic stimulation on auditory hallucinations in schizophrenia: randomized controlled study. Australian and New Zealand Journal of Psychiatry 2009;43(4):386-92. [MEDLINE: 19296295]

Barr 2013 \{published data only\}

* Barr MS, Farzan F, Rajji TK, Voineskos AN, Blumberger $\mathrm{DM}$, Arenovich T, et al. Can repetitive magnetic stimulation improve cognition in schizophrenia? Pilot data from a randomized controlled trial. Biological Psychiatry 2013;73 (6):510-7.

Barr MS, Farzan F, Tran LC, Fitzgerald PB, Daskalakis ZJ. A randomized controlled trial of sequentially bilateral prefrontal cortex repetitive transcranial magnetic stimulation in the treatment of negative symptoms in schizophrenia. Brain Stimulation 2011;3(5):337-46.

NCT01494623. The effect of repetitive transcranial magnetic stimulation (rtms) on working memory. ClinicalTrials.gov/show/NCT01494623 2011 (accessed 25th July 2015).

Blumberger 2012 \{published data only\} * Blumberger DM, Christensen BK, Zipursky RB, Moller B, Chen R, Fitzgerald PB, et al. MRI-targeted repetitive transcranial magnetic stimulation of Heschl's gyrus for refractory auditory hallucinations. Brain Stimulation 2012; 5(4):577-85.

NCT01386918. Repetitive transcranial magnetic stimulation for refractory auditory hallucinations in schizophrenia. clinicaltrials.gov/ct2/show/NCT01386918 2011 (accessed 25th July 2015).

\section{Brunelin 2006 \{published data only\}}

Brunelin J, Poulet E, Bediou B, Kallel L, Dalery J, D'amato $T$, et al. Low frequency repetitive transcranial magnetic stimulation improves source monitoring deficit in hallucinating patients with schizophrenia. Schizophrenia Research 2006;81(1):41-5. [: EMBASE 2005578713]

\section{Chen 2011 \{published data only\}}

陈海茥, 张志娟, 王继军, 陈月敏, 项志清, 施慎逊, et al. Repetitive transcranial magnetic stimulation in the adjuvant treatment of patients with schizophrenia to explore the influence of eye movements and negative symptoms: a randomized, double-blind, pseudo-stimulus-control study

[重复经硕磁刺激辅助治疗对精神分裂症患者探索性眼球运动和阴性症状的景

随机、双盲、伪刺激对照研究(英文)]. 上海精神医学 2011; Vol. 23, issue 04:200-6.

Cordes 2010 \{published data only\}

* Cordes J, Thunker J, Agelink MW, Arends M, Mobascher 
A, Wobrock T, et al. Effects of $10 \mathrm{hz}$ repetitive transcranial magnetic stimulation (rtms) on clinical global impression in chronic schizophrenia. Psychiatry Research 2010;177(1-2): 32-6. [MEDLINE: 20378181]

Mittrach M, Thunker J, Winterer G, Agelink MW, Regenbrecht G, Arends M, et al. The tolerability of rtms treatment in schizophrenia with respect to cognitive function. Pharmacopsychiatry 2010;43(3):110-7. NCT00169689. Therapeutic and biological effects of high frequency repetitive transcranial magnetic stimulation (rTMS) in schizophrenia. www.clinicaltrials.gov 2005 (accessed 25th July 2015).

De Jesus 2011 \{published data only\}

De Jesus DR, Gil A, Barbosa L, Lobato MI, Da Silva Magalhaes PV, De Souza Favalli GP, et al. A pilot double-blind sham-controlled trial of repetitive transcranial magnetic stimulation for patients with refractory schizophrenia treated with clozapine. Psychiatry Research 2011;188(2):203-7. [MEDLINE: BIOSIS: PREV201100512109]

Fitzgerald 2005 \{published and unpublished data\} Fitzgerald PB, Benitez J, Daskalakis JZ, Brown TL, Marston NA, De Castella A, et al. A double-blind sham-controlled trial of repetitive transcranial magnetic stimulation in the treatment of refractory auditory hallucinations. Journal of Clinical Psychopharmacology 2005;25(4):358-62.

Fitzgerald 2008 \{published data only\}

* Fitzgerald PB, Herring S, Hoy K, McQueen S, Segrave R, Kulkarni J, et L. A study of the effectiveness of bilateral transcranial magnetic stimulation in the treatment of the negative symptoms of schizophrenia. Brain Stimulation 2008; 1(1):27-32.

Fitzgerald PB, Hoy K, Herring S, McQueen S, Karpinski A, Daskalakis ZZ. The use of rtms and tdcs in the treatment of the positive, negative and cognitive symptoms of schizophrenia. Australian and New Zealand Journal of Psychiatry 2010;1:16.

Gao 2009a \{published data only\}

高志勤, 余海鹰, 崔雪莲, 金梅, 邱旭萍. [Low-frequency repetitive transcranial magnetic stimulation treatment of schizophrenia and the effect of chronic auditory hallucinations follow-up study] Google Translate
高志勤，余海度，金梅，邱旭辇. [Repetitive transcranial magnetic stimulation on the negative symptoms of chronic schizophrenia soldiers and the efficacy of cognitive function] Google Translate

\section{[重复经颅磁刺激对军人慢性精神分裂症患者阴性症状及认知功能的疗效分标}

Sichuan Mental Health [四川精神卫生] 2009;22(4):

$193-5$.

\section{Gao 2010 \{published data only\}}

高志勤, 余海麿, 崔雪莲, 邱叴萍. Low-frequency repet-

itive transcranial magnetic stimulation treat-

ment of chronic auditory hallucinations of

schizophrenia efficacy soldiers] Google Translate

\section{[低频重复经炒磁刺激治疗军人精神分裂症慢性幻听疗效观察}

[]. People's Military Surgeon /人民军医] 2010;53(1):5-6.

Guse 2013 \{published data only\}

Cordes J, Falkai P, Guse B, Hasan A, Schneider-Axmann

$\mathrm{T}$, Arends $\mathrm{M}$, et al. Repetitive transcranial magnetic stimulation for the treatment of negative symptoms in residual schizophrenia: rationale and design of a shamcontrolled, randomized multicenter study. European Archives of Psychiatry and Clinical Neuroscience 2009;259 (Suppl 2):189-97. [MEDLINE: 19876678]

* Guse B, Falkai P, Gruber O, Whalley H, Gibson L, Hasan A, et al. The effect of long-term high frequency repetitive transcranial magnetic stimulation on working memory in schizophrenia and healthy controls-a randomized placebocontrolled, double-blind fmri study. Behavioural Brain Research 2013;237(1):300-7.

NCT00783120. Repetitive transcranial magnetic stimulation (rTMS) for the treatment of negative symptoms in schizophrenia. www.clinicaltrials.gov 2008 (accessed 25th July 2015).

\section{Hao 2008 \{published data only\}}

Hao L, Hui L, Rui L, Jijun W. The analysis of curative effect of negative symptoms in schizophrenic patients after the treatment of repetitive transcranial magnetic stimulation (rTMS)

[重复经秒磁刺激治疗精神分裂症阴性症状的疗效分析].

Journal of Modern Electrophysiology [现代电生理学杂志] 2008;15(3):134-7.
* Hoffman RE, Gueorguieva R, Hawkins KA, Varanko M, Boutros NN, Wu Y, et al. Temporoparietal transcranial magnetic stimulation for auditory hallucinations: safety, efficacy and moderators in a fifty patient sample. Biological Psychiatry 2005;58(2):97-104.

Hoffman RE, Hawkins KA, Gueorguieva R, Boutros NN, Rachid F, Carroll K, et al. Transcranial magnetic stimulation of left temporoparietal cortex and medication-resistant auditory hallucinations. Archives of General Psychiatry 2003; 60(1):49-56. [MEDLINE: 22399428; : 12511172] NCT00004980. Randomized study of repetitive magnetic stimulation of speech processing brain areas in schizophrenic 
patients who hear "voices". www.clinicaltrials.gov 2000 (accessed 25th July 2015).

NCT00042159. TMS intervention development for auditory hallucinations. www.clinicaltrials.gov 2002 (accessed 25th July 2015).

Holi 2004 \{published data only\}

Holi MM, Eronen M, Toivonen K, Toivonen P, Marttunen M, Naukkarinen H. Left prefrontal rTMS in schizophrenia. Nordic Journal of Psychiatry 2002; Vol. 56:19. M, Naukkarinen H. Left prefrontal repetitive transcranial magnetic stimulation in schizophrenia. Schizophrenia Bulletin 2004;30(2):429-34. [MEDLINE: 15279057; : EMBASE 2004274074]

Klein 1999 \{published data only\}

Klein E, Kolsky Y, Puyerovsky M, Koren D, Chistyakov A, Feinsod M. Right prefrontal slow repetitive transcranial magnetic stimulation in schizophrenia: a double blind sham controlled pilot study. Biological Psychiatry 1999; 46(10):1451-4. [MEDLINE: 10578460; : EMBASE 1999401053]

Klirova 2010 \{published data only\}

* Klirova M, Horacek J, Novak T, Cermak J, Tislerova B, Tintera J. Clinical response of neuronavigated repetitivetms in the treatment of auditory hallucinations. European Neuropsychopharmacology 2010;1:304-5.

Klirova M, Horek J, Ermk J, Novk T, Tilerov B. Clinical response of neuronavigated rtms in the treatment of auditory hallucinations. Proceedings of the 17th European Psychiatric Association, EPA Congress; 2009 Jan 24-28; Lisbon Portugal. 2009:S773.

Lee 2005 \{published and unpublished data\} Lee S-H, Kim W, Chung Y-C, Jung K-H, Bahk WM, Jun T-Y, et al. A double blind study showing that two weeks of daily repetitive TMS over the left or right temporoparietal cortex reduces symptoms in patients with schizophrenia who are having treatment-refractory auditory hallucinations. Neuroscience Letters 2005;376(3):177-81. [MEDLINE: 15721217; : EMBASE 2005083871]

Liu 2008 \{published data only\}

Liu R, Wang J, Liu H, Li H. Comparative study for influence of rTMS on cognitive function in schizophrenia
* Holi MM, Eronen M, Toivonen K, Toivonen P, Marttunen

McIntosh 2004 \{published and unpublished data\} McIntosh AM, Semple D, Tasker K, Harrison LK, Owens DGC, Johnstone EC, et al. Transcranial magnetic stimulation for auditory hallucinations in schizophrenia. Psychiatry Research 2004;127(1-2):9-17.

Mogg 2005 \{published data only\} McLoughlin D. Clinical effectiveness of repetitive transcranial magnetic stimulation (rTMS) for auditory hallucinations in schizophrenia- a randomised controlled trial. Unpublished report. 1994. [: 7th World Congress of Biological Psychiatry [CD-ROM]: Conifer, Excerpta Medica Medical Communications BV, 2001 S019-05] McLoughlin DM, Mogg A, Purvis R, Eranti S, Brown R, Contell F, et al. Transcranial magnetic stimulation for negative symptoms in schizophrenia; a randomised pilot study. Biological Psychiatry 2006;59(8 Suppl):34S. McLoughlin DM, Mogg A, Purvis R, Eranti S, Brown R, Contell F, et al. Transcranial magnetic stimulation for negative symptoms in schizophrenia; a randomised pilot study. Proceedings of the 61st Annual Convention of the Society of Biological Psychiatry; 2006 May 18-20; Toronto, Canada. Toronto, CANADA: Elsevier Science Inc, 2006: 110.

* Mogg A, Purvis R, Eranti S, Contell F, Taylor JP, Nicholson T, et al. Repetitive transcranial magnetic stimulation for negative symptoms of schizophrenia: A randomized controlled pilot study. Schizophrenia Research 2005;93(1-3):221-8.

\section{NCT00308997 \{published data only\}}

* NCT00308997. Transcranial magnetic stimulation guided by neuroimaging for patients with persistent "voices". www.clinicaltrials.gov 2006 (accessed 25th July 2015).

NCT00567281. (Re-enrollment) Bilateral repetitive transcranial magnetic stimulation trial for auditory hallucinations. www.clinicaltrials.gov 2007 (accessed 25th July 2015).

Novak 2006 \{published and unpublished data\}

Novak T, Horacek J, Mohr P, Kopecek M, Rodriguez M, Spaniel F, et al. The double-blind sham-controlled study of high-frequency rTMS $(20 \mathrm{~Hz})$ fro negative symptoms in schizophrenia: a negative results. Neuroendocrinology Letters 2006;27(1-2):101-5.

\section{[重复经硕磁刺激治疗对精神分裂症认知功能影响的对照研究]. Poulet 2005 \{published and unpublished data\}}

Shanghai Archives of Psychiatry [上海精神医学]

Poulet E, Brunelin J, Bediou B, Bation R, Forgeard L, Dalery J, et al. Slow transcranial magnetic stimulation can rapidly reduce resistant auditory hallucinations in schizophrenia. Biological Psychiatry 2005;57(2):188-91. [MEDLINE: PUBMED 15652879; : CN-00513935]

Prikryl 2007 \{published data only\} Prikryl R, Kasparek T, Skotakova S, Ustohal L, Kucerova H, Ceskova E. Erratum to "Treatment of negative symptoms 研究] schizophrenia using repetitive transcranial magnetic stimulation in a double-blind, randomized controlled study" [Schizophrenia Research 95 (1-3) (2007) 151-157] 
(DOI:101016/jschres200706019). Schizophrenia Research 2008;99:380-1.

* Prikryl R, Kasparek T, Skotakova S, Ustohal L, Kucerova

$\mathrm{H}$, Ceskova E. Treatment of negative symptoms of schizophrenia using repetitive transcranial magnetic stimulation in a double-blind, randomized controlled study. Schizophrenia Research 2007;95(1-3):151-7.

Prikryl R, Kasperek T, Kucerova H, Ustohal L, Venclikova $S$, Ceskova E, et al. Has high frequency repetitive transcranial magnetic stimulation therapeutic potential in schizophrenia?. 26th Collegium Internationale NeuroPsychopharmacologicum Congress (CINP). 2008; Vol. 11: 91.

Prikryl R, Ustohal L, Kasparek T, Kucerova H, Ceskova E, Skotakova S. Influencing negative symptoms of schizophrenia with repetitive transcranial magnetic stimulation: a pilot study. European Neuropsychopharmacology. Amsterdam: Elsevier, 2006; Vol. 16 Suppl.4:S444-5.

Ren 2010 \{published data only\}

任䎦萍, 周东丰, 蔡焯基, 黄青, 卢荟, 陈琦. Low-frequency repetitive transcranial magnetic stimulation in the treatment of refractory auditory hallucinations of schizophrenia randomized double-blind controlled study Google Translate [低频重复经颖磁刺激治疗精神分裂症顽固性幻听的随机双盲对照研窈

Chinese Mental Health Journal [中国心理卫生杂志] 2010; 24(3): 195-7, 205.

Ren 2011 \{published data only\} Ren Y-P, Zhou D-F, Cai Z-J, Huang Q, Lu L, Chen Q. Effects of high frequency repetitive transcranial magnetic stimulation on refractory negative symptom of schizophrenia: A double blind, randomized controlled trial.

Chinese Mental Health Journal [中国心理卫生杂志] 2011; 25(2):89-92.

Rosa 2007 \{published data only\}

Rosa MO, Gattaz WF, Rosa MA, Rumi DO, Tavares H, Myczkowski M, et al. Effects of repetitive transcranial magnetic stimulation on auditory hallucinations refractory to clozapine. Journal of Clinical Psychiatry 2007; Vol. 68, issue 10:1528-32.

Rosenberg 2012 \{published data only\} Rosenberg O, Gersner R, Klein LD, Kotler M, Zangen A, Dannon P. Deep transcranial magnetic stimulation addon for the treatment of auditory hallucinations: A doubleblind study. Annals of General Psychiatry 2012;11:13.

Saba 2006a \{published data only\}

Saba G, Verdon CM, Kalalou K, Rocamora JF, Dumortier G, Benadhira R, et al. Transcranial magnetic stimulation in the treatment of schizophrenic symptoms: a double blind sham controlled study. Journal of Psychiatric Research 2006; 40(2):147-52.

Schneider 2008 \{published and unpublished data\}

Schneider A, Schneider T, Stark H. Repetitive transcranial magnetic stimulation (rTMS) as an augmentation treatment for the negative symptoms of schizophrenia: A 4-week randomized placebo controlled study. Brain Stimulation 2008;1(2):106-11.

\section{Slotema 2011 \{published data only\}}

Slotema CC, Blom JD, Hoek HW, Kahn RS, Sommer IE. The efficacy of low-frequency repetitive transcranial magnetic stimulation treatment for auditory verbal hallucinations may be low. Proceedings of the 163rd Annual Meeting of the American Psychiatric Association; 2010 May 22-26; New Orleans, LA. 2010.

* Slotema CW, Blom JD, De Weijer AD, Diederen KM, Goekoop R, Looijestijn J, et al. Can low-frequency repetitive transcranial magnetic stimulation really relieve medication-resistant auditory verbal hallucinations? Negative results from a large randomized controlled trial. Biological Psychiatry 2011;69(5):450-6. [MEDLINE: BIOSIS:PREV201100154047]

Slotema CW, Blom JD, Hoek HW, Kahn RS, Sommer IE. Can low-frequency rtms really relieve medicationresistant auditory verbal hallucinations? Negative results from a large rct. Schizophrenia Research 2010;117(2-3):534. [MEDLINE: ISI:000276936801402]

Vercammen 2009a \{published data only\} Vercammen A, Knegtering H, Bruggeman R, Westenbroek 研究M, Jenner JA, Slooff CJ, et al. Effects of bilateral repetitive transcranial magnetic stimulation on treatment resistant auditory-verbal hallucinations in schizophrenia: A randomized controlled trial. Australian and New Zealand Journal of Psychiatry 2010;1(1):15.

* Vercammen A, Knegtering H, Bruggeman R, Westenbroek Hanneke M, Jenner JA, Slooff CJ, et al. Effects of bilateral repetitive transcranial magnetic stimulation on treatment resistant auditory-verbal hallucinations in schizophrenia: a randomized controlled trial. Schizophrenia Research 2009; 114(1-3):172-9. [MEDLINE: 19679450]

Vercammen A, Knegtering H, Liemburg EJ, Den Boer JA, Aleman A. Functional connectivity of the temporoparietal region in schizophrenia: Effects of rtms treatment of auditory hallucinations. Journal of Psychiatric Research 2010;44(11):725-31. [MEDLINE: 20189190]

\section{Wing 2012 \{published data only\}}

NCT00736710. rTMS effects on smoking cessation and cognition in schizophrenia. www.clinicaltrials.gov 2008 (accessed 25th July 2015).

Wing VC, Bacher I, Daskalakis ZJ, George T. A preliminary study of repetitive transcranial magnetic stimulation for smoking cessation in schizophrenia. Neuropsychopharmacology 2010;35:S163.

Wing VC, Bacher I, Daskalakis ZJ, George T. A preliminary study of repetitive transcranial magnetic stimulation for smoking cessation in schizophrenia. Proceedings of the 49th Annual Meeting of the American College of Neuropsychopharmacology; 2010 Dec 5-9; Miami, Florida. 2010.

* Wing VC, Bacher I, Wu BS, Daskalakis ZJ, George TP. High frequency repetitive transcranial magnetic stimulation 
reduces tobacco craving in schizophrenia. Schizophrenia

Research 2012;139(1-3):264-6.

\section{Xu 2011 \{published data only\}}

徐亚秋, 谢世平, 杜经堬. Clinical study of the treatment of schizophrenia refractory auditory hallucinations low frequency repetitive transcranial magnetic stimulation

[低频重复经硕磁刺激治疗精神分裂症顽固性幻听的临床研究]

临床精神医学杂志 2011; Vol. 21, issue 03:177-80.

Yu 2010 \{published data only\}

余海鹰, 高志勤, 金梅, 孙剑, 丁松柏, 赵林, et al. Transcranial magnetic stimulation on prolactin levels in patients with schizophrenia

\section{[经颖磁刺激对精神分裂症患者催乳素水平的影响].}

东南国防医药 2010; Vol. 12, issue 06:512-4.

高志勤, 余海鹰, 金梅, 孙剑, 杨春, 丁松柏, et al. Low-frequency repetitive transcranial magnetic stimulation on serum prolactin levels in patients with chronic schizophrenia

[低频重复经点磁刺激对慢性精神分裂症患者血清催乳素水平的影响]

精神医学杂志 2011;24(03):192-5.

Zhang 2010 \{published data only\}

张志娟, 张新凯，李㯖，钟晓莲，成祖伟，睥力维，et al. Randomized， double-blind study of repetitive transcranial magnetic stimulation treatment of negative symptoms of schizophrenia

\section{[重复经乑磁刺激治疗精神分裂症阴性症状的随机双盲研究].}

上海精神医学 2010;22(05):262-5.

Zheng 2012 \{published data only\}

Zheng LN, Guo Q, Li H, Li C B, Wang JJ. Effects of repetitive transcranial magnetic stimulation with different paradigms on the cognitive function and psychotic symptoms of schizophrenia patients. Beijing Da Xue Xue Bao 2012;44:732-6.

\section{References to studies excluded from this review}

\section{ACTRN12611000731998 \{published data only\}}

ACTRN12611000731998. Transcranial direct current stimulation (tdcs) treatment for auditory hallucinations and thinking problems in schizophrenia. www.anzctr.org.au 2010 (accessed 25th July 2015).

\section{ACTRN12612000217808 \{published data only\}}

ACTRN12612000217808. Non-invasive brain stimulation and working memory enhancement in schizophrenia and healthy controls: Investigating transcranial direct current stimulation (tdcs) and transcranial alternating current stimulation (tacs). www.anzctr.org.au/ ACTRN12612000217808.aspx 2012 (accessed 25th July 2015).

ACTRN12612001112853 \{published data only\} ACTRN12612001112853. Using transcranial direct current stimulation (tdcs) to improve working memory in schizophrenia and healthy controls: Investigating the role of current strength at three time points post stimulation.
www.anzctr.org.au/ACTRN12612001112853.aspx 2012 (accessed 25th July 2015).

Alva 2001 \{published data only\}

Alva G, Cohen E, Jin Y, Highum DM, Fleming K, Bunney WE, et al. Differential effects of high and low frequency RTMS in schizophrenia. Schizophrenia Research 2001;49(2, Suppl 1):219.

Arends 2005 \{published data only\} Arends M, Mobascher A, Kratz J, Brinkmeyer J, Jänner M, Agelink MW, et al. Left dorsolateral prefrontal high frequency repetitive transcranial magnetic stimulation (rtms) and cognition in schizophrenic patients. XIII World Congress of Psychiatry; 2005 10-15th Sept; Cairo, Egypt. 2005. [: P11.P065]

Benitez 2005 \{published data only\}

Benitez J, Fitzgerald PB, Marston N, De Castella AR, Kulkarni J. A double-blind sham controlled trial of repetitive transcranial magnetic stimulation in the treatment of refractory auditory hallucinations. Schizophrenia Bulletin

\section{Brunelin 2012 \{published data only\}}

Brunelin J, Mondino M, Gassab L, Haesebaert F, Gaha L, Suaud-Chagny M-F, et al. Examining transcranial directcurrent stimulation (tdcs) as a treatment for hallucinations in schizophrenia. American Journal of Psychiatry 2012;169 (7):719-24. [MEDLINE: BIOSIS:PREV201200520535]

Chibbaro 2005 \{published data only\}

Chibbaro G, Daniele M, Alagona G, Di Pasquale C, Cannavo M, Rapisarda V, et al. Repetitive transcranial magnetic stimulation in schizophrenic patients reporting auditory hallucinations. Neuroscience Letters 2005;383(12):54-7. [: EMBASE: 2005252385]

Cohen 1999 \{published data only\}

Cohen E, Bernardo M, Masana J, Arrufat FJ, Navarro $\mathrm{V}$, Valls-Sole J, et al. Repetitive transcranial magnetic stimulation in the treatment of chronic negative schizophrenia: a pilot study. Journal of Neurology, Neurosurgery, and Psychiatry 1999;67(1):129-30.

Cordes 2008 \{published data only\}

Cordes J, Mittrach M, Kotrotsios G, Arends M, Wölwer W, Winterer G, et al. Effect of a treatment with $10 \mathrm{hz}$ repetitive transcranial magnetic stimulation (rTMS) on the EEG alpha activity of schizophrenic patients. Proceedings of the 161st Annual Meeting of the American Psychiatric Association; 2008 May 3-8; Washington DC, USA. 2008.

D'Alfonso 2002 \{published data only\}

D’Alfonso AA, Aleman A, Kessels RP, Schouten EA, Postma A, Van der Linden JA, et al. Transcranial magnetic stimulation of left auditory cortex in patients with schizophrenia: effects on hallucinations and neurocognition. Journal of Neuropsychiatry and Clinical Neuroscience 2002; 14(1):77-9.

Daskalakis 2003 \{published data only\} Daskalakis ZJ, Christensen BK, Chen R, Fitzgerald PB, Zipursky RB, Kapur S. Effect of antipsychotics on 
cortical inhibiition using transcranial magnetic stimulation. Psychopharmacology 2003;170(3):255-62.

Daskalakis 2007 \{published data only\}

Daskalakis Z. Repetitive transcranial magnetic stimulation (RTMS) in the neurophysiology and treatment of schizophrenia. Schizophrenia Bulletin 2007;33:402.

Davey 1997 \{published data only\} Davey NJ, Puri BK, Lewis HS, Lewis SW, Ellaway PH. Effects of antipsychotic medication on electromyographic responses to transcranial magnetic stimulation of the motor cortex in schizophrenia. Journal of Neurology, Neurosurgery, and Psychiatry 1997;63(4):468-73.

Feinsod 1998 \{published data only\}

Feinsod M, Kreinin B, Chistyakov A, Klein E. Preliminary evidence for a beneficial effect of low-frequency, repetitive transcranial magnetic stimulation in patients with major depression and schizophrenia. Depression and Anxiety 1998; 7(2):65-8.

Fitzgerald 2003 \{published data only\}

Fitzgerald PB, Brown TL, Marston NA, Oxley TJ, De Castella A, Daskalakis ZJ, et al. A transcranial magnetic stimulation study of abnormal cortical inhibition in schizophrenia. Psychiatry Research 2003;118(3):197-207.

Geller 1997 \{published data only\}

Geller V, Grisaru N, Abarbanel JM, Lemberg T, Belmaker RH. Slow magnetic stimulation of prefrontal cortex in depression and schizophrenia. Progressive NeuroPsychopharmacology \& Biological Psychiatry 1997;21(1): 105-10.

Goyal 2007 \{published data only\}

Goyal N, Nizamie SH, Desarker P. Efficacy of adjuvant high frequency repetitive transcranial magnetic stimulation on negative and positive symptoms of schizophrenia: preliminary results of a double-blind sham-controlled study. Journal of Neuropsychiatry and Clinical Neuroscience 2007; 19(4):464-7.

\section{Grenier 2008 \{published data only\}}

Grenier S, Fouldrin G, Allio G, Opolczynski G, Thibaut F. Repetitive transcranial magnetic stimulation efficiency in treatment-resistant auditory hallucinations. Schizophrenia Research 2008;98:56.

Hajak 2004 \{published data only (unpublished sought but not used)\} Hajak G, Marienhagen J, Langguth B, Werner S, Binder $\mathrm{H}$, Eichhammer P. High-frequency repetitive transcranial magnetic stimulation in schizophrenia: a combined treatment and neuroimaging study. Psychological Medicine 2004;34(7):1157-63.

Hasan 2010 \{published data only\}

Hasan A, Guse B, Heine Y, Heyer S, Schneider-Axmann T, Falkai $\mathrm{P}$, et al. Effects of long-term prefrontal repetitive transcranial magnetic stimulation on motor-cortical excitability. European Archives of Psychiatry and Clinical Neuroscience 2010;1:52.

\section{Hasey 2000 \{published data only\}}

Hasey G. Repeated transcranial magnetic stimulation (rTMS) for severe depression. Stanley Foundation Research Programs 2000.

\section{Hoffman 1999 \{published data only\}}

Hoffman RE, Berman RM, Roessler E, Belger A, Krystal $\mathrm{JH}$, Charney DS. Low-frequency transcranial magnetic stimulation in patients reporting voices. 152nd Annual Meeting of the American Psychiatric Association; 1999 May 15-20; Washington DC, USA. 1999. [MEDLINE: 91114065]

\section{Hoffman 2000 \{published data only\}}

Hoffman R, Boutros N, Preda A, Rachid F, Krystal J. One hertz repetitive transcranial magnetic stimulation reduces auditory hallucinations in patients with schizophrenia. Proceedings of the 7th World Congress of Biological Psychiatry. 2001 Jul 1-6; Berlin, Germany.

* Hoffman RE, Boutros NN, Hu S, Berman RM, Krystal $\mathrm{JH}$, Charney-DS. Transcranial magnetic stimulation and auditory hallucinations in schizophrenia. Lancet 2000;355 (9209):1073-5. [MEDLINE: 10744097]

\section{Hoffman 2003 \{published data only\}}

Hoffman RE, Hawkins KA, Anderson AW, Buchanan $\mathrm{R}$, Wu K, Hampson M, et al. One hertz repetitive transcranial magnetic stimulation delivered to brain areas underlying speech perception reduces persistent auditory hallucinations. Schizophrenia Research 2003;60(1, Suppl 1): 285-6. [MEDLINE: 22399428; : 12511172]

\section{Hoffman 2007 \{published data only\}}

Hoffman RE, Hampson M, Wu K, Anderson AW, Gore JC, Buchanan RJ, et al. Proving the pathophysiology of auditory/verbal hallucinations by combining functional magnetic resonance imaging and transcranial magnetic stimulation. Cerebral Cortex 2007;17(11):2733-43.

Jandl 2005 \{published data only\} Jandl M, Bittner R, Sack A, Weber B, Gunther T, Pieschl $\mathrm{D}$, et al. Changes in negative symptoms and EEG in schizophrenic patients after repetitive transcranial magnetic stimulation (rTMS): an open-label pilot study. Journal of Neural Transmission 2005;112(7):955-67.

\section{Jandl 2006 \{published and unpublished data\}} Jandl M, Steyer J, Weber M, Linden DE, Rothmeier J, Maurer K, et al. Treating auditory hallucination by transcranial magnetic stimulation: a randomized controlled cross-over trial. Neuropsychobiology 2006;53(2):63-9.

\section{Jandl 2010 \{published data only\}}

Jandl M, Kaschka WP. Treatment of therapy-resistant auditory verbal hallucinations in schizophrenia patients by repetitive transcranial magnetic stimulation. In: Elkis $\mathrm{H}$, Meltzer H editor(s). Therapy-Resistant Schizophrenia. Basel: Karger, 2010:177-94.

\section{Jin 2003 \{published data only\}}

Jin Y, Potkin SG, Huerta S, Alva G, Kang P, Bunney WE. EEG-guided RTMS improves negative symptoms in schizophrenia. Schizophrenia Research 2003;60(1, Suppl 
1):287-8. [DOI: S0920996403804735; MEDLINE: 22399428]

Jin 2006 \{published data only\}

Jin Y, Potkin SG, Kemp AS, Huerta ST, Alva G, Thai TM, et al. Therapeutic effects of individualized alpha frequency transcranial magnetic stimulation (TMS) on the negative symptoms of schizophrenia. Schizophrenia Bulletin 2006;32 (3):556-61.

Jin 2012 \{published data only\}

Jin Y, Kemp AS, Huang Y, Thai TM, Liu Z, Xu W, et al. Alpha EEG guided TMS in schizophrenia. Brain Stimulation 2012;5(4):560-8.

Levit-Binnun 2007 \{published data only\}

Levit-Binnun N, Handzy NZ, Moses E, Modai I, Peled A. Transcranial Magnetic Stimulation at M1 disrupts cognitive networks in schizophrenia. Schizophrenia Research 2007;93 (1-3):334-44.

Lifshitz 1968 \{published data only\}

Lifshitz K, Harper P. A trial of transcranial polarization in chronic schizophrenics. British Journal of Psychiatry 1968; 114(510):635-7. [MEDLINE: 68276552]

Loo 2010 \{published data only\} Loo CK, Sainsbury K, Mitchell P, Hadzi-Pavlovic D, Sachdev PS. A sham-controlled trial of left and right temporal rTMS for the treatment of auditory hallucinations. Psychological Medicine 2010;40(4):541-6. [MEDLINE: ISI:000276575300002]

Luber 2007 \{published data only\}

Luber B, Stanford AD, Malaspina D, Lisanby SH. Revisiting the backward masking deficit in schizophrenia: individual differences in performance and modeling with transcranial magnetic stimulation. Biological Psychiatry 2007;62(7): 793-9.

Mattai 2011 \{published data only\} Mattai A, Miller R, Weisinger B, Greenstein D, Bakalar J, Tossell J, et al. Tolerability of transcranial direct current stimulation in childhood-onset schizophrenia. Brain Stimulation 2011;4(4):275-80. [MEDLINE: 22032743]

Mobascher 2005 \{published data only\}

Mobascher A, Agelink MW, Arends M, Brinkmeyer J, Jaenner $M$, Henning $U$, et al. Influence of high frequency repetitive transcranial magnetic stimulation (rTMS) on cardiovagal modulation and monoaminergic activity in schizophrenia. Schizophrenia Bulletin 2005;31:514.

NCT00517075 \{published data only\}

NCT00517075. Treatment of negative symptoms of schizophrenia with transcranial magnetic stimulation (TMS). www.clinicaltrials.gov 2007 (accessed 25th July 2015).

NCT00757497 \{published data only\}

NCT00757497. Transcranial direct current brain stimulation to treat patients with childhood-onset schizophrenia. www.clinicaltrials.gov 2008 (accessed 25th July 2015).

\section{NCT00870909 \{published data only\}}

NCT00870909. Transcranial direct current stimulation (tDCS) and hallucinations in schizophrenia. www.clinicaltrials.gov 2009 (accessed 25th July 2015).

\section{NCT01041274 \{published data only\}} NCT01041274. DECIFER: DEpression and Citalopram In First Episode Recovery. www.clinicaltrials.gov 2009 (accessed 25th July 2015).

\section{NCT01378078 \{published data only\}}

NCT01378078. Transcranial direct current stimulation (tdcs) for treatment of negative syndrome in patients with schizophrenia. ClinicalTrials.gov/show/NCT01378078 2011 (accessed 25th July 2015).

NCT01595503 \{published data only\} NCT01595503. Transcranial magnetic stimulation for the treatment of auditory hallucinations in schizophrenia. ClinicalTrials.gov/show/NCT01595503 2012 (accessed 25th July 2015).

NCT01607840 \{published data only\} NCT01607840. Effects of transcranial direct current stimulation in individuals with schizophrenia. ClinicalTrials.gov/show/NCT01607840 2012 (accessed 25th July 2015).

\section{NCT01620086 \{published data only\}}

NCT01620086. Effect of repetitive transcranial magnetic stimulation on resting state brain activity in schizophrenia. ClinicalTrials.gov/show/NCT01620086 2012 (accessed 25th July 2015).

\section{NCT01623726 \{published data only\}} NCT01623726. Transcranial direct current stimulation (tdcs) as therapeutical strategy for negative symptoms in schizophrenia. ClinicalTrials.gov/show/NCT01623726 2012 (accessed 25th July 2015).

Potkin 2000 \{published data only\}

Potkin S. A randomized, sham-controlled trial of repetitive transcranial magnetic stimulation in schizophrenia. Stanley Foundation Research Programs 2000.

Puri 1996 \{published data only\} Puri BK, Davey NJ, Lewis SW. The effects of antipsychotic medication on electromyographic responses to transcranial magnetic stimulation of the motor cortex in schizophrenic patients. Schizophrenia Research 1996;18(2):234.

Rollnik 2000 \{published data only\}

Huber TJ, Schneider U, Rollnik J. Gender differences in the effect of repetitive transcranial magnetic stimulation in schizophrenia. Psychiatry Research 2003;120(1):103-5.

* Rollnik JD, Huber TJ, Mogk H, Siggelkow S, Kropp S, Dengler R, et al. High frequency repetitive transcranial magnetic stimulation (rTMS) of the dorsolateral prefrontal cortex in schizophrenic patients. Neuroreport 2000;11(18): 4013-5. [: Biological Abstracts 00073700]

Rushby 2010 \{published data only\} Rushby JA, Loo C, Weickert CS, Weickert TW. Effects of transcranial direct current stimulation on probabilistic 
feedback learning in people with schizophrenia. Schizophrenia Research 2010;117(2-3):177.

Sachdev 2005 \{published data only\}

Sachdev P, Loo C, Mitchell P, Malhi G. Transcranial

Magnetic Stimulation for the deficit syndrome of schizophrenia: A pilot investigation. Psychiatry and Clinical Neurosciences 2005;59(3):354-7.

Schneider 2001 \{published data only\}

Schneider A. A 2-week double-blind, randomized controlled trial of repetitive transcranial magnetic stimulation in schizophrenia. Stanley Foundation Research Programs 2001.

Schonfeldt-Lecuona 2004 \{published data only\} Schonfeldt-Lecuona C, Gron G, Walter H, Buchler N, Wunderlich A, Spitzer M, et al. Stereotaxic rTMS for the treatment of auditory hallucinations in schizophrenia. Neuroreport 2004;15(10):1669-73. [: CN-00516247]

Slotema 2012 \{published data only\}

Slotema CW, Blom JD, De Weijer AD, Hoek HW, Sommer IE. Priming does not enhance the efficacy of 1 hertz repetitive transcranial magnetic stimulation for the treatment of auditory verbal hallucinations: results of a randomized controlled study. Brain Stimulation 2012;5(4): 554-9.

Weickert 2010 \{published data only\}

Weickert TW, Rushby JA, Vercammen A, Weickert CS, Loo CK. Effects of transcranial direct current stimulation on probabilistic feedback learning in people with schizophrenia. Australian and New Zealand Journal of Psychiatry 2010;1(1): 16-7.

Xu 2006 \{published data only\}

Xu W-J, Jin YO, Huang Y, Liu Z, He H, Jin C. Doubleblind control trial of alpha electroencephalogramguided transcranial magnetic stimulation treatment for schizophrenia. Chinese Journal of Clinical Rehabilitation 2006;10(46):22-4.

Yu 2002 \{published data only\}

Yu H-C, Liao K-K, Chang T-J, Tsai S-J. Transcranial magnetic stimulation in schizophrenia. Americal Journal of Psychiatry 2002;159(3):494-5.

\section{References to studies awaiting assessment}

Mohr 2006 \{published data only\}

Mohr P, Rodriguez M, Novak T, Kopecek M, Horacek J, Hendrychova Y, et al. Repetitive transcranial magnetic stimulation and rehabilitation of cognitive functions in schizophrenia. European Psychiatry 2007;22:S127.

* Mohr P, Rodriguez M, Novak T, Kopecek M, Horacek J, Hendrychova Y, et al. Repetitive transcranial magnetic stimulation and rehabilitation of cognitive functions in schizophrenia. Psychiatrie (Stuttgart, Germany) 2006;10: $7-15$.

\section{References to ongoing studies}

Dlabac-de 2008 \{published data only\}

Dlabac-de Lange J, Aleman A. Effect of high frequency rTMS on negative symptoms and cognitive functioning in schizophrenia. www.trialregister.nl/trialreg/index.asp 2008 (accessed 25th July 2015).

Ebmeier 2001 \{published data only\} Ebmeier K. TMS and auditory hallucination in schizophrenia. National Research Register 2001.

Hunter 2003 \{published data only\}

Hunter M. A double-blind randomised controlled trial of repetitive transcranial magnetic stimulation (rTMS) in the treatment of persistent auditory hallucinations in schizophrenia. www.controlled-trials.com 2003 (accessed 25th July 2015).

\section{IRCT138903254191N1 \{published data only\}} IRCT138903254191N1. The comparison of effectiveness of repetitive tms and itbs on negative symptoms and cognition in patients with schizophrenia:A study randomized and double blind. www.irct.ir/ 2011 (accessed 25th July 2015).

ISRCTN61109178 \{published data only\} ISRCTN61109178. Transcranial magnetic stimulation (tms) treatment study in auditory verbal hallucinations: A randomised controlled trial. isrctn.org/ISRCTN61109178 2012 (accessed 25th July 2015).

Lee 2007 \{published data only\}

Lee KH. Pilot study for a new treatment of schizophrenia: a double-blind crossover transcranial magnetic stimulation. www.controlled-trials.com 2007 (accessed 25th July 2015).

\section{NCT00186771 \{published data only\}}

NCT00186771. Transcranial magnetic stimulation used to treat auditory hallucinations in schizophrenia. www.clinicaltrials.gov 2005 (accessed 25th July 2015).

\section{NCT00685321 \{published data only\}}

NCT00685321. Tolerability, safety and efficacy of the h1coil deep transcranial magnetic stimulation in subjects with negative symptoms and cognitive deficits of schizophrenia. www.clinicaltrials.gov 2008 (accessed 25th July 2015).

\section{NCT00763841 \{published data only\}}

NCT00763841. Transcranial magnetic stimulation (TMS) for treatment of auditory hallucinations. www.clinicaltrials.gov 2008 (accessed 25th July 2015).

\section{NCT00875498 \{published data only\}}

NCT00875498. Intermittent theta burst stimulation (iTBS) for the treatment of negative symptoms in schizophrenia. www.clinicaltrials.gov 2009 (accessed 25th July 2015).

\section{NCT01015001 \{published data only\}} NCT01015001. Effects of low frequency repetitive transcranial magnetic stimulation (rTMS) over temporoparietal cortex on the quality of life of refractory schizophrenic patients with auditory hallucinations. www.clinicaltrials.gov 2009 (accessed 25th July 2015). 


\section{NCT01022489 \{published data only\}}

NCT01022489. High frequency repetitive transcranial magnetic stimulation (rTMS) in schizophrenia: a randomized controlled study. www.clinicaltrials.gov 2009 (accessed 25th July 2015).

NCT01315587 \{published data only\}

NCT01315587. Repetitive transcranial magnetic stimulation and intermittent theta burst (itbs) in schizophrenia. ClinicalTrials.gov/show/NCT01315587 2011 (accessed 25th July 2015).

NCT01370291 \{published data only\}

NCT01370291. Repetitive transcranial magnetic stimulation for first-episode schizophrenia patients. ClinicalTrials.gov/show/NCT01370291 2011 (accessed 25th July 2015).

NCT01512290 \{published data only\}

NCT01512290. Theta burst transcranial magnetic stimulation as treatment for auditory verbal hallucinations. ClinicalTrials.gov/show/NCT01512290 2012 (accessed 25th July 2015).

NCT01523730 \{published data only\} NCT01523730. Effects of rtms on cigarette smoking and cognition in schizophrenia. ClinicalTrials.gov/show/ NCT01523730 2012 (accessed 25th July 2015).

NCT01551979 \{published data only\} NCT01551979. Therapeutic efficacy of transcranial magnetic stimulation in schizophrenia. ClinicalTrials.gov/ show/NCT01551979 2012 (accessed 25th July 2015).

Vercammen 2009b \{published data only\}

Vercammen A, Aleman A. Treatment of hallucinated "voices" with repetitive transcranial magnetic stimulation: mechanism and efficacy. www.trialregister.nl/trialreg/ index.asp 2009 (accessed 25th July 2015).

\section{Additional references}

\section{Altman 1996}

Altman DG, Bland JM. Statistics notes: detecting skewness from summary information. BMJ 1996;313(7066): 1200.

Andreasen 1983

Andreasen NC. The Scale for the Assessment of Negative Symptoms (SANS). Iowa City, Iowa: University of Iowa, 1983.

\section{Andreasen 1984}

Andreasen NC. The Scale for the Assessment of Positive Symptoms (SAPS). Iowa City, Iowa: Univ. of Iowa, 1984.

APA 1987

American Psychiatric Association. Global assessment of functioning. American Psychiatric Association Diagnostic and Statistical Manual of Mental Disorders. 3rd Edition.

Washington, DC: American Psychiatric Association, 1987.

Barker 2002

Barker AT. The history and basic principles of magnetic nerve stimulation. In: Pascual-Leone A, Davey N, Rothwell J, Wassermann EM, Puri BK editor(s). Handbook of
Transcranial Magnetic Stimulation. 1st Edition. New York: Oxford University Press, 2002:3-17.

Bland 1997

Bland JM. Statistics notes. Trials randomised in clusters. BMJ 1997;315:600.

\section{Boissel 1999}

Boissel JP, Cucherat M, Li W, Chatellier G, Gueyffier F, Buyse $\mathrm{M}$, et al. The problem of therapeutic efficacy indices. 3. Comparison of the indices and their use. Therapie 1999; 54(4):405-11.

\section{Chen 1997}

Chen R, Classen J, Gerloff C, Celnik P, Wassermann EM, Hallett $M$, et al. Depression of motor cortex excitability by low-frequency transcranial magnetic stimulation. Neurology 1997;48(5):1398-403.

\section{Chouinard 2003}

Chouinard PA, Van der Werf YD, Leonard G, Paus T. Modulating neural networks with transcranial magnetic stimulation applied over the dorsal premotor and primary motor cortices. Journal of Neurophysiology 2003;90(2): 1071-83.

\section{Deeks 2000}

Deeks J. Issues in the selection for meta-analyses of binary data. Proceedings of the 8th International Cochrane Colloquium; 2000 Oct 25-28th; Cape Town, South Africa. 2000.

\section{Deeks 2011}

Deeks JJ, Higgins JPT, Altman DG (editors). Chapter 9: Analysing data and undertaking meta-analyses. in: Higgins JPT, Green S (editors). Cochrane Handbook for Systematic Reviews of Interventions Version 5.1.0 (updated March 2011). The Cochrane Collaboration, 2011. Available from www.cochrane-handbook.org.

Derogatis 1973

Derogatis LR, Lipman RS, Covi L. SCL-90: an outpatient psychiatric rating scale--preliminary report. Psychopharmacol Bulletin 1973;9(1):13-28.

Divine 1992

Divine GW, Brown JT, Frazier LM. The unit of analysis error in studies about physicians' patient care behavior. Journal of General Internal Medicine 1992;7(6):623-9.

Dlabac-de Lange 2010

Dlabac-de Lange J, Knegtering R, Aleman A. Repetitive transcranial magnetic stimulatoin for negative symptoms of schizophrenia: review and meta-Analysis. Journal of Clinical Psychiatry 2010;71(4):411-8.

\section{Donner 2002}

Donner A, Klar N. Issues in the meta-analysis of cluster randomized trials. Statistics in Medicine 2002;21(19): 2971-80.

\section{Egger 1997}

Egger M, Smith GD, Schneider M, Minder C. Bias in meta-analysis detected by a simple, graphical test. $B M J$ 1997;315(7109):629-34. 


\section{Elbourne 2002}

Elbourne DR, Altman DG, Higgins JP, Curtin F, Worthington HV, Vail A. Meta-analyses involving crossover trials:methodological issues. International Journal of Epidemiology 2002;31(1):140-9. [PUBMED: 11914310]

\section{Endicott 1993}

Endicott J, Nee J, Harrison W, Blumenthal R. Quality of Life Enjoyment and Satisfaction Questionnaire: a new measure. Psychopharmacology Bulletin 1993;29(2):321-6.

\section{Freitas 2009}

Freitas C, Fregni F, Pascual-Leone A. Meta-analysis of the effects of repetitive transcranial magnetic stimulation (rTMS) on negative and positive symptoms in schizophrenia. Schizophrenia Research 2009;108(1-3):11-24.

\section{Furukawa 2006}

Furukawa TA, Barbui C, Cipriani A, Brambilla P, Watanabe $\mathrm{N}$. Imputing missing standard deviations in meta-analyses can provide accurate results. Journal of Clinical Epidemiology 2006;59(1):7-10

\section{Geffen 1994}

Geffen GM, Butterworth P, Forrester GM, Geffen LB. Auditory verbal learning test components as measures of the severity of closed-head injury. Brain Injury 1994;8(5): $405-11$.

\section{Gulliford 1999}

Gulliford MC, Ukoumunne OC, Chinn S. Components of variance and intraclass correlations for the design of community-based surveys and intervention studies: data from the Health Survey for England 1994. American Journal of Epidemiology 1999;149(9):876-83.

Guy 1976

Guy U. Early Clinical Drug Evaluation (ECDEU) Assessment Manual for Psychopharmacology. National Institute of Mental Health, 1976.

\section{Haddock 1999}

Haddock G, McCarron J, Tarrier N, Faragher EB. Scales to measure dimensions of hallucinations and delusions: the psychotic symptom rating scales (PSYRATS). Psychological Medicine 1999;29(4):879-89.

Hamilton 1967

Hamilton M. Development of a rating scale for primary depressive illness. British Journal of Social and Clinical Psychology 1967;6(4):278-96.

\section{Higgins 2003}

Higgins JP, Thompson SG, Deeks JJ, Altman DG Measuring inconsistency in meta-analyses. BMJ 2003;327 (7414):557-60

\section{Higgins 2011a}

Higgins JPT, Altman DG, Sterne JAC (editors). Chapter 8: Assessing risk of bias in included studies. In: Higgins JPT, Green S (editors). Cochrane Handbook for Systematic Reviews of Interventions Version 5.1.0 (updated March 2011). The Cochrane Collaboration, 2011. Available from www.cochrane-handbook.org.

\section{Higgins 2011b}

Higgins JPT, Green S (editors). Cochrane Handbook for Systematic Reviews of Interventions Version 5.1.0 [updated March 2011]. The Cochrane Collaboration, 2011. Available from www.cochrane-handbook.org.

\section{Kay 1986}

Kay SR, Opler LA, Fiszbein A. Positive and negative syndrome scale (PANSS) manual. Positive and negative syndrome scale (PANSS) manual. North Tonawanda, NY: Multi-Health Systems, 1986.

\section{Leucht 2005a}

Leucht S, Kane JM, Kissling W, Hamann J, Etschel E, Engel R. Clinical implications of Brief Psychiatric Rating Scale scores. British Journal of Psychiatry 2005;187:366-71. [PUBMED: 16199797]

\section{Leucht 2005b}

Leucht S, Kane JM, Kissling W, Hamann J, Etschel E, Engel RR. What does the PANSS mean?. Schizophrenia Research 2005;79(2-3):231-8. [PUBMED: 15982856]

\section{Leucht 2007}

Leucht $S$, Engel RR, Bauml J, Davis JM. Is the superior efficacy of new generation antipsychotics an artifact of LOCF?. Schizophrenia Bulletin 2007;33(1):183-91. [PUBMED: 16905632]

\section{Lingjaerde 1987}

Lingjaerde O, Ahlfors UG, Bech P, Dencker SJ, Elgen K. The UKU side effect rating scale. A new comprehensive rating scale for psychotropic drugs and across-sectional study of side effects in neuroleptic-treated patients. Acta Psychiatrica Scandinavica. Supplementum 1987;334:1-100.

\section{Marshall 2000}

Marshall M, Lockwood A, Bradley C, Adams C, Joy C, Fenton M. Unpublished rating scales: a major source of bias in randomised controlled trials of treatments for schizophrenia. British Journal of Psychiatry 2000;176: 249-52. [PUBMED: 8932886]

Matheson 2010a

Matheson SL, Green MJ, Loo C, Carr VJ. Quality assessment and comparison of evidence for electroconvulsive therapy and repetitive transcranial magnetic stimulation for schizophrenia: a systematic meta-review. Schizophrenia Research 2010;118(1-3):201-10.

\section{Matheson 2010b}

Matheson SL, Green MJ, Loo C, Carr VJ. A change in the conclusions of a recent systematic meta-review: Repetitive transcranial magnetic stimulation is effective for the negative symptoms of schizophrenia. Schizophrenia Research 2010; 122(1-3):276-7.

\section{Montgomery 1979}

Montgomery SA, Asberg M. A new depression scale designed to be sensitive to change. British Journal of Psychiatry 1979;134:382-89.

\section{Overall 1962}

Overall J, Gorham D. The Brief Psychiatric Rating Scale. Psychological Reports 1962;10:799-812. 


\section{Pascual-Leone 1998}

Pascual-Leone A, Tormos JM, Keenan J, Tarazona F, Canete C, Catala MD. Study and modulation of human cortical excitability with transcranial magnetic stimulation. Journal of Clinical Neurophysiology 1998;15(4):333-4.

Rey 1964

Rey A. L'Examen Clinique en Psychologie. Paris: Presses Universitaires de France, 1964.

\section{Rosenberg 1984}

Rosenberg SJ, Ryan JJ, Prifitera A. Rey Auditory-Verbal Learning Test performance of patients with and without memory impairment. Journal of Clinical Psychology 1984;40 (3):785-7.

\section{Saba 2006b}

Saba G, Verdon CM, Kalalou K, Rocamora JF, Dumortier G, Benadhira R, Stamatiadis L, Vicaut E, Lipski H, Januel D. Transcranial magnetic stimulation in the treatment of schizophrenic symptoms: A double blind sham controlled study. Journal of Psychiatric Research 2006;40(2):147-52.

\section{Sackeim 1987}

Sackeim HA, Ross FR, Hopkins N, Calev L, Devanand DP. Subjective side effects acutely following ECT: associations with treatment modality and clinical response. Convulsive Therapy 1987;3(2):100-110.

\section{Schünemann 2008}

Schünemann HJ, Oxman AD, Vist GE, Higgins JPT, Deeks JJ, Glasziou P, Guyatt GH. Chapter 12: Interpreting results and drawing conclusions. In: Higgins JPT, Green
S (editors). Cochrane Handbook for Systematic Reviews of Interventions Version 5.1.0 [updated March 2011].

The Cochrane Collaboration, 2011. Available from www.cochrane-handbook.org. Chichester: John Wiley \& Son.

\section{Shergill 2000}

Shergill SS, Brammer MJ, Williams SC, Murray RM, McGuire PK. Mapping auditory hallucinations in schizophrenia using functional magnetic resonance imaging. Archives of General Psychiatry 2000;57:1033-8.

\section{Ukoumunne 1999}

Ukoumunne OC, Gulliford MC, Chinn S, Sterne JA, Burney PG. Methods for evaluating area-wide and organistation-based intervention in health and health care: a systematic review. Health Technology Assessment 1999;3(5): $1-75$.

\section{Weinberger 1996}

Weinberger DR, Berman KF. Prefrontal function in schizophrenia: confounds and controversies. Philosophical Transactions of the Royal Society of London. Series B, Biological Sciences 1996;351(1346):1495-503.

Xia 2009

Xia J, Adams CE, Bhagat N, Bhagat V, Bhoopathi P, ElSayeh H, et al. Loss to outcomes stakeholder survey: the LOSS study. Psychiatric Bulletin 2009;33(7):254-7.

\section{Zung 1965}

Zung WW. A self-rating depression scale. Arch Gen Psychiatry 1965;12:63-70.

* Indicates the major publication for the study 


\section{CHARACTERISTICS OF STUDIES}

\section{Characteristics of included studies [ordered by study ID]}

\section{Bagati 2009}

Methods

Blinding: assessor blind
Duration: 2 weeks
Design: parallel
Setting: inpatients and outpatients
Country: India

Diagnosis: schizophrenia (ICD-10 criteria)

$\mathrm{N}=40$

Age: rTMS group mean 29.40 years $(\mathrm{SD}=7.32)$; control group mean 7.25 years $(\mathrm{SD}=$ 9.79)

Sex: M 36, F 4

History: Auditory Hallucinations Rating Scale (AHRS) score $>20$, duration of illness in the active group 5.36 years and in the control group, 4.35 years

Interventions

1. TMS: Low-frequency rTMS to the left temporoparietal region at the centre of T3T4, $1 \mathrm{~Hz}$ and $90 \%$ motor threshold, 10 sessions 5 days per week for 2 weeks, 2400 pulses/ sessions, 60 trains, $2 \mathrm{sec}$ stimulation, $28 \mathrm{sec}$ inter-train interval. Add on to conventional antipsychotic treatment $(\mathrm{N}=20)$

2. Control: Antipsychotics only $(\mathrm{N}=20)$

Both groups received FGAs and SGAs

\begin{tabular}{l|ll}
\hline Outcomes & $\begin{array}{l}\text { Adverse events: leaving the study early } \\
\text { Unable to use - } \\
\text { Global state: CGI (no data reported) } \\
\text { Mental state: PANSS (no data reported), AHSR (skewed data) }\end{array}$ \\
\hline Notes & Source of funding: not reported & \\
\hline Risk of bias & & Support for judgement \\
\hline Bias & Authors' judgement & Allocation by coin-toss method \\
\hline $\begin{array}{l}\text { Random sequence generation (selection } \\
\text { bias) }\end{array}$ & Low risk & Allocation concealment procedures not re- \\
\hline $\begin{array}{l}\text { Allocation concealment (selection bias) } \\
\text { ported }\end{array}$ & Unclear risk & $\begin{array}{l}\text { "The patients receiving rTMS were not } \\
\text { blind to the procedure", blinding of per- } \\
\text { (performance bias) } \\
\begin{array}{l}\text { All outcomes } \\
\text { slinding not reported }\end{array}\end{array}$
\end{tabular}


Bagati 2009 (Continued)

\begin{tabular}{|c|c|c|}
\hline $\begin{array}{l}\text { Blinding of outcome assessment (detection } \\
\text { bias) } \\
\text { All outcomes }\end{array}$ & Low risk & $\begin{array}{l}\text { "The rater was blind to the procedure. } \\
\text { The ratings and the rTMS application were } \\
\text { done by different individuals so as to pre- } \\
\text { vent the bias" }\end{array}$ \\
\hline $\begin{array}{l}\text { Incomplete outcome data (attrition bias) } \\
\text { All outcomes }\end{array}$ & Unclear risk & Number lost to follow-up not reported \\
\hline Selective reporting (reporting bias) & High risk & $\begin{array}{l}\text { The study does not report all outcomes: } \\
\text { PANSS, CGI }\end{array}$ \\
\hline Other bias & Unclear risk & $\begin{array}{l}\text { Insufficient information. Source of funding } \\
\text { not reported }\end{array}$ \\
\hline
\end{tabular}

Barr 2013

\begin{tabular}{|c|c|}
\hline Methods & $\begin{array}{l}\text { Allocation: randomised } \\
\text { Blinding: double-blind } \\
\text { Duration: } 6 \text { weeks } \\
\text { Design: parallel } \\
\text { Setting: not reported } \\
\text { Country: Canada }\end{array}$ \\
\hline Participants & $\begin{array}{l}\text { Diagnosis: schizophrenia or schizoaffective disorder (DSM-IV) } \\
\mathrm{N}=33 \text { ( } 25 \text { completed) } \\
\text { Age: TMS group mean } 41.15 \text { (SD 12.01); sham group mean } 49 \text { (SD 12.42) } \\
\text { Sex: M 17, F 8* } \\
\text { History: score of } 85 \text { or below on the Repeated Battery for the assessment of Neuropsy- } \\
\text { chological Status }\end{array}$ \\
\hline Interventions & $\begin{array}{l}\text { 1. TMS: bilateral MRI-guided rTMS in the dorsolateral prefrontal cortex (DLPFC) at } \\
20 \mathrm{~Hz}, 90 \% \text { resting motor threshold for } 25 \text { trains, } 30 \text { pulses/train, inter-train interval } \\
\text { of } 30 \mathrm{sec}, 20 \text { sessions ( } 5 \text { days/week for } 4 \text { weeks) }(\mathrm{N}=16) \\
\text { 2. Sham: at the same parameters with the coil held in a single wing-tilt position at } 90^{\circ} \text { to } \\
\text { induce similar somatic sensations as in the active stimulation with minimal direct brain } \\
\text { effects }(\mathrm{N}=17 \text { ) } \\
\text { Both groups received FGAs and SGAs }\end{array}$ \\
\hline Outcomes & $\begin{array}{l}\text { Mental state: PANSS, SANS, CDS } \\
\text { Unable to use - } \\
\text { Cognitive state: n-back performance (skewed data) }\end{array}$ \\
\hline Notes & $\begin{array}{l}\text { The randomised clinical trial is ongoing, only pilot data reported } \\
\mathrm{N} \text { is different for Mental state and Cognitive state outcomes as the trial was at an earlier } \\
\text { stage when the mental state outcomes were reported }(\mathrm{N}=31 \text { ) } \\
\text { Source of funding: Canadian Institutes of Health Research (CIHR) CIHR Operating } \\
\text { Grant, CIHR Post-Doctoral Award, Operating and Studentship Award from the Ontario } \\
\text { Mental Health Foundation, National Health and Medical Research Council (NHMRC) }\end{array}$ \\
\hline
\end{tabular}

Transcranial magnetic stimulation (TMS) for schizophrenia (Review) 
Barr 2013 (Continued)

Practitioner Fellowship (PBF), Brain and Behaviour Research Foundation Young Investigator award, the Grant Family through the Centre for Addiction and Mental Health (CAMH) Foundation

Risk of bias

\begin{tabular}{|c|c|c|}
\hline Bias & Authors' judgement & Support for judgement \\
\hline $\begin{array}{l}\text { Random sequence generation (selection } \\
\text { bias) }\end{array}$ & Unclear risk & $\begin{array}{l}\text { "Randomly assigned", "computer-gener- } \\
\text { ated random number sequence" }\end{array}$ \\
\hline Allocation concealment (selection bias) & Unclear risk & No information reported \\
\hline $\begin{array}{l}\text { Blinding of participants and personnel } \\
\text { (performance bias) } \\
\text { All outcomes }\end{array}$ & Unclear risk & "Double-blind", no further details reported \\
\hline $\begin{array}{l}\text { Blinding of outcome assessment (detection } \\
\text { bias) } \\
\text { All outcomes }\end{array}$ & Low risk & $\begin{array}{l}\text { Outcome assessors "were blind to treat- } \\
\text { ment" }\end{array}$ \\
\hline $\begin{array}{l}\text { Incomplete outcome data (attrition bias) } \\
\text { All outcomes }\end{array}$ & Low risk & $\begin{array}{l}6 \text { schizophrenic participants did not com- } \\
\text { plete the study ( } 3 \text { in the active and } 3 \text { in the } \\
\text { sham group) }\end{array}$ \\
\hline Selective reporting (reporting bias) & Low risk & All outcomes are reported \\
\hline Other bias & Low risk & None detected \\
\hline
\end{tabular}

Blumberger 2012

$\begin{array}{ll}\text { Methods } & \text { Allocation: randomised } \\ \text { Blinding: double-blind } \\ \text { Duration: } 8 \text { weeks } \\ \text { Design: parallel } \\ \text { Setting: not reported } \\ \text { Country: Canada }\end{array}$


Blumberger 2012 (Continued)

\begin{tabular}{|c|c|}
\hline Interventions & $\begin{array}{l}\text { 1. TMS: MRI-guided left-sided rTMS (LFL) to the temporoparietal cortex (TPC), at } \\
\text { an intensity of } 115 \% \text { RMT for } 20 \text { min, } 20 \text { trains with an inter-train interval of } 25 \text { secs. } \\
20 \text { sessions ( } 5 \text { days/week for } 4 \text { weeks) }(\mathrm{N}=17 \text { ) } \\
\text { 2. Priming TMS: ( } 6 \mathrm{~Hz} \text { followed by } 1 \mathrm{~Hz} \text { rTMS), } 10 \text { min of } 6 \mathrm{~Hz} \text { ( } 205 \text { second trains } \\
\text { with } 25 \text { second inter-train interval) at } 90 \% \text { RMT followed by } 10 \text { min of } 1 \mathrm{~Hz} \text { stimulation } \\
\text { at } 115 \% \text { RMT, a total of } 20 \text { min of stimulation, } 20 \text { sessions ( } 5 \text { days/week for } 4 \text { weeks) } \\
(\mathrm{N}=17) \\
\text { 3. Sham: identical parameters to those for the LFL condition but with the coil angled } \\
\text { at } 90^{\circ} \text { off the scalp in a single wing-tilt position, } 1 \mathrm{~Hz} \text { for } 20 \text { min, } 20 \text { sessions ( } 5 \text { days/ } \\
\text { week for } 4 \text { weeks) ( } \mathrm{N}=17 \text { ) } \\
\text { Stimulation site: Heschl's gyrus } \\
\text { Both groups received FGAs and SGAs }\end{array}$ \\
\hline Outcomes & $\begin{array}{l}\text { Mental state: PSYRATS hallucinations subscale, PSYRATS, PANSS, HCS, AHRS } \\
\text { Cognitive state: RBANS }\end{array}$ \\
\hline Notes & $\begin{array}{l}\text { Data from the } 2 \text { TMS groups were combined in the analyses } \\
\text { N not reported for RBANS data - assumed to be } 14 \text { for rTMS, } 13 \text { for priming TMS } \\
\text { and } 13 \text { for sham TMS } \\
\text { Source of funding: Ontario Mental Health Foundation (OMHF), Canadian Institutes } \\
\text { of Health Research (CIHR) Clinician Scientist Award, CIHR Fellowship, by a National } \\
\text { Health and Medical Research Council (NHMRC) Practitioner Fellowship and by Con- } \\
\text { stance and Stephen Lieber through a National Alliance for Research on Schizophrenia } \\
\text { and Depression (NARSAD) Lieber Young Investigator award }\end{array}$ \\
\hline
\end{tabular}

Risk of bias

\begin{tabular}{|c|c|c|}
\hline Bias & Authors' judgement & Support for judgement \\
\hline $\begin{array}{l}\text { Random sequence generation (selection } \\
\text { bias) }\end{array}$ & Unclear risk & "Randomised" no further details reported \\
\hline Allocation concealment (selection bias) & Unclear risk & "Randomised" no further details reported \\
\hline $\begin{array}{l}\text { Blinding of participants and personnel } \\
\text { (performance bias) } \\
\text { All outcomes }\end{array}$ & Unclear risk & $\begin{array}{l}\text { "Subjects ... were blind to randomization } \\
\text { group." }\end{array}$ \\
\hline $\begin{array}{l}\text { Blinding of outcome assessment (detection } \\
\text { bias) } \\
\text { All outcomes }\end{array}$ & Low risk & $\begin{array}{l}\text { "Clinical raters were blind to randomiza- } \\
\text { tion group." }\end{array}$ \\
\hline
\end{tabular}

Incomplete outcome data (attrition bias) Low risk All outcomes
"The analysis was conducted on an intention-to-treat basis. A completer analysis was also conducted."

There were 3 losses to follow-up in the rTMS group, 4 in the priming group and 4 in the sham control group. "Subjects re- 
Blumberger 2012 (Continued)

\begin{tabular}{|c|c|c|}
\hline & & $\begin{array}{l}\text { ported lack of perceived benefit and inabil- } \\
\text { ity to attend appointments as reasons for } \\
\text { discontinuation. One subject was hospi- } \\
\text { talised due to hyponatremia and could not } \\
\text { complete the study protocol." }\end{array}$ \\
\hline Selective reporting (reporting bias) & Low risk & All outcomes were reported \\
\hline Other bias & Low risk & None detected \\
\hline
\end{tabular}

\section{Brunelin 2006}

Methods
Allocation: randomised

Blindness: double-blind

Duration: 5 days

Design: parallel

Setting: not reported

Country: France

\begin{tabular}{|c|c|c|}
\hline Participants & \multicolumn{2}{|c|}{$\begin{array}{l}\text { Diagnosis: schizophrenia (DSM-IV) } \\
\mathrm{N}=24 \\
\text { Age: average } 34.5 \text { years } \\
\text { Sex: not reported } \\
\text { History: antipsychotic medication-resistant auditory hallucinations }\end{array}$} \\
\hline Interventions & \multicolumn{2}{|c|}{$\begin{array}{l}\text { 1. TMS: left temporoparietal rTMS, } 1 \mathrm{~Hz} \text { at } 90 \% \text { of motor threshold, } 10 \text { sessions over } \\
5 \text { days }(2 \text { treatments of } 1000 \text { stimulations per day) }(\mathrm{N}=14) \\
\text { 2. Sham: Simulation was as for active TMS but with a sham coil designed to produce } \\
\text { an identical sound. ( } \mathrm{N}=10) \\
\text { Not reported whether antipsychotics were used }\end{array}$} \\
\hline Outcomes & \multicolumn{2}{|c|}{$\begin{array}{l}\text { Mental state: AHRS, SAPS } \\
\text { Cognitive state: Source memory task }\end{array}$} \\
\hline Notes & \multicolumn{2}{|c|}{ Source of funding: Conseil Scientifique de la Recherche, CH "Le Vinatier" } \\
\hline \multicolumn{3}{|l|}{ Risk of bias } \\
\hline Bias & Authors' judgement & Support for judgement \\
\hline $\begin{array}{l}\text { Random sequence generation (selection } \\
\text { bias) }\end{array}$ & Unclear risk & $\begin{array}{l}\text { "Randomly allocated" - no further details } \\
\text { provided }\end{array}$ \\
\hline Allocation concealment (selection bias) & Unclear risk & No details provided \\
\hline $\begin{array}{l}\text { Blinding of participants and personnel } \\
\text { (performance bias) } \\
\text { All outcomes }\end{array}$ & Low risk & $\begin{array}{l}\text { "The protocol was carried out under dou- } \\
\text { ble blind condition." } \\
\text { "Ten patients received sham rTMS stimu- }\end{array}$ \\
\hline
\end{tabular}

Transcranial magnetic stimulation (TMS) for schizophrenia (Review)

Copyright @ 2015 The Cochrane Collaboration. Published by John Wiley \& Sons, Ltd. 
lations given at the same location, strength and frequency with a placebo-coil indistinguishable to the active coil. The placebo coil and its active counterpart look identical and produce an identical sound without superficial scalp stimulation."

Blinding of outcome assessment (detection Low risk

"Cognitive and clinical evaluations were asbias) sessed by a blinded investigator."

All outcomes

Incomplete outcome data (attrition bias) Unclear risk

All outcomes

\begin{tabular}{lll}
\hline Selective reporting (reporting bias) & Low risk & All outcomes reported \\
\hline Other bias & Unclear risk & None detected \\
\hline
\end{tabular}

Chen 2011

\begin{tabular}{ll}
\hline Methods & Allocation: randomised \\
& Blinding: double-blind \\
& Duration: 4 weeks \\
& Design: parallel \\
Setting: inpatients & \\
& Country: China \\
\hline Participants & Diagnosis: schizophrenia (DSM-IV) \\
& N $=46$ \\
& Age: $23-55$, mean 37.4 (SD 1.8) \\
& Sex: $\mathrm{M} 27, \mathrm{~F} 15$ (Gender is reported only for completed patients. 42 patients completed \\
the trial: Intervention $\mathrm{N}=23$, control $\mathrm{N}=19)$ \\
History: PANSS negative subscale score $\geq 20$; stable medication regimen
\end{tabular}

Interventions

1. TMS: left DLPFC rTMS, intermittent theta burst stimulation pattern $50 \mathrm{~Hz}$ at $80 \%$ of motor threshold, 2400 pulses over 22 minutes. 4 weeks, 5 days/week, total 20 sessions $(\mathrm{N}=24)$

2. Sham: Simulation was as for active TMS but coil designed to produce an identical sound without magnets being activated $(\mathrm{N}=22)$

Both groups received FGAs and SGAs

Outcomes

Mental state: PANSS

Not used in the review -

EEM (Exploratory Eye Movements): Number of eye fixations, Responsive search score,

Discriminant (D) score

Notes

Source of funding: National High Tech Research and Development (863 Program of China; the Natural Science Foundation of China; the Janssen Science Foundation; and 
Chen 2011 (Continued)

the Shanghai Science Committee Foundation

\section{Risk of bias}

\begin{tabular}{|c|c|c|}
\hline Bias & Authors' judgement & Support for judgement \\
\hline $\begin{array}{l}\text { Random sequence generation (selection } \\
\text { bias) }\end{array}$ & Low risk & $\begin{array}{l}\text { "Eligible subjects were randomized to } \\
\text { rTMS therapy or sham rTMS therapy } \\
\text { based on a computerized algorithm" }\end{array}$ \\
\hline Allocation concealment (selection bias) & Unclear risk & $\begin{array}{l}\text { "Provided to the rTMS technician the first } \\
\text { time the patient entered the rTMS treat- } \\
\text { ment room." }\end{array}$ \\
\hline $\begin{array}{l}\text { Blinding of participants and personnel } \\
\text { (performance bias) } \\
\text { All outcomes }\end{array}$ & Unclear risk & "Double-blind", details not reported \\
\hline
\end{tabular}

Blinding of outcome assessment (detection Low risk bias)

All outcomes

Incomplete outcome data (attrition bias) Low risk All outcomes
"The technician who conducted the EEM tests was blind to the treatment status of the patients."

"The evaluating researchers were blind to the treatment status and EEM results of the subject they evaluated"

"Four subjects dropped out in the first week of the trial : 1 patient from the intervention group refused to continue rTMS because of transient headaches during the treatment sessions, 2 control group subjects were discharged from the hospital by the ir family members for reasons unrelated to the rTMS treatment and one control group subject stopped because of an exacerbation of hallucinations and delusions that required changing his medication regimen.”

\begin{tabular}{lll}
\hline Selective reporting (reporting bias) & Low risk & All outcomes have been reported \\
\hline Other bias & Low risk & None detected \\
\hline
\end{tabular}


Methods

Blinding: double-blind
Duration: 2 weeks
Design: parallel
Setting: inpatients
Country: Germany

Diagnosis: schizophrenia (DSM-IV)

$\mathrm{N}=32$

Age: TMS group mean 34.3 (SD 9.7); sham group mean 34.4 (SD 10.5)

Sex: M 25, F 7

History: at least 3 episodes documented in their medical history
1. TMS: $10 \mathrm{~Hz}$ rTMS applied over the left dorsolateral prefrontal cortex (LDPC) for 10 times during 2 weeks ( 5 days/week for 2 weeks), 1000 stimuli applied at a frequency of $10 \mathrm{~Hz}$ during 20 trains, $5 \mathrm{sec} /$ train, stimulation intensity $110 \%$ of the motor threshold $(\mathrm{N}=18)$

2. Sham: conducted in a similar manner by using a sham coil system without induction of a magnetic field $(\mathrm{N}=14)$

Both groups received FGAs and SGAs

Global state: CGI

Mental state: PANSS

General functioning: GAF

Adverse events: UKU side effect rating scale

Unable to use -

Adverse events: headaches (not reported)

Notes

\section{Risk of bias}

\begin{tabular}{|c|c|c|}
\hline Bias & Authors' judgement & Support for judgement \\
\hline $\begin{array}{l}\text { Random sequence generation (selection } \\
\text { bias) }\end{array}$ & Unclear risk & $\begin{array}{l}\text { "Block-wise randomisation (active rTMS } \\
\text { to sham group relation } 4: 3 \text { )", further details } \\
\text { not reported }\end{array}$ \\
\hline Allocation concealment (selection bias) & Unclear risk & Details not reported \\
\hline
\end{tabular}

Blinding of participants and personnel Unclear risk (performance bias)

All outcomes

Blinding of outcome assessment (detection Low risk bias)

All outcomes
"Study participants...and all personnel responsible for the clinical care of the patients remained blind to the allocated treatment conditions." Details of blinding procedure not reported

"Clinical raters ... remained blind to the allocated treatment conditions" 
Cordes 2010 (Continued)

\begin{tabular}{|c|c|c|}
\hline $\begin{array}{l}\text { Incomplete outcome data (attrition bias) } \\
\text { All outcomes }\end{array}$ & Low risk & $\begin{array}{l}35 \text { participants were randomised, } 3 \text { ( } 2 \text { in } \\
\text { the TMS group and } 1 \text { in the sham group) } \\
\text { refused to participate after randomisation. } \\
\text { All participants receiving allocated inter- } \\
\text { vention completed the study and were anal- } \\
\text { ysed }\end{array}$ \\
\hline Selective reporting (reporting bias) & Low risk & All outcomes are reported \\
\hline Other bias & Low risk & $\begin{array}{l}\text { "The funding source had no involvement } \\
\text { in study design, in collection, analysis, in- } \\
\text { terpretation of data, writing of the report } \\
\text { and in the decision to submit the paper for } \\
\text { publication" }\end{array}$ \\
\hline
\end{tabular}

De Jesus 2011

\begin{tabular}{|c|c|}
\hline Methods & $\begin{array}{l}\text { Allocation: randomised } \\
\text { Blinding: double blind } \\
\text { Duration: } 4 \text { weeks } \\
\text { Design: parallel } \\
\text { Setting: not reported } \\
\text { Country: Brazil }\end{array}$ \\
\hline Participants & $\begin{array}{l}\text { Diagnosis: schizophrenia (OPCRIT } 4.0 \text { criteria) } \\
\mathrm{N}=17 \\
\text { Age: TMS group mean } 46 \text { (SD 9.84); sham group mean } 36.5 \text { (SD 6.36) } \\
\text { Sex: M } 12, \mathrm{~F} 5 \\
\text { History: Refractory schizophrenia with daily AHs at least } 5 \text { times/day despite treatment } \\
\text { with a stable dose of } \geq 400 \mathrm{mg} / \text { day of clozapine for a period longer than } 4 \text { months and } \\
\geq 2 \text { adequate trials of antipsychotic medications in the past, including } \geq 1 \text { SGA drug } \\
\text { other than clozapine, BPRS score of } \geq 27\end{array}$ \\
\hline
\end{tabular}

Interventions

1. TMS: stimulation administered to the LTPC using 10 - 20 EEG electrode position system, $1 \mathrm{~Hz}$ at $90 \%$ of the motor threshold, $8 \mathrm{~min}$ of stimulation on day $1,16 \mathrm{~min}$ on day 2, and $20 \mathrm{~min}$ for the next 18 days, a total of 20 sessions, (5 sessions/week for 4 weeks $(\mathrm{N}=8)$

2. Sham: using the same coil at $45^{\circ}$ angle with stimulation intensity reduced to $80 \%$ of MT $(\mathrm{N}=9)$

Both groups also received clozapine

Outcomes

Global state: CGI, FAST

Mental state: BPRS, AHRS

Quality of life: QLS

Notes

After the completion of the study, participants randomised to the sham condition were offered active rTMS utilising the same parameters

Source of funding: Fundo de Incentivo a Pesquisa (FIPE) from Hospital de Clinicas de

Transcranial magnetic stimulation (TMS) for schizophrenia (Review)

Copyright @ 2015 The Cochrane Collaboration. Published by John Wiley \& Sons, Ltd. 
De Jesus 2011 (Continued)

Porto Alegre, UFRGS (Project No. 06382), Neuro-MS magnetic stimulator donated by Gerdau S.A

Risk of bias

\begin{tabular}{|c|c|c|}
\hline Bias & Authors' judgement & Support for judgement \\
\hline $\begin{array}{l}\text { Random sequence generation (selection } \\
\text { bias) }\end{array}$ & Low risk & $\begin{array}{l}\text { "Randomly allocated", allocation conceal- } \\
\text { ment method reported, assume that the } \\
\text { randomisation procedure is adequate }\end{array}$ \\
\hline Allocation concealment (selection bias) & Low risk & $\begin{array}{l}\text { "Sequentially-Numbered, Opaque, Sealed } \\
\text { Envelopes (SNOSE)" }\end{array}$ \\
\hline $\begin{array}{l}\text { Blinding of participants and personnel } \\
\text { (performance bias) } \\
\text { All outcomes }\end{array}$ & Unclear risk & $\begin{array}{l}\text { "Study participants ... and all personnel re- } \\
\text { sponsible for the clinical care of the pa- } \\
\text { tient remained masked to allocated condi- } \\
\text { tion and allocation parameters." }\end{array}$ \\
\hline $\begin{array}{l}\text { Blinding of outcome assessment (detection } \\
\text { bias) } \\
\text { All outcomes }\end{array}$ & Low risk & $\begin{array}{l}\text { "Clinical raters ... remained masked to allo- } \\
\text { cated condition and allocation parameters. } \\
\text { " }\end{array}$ \\
\hline $\begin{array}{l}\text { Incomplete outcome data (attrition bias) } \\
\text { All outcomes }\end{array}$ & Unclear risk & $\begin{array}{l}\text { Number of participants randomised and } \\
\text { number lost to follow-up not reported }\end{array}$ \\
\hline Selective reporting (reporting bias) & Unclear risk & $\begin{array}{l}\text { Not all outcomes reported: mean and SD } \\
\text { not reported for QLS and FAST. Outcomes } \\
\text { covered benefit and harm }\end{array}$ \\
\hline Other bias & Low risk & None detected \\
\hline
\end{tabular}

\section{Fitzgerald 2005}

Methods
Allocation: randomised

Blindness: double-blind

Duration: 2 weeks

Design: parallel

Setting: patients from 2 mental health services and several referring psychiatrists

Country: Australia
Diagnosis: schizophrenia or schizoaffective disorder (DSM-IV)

\section{$\mathrm{N}=33$}

Age: not reported

Sex: not reported

History: failed to respond to a minimum of 2 adequate trials of antipsychotic medication, experiencing auditory hallucinations 


\section{Fitzgerald 2005 (Continued)}

\begin{tabular}{ll}
\hline Interventions & $\begin{array}{l}\text { 1. TMS: left temporoparietal TMS, } 15 \text { minutes at } 1 \mathrm{~Hz}, 90 \% \text { above motor threshold, } \\
10 \text { sessions over } 2 \text { weeks (daily basis } 5 \text { days each week) }(\mathrm{N}=17) \\
\text { 2. Sham: Simulation was as for active TMS but with the coil angled away at } 45^{\circ} \text { from } 1 \\
\text { side of } 1 \text { wing of the coil }(\mathrm{N}=16) \\
\text { Both groups received FGAs and SGAs }\end{array}$ \\
\hline Outcomes & $\begin{array}{l}\text { Mental state: HCS, PANSS positive and hallucinations } \\
\text { Adverse events: leaving the study early } \\
\text { Unable to use - } \\
\text { Mental state: PSYRATS hallucination sub-scale (total scores not reported) } \\
\text { Global state: GAF (no mean and SD) } \\
\text { Cognitive state: Hopkins Verbal Learning Test immediate recall (no mean and SD) }\end{array}$ \\
\hline Notes & $\begin{array}{l}\text { Source of funding: The Stanley Medical Research Institute and by Constance and Stephen } \\
\text { Lieber through a NARSAD Lieber Young Investigator award (PF) }\end{array}$ \\
\hline
\end{tabular}

Risk of bias

\begin{tabular}{|c|c|c|}
\hline Bias & Authors' judgement & Support for judgement \\
\hline $\begin{array}{l}\text { Random sequence generation (selection } \\
\text { bias) }\end{array}$ & Unclear risk & Randomised, no further details given \\
\hline Allocation concealment (selection bias) & Low risk & Sealed envelope \\
\hline $\begin{array}{l}\text { Blinding of participants and personnel } \\
\text { (performance bias) } \\
\text { All outcomes }\end{array}$ & Unclear risk & $\begin{array}{l}\text { "The patients and raters were blind to treat- } \\
\text { ment but the clinician administering rTMS } \\
\text { was aware of the treatment group", "Sham } \\
\text { stimulation was provided with the coil an- } \\
\text { gled away from the scalp at } 45 \text { degrees from } \\
\text { the side of one wing of the coil" }\end{array}$ \\
\hline $\begin{array}{l}\text { Blinding of outcome assessment (detection } \\
\text { bias) } \\
\text { All outcomes }\end{array}$ & Low risk & Raters were blinded \\
\hline $\begin{array}{l}\text { Incomplete outcome data (attrition bias) } \\
\text { All outcomes }\end{array}$ & Unclear risk & $\begin{array}{l}\text { "One patient withdrew consent prior to } \\
\text { commencement of treatment. Thirty of the } \\
32 \text { subjects completed } 2 \text { weeks of double- } \\
\text { blind treatment: } 2 \text { patients (both in the } \\
\text { sham group) were withdrawn in the second } \\
\text { week due to a deterioration in mental state, } \\
\text { one who stopped antipsychotic medication } \\
\text { after } 7 \text { days of the trial. Both received an as- } \\
\text { sessment after } 5 \text { days of treatment and these } \\
\text { data were carried forward in the analysis." }\end{array}$ \\
\hline Selective reporting (reporting bias) & High risk & Not all outcomes fully reported \\
\hline
\end{tabular}


Fitzgerald 2005 (Continued)

\begin{tabular}{|c|c|c|}
\hline Other bias & Low risk & None detected. \\
\hline
\end{tabular}

\section{Fitzgerald 2008}

Methods
Allocation: randomised
Blindness: double-blind
Duration: 3 weeks
Design: parallel
Setting: outpatients from 2 public area mental health services and referral from private
psychiatrists
Country: Australia

Participants

Diagnosis: schizophrenia or schizoaffective disorder (DSM-IV)

$\mathrm{N}=20$

Age: average 35.6 years

Sex: M 16, F 4

History: failed to respond to a minimum of 2 adequate trials of antipsychotic medication + persistent negative symptoms of moderate-to-severe intensity (SANS total score > 50)

Interventions

1. TMS: bilateral prefrontal rTMS, $10 \mathrm{~Hz}, 110 \%$ above motor threshold, 20 trains to each hemisphere of 5 seconds each with 25 second gap (1000 stimulations per hemisphere per day, 20 trains/hemisphere, $5 \mathrm{sec} /$ train, inter-train interval $55 \mathrm{sec}$ ), left-sided stimulation always provided first, 15 sessions of treatment on daily basis 5 days per week $(\mathrm{N}=10)$ 2. Sham: stimulation as for active TMS but with side edge resting on scalp at $90^{\circ}(\mathrm{N}=$ 10)

Both groups received SGAs, except one participant in the TMS group who received FGA

Outcomes

Mental state: PANSS negative, SANS

Adverse effects: headache, TMS-related sit discomfort, leaving the study early

Unable to use -

Mental state: PANSS positive, CDRS (skewed data)

Cognitive state: Stroop test, the controlled oral word association test, and trail making $A \& B$ (no data reported)

Notes

Source of funding: Practitioner Fellowship grant from the National Health and Medical Research Council (NHMRC), by NARSAD Young Investigator awards, a grant from the Marian \& E. H. Flack Trust, a NHMRC project grant (436710), and the Neurosciences Australia Clinical Neurobiology of Psychiatry Platform. Also received support for research conducted with Neuronetics Inc, a TMS equipment manufacturer

\section{Risk of bias}

\begin{tabular}{lll} 
Bias & Authors' judgement & Support for judgement \\
\hline $\begin{array}{l}\text { Random sequence generation (selection Low risk } \\
\text { bias) }\end{array}$ & Randomised using random number se- \\
quence
\end{tabular}

Transcranial magnetic stimulation (TMS) for schizophrenia (Review) 


\section{Fitzgerald 2008 (Continued)}

\begin{tabular}{|c|c|c|}
\hline Allocation concealment (selection bias) & Low risk & Sealed envelopes \\
\hline $\begin{array}{l}\text { Blinding of participants and personnel } \\
\text { (performance bias) } \\
\text { All outcomes }\end{array}$ & Unclear risk & $\begin{array}{l}\text { "The patients and raters were blind to } \\
\text { treatment, but the clinician administering } \\
\text { rTMS was aware of the treatment group." } \\
\text { "Sham stimulation was provided at the site } \\
\text { of active treatment but with only the side } \\
\text { edge resting on the scalp at } 90 \text { degrees." }\end{array}$ \\
\hline $\begin{array}{l}\text { Blinding of outcome assessment (detection } \\
\text { bias) } \\
\text { All outcomes }\end{array}$ & Low risk & $\begin{array}{l}\text { "All assessments were performed by a } \\
\text { blinded rater." }\end{array}$ \\
\hline $\begin{array}{l}\text { Incomplete outcome data (attrition bias) } \\
\text { All outcomes }\end{array}$ & Unclear risk & $\begin{array}{l}\text { "All analyses were conducted on an inten- } \\
\text { tion to treat basis with the last observation } \\
\text { carried forward." }\end{array}$ \\
\hline Selective reporting (reporting bias) & High risk & $\begin{array}{l}\text { Not all outcomes reported - no data for } \\
\text { cognitive measures }\end{array}$ \\
\hline Other bias & Unclear risk & $\begin{array}{l}\text { Role of Neuronetics Inc in design, conduct, } \\
\text { reporting of study is not clear }\end{array}$ \\
\hline
\end{tabular}

\section{Gao 2009a}

Methods
Allocation: randomised

Blindness: double-blind

Duration: 2 weeks

Design: parallel

Setting: inpatients

Country: China

\begin{tabular}{ll}
\hline Participants & Diagnosis: schizophrenia (CCMD-3) \\
N $=46$ \\
Age: TMS mean 36.1 years (SD 13), Sham group mean 35 years (SD 12) \\
Sex: M 39, F 7 \\
History: length of illness 2 to 30 years, accepted at least 2 kinds of antipsychotic drugs \\
with sufficient dose treatment, consistent dose of antipsychotic medication use for more \\
than 4 weeks at present, hallucinations for more than 6 months
\end{tabular}

Interventions

1. TMS: left temporal and parietal lobes rTMS, $1 \mathrm{~Hz}$ at $80 \%$ motor threshold, stimulating for $90 \mathrm{sec}, 30 \mathrm{sec}$ interval, repeat for 10 times/day, 5 times/week for 2 weeks (N =23)

2. Sham: coil plane $90^{\circ}$ to the scalp, stimulation as for active TMS $(\mathrm{N}=23)$

All received antipsychotics, type not reported 


\section{Gao 2009a (Continued)}

\begin{tabular}{|c|c|c|}
\hline Outcomes & $\begin{array}{l}\text { Global state: CGI } \\
\text { Adverse events: TESS, headache } \\
\text { Unable to use - } \\
\text { Mental state: PANSS (no mean and SD) }\end{array}$ & \\
\hline Notes & $\begin{array}{l}\text { In Chinese } \\
\text { Source of funding: not reported }\end{array}$ & \\
\hline \multicolumn{3}{|l|}{ Risk of bias } \\
\hline Bias & Authors' judgement & Support for judgement \\
\hline $\begin{array}{l}\text { Random sequence generation (selection } \\
\text { bias) }\end{array}$ & Low risk & Random number table \\
\hline Allocation concealment (selection bias) & Unclear risk & Not reported \\
\hline $\begin{array}{l}\text { Blinding of participants and personnel } \\
\text { (performance bias) } \\
\text { All outcomes }\end{array}$ & Unclear risk & Double-blind, but untested \\
\hline $\begin{array}{l}\text { Blinding of outcome assessment (detection } \\
\text { bias) } \\
\text { All outcomes }\end{array}$ & Unclear risk & Double- blind, but untested \\
\hline $\begin{array}{l}\text { Incomplete outcome data (attrition bias) } \\
\text { All outcomes }\end{array}$ & Unclear risk & Losses to follow-up not reported \\
\hline Selective reporting (reporting bias) & High risk & $\begin{array}{l}\text { Detailed results of PANSS is not reported } \\
\text { except } \mathrm{P}>0.05\end{array}$ \\
\hline Other bias & Unclear risk & $\begin{array}{l}\text { Insufficient information. Source of funding } \\
\text { not reported }\end{array}$ \\
\hline
\end{tabular}

\section{Gao 2009b}

\begin{tabular}{ll}
\hline Methods & Allocation: randomised \\
& Blinding: assessor blind \\
& Duration: 5 days \\
& Design: parallel \\
& Setting: not reported \\
& Country: China \\
\hline Participants & Diagnosis: schizophrenia (CCMD-3) \\
& N $=43$ \\
Age: $19-65$, mean -34.5 \\
Sex: $M 43$ \\
History: duration of illness $2-20$ years
\end{tabular}


Gao 2009b (Continued)

\begin{tabular}{ll} 
Interventions & $\begin{array}{l}\text { 1. TMS: left DLPFC rTMS, } 10 \mathrm{~Hz} \text { at } 100 \% \text { motor threshold, } 20 \text { sequential stimulation/ } \\
\text { day, stimulation for } 5 \mathrm{sec}, 35 \mathrm{sec} \text { interval, total 1000/day. } 5 \text { sessions for } 5 \text { days }(\mathrm{N}=21)\end{array}$ \\
$\begin{array}{l}\text { 2. Sham: coil plane } 45^{\circ} \text { to the scalp }(\mathrm{N}=22) \\
\text { All participants received risperidone }\end{array}$ \\
\hline Outcomes & $\begin{array}{l}\text { Mental state: PANSS, HAMD } \\
\text { Adverse events } \\
\text { Not used in review - } \\
\text { Prolactin, event-related potential P300, EEG }\end{array}$ \\
\hline Notes & $\begin{array}{l}\text { In Chinese } \\
\text { Source of funding: not reported }\end{array}$ \\
\hline
\end{tabular}

\section{Risk of bias}

\begin{tabular}{|c|c|c|}
\hline Bias & Authors' judgement & Support for judgement \\
\hline $\begin{array}{l}\text { Random sequence generation (selection } \\
\text { bias) }\end{array}$ & Low risk & Random number table used \\
\hline Allocation concealment (selection bias) & Unclear risk & $\begin{array}{l}\text { Allocation concealment method not re- } \\
\text { ported }\end{array}$ \\
\hline $\begin{array}{l}\text { Blinding of participants and personnel } \\
\text { (performance bias) } \\
\text { All outcomes }\end{array}$ & Unclear risk & Not reported \\
\hline $\begin{array}{l}\text { Blinding of outcome assessment (detection } \\
\text { bias) } \\
\text { All outcomes }\end{array}$ & Low risk & Assessor blind \\
\hline $\begin{array}{l}\text { Incomplete outcome data (attrition bias) } \\
\text { All outcomes }\end{array}$ & Low risk & There were no losses to follow-up \\
\hline Selective reporting (reporting bias) & Low risk & All measured outcomes were reported \\
\hline Other bias & Unclear risk & $\begin{array}{l}\text { Insufficient information. Source of funding } \\
\text { not reported }\end{array}$ \\
\hline
\end{tabular}


Duration: 4 weeks

Design: parallel

Setting: not reported

Country: China

\begin{tabular}{ll}
\hline Participants & Diagnosis: schizophrenia \\
N $=42$ \\
Age: $36 \pm 6$ years \\
Sex: $M 37, \mathrm{~F} 5$ \\
History: chronic auditory hallucinations
\end{tabular}

Interventions

1. TMS: left prefrontal dorsolateral area rTMS, $15 \mathrm{~Hz}$ at $90 \%$ motor threshold, pulse count $2 \mathrm{sec} /$ train, $28 \mathrm{sec}$ interval, 60 train/day, 5 times/week for 4 weeks $(\mathrm{N}=21)$

2. Sham: coil plane $90^{\circ}$ to the scalp $(\mathrm{N}=21)$

All participants received a consistent dose of antipsychotics, type not reported

\begin{tabular}{ll}
\hline Outcomes & Mental state: PANSS negative, HAMD-17 \\
& Adverse events: TESS \\
& Unable to use - \\
& Mental state: other PANSS subscales, HAMD-17 (no mean and SD) \\
\hline \multirow{2}{*}{ Notes } & In Chinese \\
& Source of funding: not reported \\
\hline
\end{tabular}

\section{Risk of bias}

\begin{tabular}{|c|c|c|}
\hline Bias & Authors' judgement & Support for judgement \\
\hline $\begin{array}{l}\text { Random sequence generation (selection } \\
\text { bias) }\end{array}$ & Unclear risk & Randomised, no further details \\
\hline Allocation concealment (selection bias) & Unclear risk & $\begin{array}{l}\text { Allocation concealment method not re- } \\
\text { ported }\end{array}$ \\
\hline
\end{tabular}

Blinding of participants and personnel Unclear risk

Double-blind, no further details (performance bias)

All outcomes

Blinding of outcome assessment (detection Unclear risk bias)

Double-blind, no further details

All outcomes

\begin{tabular}{l|l|l}
\hline $\begin{array}{l}\text { Incomplete outcome data (attrition bias) } \\
\text { All outcomes }\end{array}$ & Low risk & There were no losses to follow-up \\
\hline Selective reporting (reporting bias) & High risk & $\begin{array}{l}\text { PANSS subscale score and HAMD17 were } \\
\text { measured, but only reported P value }>0 .\end{array}$
\end{tabular}


Gao 2009c (Continued)

$05(5)$

\begin{tabular}{|c|c|c|}
\hline Other bias & Unclear risk & $\begin{array}{l}\text { Insufficient information. Source of funding } \\
\text { not reported }\end{array}$ \\
\hline
\end{tabular}

Gao 2010

Methods

Allocation: randomised

Blinding: double-blind

Duration: 2 weeks

Design: parallel

Setting: not reported

Country: China

$\begin{array}{ll}\text { Participants } & \text { Diagnosis: schizophrenia (CCMD-3) } \\ & \text { N }=42 \\ \text { Age: } 29 \pm 5 \text { years } \\ \text { Sex: M 38, F } 4 \\ \text { History: refractory auditory hallucinations }\end{array}$

Interventions

1. TMS: left temporal and parietal lobes rTMS, $1 \mathrm{~Hz}$ at $80 \%$ motor threshold, pulse count $90 \mathrm{sec} /$ train, $30 \mathrm{sec}$ interval, 10 train/day, 10 times for 2 weeks $(\mathrm{N}=21)$

2. Sham: coil plane $90^{\circ}$ to the scalp $(\mathrm{N}=21)$

All participants received a consistent dose of antipsychotics, type not reported

\begin{tabular}{ll} 
Outcomes & $\begin{array}{l}\text { Mental state: PANSS } \\
\text { Adverse events: headache }\end{array}$ \\
\hline Notes & $\begin{array}{l}\text { In Chinese } \\
\text { Source of funding: not reported }\end{array}$
\end{tabular}

\section{Risk of bias}

\begin{tabular}{lll}
\hline Bias & Authors' judgement & Support for judgement \\
\hline $\begin{array}{l}\text { Random sequence generation (selection } \\
\text { bias) }\end{array}$ & Unclear risk & Randomised, no further detail \\
\hline Allocation concealment (selection bias) & Unclear risk & $\begin{array}{l}\text { Allocation concealment method not re- } \\
\text { ported }\end{array}$ \\
\hline $\begin{array}{l}\text { Blinding of participants and personnel } \\
\text { (performance bias) } \\
\text { All outcomes }\end{array}$ & Unclear risk & Double-blind, no further detail \\
\hline
\end{tabular}

Blinding of outcome assessment (detection Unclear risk

Double-blind, no further detail bias)

All outcomes

Transcranial magnetic stimulation (TMS) for schizophrenia (Review) 
Gao 2010 (Continued)

\begin{tabular}{lll}
\hline $\begin{array}{l}\text { Incomplete outcome data (attrition bias) } \\
\text { All outcomes }\end{array}$ & Unclear risk & $\begin{array}{l}\text { It is unclear if all participants completed } \\
\text { treatment. }\end{array}$ \\
\hline Selective reporting (reporting bias) & Low risk & All the outcomes were fully reported \\
\hline Other bias & Unclear risk & $\begin{array}{l}\text { Insufficient information. Source of funding } \\
\text { not reported }\end{array}$ \\
\hline
\end{tabular}

Guse 2013

\begin{tabular}{ll} 
Methods & Allocation: randomised \\
& Blinding: double-blind \\
& Duration: 15 weeks (3 weeks with verum or sham rTMS, and a 12-week follow-up \\
phase) & Design: parallel \\
& Setting: inpatients and outpatients \\
& Country: Germany \\
\hline Participants & Diagnosis: schizophrenia (ICD 10) \\
& N $=25$ \\
Age: mean 36 years, range $20-58$ \\
Sex: M 19, F 6 \\
History: predominant negative symptoms $(>20$ PANSS) \\
\hline
\end{tabular}

Interventions

1. rTMS: 3 weeks treatment with 5 sessions per week of the left DLPFC (LDLPFC) , $10 \mathrm{~Hz}$ rTMS, stimulation intensity $110 \%$ related to the individual resting motor threshold, 1000 stimuli per session, inter-train interval $30 \mathrm{sec}$, in total 15,000 stimuli per participant, coil position guided by the 10 - 20 EEG system over $(\mathrm{N}=13)$

2. Sham: 3 weeks treatment with 5 sessions per week, stimulation parameters identical to the treatment group but magnetic coil $45^{\circ}$ away from the skull $(\mathrm{N}=12)$

All participants received SGAs

$\begin{array}{ll}\text { Outcomes } & \text { Global state: CGI, GAF } \\ \text { Cogntive state: n-back working memory tasks, Trail Making Test (TMT-A/B), Tabinger } \\ \text { Aufmerksamkeitsprung (TAP), WCST } \\ \text { Unable to use- } \\ \text { Mental state: PANSS, MADRS, CDSS (data not reported) }\end{array}$

Notes

Trial registration: clinicaltrials.gov NCT00783120

Source of funding: German Research Foundation (DFG: grant FA 241/10-1)

\section{Risk of bias}

\begin{tabular}{|c|c|c|}
\hline Bias & Authors' judgement & Support for judgement \\
\hline $\begin{array}{l}\text { Random sequence generation (selection } \\
\text { bias) }\end{array}$ & Low risk & $\begin{array}{l}\text { "Computer-generated multi-block ran- } \\
\text { domization schedule generated at the coor- }\end{array}$ \\
\hline
\end{tabular}

Transcranial magnetic stimulation (TMS) for schizophrenia (Review) 
Guse 2013 (Continued)

dination centre for clinical trials"

\begin{tabular}{|c|c|c|}
\hline Allocation concealment (selection bias) & Unclear risk & No details reported \\
\hline $\begin{array}{l}\text { Blinding of participants and personnel } \\
\text { (performance bias) } \\
\text { All outcomes }\end{array}$ & Unclear risk & $\begin{array}{l}\text { "Rater, investigators and patients were } \\
\text { blind across all parts of the study", sham } \\
\text { coil at same position with"one wing angu- } \\
\text { lated } 45^{\circ} \text { away from the skull" }\end{array}$ \\
\hline $\begin{array}{l}\text { Blinding of outcome assessment (detection } \\
\text { bias) } \\
\text { All outcomes }\end{array}$ & Low risk & $\begin{array}{l}\text { "Rater, investigators and patients were } \\
\text { blind across all parts of the study." }\end{array}$ \\
\hline $\begin{array}{l}\text { Incomplete outcome data (attrition bias) } \\
\text { All outcomes }\end{array}$ & Unclear risk & Losses to follow-up not reported \\
\hline Selective reporting (reporting bias) & High risk & $\begin{array}{l}\text { Data for mental state outcomes not re- } \\
\text { ported }\end{array}$ \\
\hline Other bias & Low risk & None detected \\
\hline
\end{tabular}

\section{Hao 2008}

Methods

Allocation: randomised

Blinding: double-blind

Duration: 4 weeks

Design: parallel

Setting: inpatients

Country: China

\begin{tabular}{|c|c|}
\hline Participants & $\begin{array}{l}\text { Diagnosis: schizophrenia (CCMD-3) } \\
\text { N = } 25 \\
\text { Age: TMS group mean } 34.46 \text { (SD 12.99) years, control group mean } 32.42 \text { years (SD } 8 . \\
\text { 18) } \\
\text { Sex: M 20, F } 5 \\
\text { History: mean length of illness TMS group }-5 \text { years, control group }-8 \text { years }\end{array}$ \\
\hline Interventions & $\begin{array}{l}\text { 1. TMS: left temporal and parietal lobes rTMS, } 10 \mathrm{~Hz} \text { at } 110 \% \text { motor threshold; pulse } \\
\text { count: } 30,5 \mathrm{sec} / \text { pulse, } 30 \mathrm{sec} \text { interval, total } 1500,20 \mathrm{~min} / \text { day; for } 4 \text { weeks }, 5 \text { treatments/ } \\
\text { week, total } 20 \text { times }(\mathrm{N}=13) \\
\text { 2. Sham: coil plane } 180^{\circ} \text { to the scalp }(\mathrm{N}=12) \\
\text { All participants received SGAs }\end{array}$ \\
\hline
\end{tabular}

$\begin{array}{ll}\text { Outcomes } & \begin{array}{l}\text { Mental state: PANSS, SANS, SAPS, HAMD, SDS } \\ \text { Adverse events: TESS }\end{array}\end{array}$

Notes

Article in Chinese

Source of funding: not reported 
Hao 2008 (Continued)

\section{Risk of bias}

\begin{tabular}{|c|c|c|}
\hline Bias & Authors' judgement & Support for judgement \\
\hline $\begin{array}{l}\text { Random sequence generation (selection } \\
\text { bias) }\end{array}$ & Low risk & Random number table \\
\hline Allocation concealment (selection bias) & Unclear risk & $\begin{array}{l}\text { Allocation concealment method not re- } \\
\text { ported }\end{array}$ \\
\hline $\begin{array}{l}\text { Blinding of participants and personnel } \\
\text { (performance bias) } \\
\text { All outcomes }\end{array}$ & Unclear risk & Double-blind, no further details \\
\hline $\begin{array}{l}\text { Blinding of outcome assessment (detection } \\
\text { bias) } \\
\text { All outcomes }\end{array}$ & Unclear risk & Double-blind, no further details \\
\hline $\begin{array}{l}\text { Incomplete outcome data (attrition bias) } \\
\text { All outcomes }\end{array}$ & Unclear risk & $\begin{array}{l}2 \text { participants refused intervention because } \\
\text { of headache and dizziness, not reported } \\
\text { from which group }\end{array}$ \\
\hline Selective reporting (reporting bias) & Low risk & All outcomes reported \\
\hline Other bias & Unclear risk & $\begin{array}{l}\text { Insufficient information. Source of funding } \\
\text { not reported }\end{array}$ \\
\hline
\end{tabular}

Hoffman 2005

\begin{tabular}{|c|c|}
\hline Methods & $\begin{array}{l}\text { Allocation: randomised } \\
\text { Blindness: double-blind } \\
\text { Duration: } 9 \text { days } \\
\text { Design: parallel } \\
\text { Setting: unclear } \\
\text { Country: USA }\end{array}$ \\
\hline Participants & $\begin{array}{l}\text { Diagnosis: schizophrenia or schizoaffective disorder } \\
\mathrm{N}=24 \\
\text { Age: average } 35.4 \text { years } \\
\text { Sex: M } 13 \text {, F } 11 \\
\text { History: medication resistant auditory hallucinations }\end{array}$ \\
\hline Interventions & $\begin{array}{l}\text { 1. TMS: left temporoparietal rTMS using } 10 \text { - } 20 \text { EEG electrode position system, } 1 \mathrm{~Hz} \text {, } \\
90 \% \text { above motor threshold, } 10 \text { second gaps between stimulations, } 8 \text { minutes on day } 1 \text {, } \\
12 \text { on Day } 2,16 \text { minutes for next } 7 \text { days }(\mathrm{N}=12) \\
\text { 2. Sham: as for active treatment but sham stimulation at } 45^{\circ} \text { single-wing tilt }(\mathrm{N}=12) \\
\text { Participants received steady psychotropic medication for duration of trial, details not } \\
\text { reported }\end{array}$ \\
\hline
\end{tabular}




\begin{tabular}{|c|c|c|}
\hline Outcomes & \multicolumn{2}{|c|}{$\begin{array}{l}\text { Global state: CGI } \\
\text { Mental state: PANSS positive and negative } \\
\text { Adverse effects: headaches, lightheadedness, cognitive difficulties }\end{array}$} \\
\hline Notes & \multicolumn{2}{|c|}{$\begin{array}{l}\text { Source of funding: grant RR } 00125 \text { from the National institutes of Health, National } \\
\text { Center for Research Resources, General Clinical Research Centers Program, Bethesda, } \\
\text { Md }\end{array}$} \\
\hline \multicolumn{3}{|l|}{ Risk of bias } \\
\hline Bias & Authors' judgement & Support for judgement \\
\hline $\begin{array}{l}\text { Random sequence generation (selection } \\
\text { bias) }\end{array}$ & Low risk & Randomised using coin toss \\
\hline Allocation concealment (selection bias) & Unclear risk & No details provided \\
\hline $\begin{array}{l}\text { Blinding of participants and personnel } \\
\text { (performance bias) } \\
\text { All outcomes }\end{array}$ & Low risk & $\begin{array}{l}\text { "Sham simulation was administered at the } \\
\text { same location, strength, and frequency } \\
\text { with the coil angled } 45 \text { degrees away from } \\
\text { the skull in a single-wing tilt position. This } \\
\text { method reproduces sound and some so- } \\
\text { matic sensations (e.g., contraction of scalp } \\
\text { muscles) similar to those of active simula- } \\
\text { tion with minimal brain effects." } \\
\text { "Knowledge of intervention type was ex- } \\
\text { clusive to the psychiatrists administering } \\
\text { rTMS and a research technician assist- } \\
\text { ing the procedure. Their interactions with } \\
\text { the patients once the trial was underway } \\
\text { was limited to administration of rTMS } \\
\text { and assessment of safety and tolerability of } \\
\text { the procedure. Study participants, clinical } \\
\text { raters, and all personnel responsible for the } \\
\text { clinical care of the participants remained } \\
\text { blind to allocated condition and allocation } \\
\text { parameters." }\end{array}$ \\
\hline
\end{tabular}

Blinding of outcome assessment (detection Low risk bias)

All outcomes
Incomplete outcome data (attrition bias) Low risk All outcomes

\section{Raters were blind}

"A patient in the sham group withdrew from the study because of absence of clinical improvement, and second patient in the sham group was removed by clinical staff because of clinical worsening. A patient in the active double-blind group was removed 
from the study because of ischemic chest pain.” Data were analysed using an intention-to-treat-analysis

\begin{tabular}{lll}
\hline Selective reporting (reporting bias) & Low risk & All outcomes reported \\
\hline Other bias & Low risk & None detected \\
\hline
\end{tabular}

\section{Holi 2004}

\begin{tabular}{|c|c|}
\hline Methods & $\begin{array}{l}\text { Allocation: randomised } \\
\text { Blindness: double-blind } \\
\text { Duration: } 2 \text { weeks } \\
\text { Design: parallel } \\
\text { Setting: inpatients } \\
\text { Country: Finland }\end{array}$ \\
\hline Participants & $\begin{array}{l}\text { Diagnosis: schizophrenia (DSM-IV) } \\
\mathrm{N}=22 \\
\text { Age: average } 36.7 \text { years } \\
\text { Sex: M } 19, \mathrm{~F} 3 \\
\text { History: chronic inpatients, mean duration of current hospitalisation } 4.4 \text { years, mean } \\
\text { duration of illness } 13.2 \text { years }\end{array}$ \\
\hline Interventions & $\begin{array}{l}\text { 1. TMS: left prefrontal rTMS, } 10 \mathrm{~Hz}, 100 \% \text { of motor threshold, } 20 \text { trains of } 5 \text { seconds } \\
\text { each with } 30 \text { seconds gap, sessions over } 10 \text { days, treatment given over } 2 \text { weeks in } 10 \\
\text { separate treatment sessions }(\mathrm{N}=11) \\
\text { 2. Sham: as for active treatment but with coil held at } 90^{\circ} \text { to scalp with both wings } \\
\text { touching }(\mathrm{N}=11) \\
\text { Both groups received SGAs, except } 1 \text { participant in the TMS group who received FGA }\end{array}$ \\
\hline Outcomes & $\begin{array}{l}\text { Global state: SCL-90 GSI } \\
\text { Mental state: PANSS positive, negative, total, SCL-90 DEP (depression) and PSY (psy- } \\
\text { choticism) } \\
\text { Adverse events: headache, pain, leaving the study early } \\
\text { Unable to use - } \\
\text { Cognitive function: MMSE (no data reported) }\end{array}$ \\
\hline Notes & Source of funding: not reported \\
\hline
\end{tabular}

\section{Risk of bias}

\begin{tabular}{l|ll}
\hline Bias & Authors' judgement & Support for judgement \\
\hline $\begin{array}{l}\text { Random sequence generation (selection } \\
\text { bias) }\end{array}$ & Unclear risk & "Randomised”-no further details provided \\
\hline Allocation concealment (selection bias) & Low risk & Sealed envelopes
\end{tabular}




\section{Holi 2004 (Continued)}

\begin{tabular}{|c|c|c|}
\hline $\begin{array}{l}\text { Blinding of participants and personnel } \\
\text { (performance bias) } \\
\text { All outcomes }\end{array}$ & Unclear risk & $\begin{array}{l}\text { "Double-blind" "In the sham condition, } \\
\text { the coil was held at } 90 \text { degrees to the scalp } \\
\text { with both wings touching the scalp" }\end{array}$ \\
\hline $\begin{array}{l}\text { Blinding of outcome assessment (detection } \\
\text { bias) } \\
\text { All outcomes }\end{array}$ & Low risk & $\begin{array}{l}\text { "Psychiatrists blind to the treatment groups } \\
\text { assessed symptoms at baseline and at the } \\
\text { end of } 2 \text { weeks' rTMS" }\end{array}$ \\
\hline $\begin{array}{l}\text { Incomplete outcome data (attrition bias) } \\
\text { All outcomes }\end{array}$ & Unclear risk & $\begin{array}{l}\text { "One patient dropped out because of para- } \\
\text { noid thoughts about the treatment. The } \\
\text { sham group dropout had received } 5 \text { days } \\
\text { of treatment and could be rated at the end } \\
\text { of the 2-week period, whereas the rTMS } \\
\text { dropout stopped the trial during the first } \\
\text { session and refused further ratings" } \\
\text { "Intention to treat analysis was used" }\end{array}$ \\
\hline Selective reporting (reporting bias) & High risk & $\begin{array}{l}\text { Not all outcomes reported - no data for } \\
\text { MMSE }\end{array}$ \\
\hline Other bias & Unclear risk & Source of funding not reported \\
\hline
\end{tabular}

Klein 1999

Methods
Allocation: randomised

Blindness: double-blind

Duration: 2 weeks

Design: parallel

Setting: inpatients

Country: Israel

Participants

Diagnosis: schizophrenia or schizoaffective disorder (DSM-IV)

$\mathrm{N}=35$

Age: average 29.9 years

Sex: M 22, F 13

History: non-chronic (mean number of 1.7 hospitalisations) with no history of treatment refractoriness, mean duration of illness 7.9 years

Interventions

1. TMS: right prefrontal rTMS, $1 \mathrm{~Hz}, 10 \%$ above threshold, 10 sessions over 10 days, each included $2 \times 1$ min treatments with 3 min gap $(\mathrm{N}=18)$

2. Sham TMS: coil perpendicular to scalp, otherwise identical to active TMS ( $N=17)$ All participants were on antipsychotic medications prior to entering the study, did not change their medications for the duration of the trial, type not reported

Outcomes

Global state: CGI

Mental state: PANSS, BPRS, HDRS

Adverse effects: facial twitches, headache, akathisia, worsening of OCD, subjective cognitive complaints, AIMS 
Klein 1999

Notes

Source of funding: Stanley Foundation, NAMI

Risk of bias

\begin{tabular}{|c|c|c|}
\hline Bias & Authors' judgement & Support for judgement \\
\hline $\begin{array}{l}\text { Random sequence generation (selection } \\
\text { bias) }\end{array}$ & Unclear risk & "Randomised" - no further details provided \\
\hline Allocation concealment (selection bias) & Unclear risk & No details provided \\
\hline $\begin{array}{l}\text { Blinding of participants and personnel } \\
\text { (performance bias) } \\
\text { All outcomes }\end{array}$ & Unclear risk & $\begin{array}{l}\text { "Stimulation parameters for the sham treat- } \\
\text { ment group were the same except that the } \\
\text { stimulation coil was placed perpendicular } \\
\text { to the scalp surface, thus minimizing cur- } \\
\text { rent flow into the skull" }\end{array}$ \\
\hline $\begin{array}{l}\text { Blinding of outcome assessment (detection } \\
\text { bias) } \\
\text { All outcomes }\end{array}$ & Low risk & $\begin{array}{l}\text { "The ratings were performed by a psychia- } \\
\text { trist who was blind to the nature of treat- } \\
\text { ment and who avoided asking the patients } \\
\text { questions that could disclose their group } \\
\text { assignment." }\end{array}$ \\
\hline $\begin{array}{l}\text { Incomplete outcome data (attrition bias) } \\
\text { All outcomes }\end{array}$ & Unclear risk & $\begin{array}{l}\text { "Thirty-one patients ( } 16 \text { rTMS and } 15 \\
\text { sham) completed the } 2 \text {-week treatment } \\
\text { protocol. Four patients ( } 2 \text { rTMS and } 2 \\
\text { sham) withdrew after three to five sessions } \\
\text { for clinical reasons. Twenty-five ( } 13 \text { rTMS } \\
\text { and } 12 \text { sham) of these } 31 \text { subjects were } \\
\text { available for follow-up assessment } 1 \text { and } 4 \\
\text { weeks after treatment completion." }\end{array}$ \\
\hline Selective reporting (reporting bias) & High risk & $\begin{array}{l}\text { CGI reported in results but not mentioned } \\
\text { in methods. Data measured at } 1 \text { week, } 2 \\
\text { weeks (end of treatment) and } 4 \text { weeks, but } \\
\text { only reported for end of treatment }\end{array}$ \\
\hline Other bias & Low risk & None detected \\
\hline
\end{tabular}


Methods
Allocation: randomised

Blinding: double-blind

Duration: 2 weeks

Design: parallel

Setting: not reported

Country: Czech Republic

\begin{tabular}{ll}
\hline Participants & Diagnosis: schizophrenia (DSM-IV) \\
$\mathrm{N}=30$ & Age: not reported \\
Sex: not reported \\
History: paranoid schizophrenia, medication-resistant auditory hallucinations, stable on \\
antipsychotic medication $\geq 4$ weeks
\end{tabular}

Interventions

1. Neuronavigated TMS: rTMS coil focused over the highest contrast of metabolic activity in the left temporoparietal area (according to the SPM analysed 18FDG PET data), at $0.9 \mathrm{~Hz}$ of $100 \%$ motor threshold, 10 sessions over 2 weeks, 1080 pulses/each session $(\mathrm{N}=10)$

2. TMS: rTMS coil administered over the left temporoparietal region using 10/20 EEG electrode system, at $0.9 \mathrm{~Hz}$ of $100 \%$ motor threshold, 10 sessions over 2 weeks, 1080 pulses/each session $(\mathrm{N}=10)$

3. Sham: coil angled $90^{\circ}$ away from the skull $(\mathrm{N}=10)$

Patients were on a stable dose of antipsychotic medication for at least 4 weeks, type not reported

\begin{tabular}{ll}
\hline Outcomes & Mental state: PANSS, AHRS \\
\hline Notes & Data were combined for theTMS groups \\
& Source of funding: “Supported by the CNPS, VZ 00 216 208 16,CNS, MZCR \\
& MZPCP2005 and MSMT 1M0517" \\
\hline
\end{tabular}

\section{Risk of bias}

\begin{tabular}{l|l|l}
\hline Bias & Authors' judgement & Support for judgement \\
\hline $\begin{array}{l}\text { Random sequence generation (selection } \\
\text { bias) }\end{array}$ & Unclear risk & $\begin{array}{l}\text { "Randomised", details of method not re- } \\
\text { ported }\end{array}$ \\
\hline $\begin{array}{l}\text { Allocation concealment (selection bias) } \\
\text { Blinding of participants and personnel } \\
\text { (performance bias) } \\
\text { All outcomes }\end{array}$ & Unclear risk & Method not reported \\
\hline $\begin{array}{l}\text { Blinding of outcome assessment (detection } \\
\text { bias) } \\
\text { All outcomes }\end{array}$ & Unclear risk & "double blind". Details not reported \\
\hline
\end{tabular}


Klirova 2010 (Continued)

\begin{tabular}{l|ll}
\hline $\begin{array}{l}\text { Incomplete outcome data (attrition bias) } \\
\text { All outcomes }\end{array}$ & Unclear risk & Number lost to follow-up not reported \\
\hline Selective reporting (reporting bias) & Unclear risk & Outcome data for AHRS not fully reported \\
\hline Other bias & Unclear risk & Role of the funding source was unclear \\
\hline
\end{tabular}

Lee 2005

\begin{tabular}{|c|c|}
\hline Methods & $\begin{array}{l}\text { Allocation: randomised } \\
\text { Blindness: double-blind } \\
\text { Duration: } 10 \text { days } \\
\text { Design: parallel } \\
\text { Setting: unclear } \\
\text { Country: Korea }\end{array}$ \\
\hline Participants & $\begin{array}{l}\text { Diagnosis: schizophrenia (DSM-IV) } \\
\mathrm{N}=39 \\
\text { Age: average } 40.3 \text { years } \\
\text { Sex: M } 16, \mathrm{~F} 23 \\
\text { History: medication resistant auditory hallucinations, mean number previous hospital- } \\
\text { isations } 4\end{array}$ \\
\hline Interventions & $\begin{array}{l}\text { 1. TMS: left temporoparietal rTMS, } 1 \mathrm{~Hz} \text {, at motor threshold, } 10 \text { sessions over } 10 \text { days, } \\
\text { each of } 20 \text { minutes duration }(\mathrm{N}=13) \\
\text { 2. TMS: right temporoparietal rTMS delivered using same parameters but to midpoint } \\
\text { between } \mathrm{T} 4 \text { and } \mathrm{P} 4(\mathrm{~N}=12) \\
\text { 3. Sham: coil perpendicular to scalp with } 1 \text { wing touching, otherwise identical to active } \\
\text { TMS }(\mathrm{N}=14) \\
\text { Not reported whether antipsychotics were used }\end{array}$ \\
\hline Outcomes & $\begin{array}{l}\text { Global state: CGI } \\
\text { Mental state: PANSS } \\
\text { Adverse effects: twitches, headache, amnesia } \\
\text { Unable to use - } \\
\text { Mental state: AHRS (total scores not reported) }\end{array}$ \\
\hline Notes & $\begin{array}{l}\text { Data were combined for the } 2 \text { TMS groups: "either temporoparietal cortex significantly } \\
\text { reduces the symptoms in } \\
\text { patients with schizophrenia who are having refractory auditory hallucinations, but the } \\
\text { left sided rTMS is not superior to right or sham rTMS" } \\
\text { Source of funding: grant No. R01-2003-000-10432-0 from the Basic Research Program } \\
\text { of the Korea Science \& Engineering Foundation }\end{array}$ \\
\hline
\end{tabular}

Risk of bias

Bias

Authors' judgement

Support for judgement

Transcranial magnetic stimulation (TMS) for schizophrenia (Review)

Copyright @ 2015 The Cochrane Collaboration. Published by John Wiley \& Sons, Ltd. 


\begin{tabular}{|c|c|c|}
\hline $\begin{array}{l}\text { Random sequence generation (selection } \\
\text { bias) }\end{array}$ & Unclear risk & "Randomised" - no further details provided \\
\hline Allocation concealment (selection bias) & Unclear risk & No details provided \\
\hline $\begin{array}{l}\text { Blinding of participants and personnel } \\
\text { (performance bias) } \\
\text { All outcomes }\end{array}$ & Unclear risk & $\begin{array}{l}\text { "The sham group received identical rTMS } \\
\text { treatment as the group receiving real rTMS, } \\
\text { but we raised the lateral wing of the coil } 90 \\
\text { degrees off the head with the edge of the } \\
\text { medial wing of the coil still touching the } \\
\text { scalp" } \\
\text { "rTMS was administered each day by a } \\
\text { trained psychiatrist who purposefully had } \\
\text { very limited verbal interaction with the } \\
\text { subject" }\end{array}$ \\
\hline $\begin{array}{l}\text { Blinding of outcome assessment (detection } \\
\text { bias) } \\
\text { All outcomes }\end{array}$ & Low risk & $\begin{array}{l}\text { "Clinical assessments were conducted by an } \\
\text { independent investigator who was blind to } \\
\text { the stimulation condition" }\end{array}$ \\
\hline $\begin{array}{l}\text { Incomplete outcome data (attrition bias) } \\
\text { All outcomes }\end{array}$ & Unclear risk & The study does not address this outcome \\
\hline Selective reporting (reporting bias) & Low risk & All outcomes reported \\
\hline Other bias & Low risk & None detected \\
\hline
\end{tabular}

Liu 2008

Methods
Allocation: randomised

Blinding: not reported

Duration: 4 weeks

Design: parallel

Setting: inpatients

Country: China

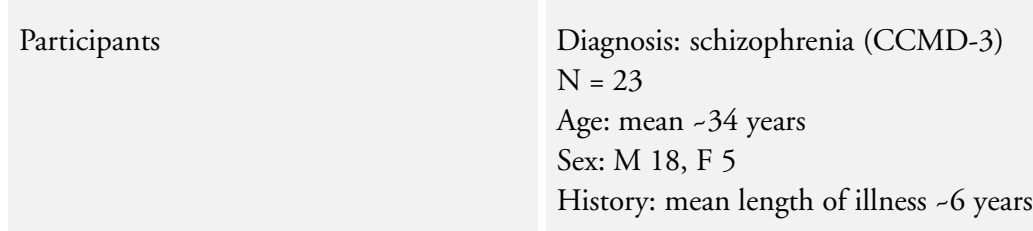

Interventions
1. TMS: left temporal and parietal lobe rTMS, $10 \mathrm{~Hz}$ at $110 \%$ motor threshold, pulse count 30, $5 \mathrm{sec} /$ pulse, $30 \mathrm{sec}$ interval, total 1500, $20 \mathrm{~min} /$ day, 5 treatments/week for 4 weeks $(\mathrm{N}=12)$

2. Sham: coil plane $180^{\circ}$ to the scalp $(\mathrm{N}=11)$

Both groups received SGAs 


\section{Liu 2008 (Continued)}

\begin{tabular}{|c|c|c|}
\hline Outcomes & \multicolumn{2}{|c|}{$\begin{array}{l}\text { Cognitive state: ANT, WCST } \\
\text { Adverse events: leaving the study early, headache }\end{array}$} \\
\hline Notes & \multicolumn{2}{|l|}{$\begin{array}{l}\text { Article in Chinese } \\
\text { Source of funding: not reported }\end{array}$} \\
\hline \multicolumn{3}{|l|}{ Risk of bias } \\
\hline Bias & Authors' judgement & Support for judgement \\
\hline $\begin{array}{l}\text { Random sequence generation (selection } \\
\text { bias) }\end{array}$ & Low risk & Randomised using random number table \\
\hline Allocation concealment (selection bias) & Unclear risk & $\begin{array}{l}\text { Allocation concealment method not re- } \\
\text { ported }\end{array}$ \\
\hline $\begin{array}{l}\text { Blinding of participants and personnel } \\
\text { (performance bias) } \\
\text { All outcomes }\end{array}$ & Unclear risk & Blinding not reported \\
\hline $\begin{array}{l}\text { Blinding of outcome assessment (detection } \\
\text { bias) } \\
\text { All outcomes }\end{array}$ & Unclear risk & Blinding not reported \\
\hline $\begin{array}{l}\text { Incomplete outcome data (attrition bias) } \\
\text { All outcomes }\end{array}$ & Low risk & $\begin{array}{l}2 \text { patients ( } 1 \text { in rTMS group, } 1 \text { in sham } \\
\text { rTMS group) refused intervention because } \\
\text { of headache. They were excluded from the } \\
\text { final analysis }\end{array}$ \\
\hline Selective reporting (reporting bias) & Low risk & All the outcomes were reported \\
\hline Other bias & Unclear risk & $\begin{array}{l}\text { Insufficient information. Source of funding } \\
\text { not reported }\end{array}$ \\
\hline
\end{tabular}

Liu 2011

Methods

Allocation: randomised

Blinding: not reported

Duration: 6 weeks

Design: parallel

Setting: not reported

Country: China

Participants

Diagnosis: schizophrenia (DSM-IV)

$\mathrm{N}=100$

Age: 18 - 56, mean 32.84 (SD 7.3)

Sex: M 51, F 49

History: length of illness mean 8.44 years (SD 6.6) 


\section{Liu 2011 (Continued)}

\begin{tabular}{|c|c|}
\hline Interventions & $\begin{array}{l}\text { 1. TMS: with } 1 \text { st generation antipsychotics, } \mathrm{rTMS} \text { to the left temporal and parietal lobes, } \\
1 \mathrm{~Hz} \text { at } 80 \% \text { motor frequency, pulse count } 30,20 \text { sec interval, repeat for } 40 \text { times, total } \\
1200 / \text { day, for } 6 \text { weeks } 5 \text { treatments/week for } 0-2 \text { weeks and } 5-6 \text { weeks, no therapy } \\
\text { during } 3 \text { - } 4 \text { weeks }(\mathrm{N}=25) \\
\text { 2. TMS: with } 2 \text { nd generation antipsychotics, } \mathrm{rTMS} \text { to the left temporal and parietal } \\
\text { lobes, } 1 \mathrm{~Hz} \text { at } 80 \% \text { motor frequency, pulse count } 30,20 \text { sec interval, repeat for } 40 \text { times, } \\
\text { total } 1200 / \text { day, for } 6 \text { weeks } 5 \text { tre atments/week for } 0-2 \text { weeks and } 5-6 \text { weeks, no } \\
\text { therapy during } 3 \text { - } 4 \text { weeks }(\mathrm{N}=25) \\
\text { 3. 2nd generation antipsychotic drugs }(\mathrm{N}=25) \\
\text { 4. 1st generation antipsychotic drugs }(\mathrm{N}=25) \\
\text { Not used - TMS: Healthy controls }(\mathrm{N}=25)\end{array}$ \\
\hline Outcomes & $\begin{array}{l}\text { Global state: improvement on CGI } \\
\text { Unable to use - } \\
\text { Mental state: PANSS, adaption of the Miller auditory hallucinations scale (data not } \\
\text { reported) }\end{array}$ \\
\hline Notes & $\begin{array}{l}\text { In Chinese } \\
5 \text { groups were included in the study: we combined data for the TMS groups and the } \\
\text { antipsychotics groups, and did not use data from healthy controls } \\
\text { Source of funding: not reported }\end{array}$ \\
\hline
\end{tabular}

\section{Risk of bias}

\section{Bias}

Random sequence generation (selection Low risk bias)

\section{Support for judgement}

Random number table used
Allocation concealment (selection bias) Unclear risk

Blinding of participants and personnel Unclear risk (performance bias)

All outcomes
Not reported

Allocation concealment method not reported

Not reported

Blinding of outcome assessment (detection Unclear risk bias)

All outcomes

Incomplete outcome data (attrition bias) Low risk All outcomes

Selective reporting (reporting bias)

High risk
No dropouts, the number of participants were reported and fully accounted for with all assessments

PANSS, CGI-GI were measured, but no score provided 
Liu 2011 (Continued)

\begin{tabular}{|c|c|c|}
\hline Other bias & Unclear risk & $\begin{array}{l}\text { Insufficient information. Source of funding } \\
\text { not reported }\end{array}$ \\
\hline
\end{tabular}

McIntosh 2004

\begin{tabular}{|c|c|c|}
\hline Methods & \multicolumn{2}{|c|}{$\begin{array}{l}\text { Allocation: randomised } \\
\text { Blindness: double-blind } \\
\text { Duration: } 4 \text { days } \\
\text { Design: cross-over } \\
\text { Setting: psychiatric hospital } \\
\text { Country: UK }\end{array}$} \\
\hline Participants & \multicolumn{2}{|c|}{$\begin{array}{l}\text { Diagnosis: schizophrenia and related disorders (DSM-IV) } \\
\mathrm{N}=16 \\
\text { Age: average } 35.9 \text { years } \\
\text { Sex: M 7, F } 9 \\
\text { History: inpatients and outpatients, medication-resistant auditory hallucinations of at } \\
\text { least } 3 \text { months duration }\end{array}$} \\
\hline Interventions & \multicolumn{2}{|c|}{$\begin{array}{l}\text { 1. TMS: left temporoparietal TMS using the } 10 \text { - } 20 \text { electrode placement system, } 1 \mathrm{~Hz} \text {, } \\
\text { at } 80 \% \text { motor threshold. For } 4 \text { days, duration: } 4 \text { mins on day } 1,8 \text { mins day } 2,12 \text { mins } \\
\text { day } 3,16 \text { mins day } 4,15 \mathrm{sec} \text { gap between each sequential minute of treatment }(\mathrm{N}=8) \\
\text { 2. Sham TMS: same as TMS, but with coil tilted by } 45^{\circ}(\mathrm{N}=8) \\
\text { Both groups received FGAs and SGAs, people on clozapine excluded from trial }\end{array}$} \\
\hline Outcomes & \multicolumn{2}{|c|}{$\begin{array}{l}\text { Mental state: PANSS total, positive; visual analogue scale for hallucinations } \\
\text { Cognitive state: AVLT } \\
\text { Unable to use - } \\
\text { Mental state: PANSS negative, depressive and hallucinations (data skewed, median and } \\
\text { IQR reported) }\end{array}$} \\
\hline Notes & \multicolumn{2}{|c|}{$\begin{array}{l}\text { Data were used only for the } 1 \text { st period of the cross-over; data provided by the authors } \\
\text { Source of funding: Stanley Medical Research Institute }\end{array}$} \\
\hline \multicolumn{3}{|l|}{ Risk of bias } \\
\hline Bias & Authors' judgement & Support for judgement \\
\hline $\begin{array}{l}\text { Random sequence generation (selection } \\
\text { bias) }\end{array}$ & Low risk & $\begin{array}{l}\text { Randomised using computer-generated } \\
\text { random numbers }\end{array}$ \\
\hline Allocation concealment (selection bias) & Low risk & $\begin{array}{l}\text { The randomisation code was held by a sin- } \\
\text { gle researcher with no clinical responsibili- } \\
\text { ties for the referred patients on his person } \\
\text { or in a locked filing cabinet }\end{array}$ \\
\hline
\end{tabular}

Transcranial magnetic stimulation (TMS) for schizophrenia (Review) 
McIntosh 2004 (Continued)

\begin{tabular}{|c|c|c|}
\hline $\begin{array}{l}\text { Blinding of participants and personnel } \\
\text { (performance bias) } \\
\text { All outcomes }\end{array}$ & Unclear risk & $\begin{array}{l}\text { "Sham TMS was administered over the } \\
\text { same point, tilting the coil to an angle of } \\
45 \text { degrees away from the skull." } \\
\text { "Patients, their clinicians and nursing staff } \\
\text { were unaware of the group to which they } \\
\text { had been randomised." } \\
\text { No details provided as to whether person- } \\
\text { nel administering the TMS were blinded }\end{array}$ \\
\hline $\begin{array}{l}\text { Blinding of outcome assessment (detection } \\
\text { bias) } \\
\text { All outcomes }\end{array}$ & Low risk & $\begin{array}{l}\text { "The investigators rating treatment re- } \\
\text { sponse were also blind to group allocation" }\end{array}$ \\
\hline $\begin{array}{l}\text { Incomplete outcome data (attrition bias) } \\
\text { All outcomes }\end{array}$ & Low risk & "No patient dropped out of the study" \\
\hline Selective reporting (reporting bias) & High risk & $\begin{array}{l}\text { Median and IQR reported for PANSS neg- } \\
\text { ative, depressive and hallucinations }\end{array}$ \\
\hline Other bias & Low risk & None detected \\
\hline
\end{tabular}

\section{Mogg 2005}

Methods

Allocation: randomised

Blindness: double-blind

Duration: 10 days over consecutive weekdays

Design: parallel

Setting: patients attending for treatment in South London hospital

Country: UK

Participants

Diagnosis: schizophrenia (DSM-IV)

$\mathrm{N}=17$

Age: average 41.7 years

Sex: M 16, F 1

History: prominent negative symptoms (> 19 on PANSS scale) and at least 3 months of stable drug treatment

Interventions

1. TMS: $10 \mathrm{~Hz}$ left prefrontal (DLPFC) rTMS at $110 \%$ motor threshold for $20 \times 10$ second trains separated by $50 \mathrm{sec}$ gaps (10 days) $4.15 \mathrm{sec}$ gap between each sequential minute of treatment $(\mathrm{N}=8)$

2. Sham: same as TMS, but with sham coil with identical appearance $(N=9)$

Both groups received FGAs and SGAs

Outcomes

Mental state: PANSS general, positive, negative

Cognitive state: Controlled oral word association test, Stroop, Hopkins Verbal Learning Test, Grooved pegboard test

Adverse effects: CSSES, leaving the study early

Unable to use -

Transcranial magnetic stimulation (TMS) for schizophrenia (Review)

Copyright $\odot 2015$ The Cochrane Collaboration. Published by John Wiley \& Sons, Ltd. 
Mental state: HADS anxiety, depression (skewed data)

Quality of life: Schizophrenia Quality of Life Scale (skewed data)

Notes

Source of funding: 2003 Ritter independent Investigator Award from the National Alliance for research on Schizophrenia and Depression, the Guy's and St Thomas' Charitable Foundation (R01126), the NHS R\&D National Coordinating Centre for Health Technology Assessment (NCCHTA) (98/11/04), and the Psychiatry Research Trust

\section{Risk of bias}

\begin{tabular}{|c|c|c|}
\hline Bias & Authors' judgement & Support for judgement \\
\hline $\begin{array}{l}\text { Random sequence generation (selection } \\
\text { bias) }\end{array}$ & Unclear risk & "Randomised" - no further details provided \\
\hline Allocation concealment (selection bias) & Low risk & $\begin{array}{l}\text { "Allocation concealment was achieved by } \\
\text { using sequentially numbered sealed opaque } \\
\text { envelopes, opened just before the first treat- } \\
\text { ment session" }\end{array}$ \\
\hline $\begin{array}{l}\text { Blinding of participants and personnel } \\
\text { (performance bias) } \\
\text { All outcomes }\end{array}$ & Unclear risk & $\begin{array}{l}\text { "Sham rTMS was similarly given but using } \\
\text { a purpose-built sham coil that is identical } \\
\text { in appearance to the real coil and makes the } \\
\text { same noise but does not deliver a substan- } \\
\text { tial stimulus" } \\
\text { "Only the research physicians administer- } \\
\text { ing rTMS knew whether real or sham treat- } \\
\text { ment was being delivered while both pa- } \\
\text { tients and rater were blind to treatment" }\end{array}$ \\
\hline $\begin{array}{l}\text { Blinding of outcome assessment (detection } \\
\text { bias) } \\
\text { All outcomes }\end{array}$ & Low risk & Raters were blinded \\
\hline $\begin{array}{l}\text { Incomplete outcome data (attrition bias) } \\
\text { All outcomes }\end{array}$ & Low risk & $\begin{array}{l}\text { "Outcomes were analysed on an intention- } \\
\text { to-treat basis" }\end{array}$ \\
\hline Selective reporting (reporting bias) & Low risk & All outcomes reported \\
\hline Other bias & Low risk & None detected \\
\hline
\end{tabular}


Methods

Blinding: double-blind
Duration: 3 weeks
Design: parallel
Setting: not reported
Country: USA

Diagnosis: Schizophrenia or schizoaffective disorder

$\mathrm{N}=85$ (83 completed)

Age: mean 35.8 (SD 10.7)

Sex: M 39, F 44

History: auditory hallucinations that occur $\geq 5$ times/day on average
1. TMS: Wernicke's area and right homologous area MRI-guided rTMS, $1 \mathrm{~Hz}, 16 \mathrm{~min} /$ day for 5 days, for week 1 , same for week 2 with switch from right to left or left to right, and 5 more stimulation sessions (16 minutes per session) to the side producing greater benefit for week 3. $(\mathrm{N}=56)$

2. Sham: placebo stimulation, which feels similar to real rTMS but does not produce direct brain effects $(\mathrm{N}=29)$

Not reported whether antipsychotics were used

Outcomes

Global state: CGI

Mental state: HCS, HCS-right, HCS-left, AHRS, change in hallucination frequency

Notes

Results posted on clinical trials website clinicaltrials.gov/ NCT00308997

NCT00567281 is an extension study of NCT00308997

Source of funding: not reported

\section{Risk of bias}

\begin{tabular}{|c|c|c|}
\hline Bias & Authors' judgement & Support for judgement \\
\hline $\begin{array}{l}\text { Random sequence generation (selection } \\
\text { bias) }\end{array}$ & Unclear risk & "Randomised", details not reported \\
\hline Allocation concealment (selection bias) & Unclear risk & Details not reported \\
\hline $\begin{array}{l}\text { Blinding of participants and personnel } \\
\text { (performance bias) } \\
\text { All outcomes }\end{array}$ & Unclear risk & "Double-blind", details not reported \\
\hline $\begin{array}{l}\text { Blinding of outcome assessment (detection } \\
\text { bias) } \\
\text { All outcomes }\end{array}$ & Low risk & "Double-blind", outcome assessors blind \\
\hline $\begin{array}{l}\text { Incomplete outcome data (attrition bias) } \\
\text { All outcomes }\end{array}$ & Low risk & $\begin{array}{l}1 \text { participant }(1 / 56) \text { in the TMS arm left } \\
\text { the study early; the reason given was "un- } \\
\text { able to tolerate intervention" and } 1 \text { partici- } \\
\text { pant }(1 / 29) \text { in the sham TMS arm did not }\end{array}$ \\
\hline
\end{tabular}

Transcranial magnetic stimulation (TMS) for schizophrenia (Review) 
NCT00308997 (Continued)

complete the trial due to "subject feigned clinical data"

\begin{tabular}{lll}
\hline Selective reporting (reporting bias) & Low risk & All outcomes fully reported \\
\hline Other bias & Unclear risk & Insufficient information \\
\hline
\end{tabular}

\section{Novak 2006}

\begin{tabular}{|c|c|}
\hline Methods & $\begin{array}{l}\text { Allocation: randomised } \\
\text { Blindness: double-blind } \\
\text { Duration: } 8 \text { weeks } \\
\text { Design: parallel } \\
\text { Setting: psychiatric inpatients and outpatients } \\
\text { Country: Czech Republic }\end{array}$ \\
\hline Participants & $\begin{array}{l}\text { Diagnosis: schizophrenia (DSM-IV) } \\
\mathrm{N}=16 \\
\text { Age: average } 34 \text { years } \\
\text { Sex: M } 12, \mathrm{~F} 4 \\
\text { History: predominantly negative symptoms on stable antipsychotic medication }\end{array}$ \\
\hline Interventions & $\begin{array}{l}\text { 1. TMS: left prefrontal rTMS } 20 \mathrm{~Hz} \text { at } 90 \% \text { motor threshold, } 10 \text { daily sessions, duration: } \\
40 \text { trains of } 2.5 \text { seconds each, } 30 \text { second gap }(\mathrm{N}=8) \\
\text { 2. Sham: same as TMS, but with coil tilted by } 90^{\circ} \text { with both coil wings in contact with } \\
\text { scalp }(\mathrm{N}=8) \\
\text { Both groups received SGAs, except one participant in the TMS group who received FGA }\end{array}$ \\
\hline Outcomes & $\begin{array}{l}\text { Mental state: non-responders ( } 20 \% \text { decrease in negative PANSS score) } \\
\text { Adverse events: leaving the study early } \\
\text { Unable to use - } \\
\text { Global state: CGI (reported as median and IQR) } \\
\text { Mental state: PANSS Positive and Negative, MADRS (reported as median and IQR) } \\
\text { Cognitive state: AVLT, CPT, ROCF, TMT (reported as median and IQR) }\end{array}$ \\
\hline Notes & Source of funding: grant of IGA Ministry of Health of Czech Republic No.7578-3 \\
\hline
\end{tabular}

\section{Risk of bias}

\begin{tabular}{l|ll}
\hline Bias & Authors' judgement & Support for judgement \\
\hline $\begin{array}{l}\text { Random sequence generation (selection } \\
\text { bias) }\end{array}$ & Unclear risk & "Randomised”, no further details provided \\
\hline Allocation concealment (selection bias) & Unclear risk & No details provided
\end{tabular}




\section{Novak 2006 (Continued)}

\begin{tabular}{|c|c|c|}
\hline $\begin{array}{l}\text { Blinding of participants and personnel } \\
\text { (performance bias) } \\
\text { All outcomes }\end{array}$ & Unclear risk & $\begin{array}{l}\text { "Double-blind" "The coil was tangential to } \\
\text { the scalp for real treatment and at } 90^{\circ} \text { (both } \\
\text { wings touching) for sham treatment" }\end{array}$ \\
\hline $\begin{array}{l}\text { Blinding of outcome assessment (detection } \\
\text { bias) } \\
\text { All outcomes }\end{array}$ & Low risk & $\begin{array}{l}\text { "An experienced psychiatrist blinded to the } \\
\text { rTMS condition performed the rating" }\end{array}$ \\
\hline $\begin{array}{l}\text { Incomplete outcome data (attrition bias) } \\
\text { All outcomes }\end{array}$ & Unclear risk & $\begin{array}{l}\text { "One patient randomized to the sham } \\
\text { group dropped out immediately after en- } \\
\text { rolment and one patient from the active } \\
\text { group concluded the study after the second } \\
\text { session because of discomfort during stim- } \\
\text { ulation" }\end{array}$ \\
\hline Selective reporting (reporting bias) & High risk & $\begin{array}{l}\text { No data for means and standard deviations } \\
\text { of outcome measures }\end{array}$ \\
\hline Other bias & Low risk & None detected \\
\hline
\end{tabular}

Poulet 2005

Methods

Participants

Interventions

Outcomes
Allocation: randomised

Blindness: double-blind

Duration: 5 working days (phase 1), 1 week wash-out, 5 working days (phase 2)

Design: cross-over

Setting: psychiatric inpatients

Country: France

Diagnosis: schizophrenia (DSM-IV)

$\mathrm{N}=10$

Age: average 34.9 years

Sex: M 7, F 3

History: right-handed patients with DSM-IV diagnosis of schizophrenia and antipsychotic-medication-resistant auditory verbal hallucinations. All participants were on antipsychotic medication for at least 3 months without changes in doses and remained on treatment throughout study period. Average illness duration 10.6 years

1. TMS: left DLPFC based on 10 - 20 placement system, rTMS at $1 \mathrm{~Hz}$ at $90 \%$ of motor threshold, 10 sessions over 5 consecutive days, 2 per day with 1000 stimulations each session, $(\mathrm{N}=5)$

2. Sham: sham placebo coil which looks and sounds the same as the active coil and produces the same sound but without the superficial scalp stimulation, $(\mathrm{N}=5)$

All participants were on antipsychotic medications prior to entering the study, did not change their medications for the duration of the trial, type not reported 
Poulet 2005 (Continued)

Notes

Only data for the 1st phase of the cross-over used, provided by the authors

Source of funding: grant from Conseil Scientifique de la Recherche, CH "Le Vinatier."

Risk of bias

\begin{tabular}{|c|c|c|}
\hline Bias & Authors' judgement & Support for judgement \\
\hline $\begin{array}{l}\text { Random sequence generation (selection } \\
\text { bias) }\end{array}$ & Unclear risk & $\begin{array}{l}\text { "Patients randomly received", no further } \\
\text { details reported }\end{array}$ \\
\hline Allocation concealment (selection bias) & Unclear risk & No details provided \\
\hline $\begin{array}{l}\text { Blinding of participants and personnel } \\
\text { (performance bias) } \\
\text { All outcomes }\end{array}$ & Low risk & $\begin{array}{l}\text { "Both patients and evaluators were blind of } \\
\text { the attributed sequence" } \\
\text { "Sham stimulation was given at the same } \\
\text { location, strength, and frequency with a } \\
\text { placebo coil being indistinguishable to the } \\
\text { active coil. The placebo coil looks identical } \\
\text { to its active counterpart and produces the } \\
\text { same sound, but there is no superficial scalp } \\
\text { stimulation, and neither the operator nor } \\
\text { the patient knew which coil is the active" }\end{array}$ \\
\hline $\begin{array}{l}\text { Blinding of outcome assessment (detection } \\
\text { bias) } \\
\text { All outcomes }\end{array}$ & Low risk & $\begin{array}{l}\text { "Both patients and evaluators were blind of } \\
\text { the attributed sequence" }\end{array}$ \\
\hline $\begin{array}{l}\text { Incomplete outcome data (attrition bias) } \\
\text { All outcomes }\end{array}$ & Low risk & $\begin{array}{l}\text { "All patients performed the entire proto- } \\
\text { col" }\end{array}$ \\
\hline Selective reporting (reporting bias) & Unclear risk & $\begin{array}{l}\text { No data for means and standard deviations } \\
\text { of outcome measures for first phase of cross- } \\
\text { over study, unpublished data provided by } \\
\text { the authors }\end{array}$ \\
\hline Other bias & Low risk & None detected \\
\hline
\end{tabular}

Prikryl 2007

Methods

Allocation: random-number generated

Blindness: double-blind

Duration: 15 consecutive days

Design: parallel

Setting: psychiatric inpatients

Country: Czech republic

Transcranial magnetic stimulation (TMS) for schizophrenia (Review) 
Prikryl 2007 (Continued)

\begin{tabular}{|c|c|}
\hline Participants & $\begin{array}{l}\text { Diagnosis: schizophrenia (ICD-10) } \\
\mathrm{N}=22 \\
\text { Age: average } 33.9 \text { years } \\
\text { Sex: } \mathrm{M} 22 \\
\text { History: significant negative symptoms without other psychiatric comorbidity such as } \\
\text { mood, anxiety or personal disorders }\end{array}$ \\
\hline Interventions & $\begin{array}{l}\text { 1. TMS: left DLPFC rTMS at } 10 \mathrm{~Hz} \text { at } 110 \% \text { of motor threshold, each session consisted } \\
\text { of } 15 \text { applications of } 10 \text { second duration with } 30 \text {-second intervals, treatments given over } \\
15 \text { consecutive days }(\mathrm{N}=11 \text { ) } \\
\text { 2. Sham: stimulation coil rotated to an angle of } 90^{\circ} \text { to scalp, given using same protocol } \\
\text { as for active treatment group }(\mathrm{N}=11 \text { ) } \\
\text { Participants were stabilised long-term (for at least } 6 \text { weeks) on antipsychotics, type not } \\
\text { reported }\end{array}$ \\
\hline Outcomes & $\begin{array}{l}\text { Mental state: PANSS positive, negative, MADRS, CDSS, SANS, SAPS } \\
\text { Adverse effects: headache } \\
\text { Unable to use - } \\
\text { Mental state CDSS (mean and SD of TMS group reported as } 0 \text { and } 0 \text {, respectively) }\end{array}$ \\
\hline Notes & $\begin{array}{l}\text { Data taken from primary reference and erratum } \\
\text { Source of funding: Internal Grant Agency of the Ministry of Health (Project No. 7986- } \\
\text { 3) and by the Ministry of } \\
\text { Education Czech Republic (Project MSM 0021622404) }\end{array}$ \\
\hline
\end{tabular}

Risk of bias

\begin{tabular}{|c|c|c|}
\hline Bias & Authors' judgement & Support for judgement \\
\hline $\begin{array}{l}\text { Random sequence generation (selection } \\
\text { bias) }\end{array}$ & Low risk & Random-number generator \\
\hline Allocation concealment (selection bias) & Unclear risk & No details provided \\
\hline $\begin{array}{l}\text { Blinding of participants and personnel } \\
\text { (performance bias) } \\
\text { All outcomes }\end{array}$ & Low risk & $\begin{array}{l}\text { "The ineffectiveness of the sham rTMS } \\
\text { was ensured by adjusting the location of } \\
\text { the stimulation coil. It formed an angle of } \\
90^{\circ} \text { against the surface of the head, which } \\
\text { was sufficient to prevent stimulation of the } \\
\text { brain cortex" } \\
\text { "Blinding of patients was also ensured using } \\
\text { a background sound that occurs during the } \\
\text { real stimulation" }\end{array}$ \\
\hline
\end{tabular}

Blinding of outcome assessment (detection Low risk bias)

All outcomes
"Evaluation of the severity of the clinical status and performance of rTMS was mutually blinded. It means that the assessor of the clinical status did not know whether 
Prikryl 2007 (Continued)

the patients were treated with the real or sham stimulation"

\begin{tabular}{l|ll}
\hline $\begin{array}{l}\text { Incomplete outcome data (attrition bias) } \\
\text { All outcomes }\end{array}$ & Unclear risk & Losses to follow-up not reported \\
\hline $\begin{array}{l}\text { Selective reporting (reporting bias) } \\
\text { Other bias }\end{array}$ & Unclear risk & $\begin{array}{l}\text { All outcomes reported, mean and SD re- } \\
\text { ported as 0 for TMS group for CDSS }\end{array}$ \\
\hline
\end{tabular}

Ren 2010

\begin{tabular}{|c|c|}
\hline Methods & $\begin{array}{l}\text { Allocation: randomised } \\
\text { Blinding: not reported } \\
\text { Duration: } 10 \text { days } \\
\text { Design: parallel } \\
\text { Setting: not reported } \\
\text { Country: China }\end{array}$ \\
\hline Participants & $\begin{array}{l}\text { Diagnosis: schizophrenia (DSM-IV) } \\
\mathrm{N}=25 \\
\text { Age: } 19-55 \text { years, mean ( } 32 \pm 7 \text { years) } \\
\text { Sex: M } 11, \mathrm{~F} 14 \\
\text { History: duration of illness } 5.1 \pm 4.2 \text { years, auditory hallucinations with stable antipsy- } \\
\text { chotic drugs }\end{array}$ \\
\hline Interventions & $\begin{array}{l}\text { 1. TMS: dorsolateral prefrontal cortex, both sides (F3, F4), rTMS } 1 \mathrm{~Hz} \text { at } 80 \% \text { motor } \\
\text { threshold, frequency } 40 / \mathrm{min} \text {, repeat for } 20 \text { minutes/day, total } 800 / \text { day for } 10 \text { days }(\mathrm{N}= \\
\text { 12) } \\
\text { 2. Sham : coil plane } 90^{\circ} \text { to the scalp }(\mathrm{N}=13 \text { ) } \\
\text { All participants received a consistent dose of antipsychotics, type not reported }\end{array}$ \\
\hline Outcomes & $\begin{array}{l}\text { Mental state: PANSS } \\
\text { Adverse events: TESS } \\
\text { Not used in the review - } \\
\text { biochemical test, blood routine examination, ECG, EEG }\end{array}$ \\
\hline Notes & $\begin{array}{l}\text { Article in Chinese } \\
\text { Source of funding: not reported }\end{array}$ \\
\hline
\end{tabular}

\section{Risk of bias}

$\begin{array}{lll}\text { Bias Authors' judgement } & \text { Support for judgement }\end{array}$

Random sequence generation (selection Unclear risk bias)

Randomised, no further details 


\begin{tabular}{l|l|l}
\hline Allocation concealment (selection bias) & Unclear risk & Allocation method not reported \\
\hline $\begin{array}{l}\text { Blinding of participants and personnel } \\
\text { (performance bias) } \\
\text { All outcomes }\end{array}$ & Unclear risk & Blinding not reported \\
\hline $\begin{array}{l}\text { Blinding of outcome assessment (detection } \\
\text { bias) } \\
\text { All outcomes }\end{array}$ & Unclear risk & Blinding not reported \\
\hline $\begin{array}{l}\text { Incomplete outcome data (attrition bias) } \\
\text { All outcomes }\end{array}$ & Low risk & There were no losses to follow-up \\
\hline $\begin{array}{l}\text { Selective reporting (reporting bias) } \\
\text { Other bias }\end{array}$ & Low risk & All the outcomes were reported \\
\hline
\end{tabular}

Ren 2011

Methods

Allocation: randomised

Blindness: double-blind

Duration: 10 days

Design: parallel

Setting: not reported

Country: China

\begin{tabular}{|c|c|}
\hline Participants & $\begin{array}{l}\text { Diagnosis: schizophrenia (DSM-IV) } \\
\mathrm{N}=23 \\
\text { Age: TMS group mean } 31 \text { years (SD 7), sham group mean } 37.7 \text { years (SD 12.3) } \\
\text { Sex: M 19, F } 4 \\
\text { History: length of illness mean } 8.2 \text { (SD 3.8) years, } 2 \text { or more antipsychotic drugs use } \\
\text { with a fixed dose for more than } 2 \text { months, with unchanged negative symptoms, PANSS } \\
\text { negative symptoms score } \geq 19 \text {,auditory hallucinations }<4\end{array}$ \\
\hline
\end{tabular}

Interventions

1. TMS: double dorsolateral prefrontal at F3 and F4, rTMS $20 \mathrm{~Hz}$ at $80 \%$ of motor threshold, repeat for 40 times/min, 20min/day for 10 days $(\mathrm{N}=12) 10 \mathrm{HZ}$ :

2. Sham: coil plane $90^{\circ}$ to the scalp, given using same protocol as for active treatment group $(\mathrm{N}=11)$

Both groups received FGAs and SGAs

Outcomes

Mental state: PANSS

Adverse events: TESS, leaving the study early

Not used in the review -

Blood routine examination, blood biochemistry, ECG, EEG

Notes

Article in Chinese

Source of funding: Beijing Science and Technology Commission Foundation 
Ren 2011 (Continued)

\section{Risk of bias}

\begin{tabular}{|c|c|c|}
\hline Bias & Authors' judgement & Support for judgement \\
\hline $\begin{array}{l}\text { Random sequence generation (selection } \\
\text { bias) }\end{array}$ & Unclear risk & Randomised: no further detail \\
\hline Allocation concealment (selection bias) & Unclear risk & Not reported \\
\hline $\begin{array}{l}\text { Blinding of participants and personnel } \\
\text { (performance bias) } \\
\text { All outcomes }\end{array}$ & Unclear risk & Double-blind, but untested \\
\hline $\begin{array}{l}\text { Blinding of outcome assessment (detection } \\
\text { bias) } \\
\text { All outcomes }\end{array}$ & Unclear risk & Double-blind, but untested \\
\hline $\begin{array}{l}\text { Incomplete outcome data (attrition bias) } \\
\text { All outcomes }\end{array}$ & Low risk & No incomplete outcome data \\
\hline Selective reporting (reporting bias) & Low risk & All measured outcomes are reported \\
\hline Other bias & Low risk & None detected \\
\hline
\end{tabular}

Rosa 2007

\begin{tabular}{|c|c|}
\hline Methods & $\begin{array}{l}\text { Allocation: randomised } \\
\text { Blinding: double-blind } \\
\text { Duration: } 10 \text { days } \\
\text { Design: parallel } \\
\text { Setting: not reported } \\
\text { Country: Brazil }\end{array}$ \\
\hline Participants & $\begin{array}{l}\text { Diagnosis: paranoid schizophrenia (DSM-IV) } \\
\mathrm{N}=11 \\
\text { Age: TMS group mean } 29.83 \text { (SD 8.40); sham group mean } 33.00 \text { (SD 12.08) } \\
\text { Sex: M 6, F } 5 \\
\text { History: Auditory hallucinations, treated with } \geq 350 \mathrm{mg} / \mathrm{d} \text { clozapine for } \geq 6 \mathrm{~m} \text {, treat- } \\
\text { ment failed } \geq 2 \text { adequate trials with standard antipsychotic medication from } 2 \text { different } \\
\text { pharmacologic groups with a minimum dose of } 1000 \mathrm{mg} \text { chlorpromazine equivalents }\end{array}$ \\
\hline Interventions & $\begin{array}{l}\text { 1. TMS: left temporoparietal cortex using the international } 10 \text { - } 20 \text { placement system, } \\
\text { rTMS } 1 \mathrm{~Hz} \text { at } 90 \% \text { of motor threshold, } 10 \text { sessions, } 16 \mathrm{~min} / \text { session, total } 9600 \text { pulses } \\
\text { in } 10 \text { days }(5 \text { days/week for } 2 \text { weeks })(\mathrm{N}=6) \\
\text { 2. Sham: same procedure with placebo coil supplied by manufacturer, magnetic field } \\
\text { reduced by } 95 \%(\mathrm{~N}=5) \\
\text { Both groups received clozapine }\end{array}$ \\
\hline
\end{tabular}


Rosa 2007 (Continued)

\begin{tabular}{|c|c|c|}
\hline Outcomes & $\begin{array}{l}\text { Global state: CGI } \\
\text { Mental state: PANSS, AHRS } \\
\text { Not used in review - } \\
\text { Subjective characteristics change: VAS }\end{array}$ & \\
\hline Notes & Source of funding: not reported & \\
\hline \multicolumn{3}{|l|}{ Risk of bias } \\
\hline Bias & Authors' judgement & Support for judgement \\
\hline $\begin{array}{l}\text { Random sequence generation (selection } \\
\text { bias) }\end{array}$ & Unclear risk & $\begin{array}{l}\text { "Randomly assigned", details of method } \\
\text { not reported. }\end{array}$ \\
\hline Allocation concealment (selection bias) & Unclear risk & Details of method not reported. \\
\hline $\begin{array}{l}\text { Blinding of participants and personnel } \\
\text { (performance bias) } \\
\text { All outcomes }\end{array}$ & Unclear risk & $\begin{array}{l}\text { "Patients were blinded to treatment". } \\
\text { "Placebo coil (produced by the manufac- } \\
\text { turer)" }\end{array}$ \\
\hline $\begin{array}{l}\text { Blinding of outcome assessment (detection } \\
\text { bias) } \\
\text { All outcomes }\end{array}$ & Low risk & "Rater blinded to treatment" \\
\hline $\begin{array}{l}\text { Incomplete outcome data (attrition bias) } \\
\text { All outcomes }\end{array}$ & Unclear risk & Number lost to follow-up not reported. \\
\hline Selective reporting (reporting bias) & Low risk & $\begin{array}{l}\text { Data not reported for VAS, other outcomes } \\
\text { fully reported }\end{array}$ \\
\hline Other bias & Low risk & $\begin{array}{l}\text { "The authors report no financial or other } \\
\text { relationships relevant to the subject of this } \\
\text { article" }\end{array}$ \\
\hline
\end{tabular}

Rosenberg 2012

Methods

Allocation: randomised

Blinding: double-blind

Duration: 10 days

Design: parallel

Setting: outpatients and inpatients

Country: Israel

Participants

Diagnosis: schizophrenia (DSM-IV-TR)

$\mathrm{N}=18$

Age: TMS group mean 40.8 (SD 16.6); sham group mean: 38.4 (SD 12.6)

Sex: M 14, F 4

History: Auditory hallucinations $\geq 5$ times/day, stable on antipsychotic medication for 
Rosenberg 2012 (Continued)

$\geq 1$ month prior to enrolment

Interventions

1. TMS: left temporoparietal cortex, $1 \mathrm{~Hz}$ at $110 \%$ of motor threshold. Deep H1 coil, single pulse stimulation, $10 \mathrm{~min} /$ day, 10 sessions ( 1 session/day for 10 days) $(\mathrm{N}=9)$

2. Sham: same stimulation as for active but with sham coil $(n=9)$

All participants were on antipsychotic medication during the study, with medication dosage kept stable throughout the study, type not reported

\begin{tabular}{ll}
\hline Outcomes & Global state: CGI \\
& Mental state: AHRS (hallucinations) \\
& Quality of Life: Q-LES-Q \\
& Adverse events \\
& Unable to use - \\
& Mental state: SANS, SAPS (skewed data) \\
\hline Notes & Source of funding: educational grant from the Brainsway Company \\
\hline
\end{tabular}

Risk of bias

\begin{tabular}{|c|c|c|}
\hline Bias & Authors' judgement & Support for judgement \\
\hline $\begin{array}{l}\text { Random sequence generation (selection } \\
\text { bias) }\end{array}$ & Unclear risk & $\begin{array}{l}\text { "Randomised", details of method not re- } \\
\text { ported }\end{array}$ \\
\hline Allocation concealment (selection bias) & Unclear risk & Method not reported. \\
\hline $\begin{array}{l}\text { Blinding of participants and personnel } \\
\text { (performance bias) } \\
\text { All outcomes }\end{array}$ & Low risk & $\begin{array}{l}\text { "Placebo stimulation was performed with } \\
\text { a sham coil placed in the same helmet en- } \\
\text { casing the active TMS coil. An electronic } \\
\text { system controlled which of the two coils } \\
\text { was connected to the stimulator in a cer- } \\
\text { tain session. This operation was carried out } \\
\text { by a magnetic card specific to each patient } \\
\text { so that both the patient and the operator } \\
\text { remained blind to the operation mode" }\end{array}$ \\
\hline $\begin{array}{l}\text { Blinding of outcome assessment (detection } \\
\text { bias) } \\
\text { All outcomes }\end{array}$ & Low risk & $\begin{array}{l}\text { "Raters were blind to the type of treatment } \\
\text { being given" }\end{array}$ \\
\hline $\begin{array}{l}\text { Incomplete outcome data (attrition bias) } \\
\text { All outcomes }\end{array}$ & High risk & $\begin{array}{l}\text { "Out of } 18 \text { patients, } 10 \text { ( } 5 \text { from each group) } \\
\text { completed the study." } \\
\text { "The dropout rate was } 44 \% \text { in both the real } \\
\text { and sham groups." } \\
\text { "Patients that dropped out of either group } \\
\text { were excluded from analysis." }\end{array}$ \\
\hline Selective reporting (reporting bias) & Low risk & All stated outcomes are reported \\
\hline
\end{tabular}

Transcranial magnetic stimulation (TMS) for schizophrenia (Review)

Copyright @ 2015 The Cochrane Collaboration. Published by John Wiley \& Sons, Ltd. 
Rosenberg 2012 (Continued)

\begin{tabular}{|l|l} 
Other bias & $\begin{array}{l}\text { Unclear risk } \\
\text { "PD the } 6 \text { authors have conflict of interest. } \\
\text { "PR received an unrestricted edu- } \\
\text { cational grant for deep TMS treatment re- } \\
\text { search from the Brainsway Company. RG } \\
\text { is a scientific consultant of the Brainsway } \\
\text { Company. AZ serves as a research consul- } \\
\text { tant and has financial interest in the Brain- } \\
\text { sway Company" }\end{array}$ \\
\hline
\end{tabular}

Saba 2006a

\begin{tabular}{|c|c|}
\hline Methods & $\begin{array}{l}\text { Allocation: randomised } \\
\text { Blindness: double-blind } \\
\text { Duration: } 2 \text { weeks } \\
\text { Design: parallel } \\
\text { Setting: inpatient adult psychiatric unit } \\
\text { Country: France }\end{array}$ \\
\hline Participants & $\begin{array}{l}\text { Diagnosis: schizophrenia (DSM-IV) } \\
\mathrm{N}=16 \\
\text { Age: average } 30.6 \text { years (SD } 8) \\
\text { Sex: M 13, F } 3 \\
\text { History: experiencing delusions and auditory hallucinations, mean hospitalisations 3.5, } \\
\text { mean duration of illness } 8 \text { years }\end{array}$ \\
\hline Interventions & $\begin{array}{l}\text { 1. TMS: left temporoparietal } \mathrm{rTMS}, 1 \mathrm{~Hz}, 20 \% \text { below motor threshold, } 14 \text { daily sessions } \\
\text { over } 2 \text { weeks, each included } 5 \times 1 \text { min treatments with } 1 \text { min gap }(\mathrm{N}=8) \\
\text { 2. Sham: Sham coil designed to produce a similar noise administered at the same location } \\
\text { on the scalp }(\mathrm{N}=8) \\
\text { All participants were maintained under antipsychotics medication at steady dosages, type } \\
\text { not reported }\end{array}$ \\
\hline Outcomes & $\begin{array}{l}\text { Global state: CGI } \\
\text { Mental state: PANSS positive, negative, total, general }\end{array}$ \\
\hline Notes & Source of funding: not reported \\
\hline
\end{tabular}

Risk of bias

\begin{tabular}{l|ll}
\hline Bias & Authors' judgement & Support for judgement \\
\hline $\begin{array}{l}\text { Random sequence generation (selection } \\
\text { bias) }\end{array}$ & Unclear risk & "Randomised”-no further details provided \\
\hline Allocation concealment (selection bias) & Unclear risk & No details provided
\end{tabular}

Transcranial magnetic stimulation (TMS) for schizophrenia (Review) 


\section{Saba 2006a (Continued)}

\begin{tabular}{|c|c|c|}
\hline $\begin{array}{l}\text { Blinding of participants and personnel } \\
\text { (performance bias) } \\
\text { All outcomes }\end{array}$ & Low risk & $\begin{array}{l}\text { "Double-blind" "Sham stimulation was ad- } \\
\text { ministered at the same location using a } \\
\text { sham coil that produces sound similar to } \\
\text { the active stimulation" }\end{array}$ \\
\hline $\begin{array}{l}\text { Blinding of outcome assessment (detection } \\
\text { bias) } \\
\text { All outcomes }\end{array}$ & Low risk & $\begin{array}{l}\text { "The ratings were performed by a psychia- } \\
\text { trist who was blind to the nature of rTMS } \\
\text { treatment" }\end{array}$ \\
\hline $\begin{array}{l}\text { Incomplete outcome data (attrition bias) } \\
\text { All outcomes }\end{array}$ & Unclear risk & $\begin{array}{l}\text { "Two patients withdrew their consent be- } \\
\text { fore beginning the session", not reported } \\
\text { which group they were from }\end{array}$ \\
\hline Selective reporting (reporting bias) & Low risk & All outcomes reported \\
\hline Other bias & Unclear risk & $\begin{array}{l}\text { Insufficient information. Source of funding } \\
\text { not reported }\end{array}$ \\
\hline
\end{tabular}

\section{Schneider 2008}

Methods

Participants

Interventions
Allocation: randomised

Blindness: double-blind

Duration: 4 weeks

Design: parallel

Setting: outpatient clinical practices and board \& care facilities

Country: USA

Diagnosis: schizophrenia

$\mathrm{N}=51$

Age: average 41.1 years

Sex: M 17, F 34

History: SANS score of $\geq 35$ with a minimum score of $\geq 2$ on items $5,9,14,16$ and 22 , mean duration of illness 18 years, diagnosis of schizophrenia of $>5$ years with $>1$ prior psychiatric hospitalisation

1. TMS: left prefrontal cortex rTMS, $1 \mathrm{~Hz}$ at $110 \%$ of motor threshold ( 100 pulses per day, 52,000 total), 5 second treatment with 15 second inter-train intervals, 20 trains each weekday (Monday - Friday) over 4 weeks $(\mathrm{N}=17)$

2. TMS: left prefrontal cortex rTMS, $10 \mathrm{~Hz}$ at $110 \%$ of motor threshold ((1000 pulses per day, 520,000 total), 5 second treatment with 15 second inter-train intervals, 20 trains each weekday (Monday - Friday) over 4 weeks $(\mathrm{N}=17)$

3.Sham: stimulation parameters as for $10 \mathrm{~Hz}$ active treatment using a magnetically nontranslucent headpiece $(\mathrm{N}=17)$

All participants received SGAs

Outcomes

Mental state: SANS

Unable to use -

Global state: CGI, SF-36 (no SDs) 
Schneider 2008 (Continued)

Cognitive state: WCST (no SDs)

$\begin{array}{ll}\text { Notes } & \text { Not reported the number randomised to each group } \\ \text { Only data from the } 10 \mathrm{~Hz} \text { TMS group used in the analysis } \\ \text { Unpublished data regarding SANS received from authors } \\ \text { Source of funding: Stanley Medical Research Institute }\end{array}$

Risk of bias

\begin{tabular}{|c|c|c|}
\hline Bias & Authors' judgement & Support for judgement \\
\hline $\begin{array}{l}\text { Random sequence generation (selection } \\
\text { bias) }\end{array}$ & Unclear risk & "Randomised" - no further details provided \\
\hline Allocation concealment (selection bias) & Unclear risk & No details provided \\
\hline $\begin{array}{l}\text { Blinding of participants and personnel } \\
\text { (performance bias) } \\
\text { All outcomes }\end{array}$ & Low risk & $\begin{array}{l}\text { "After localization of motor threshold [... } \\
\text { ] the investigator left the treatment room. } \\
\text { Then a research associate fitted one of two } \\
\text { head covers on the magnet (one allowing } \\
\text { transmission of the magnetic field and one } \\
\text { blocking it) with magnetic field strength } \\
\text { previously measured for both. This resulted } \\
\text { in blinding of the investigator and subject } \\
\text { to the nature of the } 10 \mathrm{~Hz} \text { treatment (real } \\
\text { or sham)" }\end{array}$ \\
\hline $\begin{array}{l}\text { Blinding of outcome assessment (detection } \\
\text { bias) } \\
\text { All outcomes }\end{array}$ & Low risk & $\begin{array}{l}\text { "To maintain appropriate blinding the in- } \\
\text { vestigator and rater (two different individ- } \\
\text { uals) were both blinded as to the nature of } \\
\text { treatment rendered. Only the research as- } \\
\text { sociate remained unblinded as to the actual } \\
\text { treatment each subject received" }\end{array}$ \\
\hline $\begin{array}{l}\text { Incomplete outcome data (attrition bias) } \\
\text { All outcomes }\end{array}$ & Unclear risk & $\begin{array}{l}\text { "Group A (sham) had } 15 \text { completers, group } \\
\text { B (1 Hz) had } 17 \text { completers, and group } \\
\text { C (10 Hz) had } 16 \text { completers. Three sub- } \\
\text { jects withdrew consent at baseline and were } \\
\text { not included in the analysis. Seven subjects } \\
\text { were lost to follow-up" }\end{array}$ \\
\hline Selective reporting (reporting bias) & High risk & $\begin{array}{l}\text { Not all outcomes fully reported, no SDs } \\
\text { reported }\end{array}$ \\
\hline Other bias & Low risk & None obvious \\
\hline
\end{tabular}

Transcranial magnetic stimulation (TMS) for schizophrenia (Review) 
Methods

Participants
Allocation: randomised

Blinding: double-blind

Duration: 3 weeks

Design: parallel

Setting: not reported

Country: The Netherlands

Diagnosis: schizophrenia, schizoaffective disorder, bipolar disorder, psychotic disorder NOS (criteria not reported)

$\mathrm{N}=62$

Age: fMRI guided group mean 36 (SD 10.0), left TP group mean 38 (SD 9.6), sham group mean 41 (SD 10.3)

Sex: M 36, F 26

History: AVH more frequently than once/hour, medication-resistant AVH (i.e. insufficient response to $\geq 2$ antipsychotic agents, administered at adequate dosages for $\geq 6$ weeks); stable dosage of antipsychotic medication since a month before inclusion, an $\mathrm{fMRI}$ scan showing significant hallucinatory activity in at $\geq 1$ superficially located brain area

Interventions

1. fMRI guided TMS: rTMS targeted at the area of maximal hallucinatory activation calculated for fMRI scans, $1 \mathrm{~Hz}$ at $90 \%$ of the individual motor threshold, 15 sessions of 20 min each ( 5 days/week for 3 weeks) $(\mathrm{N}=20)$

2. TMS: left temporoparietal rTMS, $1 \mathrm{~Hz}$ at $90 \%$ of the individual motor threshold, 15 sessions of 20 min each ( 5 days/week for 3 weeks) $(\mathrm{N}=22)$

3. Sham: coil tilted away from the scalp at an angle of $90^{\circ}(\mathrm{N}=20)$

All groups received FGAs and SGAs

Outcomes

Mental state: PANSS, PSYRATS

Unable to use -

Mental state: AHRS (total score not reported)

Notes

Symptoms were monitored during treatment and $3 \mathrm{~m}$ follow-up

Also did a LOCF analysis, which did not change the results

Data were combined for the 2 TMS groups

Source of funding: grants from NWO ZonMW (Dutch Scientic Research FoundationDutch National Institute of Health Research) and Stichting tot Steun (Dutch Support Foundation)

\section{Risk of bias}

\begin{tabular}{|c|c|c|}
\hline Bias & Authors' judgement & Support for judgement \\
\hline $\begin{array}{l}\text { Random sequence generation (selection } \\
\text { bias) }\end{array}$ & Low risk & $\begin{array}{l}\text { "The randomization was performed with } \\
\text { the aid of www.randomizer.org/form.htm", } \\
\text { a random generator }\end{array}$ \\
\hline
\end{tabular}

Allocation concealment (selection bias) Low risk

"The three treatment conditions were assigned in a random order by a psychologist who was not involved in the study"

Transcranial magnetic stimulation (TMS) for schizophrenia (Review) 


\section{Slotema 2011 (Continued)}

\begin{tabular}{l|l}
$\begin{array}{l}\text { Blinding of participants and personnel } \\
\text { (performance bias) }\end{array}$ & Unclear risk \\
All outcomes & $\begin{array}{l}\text { "Double-blind" "coil titled away from the } \\
\text { scalp at an angle of } 90 \text { degrees" } \\
\text { "Participants were notified of the treatment } \\
\text { condition after the last follow-up assess- } \\
\text { ment." } \\
\text { "This outcome confirms that patients were } \\
\text { actually blind for their treatment condi- } \\
\text { tions, because the vast majority of patients } \\
\text { in all three groups expected to have had ac- } \\
\text { tive rTMS treatment." }\end{array}$ \\
\hline
\end{tabular}

Blinding of outcome assessment (detection Low risk bias)

"Treatment conditions were unknown to . All outcomes ..raters."

Incomplete outcome data (attrition bias) Unclear risk All outcomes
Losses were not balanced across intervention groups: in the fMRI guided rTMS group 2/20 left the study early, in the standard rTMS group 3/22 left early, and 6/20 in the sham group

\begin{tabular}{lll}
\hline Selective reporting (reporting bias) & Low risk & All stated outcomes reported \\
\hline Other bias & Low risk & None detected \\
\hline
\end{tabular}

Vercammen 2009a

Methods

Blinding: double-blind
Duration: 6 days
Design: parallel
Setting: inpatients and outpatients
Country: The Netherlands

Diagnosis: schizophrenia (DSM-IV)

$\mathrm{N}=36$

Age: left TP group mean 33.75 (SD 14.21); bilateral TP group mean 33.83 (SD 9.27); sham group mean 36.50 (SD 12.92)

Sex: M 18, F18

History: Frequent medication-resistant AVH (the daily AVH occurring in $\geq 2$ adequate trials of antipsychotic medications; treated with stable doses of antipsychotic medication for $\geq 4$ weeks prior to study inclusion)

Interventions
1. TMS: left temporoparietal rTMS using 10 - 20 placement system, $1 \mathrm{~Hz}$ at $90 \%$ of motor threshold, 12 sessions, each lasting 20 mins with a minimum 5 hour delay between subsequent sessions (total of 14,400 pulses) $(\mathrm{N}=12)$

2. TMS: bilateral temporoparietal rTMS, $1 \mathrm{~Hz}$ at $90 \%$ of motor threshold, 12 sessions, each lasting 20 mins with a minimum 5 hour delay in between subsequent sessions (total 
Vercammen 2009a (Continued)

\begin{tabular}{|c|c|c|}
\hline & \multicolumn{2}{|c|}{$\begin{array}{l}\text { of } 14,400 \text { pulses })(\mathrm{N}=12) \\
\text { 3. Sham: on the same location as the left-sided stimulation designed to produce an } \\
\text { identical sound }(\mathrm{N}=12) \\
\text { All participants were maintained under antipsychotics at steady dosages, type not re- } \\
\text { ported }\end{array}$} \\
\hline Outcomes & \multicolumn{2}{|c|}{ Mental state: PANSS, AHRS, PANAS } \\
\hline Notes & \multicolumn{2}{|c|}{$\begin{array}{l}\text { Duration: } 6 \text { working days with a 2-day weekend delay after day } 3 \\
36 \text { completed participants } \\
\text { Data were combined for the } 2 \text { TMS groups } \\
\text { Source of funding: Ubbo Emmius Grant (180/800514) of the University of Groningen }\end{array}$} \\
\hline \multicolumn{3}{|l|}{ Risk of bias } \\
\hline Bias & Authors' judgement & Support for judgement \\
\hline $\begin{array}{l}\text { Random sequence generation (selection } \\
\text { bias) }\end{array}$ & Unclear risk & "randomised", method not reported \\
\hline Allocation concealment (selection bias) & Unclear risk & Method not reported \\
\hline $\begin{array}{l}\text { Blinding of participants and personnel } \\
\text { (performance bias) } \\
\text { All outcomes }\end{array}$ & Unclear risk & $\begin{array}{l}\text { "Participants... all personnel responsible for } \\
\text { the clinical care of the patients were blind } \\
\text { to the allocated condition.", details not re- } \\
\text { ported }\end{array}$ \\
\hline $\begin{array}{l}\text { Blinding of outcome assessment (detection } \\
\text { bias) } \\
\text { All outcomes }\end{array}$ & Low risk & $\begin{array}{l}\text { "Clinical raters were blind to the allocated } \\
\text { condition." "Sham stimulation was per- } \\
\text { formed... with the use of a Magstim sham } \\
\text { coil, which does not deliver a measurable } \\
\text { magnetic eld, but does produce the same } \\
\text { clearly audible clicking sound, at the same } \\
\text { frequency of } 1 \mathrm{~Hz} \text {." }\end{array}$ \\
\hline $\begin{array}{l}\text { Incomplete outcome data (attrition bias) } \\
\text { All outcomes }\end{array}$ & Unclear risk & $\begin{array}{l}\text { "One subject withdrew from the study, } \\
\text { during the rst week of treatment, due } \\
\text { to exacerbation of psychotic symptoms . } \\
\text {.. ascribed to personal circumstances... A } \\
\text { second subject was excluded, because she } \\
\text { failed to comply with the medication re- } \\
\text { quirement". Unclear to which the interven- } \\
\text { tion group these participants had been as- } \\
\text { signed }\end{array}$ \\
\hline Selective reporting (reporting bias) & Low risk & All outcomes stated have been reported \\
\hline Other bias & Low risk & None detected \\
\hline
\end{tabular}

Transcranial magnetic stimulation (TMS) for schizophrenia (Review) 


\begin{tabular}{|c|c|}
\hline Methods & $\begin{array}{l}\text { Allocation: randomised } \\
\text { Blinding: double-blind } \\
\text { Duration: } 10 \text { weeks } \\
\text { Design: parallel } \\
\text { Setting: outpatients } \\
\text { Country: Canada }\end{array}$ \\
\hline Participants & $\begin{array}{l}\text { Diagnosis: schizophrenia or schizoaffective disorder (DSM-IV) } \\
\mathrm{N}=15 \\
\text { Age: not reported } \\
\text { Sex: not reported } \\
\text { History: smoking } \geq \text { cigarettes/day, CO levels } \geq 10 \mathrm{ppm} \text {, Fagerstrom test of Nicotine } \\
\text { Dependence score } \geq 4, \text { motivated to quit within a month }\end{array}$ \\
\hline Interventions & $\begin{array}{l}\text { 1. TMS: bilateral DLPFC rTMS, } 20 \mathrm{~Hz} \text { at } 90 \% \text { of the resting motor threshold for } 25 \\
\text { trains ( } 30 \text { pulses/train; } 30 \mathrm{sec} \text { inter-train interval; } 750 \text { pulses/hemisphere), } 20 \text { sessions, } 5 \\
\text { treatments/week in weeks } 1-4 \text { as an adjunctive to weekly group therapy and transdermal } \\
\text { nicotine (TN; } 21 \mathrm{mg}) \text { provided in weeks } 3-9(\mathrm{~N}=6) \\
\text { 2. Sham: administered in the single-wing tilt position }(\mathrm{N}=9) \\
\text { Not reported whether antipsychotics were used }\end{array}$ \\
\hline Outcomes & $\begin{array}{l}\text { Mental state: PANSS } \\
\text { Not used in the review - } \\
\text { Smoking: self report and breath carbon monoxide }[\mathrm{CO}] \text { levels } \\
\text { Cravings: TQSU } \\
\text { Withdrawal: Minnesota Nicotine Withdrawal Scale }\end{array}$ \\
\hline Notes & $\begin{array}{l}\text { Source of funding: Idea Grant (\#19588) from the Canadian Institute for Health Research } \\
\text { and Canadian Tobacco Control Research Initiative, Chair in Addiction Psychiatry from } \\
\text { the University of Toronto, Fellowship Award from the Centre for Addiction and Mental } \\
\text { Health (CAMH) }\end{array}$ \\
\hline
\end{tabular}

\section{Risk of bias}

\begin{tabular}{|c|c|c|}
\hline Bias & Authors' judgement & Support for judgement \\
\hline $\begin{array}{l}\text { Random sequence generation (selection } \\
\text { bias) }\end{array}$ & Unclear risk & $\begin{array}{l}\text { "Randomised", details of method not re- } \\
\text { ported }\end{array}$ \\
\hline Allocation concealment (selection bias) & Unclear risk & Method not reported \\
\hline $\begin{array}{l}\text { Blinding of participants and personnel } \\
\text { (performance bias) } \\
\text { All outcomes }\end{array}$ & Unclear risk & "Double-blind", details not reported \\
\hline
\end{tabular}

Blinding of outcome assessment (detection Unclear risk bias)

All outcomes 


\begin{tabular}{l|l|l}
\hline $\begin{array}{l}\text { Incomplete outcome data (attrition bias) } \\
\text { All outcomes }\end{array}$ & High risk & $\begin{array}{l}\text { "6/9 participants in the sham group and 6/ } \\
6 \text { in the active group completed the trial." } \\
\text { Reasons for losses not reported. Losses not } \\
\text { balanced across intervention groups }\end{array}$ \\
\hline Selective reporting (reporting bias) & Unclear risk & PANSS not reported. \\
\hline Other bias & Low risk & None detected \\
\hline
\end{tabular}

\section{Xu 2011}

\begin{tabular}{|c|c|}
\hline Methods & $\begin{array}{l}\text { Allocation: randomised } \\
\text { Blinding: double-blind } \\
\text { Duration } 2 \text { weeks } \\
\text { Design: parallel } \\
\text { Setting: not reported } \\
\text { Country: China }\end{array}$ \\
\hline Participants & $\begin{array}{l}\text { Diagnosis: schizophrenia (CCMD-3) } \\
\mathrm{N}=35 \\
\text { Age: mean }-32 \text { years } \\
\text { Sex: } \mathrm{M} 24 \text {, F } 11 \\
\text { History: duration of illness }-7.5 \text { years, refractory hallucinations }\end{array}$ \\
\hline Interventions & $\begin{array}{l}\text { 1. TMS: left temporoparietal region, } 1 \mathrm{~Hz} \text { at } 80 \% \text { motor threshold, pulse count } 10 \text { for } \\
10 \mathrm{sec}, 5 \mathrm{sec} \text { interval, repeat for } 20 \text { minutes/day, total } 800 / \text { day, } 10 \text { times for } 2 \text { weeks ( } \\
=18 \text { ) } \\
\text { 2. Sham TMS: coil plane } 90^{\circ} \text { to the scalp }(\mathrm{N}=17) \\
\text { Not reported whether antipsychotics were used }\end{array}$ \\
\hline Outcomes & $\begin{array}{l}\text { Mental state: PANSS } \\
\text { Cognitive state: WCST, CPT reaction time } \\
\text { Unable to use - } \\
\text { Cognitive state: Continuous Performance Test (CPT) false items and missing items } \\
\text { (skewed data) }\end{array}$ \\
\hline Notes & $\begin{array}{l}\text { In Chinese } \\
\text { Source of funding: not reported }\end{array}$ \\
\hline
\end{tabular}

\section{Risk of bias}

Bias Authors' judgement

Random sequence generation (selection Unclear risk bias)

\section{Support for judgement}

Randomised, no further details 


\section{Xu 2011 (Continued)}

\begin{tabular}{|c|c|c|}
\hline Allocation concealment (selection bias) & Unclear risk & $\begin{array}{l}\text { Allocation concealment method not re- } \\
\text { ported }\end{array}$ \\
\hline $\begin{array}{l}\text { Blinding of participants and personnel } \\
\text { (performance bias) } \\
\text { All outcomes }\end{array}$ & Unclear risk & Double-blind, no further details \\
\hline $\begin{array}{l}\text { Blinding of outcome assessment (detection } \\
\text { bias) } \\
\text { All outcomes }\end{array}$ & Unclear risk & Double-blind, no further details \\
\hline $\begin{array}{l}\text { Incomplete outcome data (attrition bias) } \\
\text { All outcomes }\end{array}$ & Low risk & All the participants complete the treatment \\
\hline Selective reporting (reporting bias) & Low risk & All the outcomes were reported \\
\hline Other bias & Unclear risk & $\begin{array}{l}\text { Insufficient information. Source of funding } \\
\text { not reported }\end{array}$ \\
\hline
\end{tabular}

Yu 2010

Methods

Allocation: randomised

Blinding: double-blind

Duration: 10 days

Design: parallel

Setting: not reported

Country: China

\begin{tabular}{|c|c|}
\hline Participants & $\begin{array}{l}\text { Diagnosis: schizophrenia } \\
\mathrm{N}=61 \\
\text { Age: mean }-27.5 \text { years } \\
\text { Sex: M 46, F } 15 \\
\text { History: chronic schizophrenia with hyperprolactinem }\end{array}$ \\
\hline Interventions & $\begin{array}{l}\text { 1. TMS: left temporal and parietal lobes } \mathrm{rTMS}, 1 \mathrm{~Hz} \\
\text { lating for } 200 \mathrm{sec}, 10 \mathrm{sec} \text { interval, repeat for } 5 \text { times } / \mathrm{da} \\
=31) \\
\text { 2. Sham: coil placed } 90^{\circ} \text { to the scalp }(\mathrm{N}=30) \\
\text { Participants were given risperidone }(2-6 \mathrm{mg} / \text { day }) \text { trea }\end{array}$ \\
\hline Outcomes & $\begin{array}{l}\text { Adverse events: headache } \\
\text { Unable to use - } \\
\text { Mental state: PANSS, HAMD-17 (no mean and SD) } \\
\text { Not used in the review - } \\
\text { EEG, prolactin }\end{array}$ \\
\hline
\end{tabular}

Notes Article in Chinese

Source of funding: not reported 


\section{Risk of bias}

\begin{tabular}{|c|c|c|}
\hline Bias & Authors' judgement & Support for judgement \\
\hline $\begin{array}{l}\text { Random sequence generation (selection } \\
\text { bias) }\end{array}$ & Low risk & Random-number table was used \\
\hline Allocation concealment (selection bias) & Unclear risk & Allocation concealment not reported \\
\hline $\begin{array}{l}\text { Blinding of participants and personnel } \\
\text { (performance bias) } \\
\text { All outcomes }\end{array}$ & Unclear risk & Double-blind, no details reported \\
\hline $\begin{array}{l}\text { Blinding of outcome assessment (detection } \\
\text { bias) } \\
\text { All outcomes }\end{array}$ & Unclear risk & Double-blind, no details reported \\
\hline $\begin{array}{l}\text { Incomplete outcome data (attrition bias) } \\
\text { All outcomes }\end{array}$ & Low risk & There were no losses to follow-up \\
\hline Selective reporting (reporting bias) & High risk & $\begin{array}{l}\text { PANSS and HAMD-17 score were mea- } \\
\text { sured, but not reported }\end{array}$ \\
\hline Other bias & Unclear risk & $\begin{array}{l}\text { Insufficient information. Source of funding } \\
\text { not reported }\end{array}$ \\
\hline
\end{tabular}

\section{Zhang 2010}

Methods
Randomised: randomised (random number table)

Blinding: double-blind

Duration: 4 weeks

Design: parallel

Setting: not reported

Country: China
Participants
Diagnosis: schizophrenia (DSM-IV)

$\mathrm{N}=30$

Age: TMS group mean $28 \pm 8$ years, sham group $27 \pm 8$ years

Sex: M 19, F 11

History: length of illness median 16 years TMS group and 12 years sham group, negative symptoms last for more than 6 weeks

Interventions
1. TBS TMS: rTMS to the left DLPFC, $80 \%$ motor threshold TBS mode, base sequence of $5 \mathrm{~Hz}$, stimulating for $200 \mathrm{~ms}$ with 3 single pulses of $50 \mathrm{~Hz}$ for 20 minutes, total 2400/ day. 20 sessions ( 5 times/week for 4 weeks) $(\mathrm{N}=15)$

2. Sham: sham rTMS reverse side of coil plane to the scalp $(\mathrm{N}=15)$

Not reported whether antipsychotics were used 
Zhang 2010 (Continued)

\begin{tabular}{|c|c|c|}
\hline Outcomes & \multicolumn{2}{|c|}{$\begin{array}{l}\text { Global state: clinical improvement } \\
\text { Mental state: PANSS, SANS, HAMD } \\
\text { Adverse events: sleep disorder, headache, leaving the study early } \\
\text { Unable to use - } \\
\text { Mental state: HAMD (no data) }\end{array}$} \\
\hline Notes & \multicolumn{2}{|c|}{ Source of funding: not reported } \\
\hline \multicolumn{3}{|l|}{ Risk of bias } \\
\hline Bias & Authors' judgement & Support for judgement \\
\hline $\begin{array}{l}\text { Random sequence generation (selection } \\
\text { bias) }\end{array}$ & Low risk & Random-number table \\
\hline Allocation concealment (selection bias) & Unclear risk & $\begin{array}{l}\text { Allocation concealment method not re- } \\
\text { ported }\end{array}$ \\
\hline $\begin{array}{l}\text { Blinding of participants and personnel } \\
\text { (performance bias) } \\
\text { All outcomes }\end{array}$ & Unclear risk & Double-blind, no further details \\
\hline $\begin{array}{l}\text { Blinding of outcome assessment (detection } \\
\text { bias) } \\
\text { All outcomes }\end{array}$ & Unclear risk & Double-blind, no further details \\
\hline $\begin{array}{l}\text { Incomplete outcome data (attrition bias) } \\
\text { All outcomes }\end{array}$ & Low risk & $\begin{array}{l}2 \text { participants left the study early in the } \\
\text { sham group due to early discharge and } 1 \text { the } \\
\text { TMS group due to headache during rTMS } \\
\text { treatment. They were not included in the } \\
\text { final analysis }\end{array}$ \\
\hline Selective reporting (reporting bias) & High risk & Data not reported for the HAMD \\
\hline Other bias & Unclear risk & $\begin{array}{l}\text { Insufficient information. Source of funding } \\
\text { not reported }\end{array}$ \\
\hline
\end{tabular}

\section{Zheng 2012}

Methods
Allocation: randomised

Blinding: double-blind (participants and assessor blind)

Duration: 5 days

Design: parallel

Setting: inpatients

Country: China 
Zheng 2012 (Continued)

\begin{tabular}{|c|c|}
\hline Participants & $\begin{array}{l}\text { Diagnosis: schizophrenia (CCMD-3) } \\
\mathrm{N}=80 \\
\text { Age: mean }-56 \text { years } \\
\text { Sex: } \mathrm{M} 80 \\
\text { History: length of illness mean }-32 \text { years }\end{array}$ \\
\hline Interventions & $\begin{array}{l}\text { 1. TMS } 10 \mathrm{~Hz} \text { : DLPFC, } 10 \mathrm{~Hz} \text { at } 80 \% \text { motor threshold, pulse count } 40,15 \mathrm{sec} \text { interval, } \\
30 \text { series of stimulus for } 10 \mathrm{mins} \text {, total } 1200 / \text { day for } 5 \text { days }(\mathrm{N}=20) \\
\text { 2. TMS } 20 \mathrm{~Hz} \text { : DLPFC, } 20 \mathrm{~Hz} \text { at } 80 \% \text { motor threshold, pulse count: } 40,28 \mathrm{sec} \text { interval, } \\
30 \text { series of stimulus for } 15 \mathrm{~min} \text {, total } 1200 / \text { day for } 5 \text { days }(\mathrm{N}=21) \\
\text { 3. TBS TMS } 50 \mathrm{~Hz} \text { : TBS to the DLPFC, base sequence for } 5 \mathrm{~Hz} \text { every } 200 \mathrm{~ms}, 3 \text { single } \\
\text { pulses of } 50 \mathrm{~Hz} \text { at } 80 \% \text { motor threshold }(\mathrm{N}=19) \\
\text { 4. Sham: reverse side of coil plane to the scalp, stimulation as for active TMS }(\mathrm{N}=20) \\
\text { All participants received antipsychotics, type not reported }\end{array}$ \\
\hline Outcomes & $\begin{array}{l}\text { Mental state: PANSS } \\
\text { Cogntive state: Digit Span Test, verbal fluency test }\end{array}$ \\
\hline Notes & $\begin{array}{l}\text { Data combined in the analysis for the } 10 \mathrm{~Hz} \text { and } 20 \mathrm{~Hz} \text { groups } \\
\text { In Chinese } \\
\text { Source of funding: Shanghai Committee of Science and Technology,China and the } \\
\text { National Natural Science Foundation }\end{array}$ \\
\hline
\end{tabular}

\section{Risk of bias}

\begin{tabular}{|c|c|c|}
\hline Bias & Authors' judgement & Support for judgement \\
\hline $\begin{array}{l}\text { Random sequence generation (selection } \\
\text { bias) }\end{array}$ & Low risk & $\begin{array}{l}\text { Randomised, using computer-generated } \\
\text { (SAS software) random numbers }\end{array}$ \\
\hline Allocation concealment (selection bias) & Unclear risk & Not reported \\
\hline $\begin{array}{l}\text { Blinding of participants and personnel } \\
\text { (performance bias) } \\
\text { All outcomes }\end{array}$ & Unclear risk & $\begin{array}{l}\text { Double-blind. Assessors and participants } \\
\text { were blinded to the allocation and detail } \\
\text { of rTMS therapy (but, trialists are aware of } \\
\text { the allocation) }\end{array}$ \\
\hline $\begin{array}{l}\text { Blinding of outcome assessment (detection } \\
\text { bias) } \\
\text { All outcomes }\end{array}$ & Low risk & $\begin{array}{l}\text { Assessors were not allowed to enter the in- } \\
\text { tervention room and were blinded to the } \\
\text { allocation and detail of intervention }\end{array}$ \\
\hline $\begin{array}{l}\text { Incomplete outcome data (attrition bias) } \\
\text { All outcomes }\end{array}$ & Low risk & $\begin{array}{l}7 \text { people left the study early. Although rea- } \\
\text { sons for dropout were given, these } 7 \text { people } \\
\text { were not included in the final analysis }\end{array}$ \\
\hline Selective reporting (reporting bias) & Low risk & All measured outcomes were reported \\
\hline Other bias & Low risk & None detected \\
\hline
\end{tabular}

Transcranial magnetic stimulation (TMS) for schizophrenia (Review)

Copyright () 2015 The Cochrane Collaboration. Published by John Wiley \& Sons, Ltd. 
Diagnostic Manuals

DSM - Diagnosic and Statistical Manual of Mental Disorders (American Psychiatric Association)

ICD - International Classification of Diseases

General

ECG: electrocardiogram

EEG - electro-encephalogram

IM - intramuscular

Ht - haematocrit

$\mathrm{Hb}$ - haemoglobin

$\mathrm{RBC}$ - red blood cell

WBC - white blood cell

ESR - erithrocyte sedimentation rate

IV - intravenous injection

LOCF - last observation carried forward

$\mathrm{M}$ - male

F - female

FGA - first generation antipsychotics

$S D$ - standard deviation

SGA - second generation antipsychotics

Scales

AHRS - auditory hallucination rating scale

ANT - attentional networking test

AVLT - Auditory-Verbal Learning Test

BPRS - brief psychiatric rating scale

CDRS - Calgary depression rating cale

CDS - Calgary depression scale

CGI - clinical global impression

CPT - continuous performance test

CVLT - California verbal learning test

CSSES - Columbia ECT subjective side effects schedule

GSI - global severity index

HCS - Hoffman hallucination change scale

MADRS - Montgomery-Asberg depression rating scale

PANSS - positive and negative symptoms scale

ROCF - Rey-Osterrieth Complex Figure Test

PRSS - psychiatric rating scale for schizophrenia

SANS - scale for assessment of negative symptoms

SAPS - scale for the assessment of positive symptoms

SF-36 - short form

TPT - Tactile Performance Test

UKU - udvalg for kliniske undersøgelser

VAS - visual analogue scale

WCST - Wisconsin card sorting test

WRAT-R - wide range achievement test - reading 
Characteristics of excluded studies [ordered by study ID]

\begin{tabular}{|c|c|}
\hline Study & Reason for exclusion \\
\hline ACTRN12611000731998 & $\begin{array}{l}\text { Allocation: randomised } \\
\text { Participants: people with schizophrenia } \\
\text { Interventions: Transcranial Direct Current Stimulation (tDCS) vs sham treatment }\end{array}$ \\
\hline ACTRN12612000217808 & $\begin{array}{l}\text { Allocation: randomised } \\
\text { Participants: people with schizophrenia } \\
\text { Interventions: Transcranial Direct Current Stimulation (tDCS) vs sham treatment }\end{array}$ \\
\hline ACTRN12612001112853 & $\begin{array}{l}\text { Allocation: randomised } \\
\text { Participants: people with schizophrenia } \\
\text { Interventions: Transcranial Direct Current Stimulation (tDCS) vs sham treatment }\end{array}$ \\
\hline Alva 2001 & $\begin{array}{l}\text { Allocation: not randomised } \\
\text { Outcome data: insufficient data for use (conference abstract) }\end{array}$ \\
\hline Arends 2005 & $\begin{array}{l}\text { Allocation: randomised } \\
\text { Participants: people with schizophrenia } \\
\text { Interventions: Left dorsolateral prefrontal high-frequency repetitive TMS vs unknown } \\
\text { Outcome data: insufficient data for use (conference abstract) }\end{array}$ \\
\hline Benitez 2005 & $\begin{array}{l}\text { Allocation: randomised } \\
\text { Participants: people with schizophrenia and treatment-resistant auditory hallucinations } \\
\text { Interventions: TMS, } 1 \mathrm{~Hz} \text { at } 90 \% \text { of resting motor threshold for } 15 \text { minutes, } 10 \text { consecutive week days } \\
\text { vs sham TMS } \\
\text { Outcome data: insufficient data for use, no outcome measures given (conference abstract) }\end{array}$ \\
\hline Brunelin 2012 & $\begin{array}{l}\text { Allocation: randomised } \\
\text { Participants: people with schizophrenia } \\
\text { Interventions: Transcranial Direct Current Stimulation (tDCS) vs sham treatment }\end{array}$ \\
\hline Chibbaro 2005 & Allocation: not randomised \\
\hline Cohen 1999 & Allocation: not randomised \\
\hline Cordes 2008 & $\begin{array}{l}\text { Allocation: randomised } \\
\text { Participants: people with schizophrenia } \\
\text { Interventions: TMS vs sham TMS } \\
\text { Outcome data: insufficient data for use, no outcome measures given (conference abstract) }\end{array}$ \\
\hline D'Alfonso 2002 & Allocation: not randomised \\
\hline Daskalakis 2003 & Allocation: not randomised \\
\hline Daskalakis 2007 & $\begin{array}{l}\text { Allocation: randomised } \\
\text { Participants: people with schizophrenia } \\
\text { Interventions: TMS versus sham TMS }\end{array}$ \\
\hline
\end{tabular}

Transcranial magnetic stimulation (TMS) for schizophrenia (Review)

Copyright () 2015 The Cochrane Collaboration. Published by John Wiley \& Sons, Ltd. 
(Continued)

Outcome data: no usable data reported (conference proceeding)

\begin{tabular}{|c|c|}
\hline Davey 1997 & Allocation: not randomised \\
\hline Feinsod 1998 & Allocation: not randomised \\
\hline Fitzgerald 2003 & Allocation: not randomised \\
\hline Geller 1997 & Allocation: not randomised \\
\hline Goyal 2007 & Allocation: not randomised \\
\hline Grenier 2008 & $\begin{array}{l}\text { Allocation: randomised } \\
\text { Participants: people with schizophrenia } \\
\text { Interventions: TMS versus placebo (not reported whether sham TMS) } \\
\text { Outcome data: no usable data reported }\end{array}$ \\
\hline Hajak 2004 & $\begin{array}{l}\text { Allocation: randomised } \\
\text { Participants: people with schizophrenia } \\
\text { Interventions: Left dorsolateral prefrontal high-frequency repetitive TMS vs sham } \\
\text { Outcome data: insufficient data for use, wrote to author to request unpublished means and standard } \\
\text { deviations for phase one of the cross-over study with no reply }\end{array}$ \\
\hline Hasan 2010 & $\begin{array}{l}\text { Allocation: randomised } \\
\text { Participants: people with schizophrenia } \\
\text { Interventions: TMS versus sham TMS } \\
\text { Outcome data: no usable data reported }\end{array}$ \\
\hline Hasey 2000 & $\begin{array}{l}\text { Allocation: randomised } \\
\text { Participants: people with severe depression }\end{array}$ \\
\hline Hoffman 1999 & $\begin{array}{l}\text { Allocation: not randomised } \\
\text { Participants: people with schizophrenia. The number of included participants was less than } 5\end{array}$ \\
\hline Hoffman 2000 & $\begin{array}{l}\text { Allocation: randomised } \\
\text { Participants: people with schizophrenia } \\
\text { Interventions: TMS vs sham TMS } \\
\text { Outcome data: insufficient data for use; results of the 1st phase of the cross-over trial not reported }\end{array}$ \\
\hline Hoffman 2003 & $\begin{array}{l}\text { Allocation: randomised } \\
\text { Outcome data: insufficient data for use (conference abstract) }\end{array}$ \\
\hline Hoffman 2007 & Allocation: not randomised \\
\hline Jandl 2005 & Allocation: not randomised \\
\hline Jandl 2006 & $\begin{array}{l}\text { Allocation: randomised, no allocation concealment } \\
\text { Participants: people with schizophrenia but not on long-term stable antipsychotic medication ( } 1 \text { week } \\
\text { before randomisation) }\end{array}$ \\
\hline
\end{tabular}

Transcranial magnetic stimulation (TMS) for schizophrenia (Review)

Copyright () 2015 The Cochrane Collaboration. Published by John Wiley \& Sons, Ltd. 


\begin{tabular}{|c|c|}
\hline Jandl 2010 & Allocation: not randomised \\
\hline Jin 2003 & $\begin{array}{l}\text { Allocation: randomisation unclear } \\
\text { Participants: people with schizophrenia } \\
\text { Interventions: TMS versus sham TMS } \\
\text { Outcome data: insufficient data for use (conference abstract), mean scores on outcome measures are } \\
\text { not provided }\end{array}$ \\
\hline Jin 2006 & $\begin{array}{l}\text { Allocation: randomised } \\
\text { Participants: people with schizophrenia } \\
\text { Interventions: TMS vs sham TMS } \\
\text { Outcome data: insufficient data for use; wrote to author to request unpublished means and standard } \\
\text { deviations for phase one of the cross-over study with no reply }\end{array}$ \\
\hline Jin 2012 & $\begin{array}{l}\text { Allocation: randomised } \\
\text { Participants: people with schizophrenia. } \\
\text { Interventions: } \\
\text { 1. TMS: Bilateral frontal (BF) } \alpha \text { TMS } \\
\text { 2. TMS: Bilateral parietal (BP) } \alpha \text { TMS } \\
\text { 3. TMS: Sham } \\
\text { Outcomes: unable to use any data } \\
\text { Mental state: MADRS, CDS (mean and SD not reported), PANSS (N not reported, \% change and SE } \\
\text { reported graphically) } \\
\text { Adverse events: BARS, SAS (mean and SD not reported) }\end{array}$ \\
\hline Levit-Binnun 2007 & Allocation: not randomised \\
\hline Lifshitz 1968 & Allocation: not randomised \\
\hline Loo 2010 & $\begin{array}{l}\text { Allocation: randomised } \\
\text { Participants: people with schizophrenia } \\
\text { Interventions: TMS vs sham TMS } \\
\text { Outcome data: insufficient data, does not report phase } 1 \text { of the cross-over study }\end{array}$ \\
\hline Luber 2007 & Allocation: not randomised \\
\hline Mattai 2011 & $\begin{array}{l}\text { Allocation: randomised } \\
\text { Participants: people with childhood onset schizophrenia } \\
\text { Interventions: Transcranial Direct Current Stimulation (tDCS) vs sham treatment }\end{array}$ \\
\hline Mobascher 2005 & $\begin{array}{l}\text { Allocation: randomised } \\
\text { Participants: people with schizophrenia } \\
\text { Interventions: TMS versus sham TMS } \\
\text { Outcome data: no usable data reported (conference proceeding) }\end{array}$ \\
\hline NCT00517075 & $\begin{array}{l}\text { Allocation: randomised } \\
\text { Participants: people with schizophrenia } \\
\text { Intervention: TMS vs sham TMS }\end{array}$ \\
\hline
\end{tabular}


Study terminated as unable to adequately recruit participants

\begin{tabular}{ll} 
NCT00757497 & $\begin{array}{l}\text { Allocation: randomised } \\
\text { Participants: people with schizophrenia } \\
\text { Interventions: Transcranial Direct Current Stimulation (tDCS) vs sham treatment }\end{array}$ \\
\hline NCT00870909 & $\begin{array}{l}\text { Allocation: randomised } \\
\text { Participants: people with schizophrenia } \\
\text { Interventions: Transcranial Direct Current Stimulation (tDCS) vs sham treatment }\end{array}$ \\
\hline NCT01041274 & $\begin{array}{l}\text { Allocation: randomised } \\
\text { Participants: people with schizophrenia } \\
\text { Interventions: citalopram plus standardized psychoeducation, CBT and fMRI vs placebo plus stan- } \\
\text { dardized psychoeducation, CBT and fMRI }\end{array}$ \\
\hline NCT01378078 & $\begin{array}{l}\text { Allocation: randomised } \\
\text { Participants: people with schizophrenia } \\
\text { Interventions: Transcranial Direct Current Stimulation (tDCS) vs sham treatment }\end{array}$ \\
\hline
\end{tabular}

\begin{tabular}{ll}
\hline NCT01595503 & $\begin{array}{l}\text { Allocation: randomised } \\
\text { Participants: people with schizophrenia } \\
\text { Interventions: rTMS with fMRI-based targeting vs rTMS with landmark-based targeting }\end{array}$ \\
\hline NCT01607840 & $\begin{array}{l}\text { Allocation: randomised } \\
\text { Participants: people with schizophrenia } \\
\text { Interventions: Transcranial Direct Current Stimulation (tDCS) vs sham treatment }\end{array}$ \\
\hline NCT01620086 & $\begin{array}{l}\text { Allocation: randomised } \\
\text { Participants: people with schizophrenia and healthy controls } \\
\text { Intervention: TMS for people with schizophrenia vs fMRI for healthy controls }\end{array}$ \\
\hline
\end{tabular}

\begin{tabular}{ll} 
NCT01623726 & $\begin{array}{l}\text { Allocation: randomised } \\
\text { Participants: people with schizophrenia } \\
\text { Interventions: Transcranial Direct Current Stimulation (tDCS) vs sham treatment }\end{array}$ \\
\hline Potkin 2000 & $\begin{array}{l}\text { Allocation: randomised } \\
\text { Participants: people with schizophrenia } \\
\text { Interventions: TMS versus sham TMS } \\
\text { Outcome data: no usable data reported }\end{array}$ \\
\hline Puri 1996 & Allocation: not randomised \\
\hline
\end{tabular}

Rollnik 2000

Allocation: randomised

Participants: people with schizophrenia

Interventions: TMS versus sham TMS

Outcome data: no usable data reported, data for 1st phase of the cross-over not reported 
(Continued)

\begin{tabular}{|c|c|}
\hline Rushby 2010 & $\begin{array}{l}\text { Allocation: randomised } \\
\text { Participants: people with schizophrenia } \\
\text { Interventions: Transcranial Direct Current Stimulation (tDCS) vs sham treatment }\end{array}$ \\
\hline Sachdev 2005 & Allocation: not randomised. \\
\hline Schneider 2001 & $\begin{array}{l}\text { Allocation: randomised } \\
\text { Participants: people with schizophrenia } \\
\text { Intervention: TMS vs sham TMS } \\
\text { Outcome data: insufficient data - no Ns and SDs reported. Number of completers per group reported } \\
\text { but } 7 \text { participants were lost to follow-up and it was not reported from which groups and whether an } \\
\text { intention-to-treat or LOCF analysis was performed }\end{array}$ \\
\hline Schonfeldt-Lecuona 2004 & $\begin{array}{l}\text { Allocation: randomised } \\
\text { Participants: people with schizophrenia } \\
\text { Intervention: low- frequency rTMS with fMRI-based targeting (superior temporal gyrus) vs sham rTMS } \\
\text { and low- frequency rTMS with stereotaxic navigation targeting (Broca's area) vs sham rTMS (cross- } \\
\text { over trial). The number of participants in each phase } 1 \text { arm was less than } 5\end{array}$ \\
\hline Slotema 2012 & $\begin{array}{l}\text { Allocation: randomised } \\
\text { Participants: people with schizophrenia } \\
\text { Intervention: low-frequency rTMS versus low- frequency rTMS preceeded by priming rTMS }\end{array}$ \\
\hline Weickert 2010 & $\begin{array}{l}\text { Allocation: randomised } \\
\text { Participants: people with schizophrenia } \\
\text { Interventions: Transcranial Direct Current Stimulation (tDCS) vs sham treatment }\end{array}$ \\
\hline Xu 2006 & Allocation: not randomised \\
\hline Yu 2002 & Allocation: not randomised \\
\hline
\end{tabular}

IM - intramuscular injection

LOCF: last observation carried forward

RCT - randomised controlled trial

SD: standard deviation

Characteristics of studies awaiting assessment [ordered by study ID]

Mohr 2006

Methods Randomised, double-blind, placebo-controlled, parallel group

Participants Schizophrenia (DSM-IV criteria) patients treated with 2nd-generation antipsychotics (except clozapine)

$\mathrm{N}=16$

Transcranial magnetic stimulation (TMS) for schizophrenia (Review) 


\begin{tabular}{ll}
\hline Interventions & $\begin{array}{l}\text { 1. TMS: details not reported; } \mathrm{N}=8 \\
\text { 2. Sham: details not reported; } \mathrm{N}=8\end{array}$ \\
\hline Outcomes & Change in cognition \\
\hline Notes & $\begin{array}{l}\text { This is part of a larger study }(\mathrm{N}=34) \text { investigating the efficacy of computer-assisted cognitive training in improving } \\
\text { cognitive deficits in schizophrenia. TMS vs sham was applied to the study participants. All participated in an 8-week } \\
\text { computer-based cognitive training programme } \\
\text { Missing PDF of full article - not available at British Library }\end{array}$ \\
\hline
\end{tabular}

\section{Characteristics of ongoing studies [ordered by study ID]}

\section{Dlabac-de 2008}

Trial name or title Effect of high frequency transcranial magnetic stimulation on negative symptoms and cognitive functioning in schizophrenia: a combined treatment and neuroimaging study

\begin{tabular}{|c|c|}
\hline Methods & $\begin{array}{l}\text { Randomised, double-blind placebo-control, parallel assignment } \\
\text { Inclusion criteria: } \geq 18 \text { years of age; diagnosed with schizophrenia; prominent negative symptoms with a } \\
\text { PANSS negative subscore } \geq 15 \\
\text { Exclusion criteria: rTMS and MRI contraindications (e.g. a personal or family history of epileptic seizures, } \\
\text { history of brain surgery, intracerebral or pacemaker implants, inner ear prosthesis or other metal prosthetics/ } \\
\text { implants; neurological disorders; history of head injury with loss of consciousness; substance dependency } \\
\text { within the previous } 6 \text { months; previous treatment with rTMS; severe behavioural disorders; claustrophobia; } \\
\text { pregnancy) } \\
\mathrm{N}=32\end{array}$ \\
\hline Participants & People with schizophrenia, with prominent negative symptoms \\
\hline Interventions & $\begin{array}{l}\text { 1. TMS: bilateral DLPFC, high-frequency rTMS stimulation during } 15 \text { days, } 2 \text { sessions/day. } N=16 \\
\text { 2. Sham: sham stimulation during } 15 \text { days, } 2 \text { sessions /day. Details not reported. } N=16\end{array}$ \\
\hline Outcomes & $\begin{array}{l}\text { Primary outcome: } \\
\text { Mental state: significant decline of negative symptoms (measure not reported, presumably PANSS negative } \\
\text { subscale); cognitive dysfunctioning (measure not reported) } \\
\text { Secondary outcome: } \\
\text { Increased cortical activation in the DLPFC: fMRI }\end{array}$ \\
\hline Starting date & May 1, 2008 \\
\hline Contact information & $\begin{array}{l}\text { Prof. Dr. A. Aleman } \\
\text { University Medical Center Groningen (UMCG) } \\
\text { Additional contact information not provided }\end{array}$ \\
\hline Notes & Planned closing date 1 May 2012 \\
\hline
\end{tabular}

Transcranial magnetic stimulation (TMS) for schizophrenia (Review) 
Ebmeier 2001

Trial name or title TMS and auditory hallucination in schizophrenia

\begin{tabular}{ll}
\hline Methods & RCT \\
\hline Participants & $\begin{array}{l}\text { Treatment-resistant auditory hallucinations in people with schizophrenia, schizophreniform disorder and } \\
\text { schizoaffective disorder. } \mathrm{N}=16\end{array}$ \\
\hline Interventions & $\begin{array}{l}\text { 1. rTMS: left temporoparietal cortex, } 1 \mathrm{~Hz} \\
\text { 2. Sham }\end{array}$ \\
\hline Outcomes & $\begin{array}{l}\text { Hallucinations; other positive and negative symptoms of schizophrenia (scale not reported; presumably } \\
\text { PANSS) }\end{array}$ \\
\hline Starting date & $\begin{array}{l}\text { 1 June 2000 } \\
\text { Contact information }\end{array}$ \\
\hline $\begin{array}{l}\text { Professor KP Ebmeier } \\
\text { Kennedy Tower } \\
\text { Royal Edinburgh Hospital } \\
\text { Morningside Park } \\
\text { Edinburgh } \\
\text { EH10 5HF }\end{array}$ \\
\hline Notes
\end{tabular}

Hunter 2003

Trial name or title A double-blind randomised controlled trial of repetitive Transcranial Magnetic Stimulation (rTMS) in the treatment of persistent auditory hallucinations in schizophrenia

\begin{tabular}{|c|c|}
\hline Methods & Randomised, double-blind, factorial \\
\hline Participants & $\begin{array}{l}\text { Inclusion criteria: } \\
\text { 1. Men and women, aged } 18 \text { to } 65 \\
\text { 2. DSM-IV diagnostic criteria for schizophrenia } \\
\text { 3. Experience auditory hallucinations defined as a score of ' } 2 \text { on the auditory hallucinations subscale of the } \\
\text { SAPS for' } 6 \text { weeks despite standard clinical treatment } \\
\text { Exclusion criteria: } \\
\text { 1. Organic brain disorder } \\
\text { 2. Previous documented unconsciousness } \\
\text { 3. Unstable coronary heart disease } \\
\text { 4. Contra-indications to rTMS, e.g. history of fits, recent cerebrovascular accident, history of epileptic seizures, } \\
\text { metal implants, cardiac pacemakers } \\
\text { Total } \mathrm{N}=126\end{array}$ \\
\hline Interventions & $\begin{array}{l}\text { 1. Left only: rTMS at a frequency of } 1 \mathrm{~Hz} \text { and amplitude } 100 \% \mathrm{MT} \text { applied to left temporal cortex for } 20 \\
\text { minutes, } 10 \text { working days } \\
\text { 2. Right only: rTMS at a frequency of } 1 \mathrm{~Hz} \text { and amplitude } 100 \% \mathrm{MT} \text { applied to right temporal cortex for } \\
20 \text { minutes, } 10 \text { working days } \\
\text { 3. Left and right: rTMS at a frequency of } 1 \mathrm{~Hz} \text { and amplitude } 100 \% \mathrm{MT} \text { applied to left temporal cortex for }\end{array}$ \\
\hline
\end{tabular}

Transcranial magnetic stimulation (TMS) for schizophrenia (Review)

Copyright () 2015 The Cochrane Collaboration. Published by John Wiley \& Sons, Ltd. 
Hunter 2003

10 minutes followed by right temporal cortex for 10 minutes, 10 working days

4. Sham (placebo) stimulation, using a modified coil, which produces no magnetic field but has an acoustic signature similar to that of an active coil,applied to left temporal cortex for 20 minutes, 10 working days

Primary:
Mental state (auditory hallucinations): Change from baseline in auditory hallucinations score according to
a visual analogue measure of current intensity; change from baseline in the auditory hallucinations subscale
score (SAPS)
Secondary:
Mental state: total schizophrenic symptoms (SAPS, SANS)
Depression: HAMD
Psychological and social functioning: SF-36
Neuropsychological and audiometric tests (details not reported)

Starting date $\quad$ 1st December 2001

$\begin{array}{ll}\text { Contact information } & \begin{array}{l}\text { Dr Michael Hunter } \\ \text { Academic Department of Psychiatry } \\ \text { The Longley Centre }\end{array} \\ & \text { Norwood Grange Drive } \\ & \text { Sheffield } \\ & \text { United Kingdom } \\ & \text { S5 7JT } \\ & \text { phone: +44(0)114 2716231 } \\ \text { email: m.d.hunter@shef.ac.uk }\end{array}$

Notes

Trial status: completed

ISRCTN72210184

\section{IRCT138903254191N1}

Trial name or title The comparison of effectiveness of repetitive TMS and iTBS on negative symptoms and cognition in patients with schizophrenia: a study randomized and double blind

Methods Randomised, double-blind placebo-control, parallel assignment

Inclusion criteria: male and female outpatients

18 - 50 years of age; DSM-IV-TR diagnosis of schizophrenia; stable symptoms (not requiring a change in antipsychotic medication for $\geq 4$ weeks or $\geq 2$ weeks for psychotropic agents)

Exclusion criteria: history of rTMS treatment;

intracranial implant and other ferromagnetic materials close to the head; cardiac pacemaker; drug pumps; acute heart attack; risk of seizures; high intracranial pressure; history of epilepsy or seizure in first relatives; brain trauma, history of loss of consciousness for > 5 minutes, pregnancy, breastfeeding, drug dependency, high risk of suicide, significant positive symptoms

$\mathrm{N}=30$

Participants Male and female schizophrenia outpatients 


\section{IRCT138903254191N1 (Continued)}

\begin{tabular}{|c|c|}
\hline Interventions & $\begin{array}{l}\text { 1. TMS: } 15 \mathrm{~Hz} \text { rTMS, } 20 \text { sessions of } 20--30 \text {-minute duration } \\
\text { 2. iTBS: } 50 \mathrm{~Hz} \text { theta burst, } 20 \text { sessions of 5-- 10-minute duration } \\
\text { 3. Sham: Sham coil } 20 \text { sessions }\end{array}$ \\
\hline Outcomes & $\begin{array}{l}\text { Primary outcomes: } \\
\text { Mental state: PANSS negative symptoms } \\
\text { Cognitive state: Neuropsychology Battery Tests (tests are not specified) } \\
\text { Secondary outcomes: } \\
\text { Depression: CDSS } \\
\text { Quality of life: SQLS } \\
\text { Social functioning: SOFAS }\end{array}$ \\
\hline Starting date & May 1, 2011 \\
\hline Contact information & $\begin{array}{l}\text { Dr. Reza Rostami (sponsor) } \\
\text { Atieh comprehensive psyche and nerve centre } \\
23 \text { No., Valinezhad St., Valiasr Ave., Tehran, Iran } \\
\text { phone: } 009802184012000 \\
\text { e-mail: rrostami@ut.ac.ir }\end{array}$ \\
\hline Notes & Recruitment complete \\
\hline
\end{tabular}

\section{ISRCTN61109178}

Trial name or title Transcranial magnetic stimulation (TMS) treatment study in auditory verbal hallucinations: a randomised controlled trial

\begin{tabular}{ll} 
Methods & Randomised controlled trial \\
& $\begin{array}{l}\text { Inclusion criteria: age } 18-65 \text { years; diagnosis of schizophrenia or schizoaffective disorder according to ICD- } \\
10 ; \text { medication-resistant auditory verbal hallucinations; right-handed; therapy refractoriness (non response } \\
\text { to } \geq 2 \text { antipsychotic treatments in common dosages, each administered for } \geq 8 \text { weeks) }\end{array}$ \\
$\begin{array}{l}\text { Exclusion criteria: history of epileptic seizures; signs of elevated neuronal activity by EEG; MR contraindica- } \\
\text { tions; medical disorders other than schizophrenia or schizoaffective disorder } \\
\mathrm{N}=30-45\end{array}$ \\
\hline Participants & $\begin{array}{l}\text { People with treatment-resistant schizophrenic or schizoaffective disorder with auditory verbal hallucinations } \\
\text { Interventions }\end{array}$ \\
$\begin{array}{l}\text { 2. } 1 \text { Theta burst transcranial magnetic stimulation (TBS) } \\
\text { 3. Control: treatment as usual } \\
\text { Duration: } 10 \text { days }\end{array}$
\end{tabular}

Outcomes $\quad$ Mental state (psychopathology): PANSS, PSYRATS, AHRS;

Cerebral blood flow: MRI;

EEG

Starting date

15th December 2008

Transcranial magnetic stimulation (TMS) for schizophrenia (Review)

Copyright @ 2015 The Cochrane Collaboration. Published by John Wiley \& Sons, Ltd. 
ISRCTN61109178 (Continued)

\begin{tabular}{ll}
\hline Contact information & $\begin{array}{l}\text { Dr Jochen Kindler } \\
\text { University Hospital of Psychiatry, University of Bern } \\
\text { phone \#: }+41319309111 \\
\text { email: jochen.kindler@puk.unibe.ch }\end{array}$ \\
\hline Notes & Status of trial: completed \\
\hline
\end{tabular}

Lee 2007

\begin{tabular}{|c|c|}
\hline Trial name or title & Pilot study for a new treatment of schizophrenia: a double-blind crossover transcranial magnetic stimulation \\
\hline Methods & Randomised, double-blind, cross-over trial \\
\hline Participants & $\begin{array}{l}\text { Diagnosis: schizophrenia } \\
\mathrm{N}=12 \\
\text { Age: } 18 \text { - } 55 \text { years } \\
\text { History: severe negative symptoms }\end{array}$ \\
\hline Interventions & $\begin{array}{l}\text { 1. TMS: Prefrontal stimulation TBS } \\
\text { 2. TMS: Cerebellar stimulation TBS } \\
\text { 3. Sham TMS }\end{array}$ \\
\hline Outcomes & $\begin{array}{l}\text { Regional functional brain response measured with fMRI } \\
\text { A variety of standardised psychiatric ratings and neuropsychological tests will be used as secondary outcome } \\
\text { measures }\end{array}$ \\
\hline Starting date & 15 May 2006 \\
\hline Contact information & $\begin{array}{l}\text { Dr Kwang Hyuk Lee } \\
\text { Academic Department of Psychiatry } \\
\text { Longley Centre } \\
\text { Norwood Grange Drive } \\
\text { Sheffield } \\
\text { S5 7JT } \\
\text { United Kingdom } \\
\text { +44(0)114 } 2261511 \\
\text { md4khl@shef.ac.uk }\end{array}$ \\
\hline Notes & $\begin{array}{l}\text { Sponsor: Department of Health } \\
\text { ISRCTN93378085 } \\
\text { Status of trial: completed }\end{array}$ \\
\hline
\end{tabular}


Trial name or title Transcranial magnetic stimulation used to treat auditory hallucinations in schizophrenia

Methods Randomised, double-blind placebo-control, parallel assignment

Inclusion criteria: schizophrenia; auditory hallucinations occurring > 5 times/day; adequate (6 wks) trial of antipsychotic medication including $\geq 1$ atypical antipsychotic medication; medication stable for 4 wks prior to commencement of the study

Exclusion criteria: history of seizure disorder in patient or first degree relative; recent head injury; acute suicidality; alcohol or substance abuse; implanted pacemaker or metal in head or neck; pregnancy

$\mathrm{N}=10$

Participants Men and women with schizophrenia, with auditory hallucinations. Age: 18 - 65

Interventions $\quad$ 1. TMS: temporoparietal cortex rTMS

2. Sham

\begin{tabular}{ll}
\hline Outcomes & $\begin{array}{l}\text { Primary outcome: } \\
\text { Mental state (hallucinations): Hoffman auditory hallucination scale } \\
\text { Secondary outcome: } \\
\text { Mental state: PANSS }\end{array}$ \\
\hline Starting date & November 2004 \\
\hline Contact information & $\begin{array}{l}\text { Rose Marie Mueller, RN } \\
\text { phone: } 9055221155 \text { ext 36629 } \\
\text { email: rmueller@stjoes.ca } \\
\text { Sandra Chalmers, RN } \\
\text { phone: } 9055221155 \text { ext 35442 } \\
\text { email: schalmer@stjoes.ca }\end{array}$ \\
\hline
\end{tabular}

Estimated study completion date: January 2015

\section{NCT00685321}

Trial name or title

A double-blind randomized controlled trial to explore the tolerability, safety and efficacy of the H-coil deep transcranial magnetic stimulation (TMS) in subjects with negative symptoms and cognitive deficits of schizophrenia

Methods

Randomised, double-blind placebo-control, parallel assignment Inclusion criteria: age 18 - 65 years; diagnosed in the past as suffering from schizophrenia; diagnosis reaffirmed according to ICD criteria; right hand dominant; PANSS negative $\geq 21$; negative answers on safety screening questionnaire for TMS; stable on the same antipsychotic medication for $\geq 2$ months prior to entering the study; negative answers to all questions in the TMS safety

Exclusion criteria: suffering from another axis 1 disorder; PANSS positive score' 24; history of epilepsy within first-degree relatives; history of: epilepsy, seizure, or hot spasm, head injuries, metal in the head, surgery including metal implant, migraines, hearing loss (not due to aging) or cochlear implants, drug or alcohol abuse during the last year; pregnancy or not using a reliable method of birth control; suicide attempt in the year prior to treatment or suicide risk; custodians

$\mathrm{N}=45$

Transcranial magnetic stimulation (TMS) for schizophrenia (Review)

Copyright @ 2015 The Cochrane Collaboration. Published by John Wiley \& Sons, Ltd. 


\section{NCT00685321 (Continued)}

\begin{tabular}{|c|c|}
\hline Participants & Men and women with schizophrenia, currently suffering mainly from negative symptoms \\
\hline Interventions & $\begin{array}{l}\text { 1. H-Coil deep TMS } \\
\text { 2. Sham }\end{array}$ \\
\hline Outcomes & $\begin{array}{l}\text { Primary outcome: } \\
\text { Mental state: SANS } \\
\text { Secondary outcome: } \\
\text { General functioning: SOFAS }\end{array}$ \\
\hline Starting date & June 2008 \\
\hline Contact information & $\begin{array}{l}\text { Liron Rabani } \\
\text { Shalvata Mental Health Center, Israel } \\
\text { phone \#: 972- } 97478644 \\
\text { lironrab@clalit.org.il } \\
\text { PI: Yechiel Levkovitz MD }\end{array}$ \\
\hline Notes & Estimated study completion date: January 2013 \\
\hline
\end{tabular}

\section{NCT00763841}

Trial name or title A pilot study using transcranial agnetic stimulation (TMS) to investigate the role of the temporal cortex in schizophrenic patients with auditory hallucinations

\begin{tabular}{|c|c|}
\hline Methods & $\begin{array}{l}\text { Randomised, double-blind, placebo-control, cross-over assignment } \\
\text { Inclusion Criteria: age> 18; DSM-IV diagnosis of schizophrenia and auditory hallucinations of clear external } \\
\text { origins, refractory to pharmacotherapy and occurring at } \geq 5 \text { times/day } \\
\text { Exclusion criteria: contraindications to TMS (e.g. epilepsy, pacemaker) or an unacceptably high risk (e.g. } \\
\text { suicide risk) } \\
\mathrm{N}=18\end{array}$ \\
\hline Participants & Men and women with schizophrenia \\
\hline Interventions & $\begin{array}{l}\text { 1. Temporal cortex TMS } \\
\text { 2. Sham TMS }\end{array}$ \\
\hline Outcomes & Daily voices ratings \\
\hline Starting date & September 1999 \\
\hline Contact information & $\begin{array}{l}\text { Colleen Loo, MBBS, FRANZCP. MD } \\
\text { The University of New South Wales, Australia (phone, e-mail not provided) }\end{array}$ \\
\hline Notes & This study has been completed. Results have not been posted at the NIH site \\
\hline
\end{tabular}


Trial name or title Intermittent theta burst stimulation (iTBS) for the treatment of negative symptoms in schizophrenia

\begin{tabular}{|c|c|}
\hline Methods & $\begin{array}{l}\text { Randomised, double-blind placebo-control, parallel assignment } \\
\text { Inclusion criteria: DSM-IV diagnosis of schizophrenia; negative symptoms for } \geq 6 \text { weeks; medication resis- } \\
\text { tance; age } 18 \text { - } 50 \text { years } \\
\text { Exclusion criteria: contraindication to TMS; pregnancy } \\
\mathrm{N}=80\end{array}$ \\
\hline Participants & Men and women with schizophrenia with persistent negative symptoms \\
\hline Interventions & $\begin{array}{l}\text { 1. rTMS: Left dorsolateral prefrontal cortex iTBS at } 80 \% \text { motor threshold, } 20 \text { sessions of } 6 \text { minutes, } 2 / \text { day } \\
\text { 2. sham: procedure as active iTBS with sham coil }\end{array}$ \\
\hline Outcomes & $\begin{array}{l}\text { Primary outcome: } \\
\text { Mental state (negative symptoms (SANS)) } \\
\text { Secondary outcomes: } \\
\text { Neurochemical impact: } 1 \text { H-MRS, DTI and resting MRI }\end{array}$ \\
\hline Starting date & November 2008 \\
\hline Contact information & $\begin{array}{l}\text { Emmanuel Poulet, MD,PhD } \\
\text { Hopital Le Vinatier } \\
\text { phone: } 33437915100 \\
\text { e-mail: emmanuel.poulet@ch-levinatier.fr }\end{array}$ \\
\hline
\end{tabular}

Notes $\quad$ Estimated study completion date: June 2011

The recruitment status of this study is unknown because the information has not been verified recently

\section{NCT01015001}

Trial name or title A pilot double-blind sham-controlled trial of repetitive transcranial magnetic stimulation for patients with refractory schizophrenia treated with clozapine

Methods Randomised, double-blind, placebo-control, parallel assignment Inclusion criteria: DSM-IV-TR diagnosis of schizophrenia with treatment-resistant auditory hallucinations; treated by $\geq 400 \mathrm{mg} /$ day of clozapine; age $18-65$ years; BPRS score $\geq 27$

Exclusion criteria: suicide risk; epilepsy, brain surgery and/or head trauma in the past, use of cardiac pacemaker or metallic clip in the head; substance abuse/dependence; severe uncontrolled organic disease $\mathrm{N}=20$

Participants Men and women with schizophrenia, with treatment-resistant auditory hallucinations

Interventions $\quad$ 1. rTMS: LTPC rTMS, low frequency $(1 \mathrm{~Hz}), 20$ sessions of 20 minutes each

2. Sham: same coil, same number of pulses but using an angled coil $\left(90^{\circ}\right)$ over the frontotemporal region

Outcomes Primary outcome:

Quality of life; general functioning (measurement scales not reported)

Secondary outcome:

Transcranial magnetic stimulation (TMS) for schizophrenia (Review)

Copyright () 2015 The Cochrane Collaboration. Published by John Wiley \& Sons, Ltd. 


\section{NCT01015001 (Continued)}

Mental state: severity of hallucinations; general psychopathology (measurement scales not reported)

\begin{tabular}{ll}
\hline Starting date & May 2008 \\
\hline Contact information & $\begin{array}{l}\text { PI: Danilo Jesus, MD } \\
\text { Hospital de Clinicas de Porto Alegre } \\
\text { Study Director: Paulo B Abreu, PhD HCPorto Alegre } \\
\text { (phone, email not provided) }\end{array}$ \\
\hline Notes & Updated title at the NIH site. The study has been completed, results not posted \\
\hline
\end{tabular}

\section{NCT01022489}

Trial name or title Evaluation of repetitive transcranial magnetic stimulation (rTMS) at high frequency with neuronavigation in the treatment of auditory hallucinations : a randomized multicentric controlled study

Methods
Inclusion criteria: schizophrenic disorders; age from $16-65$ years; auditory hallucinations (score AHRS $>10$ )
undergoing antipsychotic treatments; clinically stabilised (no antipsychotic treatments modifications for $\geq 2$
months)
Exclusion criteria: pregnancy or breastfeeding; brain tumour; history of epilepsy; already treated once by
rTMS; counter-indication to MRI or to rTMS
$\mathrm{N}=72$

Participants Male and femaleen and women with schizophrenia or schizoaffective disorder with auditory hallucinations

\begin{tabular}{l|l}
\hline Interventions & $\begin{array}{l}\text { 1. TMS: rTMS, } 20 \mathrm{~Hz} \text {, at } 80 \% \text { of rest motor threshold, } 4 \text { sessions of } 13 \text { minutes, with } 2 \text { sessions a day } \\
\text { 2. Sham: placebo coil }\end{array}$ \\
\hline Outcomes & Mental state (hallucinations): AHRS \\
\hline Starting date & August 2009 \\
\hline Contact information & $\begin{array}{l}\text { Sonia Dollfus, MD, PhD } \\
\text { phone: }+33231064438 \\
\text { e-mail: dollfuss@chucaen.fr }\end{array}$ \\
\hline Notes & $\begin{array}{l}\text { Estimated study completion date: March } 2013 \\
\text { Study still recruiting participants }\end{array}$ \\
\hline
\end{tabular}

\section{NCT01315587}

Trial name or title Repetitive transcranial magnetic stimulation and intermittent theta burst (iTBS) in schizophrenia

$\begin{array}{ll}\text { Methods } & \text { Randomised, double-blind, active and placebo-control, parallel assignment } \\ \text { Inclusion criteria: } 18-50 \text { years of age; diagnosis of schizophrenia according to DSM-IV-TR; stable symptoms } \\ \text { (not requiring a change in antipsychotic medication for } \geq 4 \text { weeks or } \geq 2 \text { weeks for psychotropic agents prior }\end{array}$




\begin{tabular}{|c|c|}
\hline & $\begin{array}{l}\text { to entering the study) } \\
\text { Exclusion criteria: history of rTMS treatment; intracranial implant and other ferromagnetic materials close } \\
\text { to the head; cardiac pacemaker; drug pumps; acute heart attack; risk of seizure; high intracranial pressure; } \\
\text { history of epilepsy or seizure in the first relatives; brain trauma; history of loss of consciousness for more than } \\
5 \text { minutes; pregnancy; breastfeeding; drug dependency; high risk of suicide; significant positive symptoms } \\
\mathrm{N}=30\end{array}$ \\
\hline Participants & Schizophrenia (DSM-IV criteria) outpatients \\
\hline Interventions & $\begin{array}{l}\text { 1. rTMS: LDLPFC, } 15 \mathrm{~Hz} \text { at } 110 \% \text { of motor threshold } \\
\text { 2. iTBS: TMS } 3 \text { pulses, } 50 \mathrm{~Hz} \text { repeated each } 200 \mathrm{~ms} \text { for } 2 \text { seconds at } 80 \% \text { motor threshold } \\
\text { 3. Sham: sham coil } \\
\text { Duration: } 20 \text { sessions }\end{array}$ \\
\hline Outcomes & $\begin{array}{l}\text { Primary outcome: } \\
\text { Mental state: PANSS negative symptoms (primary outcome) } \\
\text { Secondary outcomes: } \\
\text { Depression: CDSS; } \\
\text { Quality of life: SQLS; } \\
\text { Social and occupational functioning: SOFAS; } \\
\text { Neuropsychological state: Digit Span in WAIS, Rey Auditory Verbal-learning Test, Stroop, Iowa Gambling } \\
\text { Task, Trail Making Test A/B, Verbal (word) Fluency Test, WCST, Wechsler Memory Scale (R-III); } \\
\text { Brainwaves patterns: QEEG and LORETA }\end{array}$ \\
\hline Starting date & January 2011 \\
\hline Contact information & $\begin{array}{l}\text { Reza Kazemi, MA } \\
\text { Atieh comprehensive psyche and nerve centre, Tehran,Iran } \\
\text { phone: +9802184012128 } \\
\text { e-mail:rezakazemi@ut.ac.ir } \\
\text { PI: Reza Rostami, MD } \\
\text { phone: +9802184012101 } \\
\text { email: rrostami@ut.ac.ir }\end{array}$ \\
\hline Notes & Estimated study completion date: January 2017 \\
\hline
\end{tabular}

\section{NCT01370291}

Trial name or title Repetitive transcranial magnetic stimulation (rTMS) for first-episode schizophrenia patients: a doubleblinded, randomized and functional magnetic resonance imaging (fMRI) study

Methods

Randomised, double-blind, placebo-control, parallel assignment Inclusion criteria: age 16 - 45 years; diagnosis of schizophrenia according to DSM-IV criteria; PANSS $\geq 60$; 1st episode; have not been treated with any antipsychotic drugs

Exclusion criteria: suicide risk; substance abuse/dependence; severe uncontrolled organic disease; contraindication to TMS (implanted pacemaker, medication pump, vagal stimulator, deep brain stimulator, metallic hardware in the head or scalp, signs of increased intracranial pressure); pregnancy or lactating; estimated IQ - 80 ; have a sibling or parent with epilepsy

$\mathrm{N}=60$ 


\section{NCT01370291 (Continued)}

\begin{tabular}{|c|c|}
\hline Participants & Men and women with first-episode schizophrenia (DSM-IV criteria) \\
\hline Interventions & $\begin{array}{l}\text { 1. Active rTMS and sham risperidone: a. auditory hallucinations: LTPC rTMS, } 1 \mathrm{~Hz} \text {; b. negative symptoms: } \\
\text { LTPC rTMS, } 10 \mathrm{~Hz} \\
\text { 2. Active risperidone and active rTMS (active comparator): same rTMS procedures + active risperidone } \\
\text { 3. Sham rTMS and active risperidone (sham comparator) }\end{array}$ \\
\hline Outcomes & $\begin{array}{l}\text { Primary outcomes: Mental state (PANSS); fMRI } \\
\text { Secondary outcomes: } \\
\text { Mental state: AHRS; } \\
\text { Depression: HAMD } \\
\text { Clinical global impression: CGI }\end{array}$ \\
\hline Starting date & August 2011 \\
\hline Contact information & $\begin{array}{l}\text { Yunchun Chen, Ph.D } \\
\text { phone: +086-13720582601 } \\
\text { email: Yunchunchen@163.com } \\
\text { Shufang Feng, Ph.D } \\
\text { phone:+086-13227807801 } \\
\text { email: fangshuan1984@yahoo.com.cn }\end{array}$ \\
\hline Notes & $\begin{array}{l}\text { Study title updated at the NIH site } \\
\text { Estimated study completion date: December } 2013\end{array}$ \\
\hline
\end{tabular}

\section{NCT01512290}

Trial name or title Theta burst transcranial magnetic stimulation as treatment for auditory verbal hallucinations; a placebocontrolled trial

Methods $\quad$ Randomised, double-blind placebo-control, parallel assignment

Inclusion criteria: diagnosis of schizophrenia, schizophreniform disorder, schizoaffective disorder or psychosis NOS; age 18+ years; frequent auditory verbal hallucinations ( $>$ once an hour)

Exclusion criteria: Metal objects in or around the head that cannot be removed; history of seizures; increased intracranial pressure; history of eye trauma with a metal object or professional metal workers; coercively treated; represented by a legal ward or under legal custody; pregnancy; changes in the prescribed medication in a period of 2 weeks prior to participation

$\mathrm{N}=60$

Participants Men and women with schizophrenia, schizophreniform disorder, schizoaffective disorder or psychosis NOS, with frequent auditory hallucinations

Interventions

1. TMS: left temporoparietal theta burst transcranial magnetic stimulation (TBS); 5 pulses at $50 \mathrm{~Hz}$ repeated at $5 \mathrm{~Hz}$ for 60 seconds with a total of 900 pulses per treatment; 10 treatments ( 5 days, 2 treatments/day) 2. Sham 


\section{NCT01512290 (Continued)}

\begin{tabular}{ll}
\hline Outcomes & $\begin{array}{l}\text { Primary outcomes: } \\
\text { Mental state (severity and frequency of hallucinations): AHAS; PSYRATS; PANSS (total hallucinations } \\
\text { subscore) } \\
\text { Secondary outcome: } \\
\text { Adverse events }\end{array}$ \\
\hline Starting date & March 2012 \\
\hline Contact information & $\begin{array}{l}\text { Anne Lotte Meijering } \\
\text { phone: }+31887559046 \\
\text { e-mail: A.L.Meijering@hotmail.nl } \\
\text { Iris Sommer, Prof, dr. } \\
\text { phone: }+3188755370 \\
\text { e-mail:I.Sommer@umcutrecht.nl }\end{array}$ \\
\hline Notes & Estimated study completion date: February 2014 \\
\hline
\end{tabular}

\section{NCT01523730}

Trial name or title

Effects of repetitive transcranial magnetic stimulation on cigarette smoking and cognitive function in smokers with and without schizophrenia

Methods Randomised, double-blind placebo-control, cross-over assignment Inclusion criteria:

1. For all participants: Full scale IQ $\geq 80$ as determined by the Shipley-2; non-treatment-seeking smokers; a score ' 5 on the FTND; smoking of $\geq 10$ cigarettes/day; expired breath CO level $>10$ ppm

2. For people with schizophrenia: DSM-IV criteria for schizophrenia or schizoaffective disorder; stable remission from positive symptoms of psychosis, psychiatric evaluation and a PANSS total score $<70$; stable dose of antipsychotic mediation(s) for $\geq 1$ month

3. For healthy controls: not meet DSM-IV criteria for any current or past psychiatric disorder except for past major depression if it has been in remission for a minimum of 1 year; not taking any psychotropic medications General Exclusion Criteria: abuse or dependence of alcohol or illicit substances within the past 3 months; use of nicotine replacement or tobacco products other than cigarettes; concomitant medical illness that may compromise study participation or neurological illness (history of seizures or a first-degree relative with a history of a seizure disorder); pregnancy; metallic implants

$\mathrm{N}=50$

Participants Men and women with schizophrenia and schizoaffective disorder, and healthy volunteers; age 18 - 55 years

Interventions

1. TMS: dorsolateral prefrontal cortex rTMS, $20 \mathrm{~Hz}$ at $90 \%$ resting motor threshold ( 25 stimulation trains of 30 stimuli each with an inter-train interval of $30 \mathrm{sec}$ ), 2 weeks (twice daily, 2 days/week)

2. Sham: Same stimulation parameters and site as active condition but with a single-wing tilt rTMS coil position producing somatic sensation and minimal brain effects

Participants will undergo 2 testing weeks (active and sham rTMS treatment), washout period $\geq 1$ month between the testing weeks 
NCT01523730 (Continued)

\begin{tabular}{|c|c|}
\hline Outcomes & $\begin{array}{l}\text { Primary outcome: } \\
\text { Cigarette craving: TQSU } \\
\text { Secondary outcomes: } \\
\text { Cigarette withdrawal: MNWS } \\
\text { Expired breath carbon monoxide (CO) levels } \\
\text { Plasma nicotine/cotinine levels } \\
\text { Sustained attention and response inhibition: CPT-X } \\
\text { Working memory: N-back; EEG recording during performance of N-back task } \\
\text { Visuospatial working memory: SDR } \\
\text { Verbal learning and memory: HVLT-R } \\
\text { Smoking Topography } \\
\text { Spontaneous smoking }\end{array}$ \\
\hline Starting date & February 2012 \\
\hline Contact information & $\begin{array}{l}\text { Centre for Addiction and Mental Health } \\
\text { Toronto, Ontario, Canada } \\
\text { Vicky C Wing, Ph.D. } \\
\text { phone: 416-5358501 ext } 4882 \\
\text { e-mail: vicky_wing@camh.net } \\
\text { Caroline E Wass, Ph.D } \\
\text { phone: 416-5358501 ext } 6225 \\
\text { e.mail: Caroline_Wass@camh.net }\end{array}$ \\
\hline
\end{tabular}

Estimated study completion date: March 2014

\section{NCT01551979}

Trial name or title Therapeutic efficacy of cerebellar repetitive transcranial magnetic stimulation in patients with schizophrenia

Methods Randomised, double-blind, placebo-control, parallel assignment

Inclusion criteria: age 18 - 65 years; diagnosis of schizophrenia according to DSM-IV criteria

Exclusion Criteria: pre-existing or progressive neurological disorders; prior neurological procedures; previous head injury; change in antipsychotic medication during the last 4 weeks; inpatient in a psychiatry clinic within the last month; any other axis 1 diagnosis; unable to undergo a brain MRI; unstable medical condition; history of seizures, diagnosis of epilepsy, history of abnormal EEG, or family history of treatment-resistant epilepsy; possible pregnancy; metal in the brain, skull; medical devices (i.e.. cardiac pacemaker, deep brain stimulator, medication infusion pump, cochlear implant, vagal nerve stimulator); substance abuse or dependence within the past 6 months

$\mathrm{N}=36$

Participants

Men and women with schizophrenia (DSM-IV criteria). Age: 18 - 65 years

Interventions $\quad$ 1. rTMS: High-frequency rTMS stimulation of the vermis (lobule VII) of the cerebellum intermittent theta burst (iTBS) pattern ( 20 trains of 10 bursts given with $8 \mathrm{sec}$ intervals) at $80 \%$ of active motor threshold. 600 pulses per session

2. Sham 


\section{NCT01551979 (Continued)}

\begin{tabular}{ll}
\hline Outcomes & $\begin{array}{l}\text { Primary outcomes: } \\
\text { Mental state: PANSS } \\
\text { Clinical improvement: CGI } \\
\text { Secondary outcomes: } \\
\text { Mood: POMS } \\
\text { Depression: CDSS } \\
\text { Subjective assessment of change: VAS }\end{array}$ \\
\hline Starting date & February 2012 \\
\hline Contact information & $\begin{array}{l}\text { Andrea Pousada-Casal, Ph.D. } \\
\text { Beth Israel Deaconess Medical Center, Boston USA } \\
\text { phone:617-724-1622 } \\
\text { e-mail: apousada@partners.org } \\
\text { PI: Alvaro Pascual-Leone, M.D., Ph.D }\end{array}$ \\
\hline Notes & \begin{tabular}{l} 
Estimated study completion date: November 2013 \\
\hline
\end{tabular}
\end{tabular}

\section{Vercammen 2009b}

Trial name or title Mechanism and efficacy of low frequency rTMS treatment in schizophrenic patients with auditory hallucinations: an fMRI study

\begin{tabular}{ll} 
Methods & $\begin{array}{l}\text { Randomised, double-blind placebo-control, parallel assignment } \\
\text { Inclusion criteria: Inpatients and outpatients; meet diagnostic criteria for schizophrenia or schizoaffective } \\
\text { disorder; report frequent auditory hallucinations }(\geq 1 \text { time/day); meet the criteria for medication resistance } \\
\text { (persistent auditory hallucinations occurring during treatment } \geq 2 \text { adequate trials of antipsychotic medication) }\end{array}$ \\
$\begin{array}{l}\text { Exclusion criteria: rTMS contraindications (e.g. a personal or family history of epileptic seizures, past neu- } \\
\text { rosurgical procedures, intracerebral or pacemaker implants, inner ear prosthesis or other metal prosthetics/ } \\
\text { implants); neurological disorders; history of significant head trauma; severe behavioural disorders; current } \\
\text { substance abuse; pregnancy; active psychosis } \\
\mathrm{N}=48\end{array}$ \\
\hline Participants & $\begin{array}{l}\text { Schizophrenia or schizoaffective disorder with auditory hallucinations } \\
\text { Interventions }\end{array}$ \\
$\begin{array}{l}\text { working days } \\
\text { 2. Placebo: Details not reported }\end{array}$ \\
\hline $\begin{array}{l}\text { Primary: } \\
\text { Mental state (hallucinations): AHRS } \\
\text { Secondary: } \\
\text { Mood: PANAS; } \\
\text { Mental state: PANSS; } \\
\text { Participant's beliefs about auditory hallucinations: (BAVQ) }\end{array}$ \\
\hline Outcomes
\end{tabular}

Starting date September 1, 2006 
Vercammen 2009b (Continued)

\author{
Contact information Prof. Dr. A. Aleman \\ Department of Neuroscience \\ University of Groningen \& University Medical Center \\ Groningen. \\ Nehterlands \\ Other contact information not provided.
}

Notes

Estimated trial completion date: not reported on trial register website

NTR1813

\author{
AHRS: Auditory hallucination rating scale \\ BAVQ: Beliefs About Voices Questionnaire \\ BPRS: brief psychiatric rating scale \\ CDSS: Calgary Depression Rating Scale for Schizophrenia \\ CPT-X: Continuous performance test-X \\ DLPFC: dorsolateral prefrontal cortex \\ EEG: electro-encephalogram \\ fMRI: functional magnetic resonance imaging \\ FTND: Fagerström test for nicotine dependence \\ HAMD: Hamilton Depression Rating Scale \\ HVLT-R: Hopkins verbal learning test revised \\ iTBS: intermittent theta burst stimulation \\ LDLPFC: left dorsolateral prefrontal cortex \\ MNWS: Minnesota nicotine withdrawal scale \\ PANAS: Positive and Negative Affect SchedulePANSS: positive and negative symptoms scale \\ POMS: profile of mood states \\ PSYRATS: Psychotic symptom rating scale \\ rTMS: repetitive transcranial magnetic stimulation \\ SAPS: scale for the assessment of positive symptoms \\ SANS: scale for the assessment of negative symptoms \\ SDR: Spatial delayed response \\ SOFAS: social and occupational functioning assessment scale \\ SQLS: Self-report quality of life measure for people with schizophrenia \\ TQSU: Tiffany questionnaire for smoking urges \\ VAS: visual analogue scale
}


DATA AND ANALYSES

\section{Comparison 1. TEMPOROPARIETAL TMS vs SHAM TMS}

\begin{tabular}{|c|c|c|c|c|}
\hline Outcome or subgroup title & $\begin{array}{l}\text { No. of } \\
\text { studies }\end{array}$ & $\begin{array}{c}\text { No. of } \\
\text { participants }\end{array}$ & Statistical method & Effect size \\
\hline $\begin{array}{l}1 \text { Global state: } 1 \text {. Clinical } \\
\text { improvement (CGI) }\end{array}$ & 1 & 46 & Risk Ratio (M-H, Fixed, 95\% CI) & $7.0[0.38,128.33]$ \\
\hline $\begin{array}{l}2 \text { Global state: } 2 \text {. Average score for } \\
\text { clinical improvement (CGI, } \\
\text { high = poor) }\end{array}$ & 7 & 224 & Mean Difference (IV, Fixed, 95\% CI) & $-0.50[-0.76,-0.23]$ \\
\hline $\begin{array}{l}3 \text { Mental state: } 1 . \text { General: a. } \\
\text { Clinical improvement (PANSS } \\
>30 \% \text { reduction) }\end{array}$ & 1 & 51 & Risk Ratio (M-H, Fixed, 95\% CI) & $1.0[0.10,10.27]$ \\
\hline $\begin{array}{l}4 \text { Mental state: } 1 . \text { General: b. } \\
\text { Average total score (various } \\
\text { scales) }\end{array}$ & 6 & & Mean Difference (IV, Fixed, 95\% CI) & Subtotals only \\
\hline 4.1 BPRS (high = poor) & 1 & 17 & Mean Difference (IV, Fixed, 95\% CI) & $-5.68[-12.98,1.62]$ \\
\hline 4.2 PANSS total $($ high $=$ poor $)$ & 5 & 127 & Mean Difference (IV, Fixed, 95\% CI) & $-6.09[-10.95,-1.22]$ \\
\hline $\begin{array}{l}5 \text { Mental state: } 1 \text {. General: } \\
\text { c. Average general } \\
\text { psychopathology score (PANSS } \\
\text { general, high }=\text { poor) }\end{array}$ & 4 & 87 & Mean Difference (IV, Fixed, 95\% CI) & $-2.34[-5.26,0.59]$ \\
\hline $\begin{array}{l}6 \text { Mental state: } 2 . \text { Specific: a. } \\
\text { Average depression score } \\
\text { (various scales) }\end{array}$ & 1 & & Mean Difference (IV, Fixed, 95\% CI) & Subtotals only \\
\hline 6.1 HAMD (high = poor) & 1 & 25 & Mean Difference (IV, Fixed, 95\% CI) & $-3.92[-7.84,-0.00]$ \\
\hline 6.2 SDS (high = poor) & 1 & 25 & Mean Difference (IV, Fixed, 95\% CI) & $-5.59[-11.57,0.39]$ \\
\hline $\begin{array}{l}7 \text { Mental state: } 2 \text {. Specific: b.i. } \\
\text { Hallucinations - clinical } \\
\text { improvement (various scales) }\end{array}$ & 5 & & Risk Ratio (M-H, Fixed, 95\% CI) & Subtotals only \\
\hline $\begin{array}{l}7.1 \text { AHRS }>30 \% \text { decrease in } \\
\text { symptoms }\end{array}$ & 3 & 120 & Risk Ratio (M-H, Fixed, 95\% CI) & $2.99[1.12,7.98]$ \\
\hline $7.2 \mathrm{HCS}$ score $\leq 5$ & 3 & 133 & Risk Ratio (M-H, Fixed, 95\% CI) & $2.26[1.18,4.35]$ \\
\hline $\begin{array}{l}\text { 7.3 PANSS hallucination item } \\
\text { improvement } \geq 1 \text { point }\end{array}$ & 1 & 36 & Risk Ratio (M-H, Fixed, 95\% CI) & $1.33[0.43,4.13]$ \\
\hline $\begin{array}{l}\text { 7.4 PSYRATS > 30\% } \\
\text { reduction }\end{array}$ & 1 & 51 & Risk Ratio (M-H, Fixed, 95\% CI) & $3.6[0.20,65.96]$ \\
\hline $\begin{array}{l}8 \text { Mental state: } 2 . \text { Specific: b.ii. } \\
\text { Average hallucinations score } \\
\text { (various scales) }\end{array}$ & 13 & & Mean Difference (IV, Random, 95\% CI) & Subtotals only \\
\hline 8.1 AHRS $($ high = poor $)$ & 9 & 327 & Mean Difference (IV, Random, 95\% CI) & $-2.11[-4.38,0.16]$ \\
\hline 8.2 AVH-related items & 2 & 624 & Mean Difference (IV, Random, 95\% CI) & $-0.51[-3.38,2.36]$ \\
\hline \multicolumn{5}{|l|}{ PSYRATS (high = poor) } \\
\hline 8.3 HCS (high = poor) & 3 & 162 & Mean Difference (IV, Random, 95\% CI) & $-1.64[-2.80,-0.48]$ \\
\hline $\begin{array}{l}\text { 8.4 PANSS hallucination item } \\
\text { (high = poor) }\end{array}$ & 4 & 125 & Mean Difference (IV, Random, 95\% CI) & $-1.01[-1.97,-0.04]$ \\
\hline
\end{tabular}

Transcranial magnetic stimulation (TMS) for schizophrenia (Review)

Copyright $\odot 2015$ The Cochrane Collaboration. Published by John Wiley \& Sons, Ltd. 
9 Mental state: 2. Specific: c. Average negative symptom score (various scales)

9.1 BPRS (high = poor) 9.2 PANSS (high = poor) 9.3 SANS (high = poor)

10 Mental state: 2. Specific: d.i. Positive symptoms - clinical improvement (PANSS > 30\% reduction)

11 Mental state: 2. Specific: d.ii. Average positive symptom score (various scales)

11.1 BPRS (high = poor) 11.2 PANSS (high = poor) 11.3 SAPS (high = poor)

12 Adverse effects: 1 . General: a. Serious

13 Adverse effects: 1. General: b. Leaving the study early

14 Adverse effects: 2. Specific 14.1 cardiovascular lightheaded/Dizziness 14.2 central nervous system tinnitus

14.3 cognitive - concentration problems

14.4 cognitive - mild memory impairment/amnesia

14.5 movement disorder - jaw and facial contraction

14.6 movement disorder restless legs

14.7 psychiatric - worsening hallucinations/audible

Thoughts

14.8 others - earache

14.9 others - headache

14.10 others - somatic discomfort

14.11 others - tingling sensation in the arm

15 Quality of life: Average score (Q-LES-Q, low = poor)
$-3.06[-7.15,1.03]$

$-0.31[-1.87,1.25]$

$-23.58[-37.06,-10$.

$10]$

$1.0[0.10,10.27]$

Mean Difference (IV, Fixed, 95\% CI)

Subtotals only

$0.53[-2.78,3.84]$

$-2.14[-3.15,-1.14]$

$-3.22[-7.86,1.42]$

$0.0[0.0,0.0]$

$0.78[0.46,1.32]$

Subtotals only $1.60[0.45,5.75]$

$3.63[0.19,67.82]$

$1.59[0.26,9.73]$

$2.90[0.35,24.18]$

$8.32[1.13,61.17]$

$1.56[0.07,35.67]$

$2.55[0.31,20.75]$

$1.56[0.07,35.67]$

$2.65[1.56,4.50]$

$1.78[0.65,4.91]$

$1.56[0.07,35.67]$

$-1.0[-14.26,12.26]$ 


\begin{tabular}{lcccc} 
Outcome or subgroup title & $\begin{array}{c}\text { No. of } \\
\text { studies }\end{array}$ & $\begin{array}{c}\text { No. of } \\
\text { participants }\end{array}$ & Statistical method & Effect size \\
\hline $\begin{array}{l}1 \text { Global state: Clinical } \\
\text { improvement (CGI } \leq 2)\end{array}$ & 1 & 100 & Risk Ratio (M-H, Fixed, 95\% CI) & $1.19[0.91,1.57]$ \\
$\begin{array}{c}2 \text { Adverse effects: Leaving the } \\
\text { study early }\end{array}$ & 2 & 140 & Risk Ratio (M-H, Fixed, 95\% CI) & $0.33[0.08,1.46]$ \\
\hline
\end{tabular}

\section{Comparison 3. PREFRONTAL TMS vs SHAM TMS}

\begin{tabular}{|c|c|c|c|c|}
\hline Outcome or subgroup title & $\begin{array}{l}\text { No. of } \\
\text { studies }\end{array}$ & $\begin{array}{c}\text { No. of } \\
\text { participants }\end{array}$ & Statistical method & Effect size \\
\hline $\begin{array}{l}1 \text { Global state: Average score } \\
\text { (various scales) }\end{array}$ & 3 & & Mean Difference (IV, Fixed, 95\% CI) & Subtotals only \\
\hline 1.1 CGI $($ high = poor $)$ & 1 & 31 & Mean Difference (IV, Fixed, 95\% CI) & $0.60[-0.15,1.35]$ \\
\hline 1.2 CGI-S (high = poor) & 1 & 32 & Mean Difference (IV, Fixed, 95\% CI) & $-0.09[-0.63,0.45]$ \\
\hline 1.3 GAF (low = poor $)$ & 1 & 32 & Mean Difference (IV, Fixed, 95\% CI) & $3.43[-5.22,12.08]$ \\
\hline 1.4 SCL-90 GSI (high = poor) & 1 & 22 & Mean Difference (IV, Fixed, 95\% CI) & $-0.05[-0.66,0.56]$ \\
\hline $\begin{array}{l}2 \text { Mental state: } 1 . \text { General: a. } \\
\text { Clinical improvement (> 20\% } \\
\text { decrease in total PANSS score) }\end{array}$ & 1 & 22 & Risk Ratio (M-H, Fixed, 95\% CI) & $0.14[0.02,0.98]$ \\
\hline $\begin{array}{l}3 \text { Mental state: } 1 . \text { General: b. } \\
\text { Average total score (various } \\
\text { scales) }\end{array}$ & 7 & & Mean Difference (IV, Random, 95\% CI) & Totals not selected \\
\hline 3.1 BPRS (high = poor) & 1 & & Mean Difference (IV, Random, 95\% CI) & $0.0[0.0,0.0]$ \\
\hline 3.2 PANSS (high = poor) & 6 & & Mean Difference (IV, Random, 95\% CI) & $0.0[0.0,0.0]$ \\
\hline $\begin{array}{l}4 \text { Mental state: } 1 \text {. General: } \\
\text { c. Average general } \\
\text { psychopathology score } \\
\text { (PANSS, high }=\text { poor) }\end{array}$ & 6 & & Mean Difference (IV, Random, 95\% CI) & Subtotals only \\
\hline $\begin{array}{l}5 \text { Mental state: } 2 . \text { Specific: a. } \\
\text { Average depression score } \\
\text { (various scales) }\end{array}$ & 4 & & Mean Difference (IV, Fixed, 95\% CI) & Subtotals only \\
\hline 5.1 HAMD-17 (high = poor $)$ & 1 & 43 & Mean Difference (IV, Fixed, 95\% CI) & $-2.40[-3.88,-0.92]$ \\
\hline 5.2 HDRS $($ high $=$ poor $)$ & 1 & 31 & Mean Difference (IV, Fixed, 95\% CI) & $1.70[-0.95,4.35]$ \\
\hline 5.3 MADRS (high = poor) & 1 & 22 & Mean Difference (IV, Fixed, 95\% CI) & $-4.36[-7.05,-1.67]$ \\
\hline $\begin{array}{l}5.4 \text { SCL-90 DEP }(\text { high }= \\
\text { poor })\end{array}$ & 1 & 22 & Mean Difference (IV, Fixed, 95\% CI) & $0.01[-0.61,0.63]$ \\
\hline $\begin{array}{l}6 \text { Mental state: } 2 . \text { Specific: } b . \\
\text { Average hallucinations score } \\
\text { (PANSS, high }=\text { poor) }\end{array}$ & 1 & 25 & Mean Difference (IV, Fixed, 95\% CI) & $-0.68[-1.68,0.32]$ \\
\hline $\begin{array}{l}7 \text { Mental state: } 2 \text {. Specific: c. i. } \\
\text { Negative symptoms - clinical } \\
\text { improvement (> 20\% decrease } \\
\text { in PANSS negative) }\end{array}$ & 1 & 16 & Risk Ratio (M-H, Fixed, 95\% CI) & $0.25[0.04,1.77]$ \\
\hline
\end{tabular}

Transcranial magnetic stimulation (TMS) for schizophrenia (Review)

Copyright @ 2015 The Cochrane Collaboration. Published by John Wiley \& Sons, Ltd. 
8 Mental state: 2. Specific: c. ii.

Average negative symptom score (various scales)

8.1 PANSS $($ high = poor $)$

8.2 SANS $($ high $=$ poor $)$

9 Mental state: 2. Specific: d. Average positive symptom score (various scales)

9.1 PANSS $($ high = poor $)$

9.2 SAPS (high = poor)

10 Mental state: 2. Specific: e. Average psychotism score (SCL-90 PSY, high = poor)

11 Adverse effects: 1. General: a. Adverse events (UKU)

12 Adverse effects: 1 . General: b. Leaving the study early

13 Adverse effects: 2 . Specific: a. Various

13.1 cognition - cognitive difficulties

13.2 movement disorder facial twitching

13.3 movement disorder

- worsening of pre-existing akathesia

13.4 psychiatric - worsening of pre-existing OCD

13.5 other - headache

13.6 other - TMS-related site discomfort/pain

14 Adverse effects: 2 . Specific: b. Average score (CSSES, high = poor)

14.1 cognitive complaints 14.2 subjective side effects
Mean Difference (IV, Random, 95\% CI)

Mean Difference (IV, Random, 95\% CI)

Mean Difference (IV, Random, 95\% CI)

Mean Difference (IV, Fixed, 95\% CI)

Mean Difference (IV, Fixed, 95\% CI)

Mean Difference (IV, Fixed, 95\% CI)

Mean Difference (IV, Fixed, 95\% CI)

Risk Ratio (M-H, Fixed, 95\% CI)

Risk Ratio (M-H, Fixed, 95\% CI)

Risk Ratio (M-H, Fixed, 95\% CI)

Risk Ratio (M-H, Fixed, 95\% CI)

Risk Ratio (M-H, Fixed, 95\% CI)

Risk Ratio (M-H, Fixed, 95\% CI)

Risk Ratio (M-H, Fixed, 95\% CI)

Risk Ratio (M-H, Fixed, 95\% CI)

Risk Ratio (M-H, Fixed, 95\% CI)

Mean Difference (IV, Fixed, 95\% CI)

Mean Difference (IV, Fixed, 95\% CI)

Mean Difference (IV, Fixed, 95\% CI)
Subtotals only

$-1.59[-4.68,1.50]$

$-12.68[-18.60,-6$.

$77]$

Subtotals only

$-0.33[-0.99,0.33]$

$-0.27[-2.61,2.07]$

$-0.01[-0.48,0.46]$

$0.0[0.0,0.0]$

$1.19[0.56,2.50]$

Subtotals only

$0.0[0.0,0.0]$

$6.59[0.37,117.77]$

$4.71[0.24,90.69]$

$4.71[0.24,90.69]$

$2.77[1.22,6.26]$

$8.33[1.68,41.27]$

Subtotals only

$-0.6[-2.69,1.49]$

$-1.90[-10.31,6.51]$

\section{Comparison 4. PREFRONTAL THETA BURST STIMULATION TMS vs SHAM TMS}

\begin{tabular}{lcccr} 
Outcome or subgroup title & $\begin{array}{c}\text { No. of } \\
\text { studies }\end{array}$ & $\begin{array}{c}\text { No. of } \\
\text { participants }\end{array}$ & Statistical method & Effect size \\
\hline $\begin{array}{l}1 \text { Global state: Clinical } \\
\text { improvement }\end{array}$ & 1 & 27 & Risk Ratio (M-H, Fixed, 95\% CI) & $4.06[0.21,77.37]$ \\
$\begin{array}{l}\text { Mental state: } 1 \text {. General: a. } \\
\text { Average overall mental state } \\
\text { score (PANSS total, high }=\end{array}$ & 3 & 108 & Mean Difference (IV, Fixed, 95\% CI) & $-5.71[-9.32,-2.10]$ \\
poor)
\end{tabular}

Transcranial magnetic stimulation (TMS) for schizophrenia (Review)

Copyright @ 2015 The Cochrane Collaboration. Published by John Wiley \& Sons, Ltd. 
3 Mental state: 1. General:

b. Average general psychopathology score (PANSS, high = poor)

4 Mental state: 2. Specific: a. Average negative symptom score (various scales)

4.1 PANSS $($ high = poor)

4.2 SANS (high = poor)

5 Mental state: 2. Specific: b. Average positive symptom score (PANSS, high = poor)

6 Cognitive state: Average score (various measures)

6.1 digit span test 6.2 verbal fluency test

7 Adverse effects: 1 . Leaving the study early

8 Adverse effects: 2 . Specific

8.1 headache

8.2 sleep disorder
3

Subtotals only

$-2.67[-4.25,-1.09]$

$-11.55[-21.90,-1$.

20]

3

108 Mean Difference (IV, Fixed, 95\% CI)

$-0.42[-1.64,0.80]$

Mean Difference (IV, Fixed, 95\% CI)

Subtotals only

$2.10[-0.23,4.43]$

$2.10[-2.87,7.07]$

$0.36[0.07,1.74]$

Subtotals only

$0.53[0.11,2.70]$

$0.27[0.01,6.11]$

\section{Comparison 5. SENSITIVITY ANALYSIS: PREFRONTAL THETA BURST STIMULATION TMS vs SHAM}

TMS

\begin{tabular}{lcccc} 
Outcome or subgroup title & $\begin{array}{c}\text { No. of } \\
\text { studies }\end{array}$ & $\begin{array}{c}\text { No. of } \\
\text { participants }\end{array}$ & Statistical method & Effect size \\
\hline $\begin{array}{l}1 \text { Global state: Clinical } \\
\text { improvement }\end{array}$ & 1 & & Risk Ratio (M-H, Fixed, 95\% CI) & Subtotals only \\
$\begin{array}{l}1.1 \text { including only people who } \\
\text { completed the studies }\end{array}$ & 1 & 27 & Risk Ratio (M-H, Fixed, 95\% CI) & $4.06[0.21,77.37]$ \\
\begin{tabular}{l}
1.2 Intention-to-treat analysis \\
\hline
\end{tabular} & 1 & 30 & Risk Ratio (M-H, Fixed, 95\% CI) & $4.41[0.23,84.79]$ \\
\hline
\end{tabular}


Analysis I.I. Comparison I TEMPOROPARIETAL TMS vs SHAM TMS, Outcome I Global state: I. Clinical improvement (CGI).

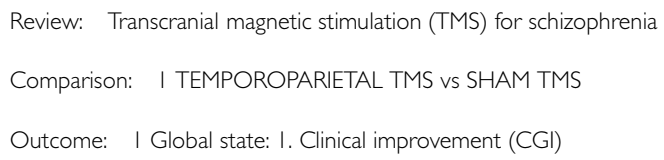

\begin{tabular}{ccccc} 
Study or subgroup & Favours sham TMS & Sham TMS & Risk Ratio & Wisk Ratio \\
& n/N & n/N & M-H,Fixed,95\% Cl & M-H,Fixed,95\% Cl \\
\hline Gao 2009a (I) & $3 / 23$ & $0 / 23$ & 100.0 \%
\end{tabular}

Total (95\% CI) 23

Total events: 3 (Favours sham TMS), 0 (Sham TMS)

Heterogeneity: not applicable

Test for overall effect: $Z=1.31(P=0.19)$

Test for subgroup differences: Not applicable

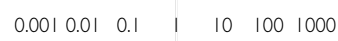

Favours sham TMS Favours TMS

(I) Markedly improved, response criteria not reported 
Analysis I.2. Comparison I TEMPOROPARIETAL TMS vs SHAM TMS, Outcome 2 Global state: 2. Average score for clinical improvement (CGI, high = poor).

Review: Transcranial magnetic stimulation (TMS) for schizophrenia

Comparison: I TEMPOROPARIETAL TMS vs SHAM TMS

Outcome: 2 Global state: 2 . Average score for clinical improvement $(\mathrm{CGl}$, high = poor)

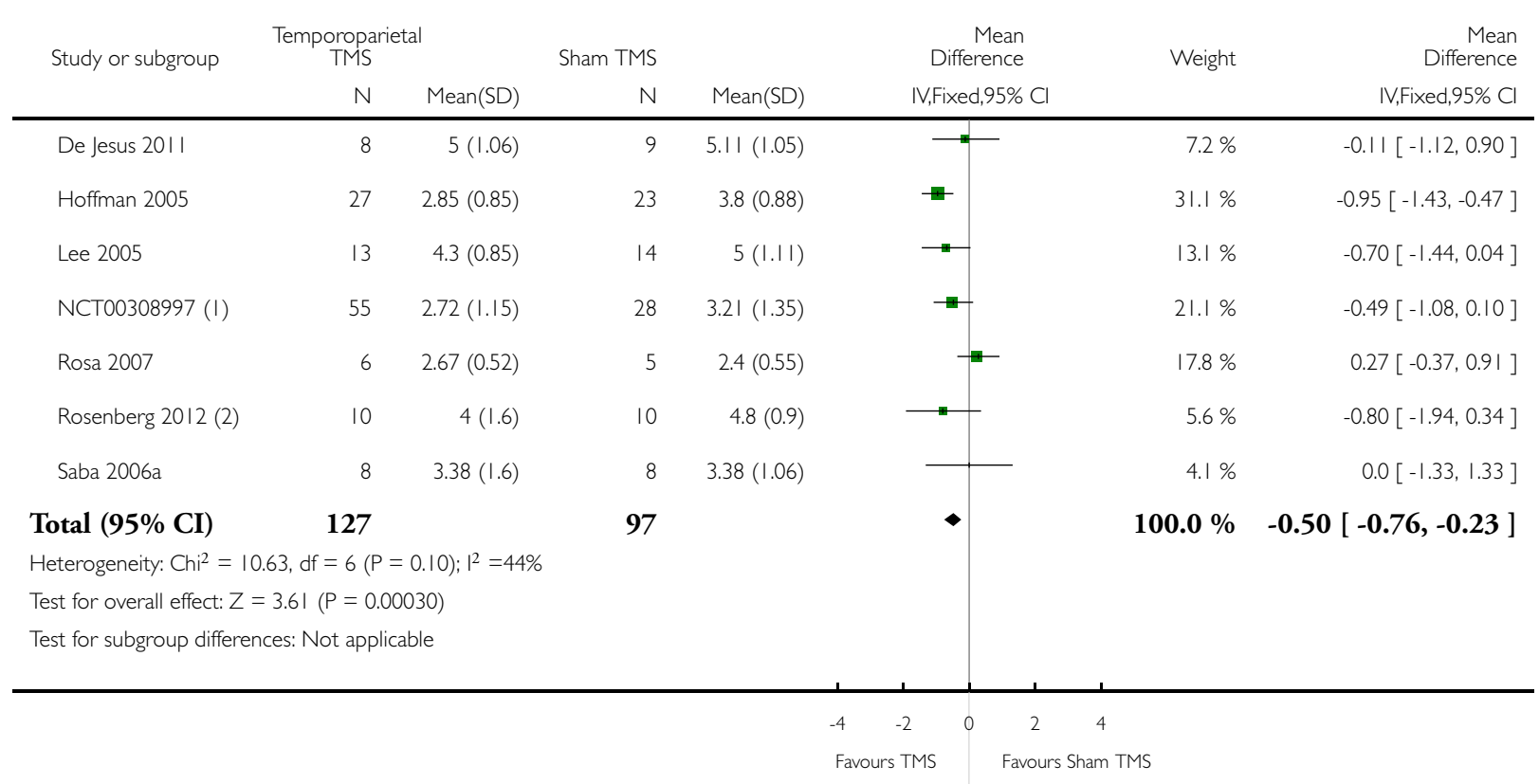

( I) LOCF

(2) Deep TMS, data extracted from a graph 
Analysis I.3. Comparison I TEMPOROPARIETAL TMS vs SHAM TMS, Outcome 3 Mental state: I. General: a. Clinical improvement (PANSS > 30\% reduction).

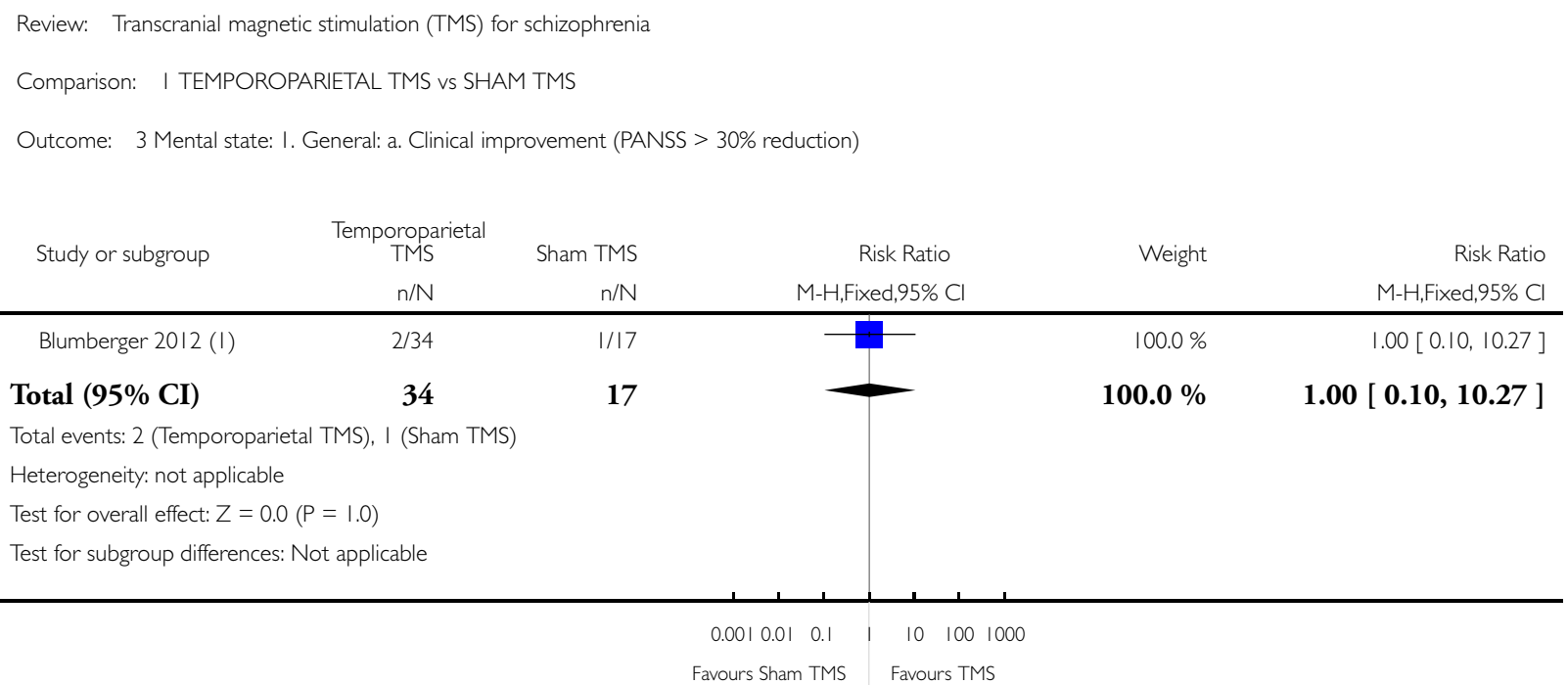

(I) Response criteria provided by the study 
Analysis I.4. Comparison I TEMPOROPARIETAL TMS vs SHAM TMS, Outcome 4 Mental state: I. General: b. Average total score (various scales).

Review: Transcranial magnetic stimulation (TMS) for schizophrenia

Comparison: I TEMPOROPARIETAL TMS vs SHAM TMS

Outcome: 4 Mental state: I. General: b. Average total score (various scales)

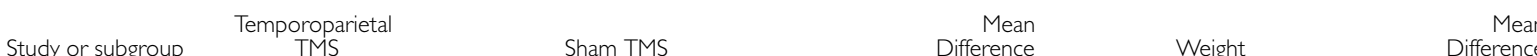

Study or subgroup ThS Tham TMS

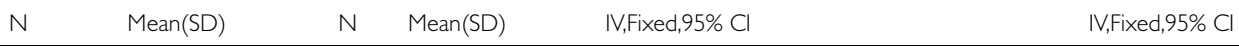

\begin{tabular}{|c|c|c|}
\hline \multicolumn{3}{|l|}{ I BPRS (high = poor) } \\
\hline De Jesus 2011 & 8 & $23.88(7.99$ \\
\hline Subtotal (95\% CI) & \multicolumn{2}{|l|}{8} \\
\hline \multicolumn{3}{|c|}{ Heterogeneity: not applicable } \\
\hline \multicolumn{3}{|c|}{ Test for overall effect: $Z=1.52(P=0.13)$} \\
\hline \multicolumn{3}{|c|}{2 PANSS total (high = poor) } \\
\hline Blumberger 2012 & 27 & $61.0022(\mid 4.0203$ \\
\hline Hao 2008 & 13 & $61.69(13.9$ \\
\hline Rosa 2007 & 6 & $83(16.5$ \\
\hline Saba $2006 a$ & 8 & $65.38(19.73$ \\
\hline Xu 2011 & 18 & $69.44(15.3$ \\
\hline
\end{tabular}

Subtotal (95\% CI) $\quad 72$

Heterogeneity: $\mathrm{Chi}^{2}=1.10, \mathrm{df}=4(\mathrm{P}=0.89) ; \mathrm{I}^{2}=0.0 \%$

Test for overall effect: $Z=2.45(P=0.014)$

$929.56(7.29)$

9

.

$363.92(17.66)$

$1267.83(12.13)$

$5 \quad 85.75(3.86)$

$80.5(15.25)$

$78.53(7.75)$

55
$100.0 \%$

$-5.68[-12.98,1.62]$

$100.0 \%-5.68[-12.98,1.62]$

$19.7 \%$

$-2.92[-13.88,8.04]$

$22.7 \%$

$-6.14[-16.35,4.07]$

$12.7 \%$

$-2.75[-16.42,10.92]$

$7.9 \%$

$-5.12[-22.40,12.16]$

$37.0 \%$

$-9.09[-17.08,-1.10]$

$100.0 \%-6.09[-10.95,-1.22]$

( 
Analysis I.5. Comparison I TEMPOROPARIETAL TMS vs SHAM TMS, Outcome 5 Mental state: I. General: c. Average general psychopathology score (PANSS general, high = poor).

Review: Transcranial magnetic stimulation (TMS) for schizophrenia

Comparison: I TEMPOROPARIETAL TMS vs SHAM TMS

Outcome: 5 Mental state: I. General: c. Average general psychopathology score (PANSS general, high = poor)

\begin{tabular}{|c|c|c|c|c|c|c|c|c|}
\hline \multirow[t]{2}{*}{ Study or subgroup } & \multicolumn{2}{|c|}{$\begin{array}{c}\text { Temporoparietal } \\
\text { TMS }\end{array}$} & \multicolumn{2}{|l|}{ Sham TMS } & \multicolumn{2}{|r|}{$\begin{array}{r}\text { Mean } \\
\text { Difference }\end{array}$} & \multicolumn{2}{|r|}{$\begin{array}{r}\text { Mean } \\
\text { Difference }\end{array}$} \\
\hline & $\mathrm{N}$ & Mean(SD) & $\mathrm{N}$ & Mean(SD) & & IV,Fixed,95\% Cl & & IV,Fixed,95\% Cl \\
\hline Hao 2008 & 13 & $31.85(5.57)$ & 12 & $32.83(6.37)$ & & $\longrightarrow$ & $38.6 \%$ & $-0.98[-5.69,3.73]$ \\
\hline Rosa 2007 & 6 & $45.2(8.23)$ & 5 & $44.75(1.5)$ & & & $19.0 \%$ & $0.45[-6.27,7.17]$ \\
\hline Saba 2006a & 8 & $33.63(10.64)$ & 8 & $35.63(6.68)$ & & $\longrightarrow$ & $11.3 \%$ & $-2.00[-|0.7|, 6.7 \mid]$ \\
\hline Xu 2011 & 18 & $34.11(9.82)$ & 17 & $39.94(5.5)$ & & $\longrightarrow$ & $31.2 \%$ & $-5.83[-11.07,-0.59]$ \\
\hline Total $(95 \% \mathrm{CI})$ & 45 & & 42 & & & $<$ & $100.0 \%$ & $-2.34[-5.26,0.59]$ \\
\hline \multicolumn{9}{|c|}{ Heterogeneity: $\mathrm{Chi}^{2}=2.70, \mathrm{df}=3(\mathrm{P}=0.44) ; \mathrm{I}^{2}=0.0 \%$} \\
\hline \multicolumn{9}{|c|}{ Test for overall effect: $Z=1.57(P=0.12)$} \\
\hline \multicolumn{9}{|c|}{ Test for subgroup differences: Not applicable } \\
\hline & & & & & -20 & -10 & 20 & \\
\hline & & & & & & rs TMS & nam TMS & \\
\hline
\end{tabular}


Analysis I.6. Comparison I TEMPOROPARIETAL TMS vs SHAM TMS, Outcome 6 Mental state: 2. Specific: a. Average depression score (various scales).

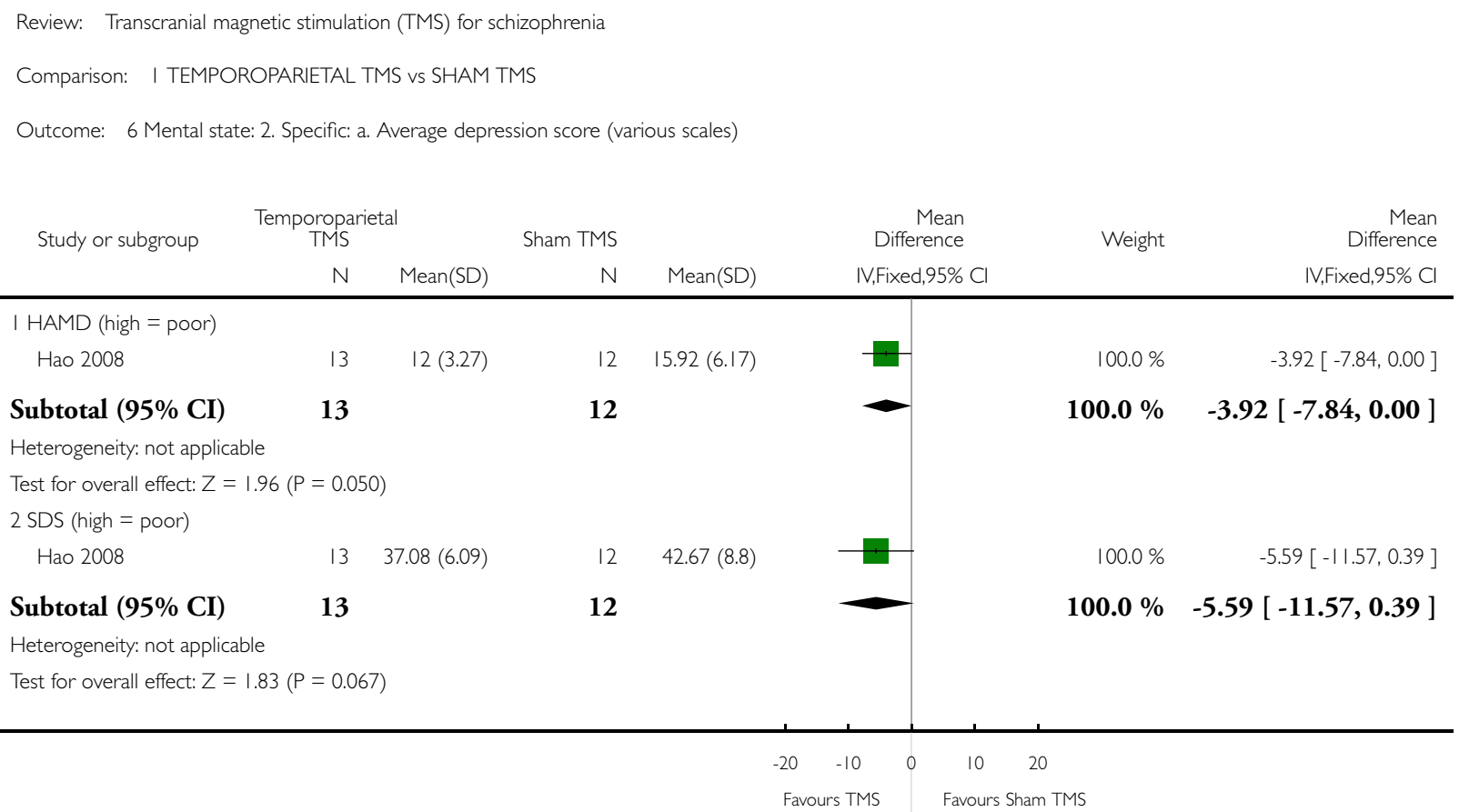


Analysis I.7. Comparison I TEMPOROPARIETAL TMS vs SHAM TMS, Outcome 7 Mental state: 2. Specific: b.i. Hallucinations - clinical improvement (various scales).

Review: Transcranial magnetic stimulation (TMS) for schizophrenia

Comparison: I TEMPOROPARIETAL TMS vs SHAM TMS

Outcome: 7 Mental state: 2. Specific: b.i. Hallucinations - clinical improvement (various scales)

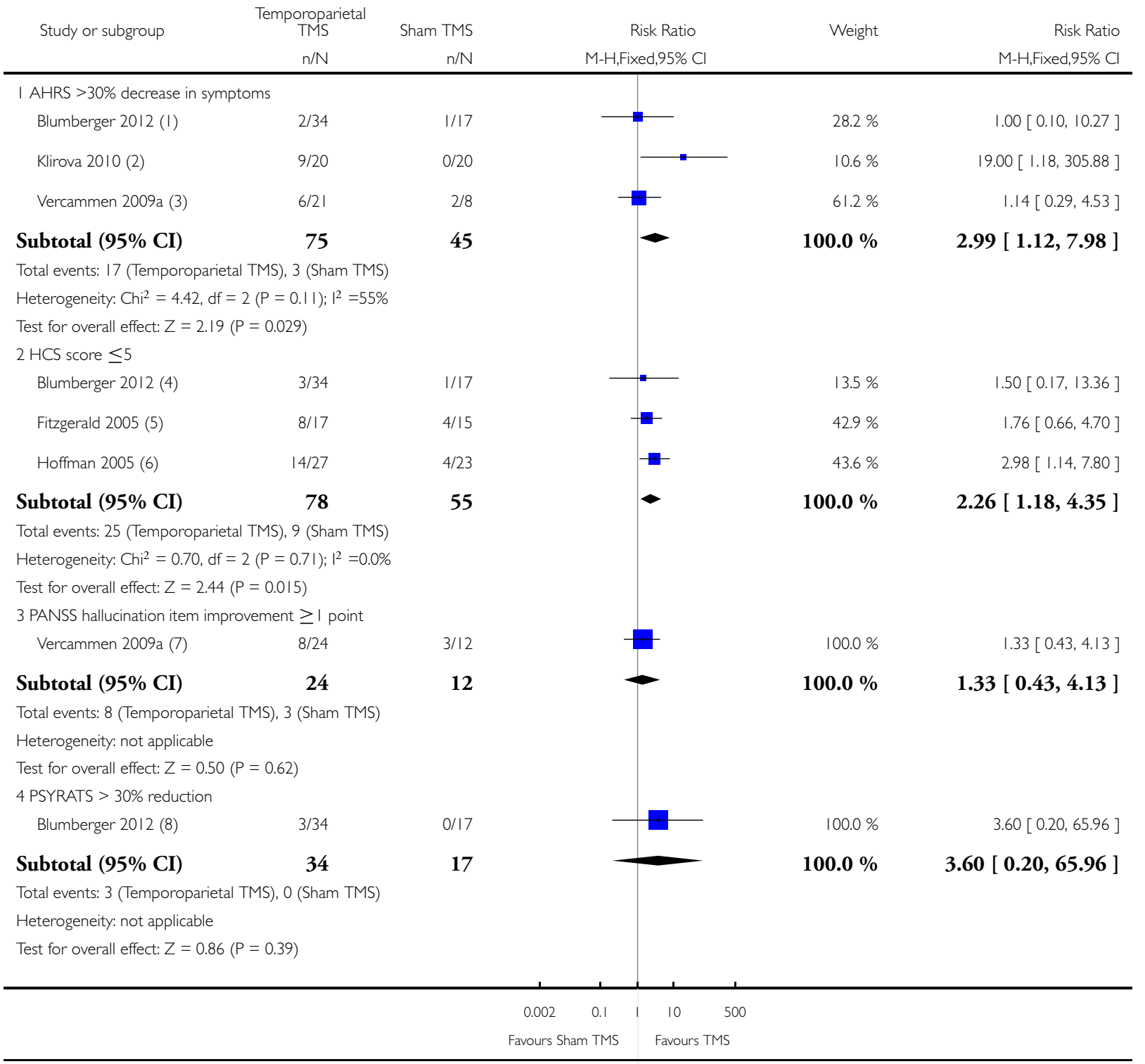

Transcranial magnetic stimulation (TMS) for schizophrenia (Review)

Copyright @ 2015 The Cochrane Collaboration. Published by John Wiley \& Sons, Ltd. 

( I) Response criteria not reported
(2) Response criteria provided by the study
(3) Response criteria provided by the study
(4) Response criteria provided by the study
(5) Response criteria not reported
(6) Response criteria provided by the study
(7) Response criteria provided by the study
(8) Response criteria provided by the study

\section{Analysis I.8. Comparison I TEMPOROPARIETAL TMS vs SHAM TMS, Outcome 8 Mental state: 2. Specific: b.ii. Average hallucinations score (various scales).}

Review: Transcranial magnetic stimulation (TMS) for schizophrenia

Comparison: I TEMPOROPARIETAL TMS vs SHAM TMS

Outcome: 8 Mental state: 2. Specific: b.ii. Average hallucinations score (various scales)

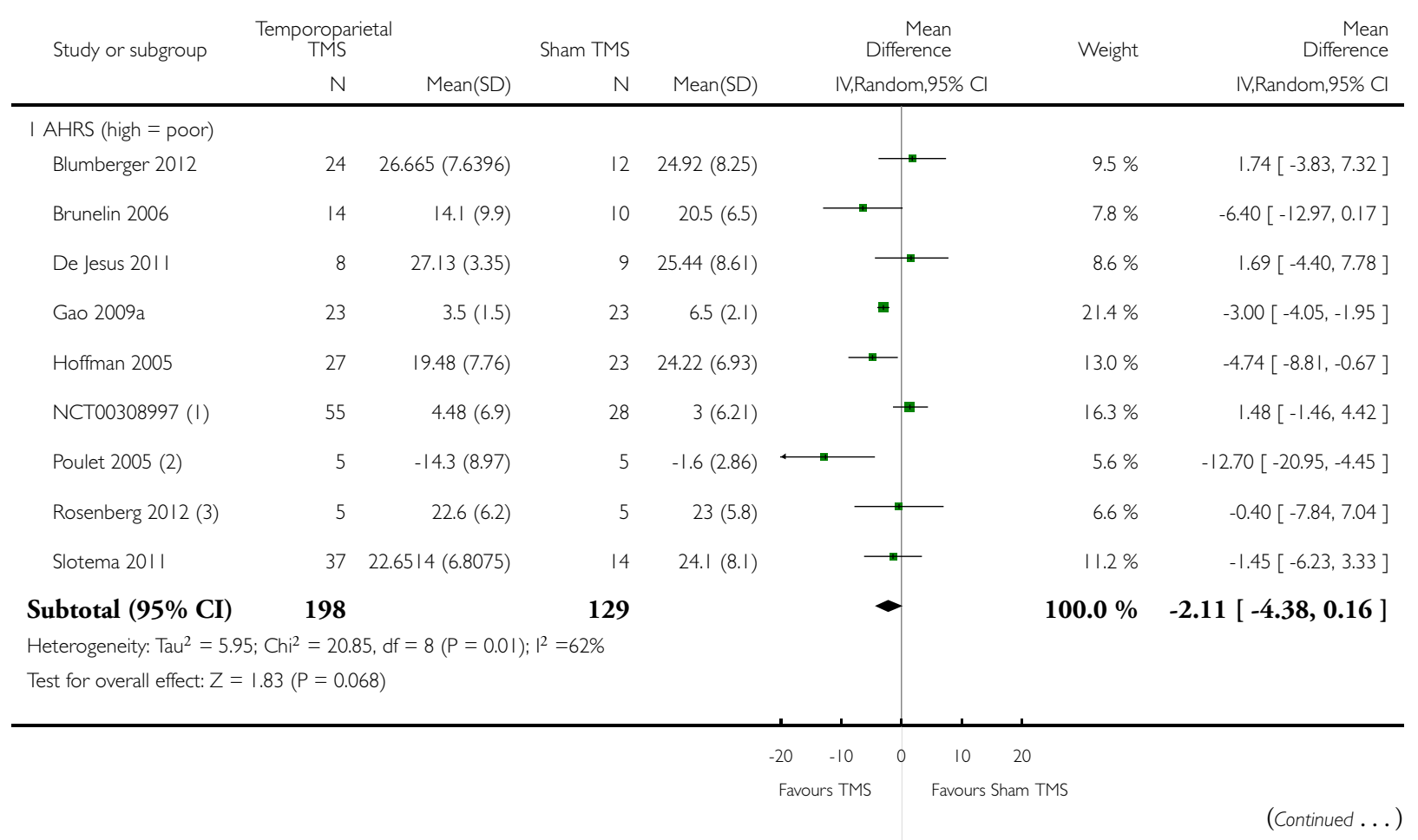

Transcranial magnetic stimulation (TMS) for schizophrenia (Review) 


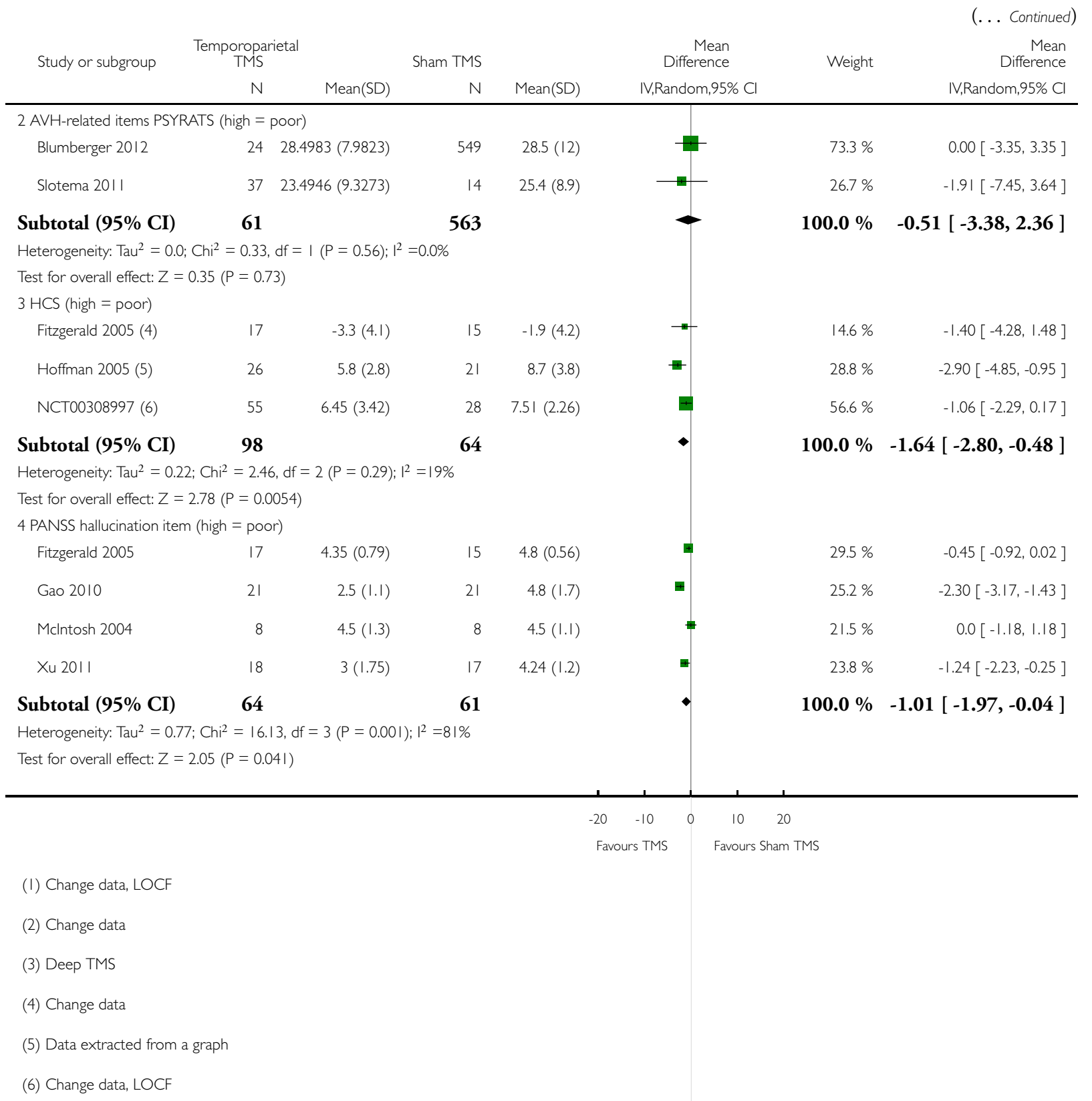


Analysis I.9. Comparison I TEMPOROPARIETAL TMS vs SHAM TMS, Outcome 9 Mental state: 2. Specific: c. Average negative symptom score (various scales).

Review: Transcranial magnetic stimulation (TMS) for schizophrenia

Comparison: I TEMPOROPARIETAL TMS vs SHAM TMS

Outcome: 9 Mental state: 2. Specific: c. Average negative symptom score (various scales)

\begin{tabular}{|c|c|c|c|c|c|c|c|}
\hline \multirow[t]{2}{*}{ Study or subgroup } & \multicolumn{2}{|c|}{$\begin{array}{c}\text { Temporoparietal } \\
\text { TMS }\end{array}$} & \multicolumn{2}{|l|}{ Sham TMS } & \multirow{2}{*}{$\begin{array}{c}\text { Mean } \\
\text { Difference } \\
\text { IV,Fixed,95\% Cl }\end{array}$} & \multirow[t]{2}{*}{ Weight } & \multirow{2}{*}{$\begin{array}{r}\text { Mean } \\
\text { Difference } \\
\text { IV,Fixed,95\% Cl }\end{array}$} \\
\hline & $\mathrm{N}$ & Mean(SD) & $N$ & Mean(SD) & & & \\
\hline \multicolumn{8}{|l|}{ BPRS (high = poor) } \\
\hline De Jesus 201। & 8 & $9.5(3.81)$ & 9 & I2.56 (4.79) & + & $100.0 \%$ & $-3.06[-7.15,1.03]$ \\
\hline
\end{tabular}

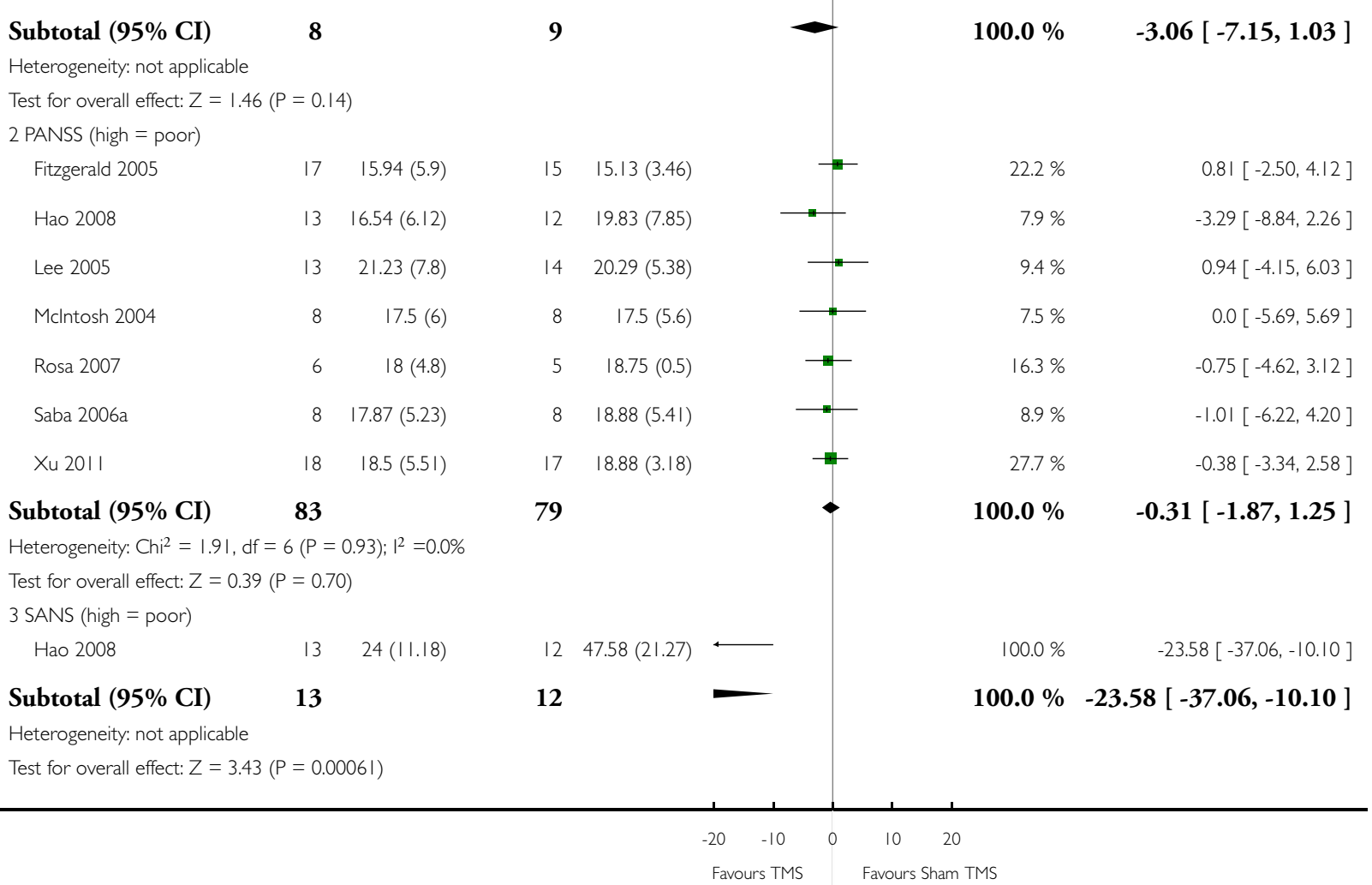


Analysis I.I0. Comparison I TEMPOROPARIETAL TMS vs SHAM TMS, Outcome I0 Mental state: 2. Specific: d.i. Positive symptoms - clinical improvement (PANSS > 30\% reduction).

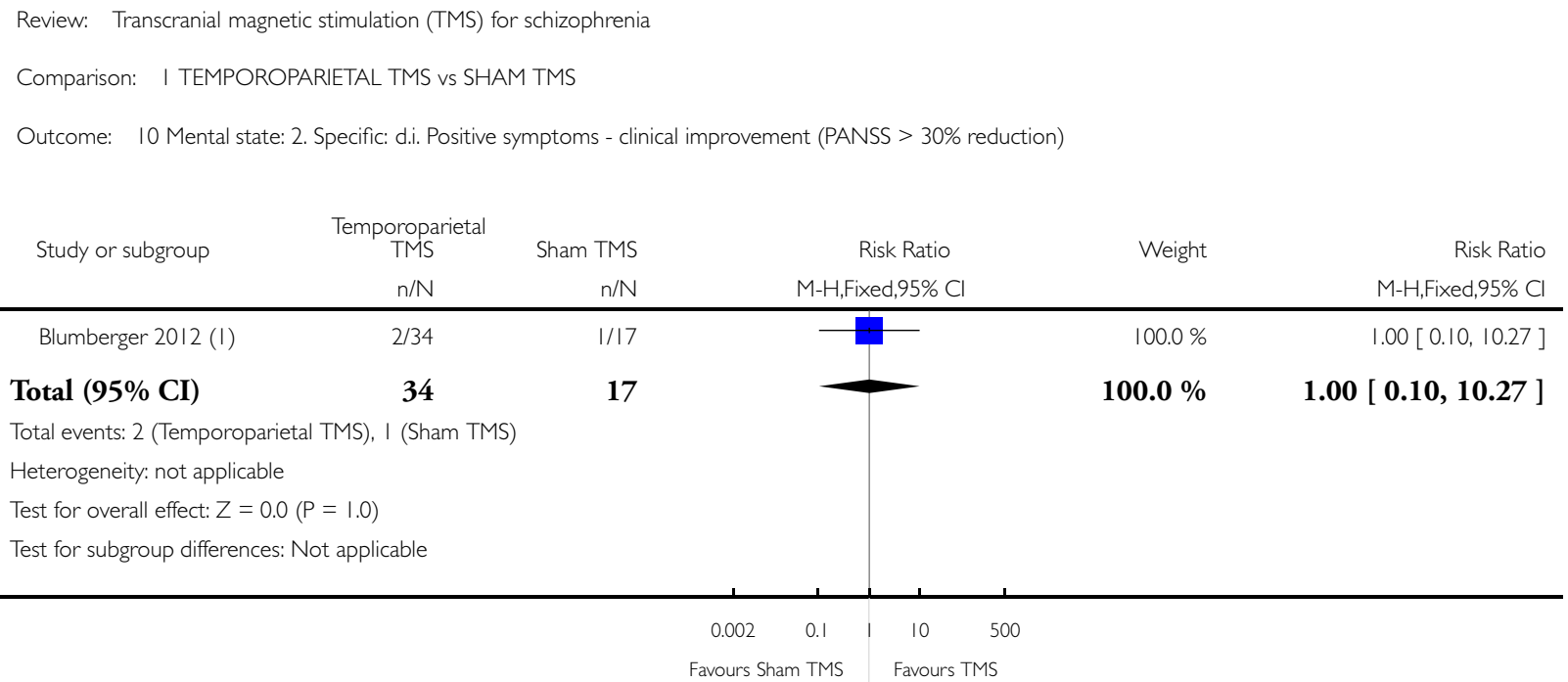

( I) Response criteria provided by the study 
Analysis I.II. Comparison I TEMPOROPARIETAL TMS vs SHAM TMS, Outcome I I Mental state: 2. Specific: d.ii. Average positive symptom score (various scales).

Review: Transcranial magnetic stimulation (TMS) for schizophrenia

Comparison: I TEMPOROPARIETAL TMS vs SHAM TMS

Outcome: II Mental state: 2. Specific: d.ii. Average positive symptom score (various scales)

\begin{tabular}{|c|c|c|c|c|c|c|c|}
\hline Study or subgroup & $\begin{array}{c}\text { Temporoparietal } \\
\text { TMS }\end{array}$ & & Sham TMS & & $\begin{array}{r}\text { Mean } \\
\text { Difference }\end{array}$ & Weight & $\begin{array}{r}\text { Mean } \\
\text { Difference }\end{array}$ \\
\hline & $N$ & Mean(SD) & $N$ & Mean(SD) & IV,Fixed,95\% Cl & & IV,Fixed,95\% Cl \\
\hline
\end{tabular}

\begin{tabular}{|c|c|c|c|c|c|c|c|}
\hline De Jesus 201 I & 8 & $9.75(4.16)$ & 9 & $9.22(2.48)$ & & $100.0 \%$ & $0.53[-2.78,3.84]$ \\
\hline Subtotal (95\% CI) & 8 & & 9 & & & $100.0 \%$ & $0.53[-2.78,3.84]$ \\
\hline \multicolumn{8}{|c|}{ Heterogeneity: not applicable } \\
\hline \multicolumn{8}{|c|}{ Test for overall effect: $Z=0.31$ ( $P=0.75)$} \\
\hline \multicolumn{8}{|c|}{ PANSS (high = poor) } \\
\hline Blumberger 2012 & 27 & | $5.6626(3.8029)$ & 13 & $17.08(4.55)$ & $\rightarrow$ & $12.3 \%$ & $-1.42[-4.28,1.44]$ \\
\hline Fitzgerald 2005 & 17 & $|7.4|(4.06)$ & 15 & $20.87(4.49)$ & $\rightarrow$ & $11.3 \%$ & $-3.46[-6.44,-0.48]$ \\
\hline Hao 2008 & 13 & |3.3| (4.09) & 12 & $15.17(4.8)$ & $\longrightarrow$ & $8.2 \%$ & $-1.86[-5.37,1.65]$ \\
\hline Hoffman 2005 & 27 & $14.29(3.95)$ & 23 & I $6.48(4.94)$ & $\mp$ & $16.0 \%$ & $-2.19[-4.70,0.32]$ \\
\hline Klirova 2010 & 20 & $16.05(6.6823)$ & 10 & $22.6(6.4 I)$ & $\longrightarrow$ & $4.1 \%$ & $-6.55[-|1.49,-1.6|]$ \\
\hline Lee 2005 & 13 & $23.07(7.26)$ & 14 & $21.64(4.81)$ & & $4.6 \%$ & $1.43[-3.25,6.11]$ \\
\hline Mclntosh 2004 & 8 & $15.9(4.6)$ & 8 & $18.9(6.4)$ & & $3.4 \%$ & $-3.00[-8.46,2.46]$ \\
\hline Rosa 2007 & 6 & $19.8(5.63)$ & 5 & $22.25(3.5)$ & & $3.4 \%$ & $-2.45[-7.90,3.00]$ \\
\hline Saba 2006a & 8 & $16.38(6.26)$ & 8 & I7.25 (4.59) & $\longrightarrow$ & $3.5 \%$ & $-0.87[-6.25,4.51]$ \\
\hline Slotema 201 I & 37 & | 4.7703 (4.8503) & 14 & $15.9(3.5)$ & $\rightarrow$ & $17.3 \%$ & $-1.13[-3.54,1.28]$ \\
\hline Xu 201 I & 18 & I6.83 (3.65) & 17 & |9.7| (3.9) & 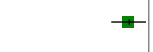 & $16.0 \%$ & $-2.88[-5.39,-0.37]$ \\
\hline Subtotal (95\% CI) & 194 & & 139 & & $\bullet$ & $100.0 \%$ & $-2.14[-3.15,-1.14]$ \\
\hline \multicolumn{8}{|c|}{ Heterogeneity: $\mathrm{Chi}^{2}=7.66, d f=10(P=0.66) ; 1^{2}=0.0 \%$} \\
\hline \multicolumn{8}{|c|}{ Test for overall effect: $Z=4.19(P=0.000028)$} \\
\hline \multicolumn{8}{|c|}{ SAPS (high $=$ poor) } \\
\hline Brunelin 2006 & 14 & $49.1(22.7)$ & 10 & $58.3(25.9)$ & $\longleftarrow$ & $5.4 \%$ & $-9.20[-29.18,10.78]$ \\
\hline Hao 2008 & 13 & $9.62(5.95)$ & 12 & $12.5(6.19)$ & & $94.6 \%$ & $-2.88[-7.65,1.89]$ \\
\hline
\end{tabular}

Subtotal (95\% CI) 27

22

$100.0 \% \quad-3.22[-7.86,1.42]$

Heterogeneity: Chi $^{2}=0.36, \mathrm{df}=\mathrm{I}(\mathrm{P}=0.55) ; \mathrm{I}^{2}=0.0 \%$

Test for overall effect: $Z=1.36(P=0.17)$ 
Analysis I.I2. Comparison I TEMPOROPARIETAL TMS vs SHAM TMS, Outcome I 2 Adverse effects: I. General: a. Serious.

Review: Transcranial magnetic stimulation (TMS) for schizophrenia

Comparison: I TEMPOROPARIETAL TMS vs SHAM TMS

Outcome: 12 Adverse effects: I. General: a. Serious

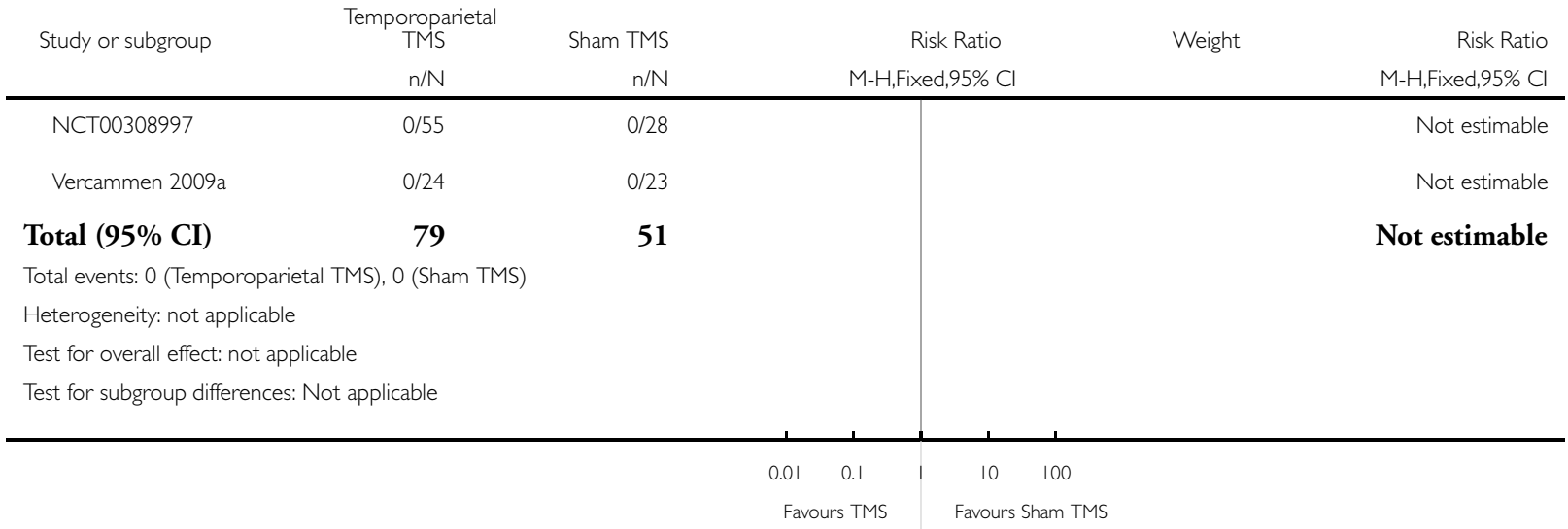


Analysis I.13. Comparison I TEMPOROPARIETAL TMS vs SHAM TMS, Outcome I3 Adverse effects: I. General: b. Leaving the study early.

Review: Transcranial magnetic stimulation (TMS) for schizophrenia

Comparison: I TEMPOROPARIETAL TMS vs SHAM TMS

Outcome: 13 Adverse effects: I. General: b. Leaving the study early

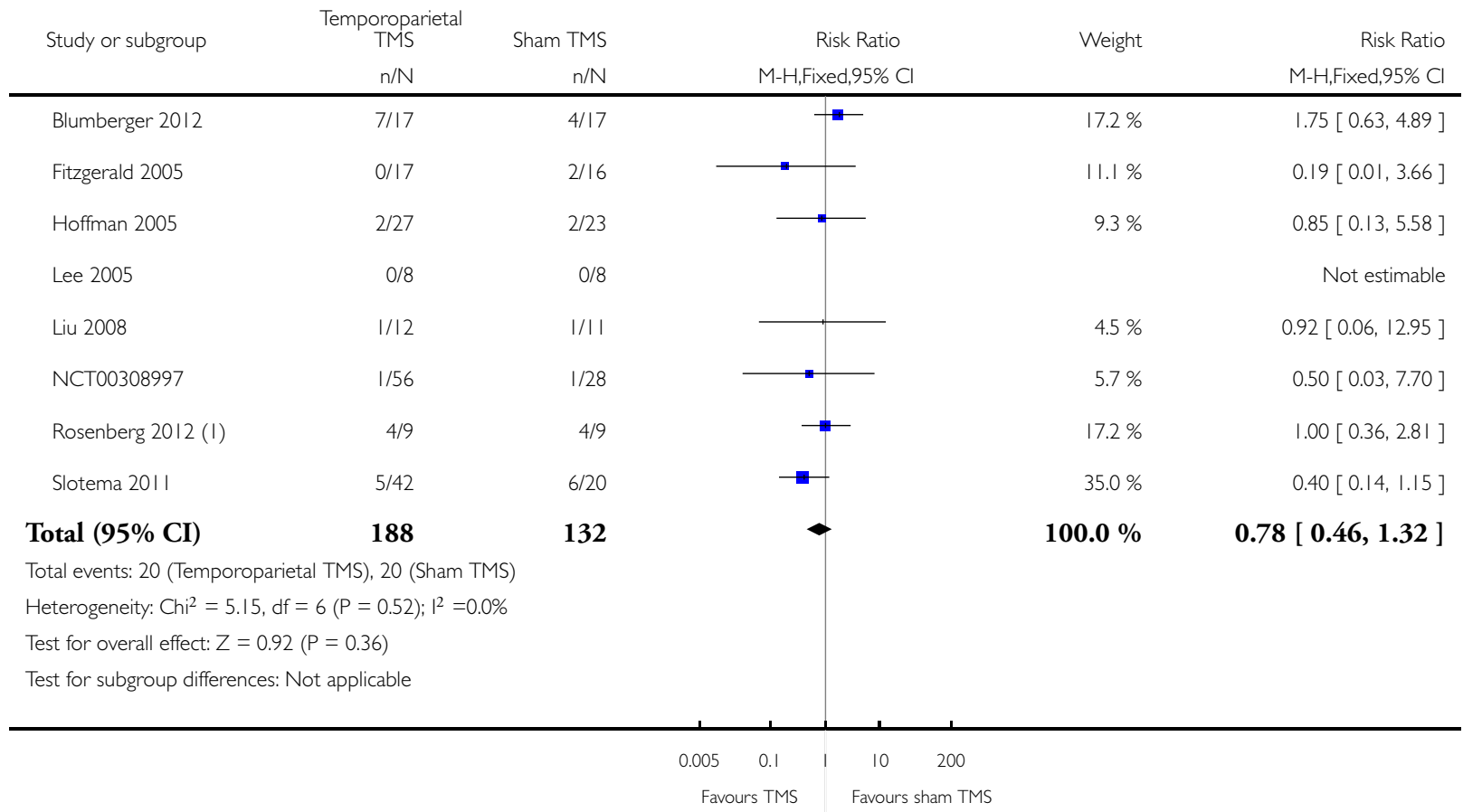

( 1 ) Deep TMS 


\section{Analysis I.14. Comparison I TEMPOROPARIETAL TMS vs SHAM TMS, Outcome I4 Adverse effects: 2.}

Specific.

Review: Transcranial magnetic stimulation (TMS) for schizophrenia

Comparison: I TEMPOROPARIETAL TMS vs SHAM TMS

Outcome: 14 Adverse effects: 2. Specific

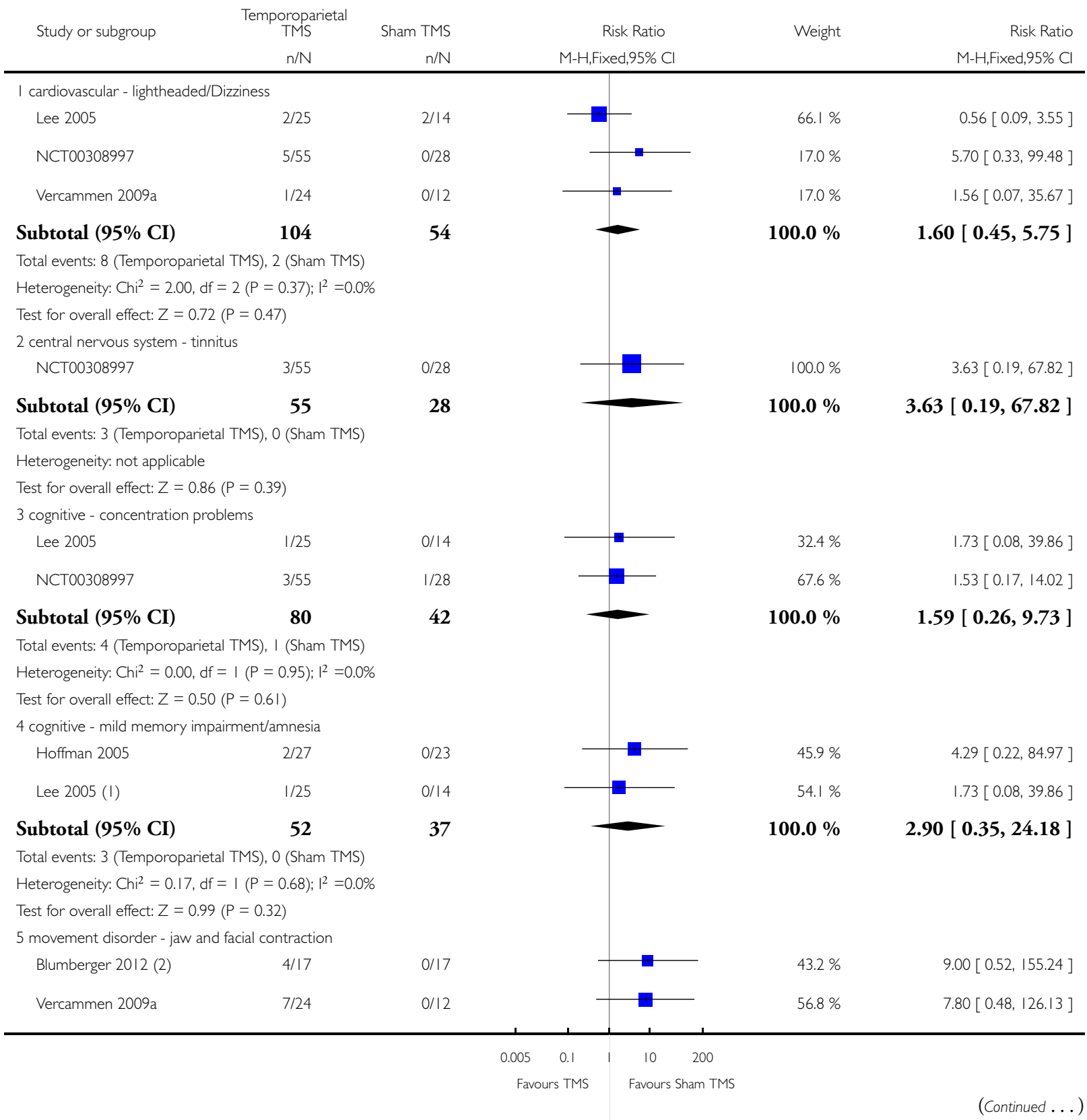

Transcranial magnetic stimulation (TMS) for schizophrenia (Review)

Copyright @ 2015 The Cochrane Collaboration. Published by John Wiley \& Sons, Ltd. 


\section{Subtotal (95\% CI)}

\section{1}

Total events: II (Temporoparietal TMS), 0 (Sham TMS)

Heterogeneity: $\mathrm{Ch}^{2}=0.00, \mathrm{df}=\mathrm{I}(\mathrm{P}=0.94) ; \mathrm{I}^{2}=0.0 \%$

Test for overall effect: $Z=2.08(P=0.037)$

6 movement disorder - restless legs

Vercammen 2009a

$1 / 24$

24

Subtotal $(95 \%$ CI)

0 (Sham TMS)

Total events: I (Temporoparie

Heterogeneity: not applicable

Test for overall effect: $Z=0.28(P=0.78)$

7 psychiatric - worsening hallucinations/audible Thoughts

$$
\text { NCT00308997 }
$$

55

$1 / 28$

Subtotal $\mathbf{( 9 5 \% ~ C I ) ~}$

28

Total events: 5 (Temporoparietal TMS), I (Sham TMS)

Heterogeneity: not applicable

Test for overall effect: $Z=0.87(P=0.38)$

8 others - earache

Vercammen 2009a

$1 / 24$

\section{Subtotal $(\mathbf{9 5 \%}$ CI)}

24

Total events: I (Temporoparietal TMS), 0 (Sham TMS)

Heterogeneity: not applicable

Test for overall effect: $Z=0.28(P=0.78)$

9 others - headache

\begin{tabular}{|c|c|c|}
\hline Blumberger 2012 & $4 / 17$ & \\
\hline De Jesus 2011 & 2/8 & \\
\hline Gao 2009a & $6 / 23$ & \\
\hline Gao 2010 & $6 / 21$ & \\
\hline Lee 2005 & $5 / 25$ & \\
\hline Liu 2008 & $1 / 12$ & \\
\hline NCT00308997 & 12/55 & \\
\hline Rosa 2007 & 1/6 & \\
\hline Vercammen 2009a & $8 / 24$ & \\
\hline Yu 2010 & $8 / 31$ & \\
\hline ubtotal $(95 \% \mathrm{CI})$ & 222 & \\
\hline \multicolumn{3}{|c|}{ otal events: 53 (Temporoparietal TMS), 14 (Sham TMS) } \\
\hline \multicolumn{3}{|c|}{ leterogeneity: $\mathrm{Chi}^{2}=4.44, \mathrm{df}=9(\mathrm{P}=0.88) ; \mathrm{I}^{2}=0.0 \%$} \\
\hline \multicolumn{3}{|c|}{ est for overall effect: $Z=3.62(P=0.00030)$} \\
\hline
\end{tabular}

12
$0 / 12$

12

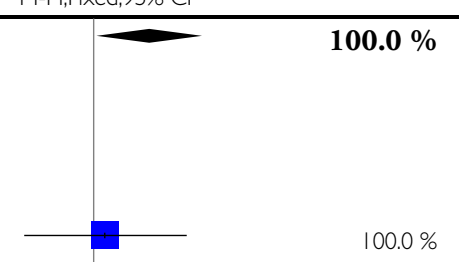

M-H,Fixed,95\% Cl

$00.0 \%$

$100.0 \%$

$100.0 \%$

$2.55[0.31,20.75]$

$100.0 \%$

$100.0 \%$

$11.6 \%$

$2.7 \%$

$5.8 \%$

$5.8 \%$

$14.8 \%$

$6.0 \%$

$30.7 \%$

$3.1 \%$

$7.7 \%$

$11.8 \%$

$100.0 \%$
$2.55[0.31,20.75]$

$1.56[0.07,35.67]$

$1.56[0.07,35.67]$

$2.00[0.42,9.50]$

$1.56[0.07,35.67]$

$5.56[0.31,100.94$ ]

$6.00[0.78,45.99]$

$6.00[0.79,45.63]$

$1.40[0.31,6.30]$

$0.92[0.06,12.95]$

$1.53[0.54,4.30]$

$2.57[0.13,52.12]$

$4.00[0.56,28.40]$

$3.87[0.89,16.77]$

$2.65[1.56,4.50]$ 


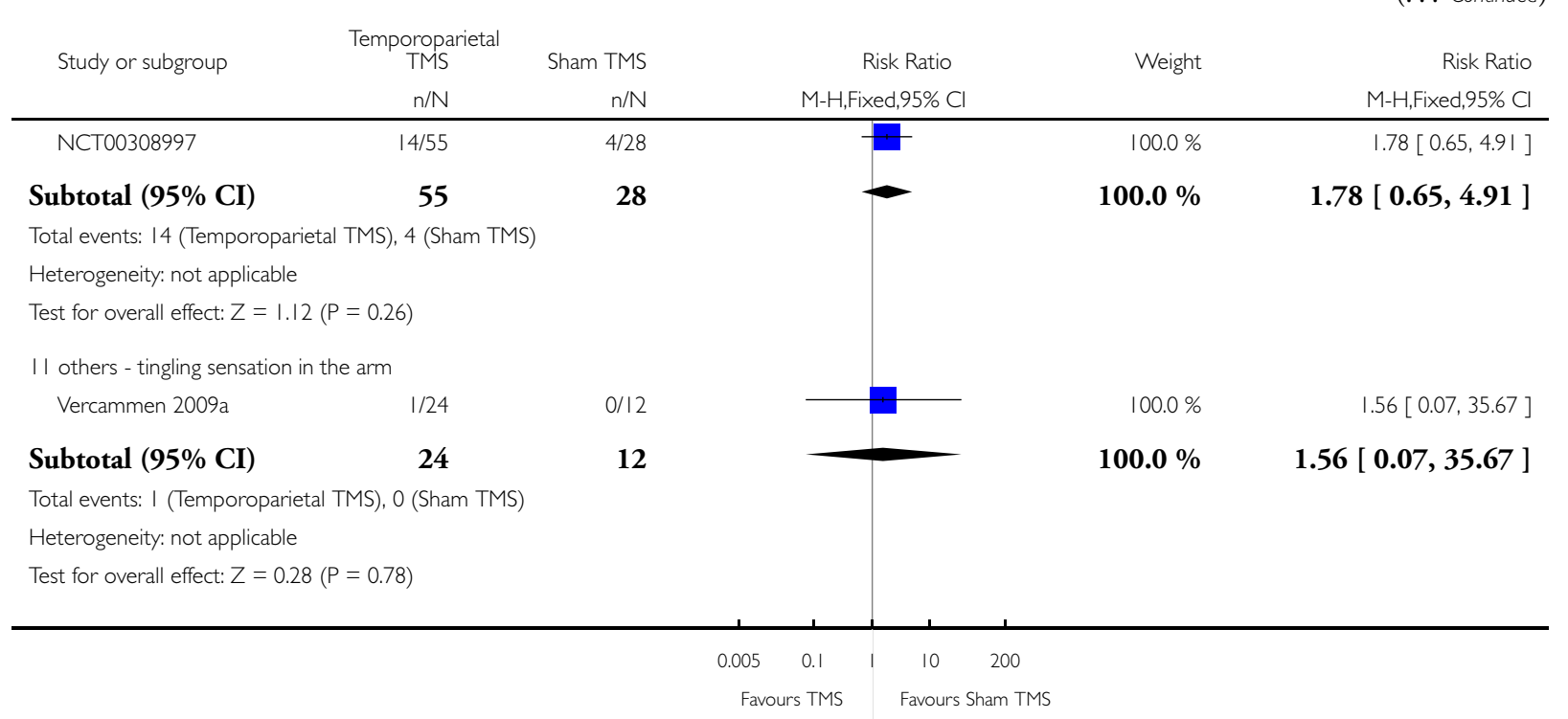
(1) Amnesia
(2) discomfort

\section{Analysis I.15. Comparison I TEMPOROPARIETAL TMS vs SHAM TMS, Outcome I5 Quality of life: Average score (Q-LES-Q, low = poor).}

Review: Transcranial magnetic stimulation (TMS) for schizophrenia

Comparison: I TEMPOROPARIETAL TMS vs SHAM TMS

Outcome: 15 Quality of life: Average score (Q-LES-Q, low = poor)

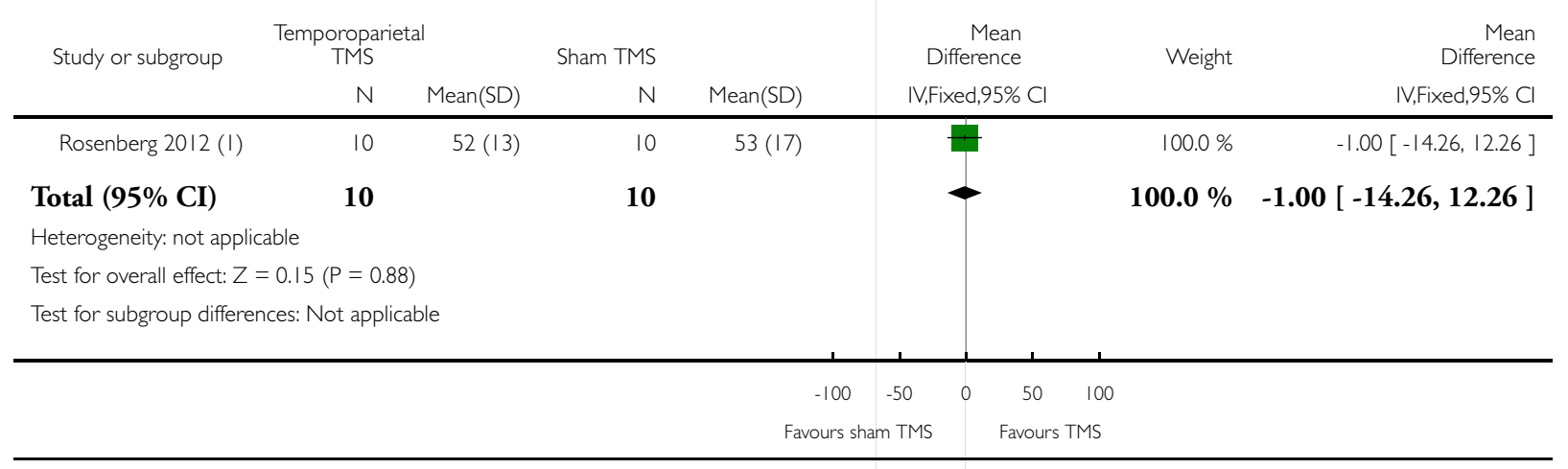

Transcranial magnetic stimulation (TMS) for schizophrenia (Review) 
(I) Deep TMS, data extracted from a graph

\section{Analysis 2.I. Comparison 2 TEMPOROPARIETAL TMS vs STANDARD TREATMENT, Outcome I Global state: Clinical improvement (CGI $\leq 2)$.}

Review: Transcranial magnetic stimulation (TMS) for schizophrenia

Comparison: 2 TEMPOROPARIETAL TMS vs STANDARD TREATMENT

Outcome: | Global state: Clinical improvement (CGI $\leq 2)$

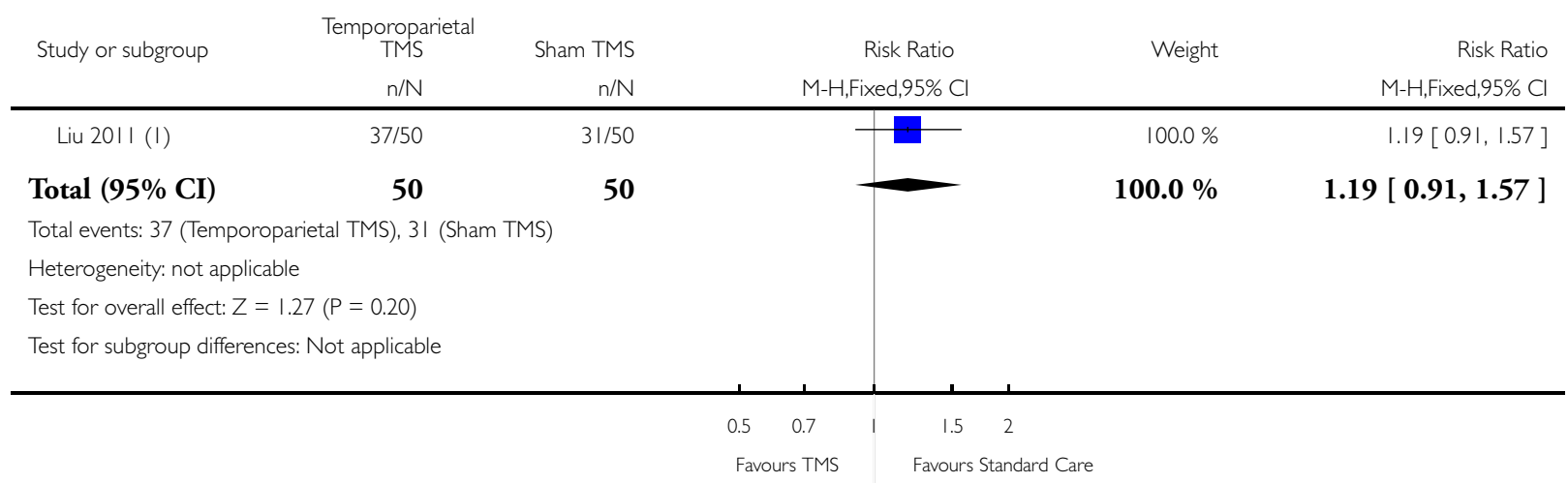

( I) Response criteria provided by the study 
Analysis 2.2. Comparison 2 TEMPOROPARIETAL TMS vs STANDARD TREATMENT, Outcome 2 Adverse effects: Leaving the study early.

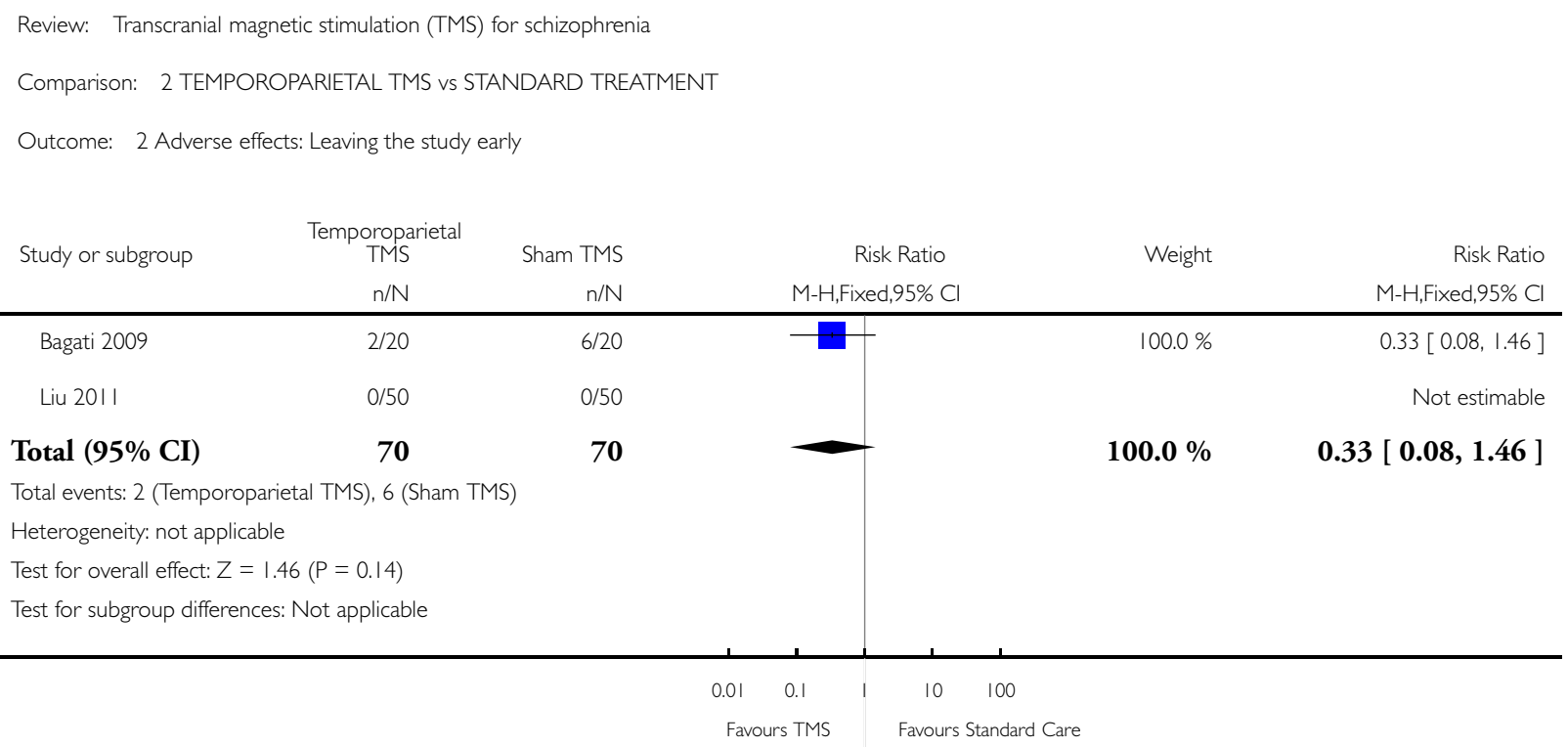


Analysis 3.I. Comparison 3 PREFRONTAL TMS vs SHAM TMS, Outcome I Global state: Average score (various scales).

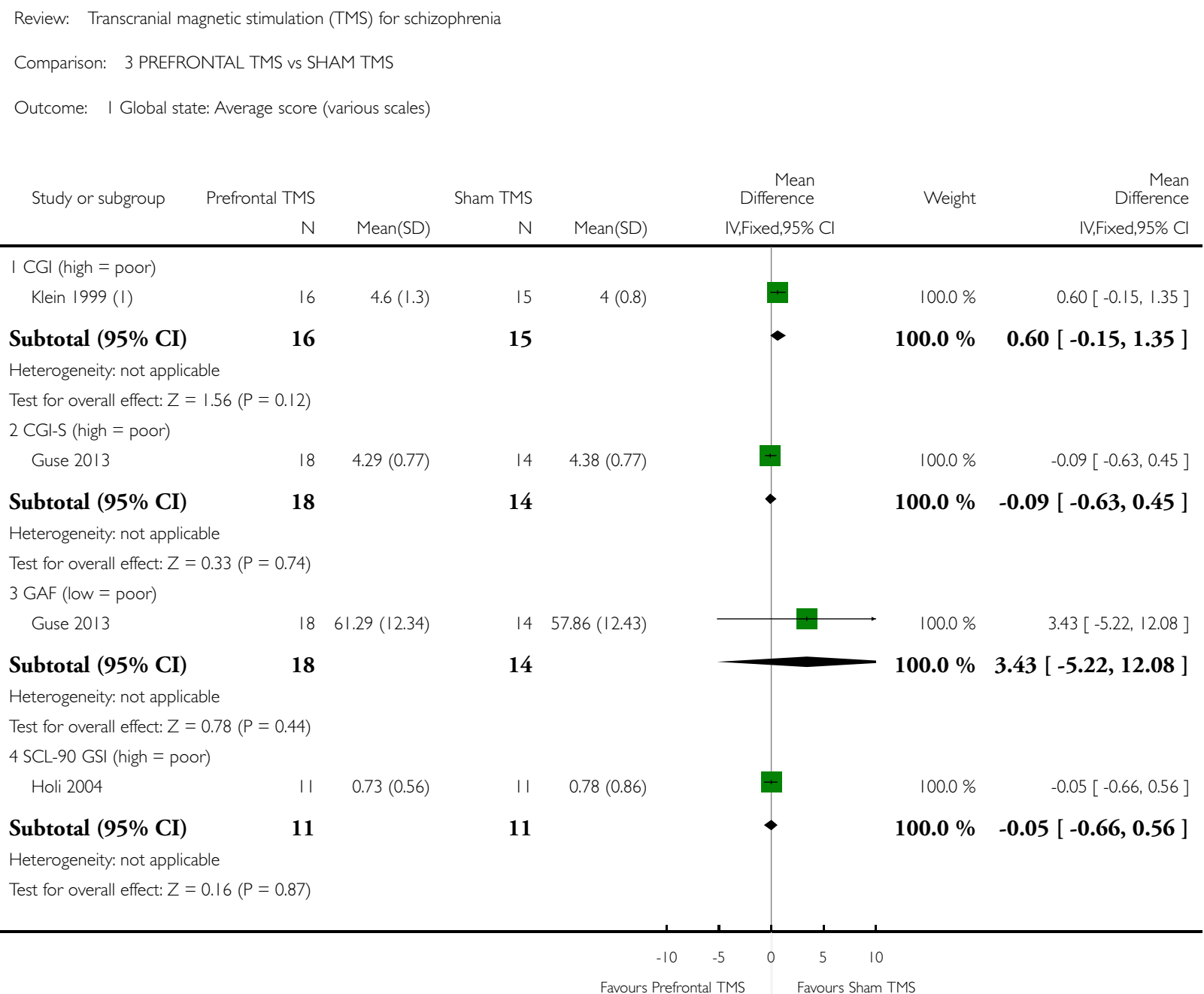

(I) Right prefrontal, low frequency $(\mathrm{IHz})$ 
Analysis 3.2. Comparison 3 PREFRONTAL TMS vs SHAM TMS, Outcome 2 Mental state: I. General: a. Clinical improvement ( $>20 \%$ decrease in total PANSS score).

Review: Transcranial magnetic stimulation (TMS) for schizophrenia

Comparison: 3 PREFRONTAL TMS vs SHAM TMS

Outcome: 2 Mental state: I. General: a. Clinical improvement (> 20\% decrease in total PANSS score)

\begin{tabular}{|c|c|c|c|c|c|}
\hline \multirow[t]{2}{*}{ Study or subgroup } & Prefrontal TMS & Sham TMS & Risk Ratio & Weight & Risk Ratio \\
\hline & $n / N$ & $n / N$ & M-H,Fixed,95\% Cl & & M-H,Fixed,95\% Cl \\
\hline Holi 2004 (I) & $|/| \mid$ & $7 / 11$ & $\longrightarrow$ & $100.0 \%$ & $0.14[0.02,0.98]$ \\
\hline Total (95\% CI) & 11 & 11 & & $100.0 \%$ & $0.14[0.02,0.98]$ \\
\hline
\end{tabular}

Total events: I (Prefrontal TMS), 7 (Sham TMS)

Heterogeneity: not applicable

Test for overall effect: $Z=1.98(P=0.047)$

Test for subgroup differences: Not applicable

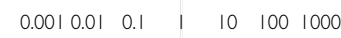

Favours Sham TMS Favours Prefrontal TMS

(I) Response criteria provided by the study 
Analysis 3.3. Comparison 3 PREFRONTAL TMS vs SHAM TMS, Outcome 3 Mental state: I. General: b. Average total score (various scales).

Review: Transcranial magnetic stimulation (TMS) for schizophrenia

Comparison: 3 PREFRONTAL TMS vs SHAM TMS

Outcome: 3 Mental state: I. General: b. Average total score (various scales)

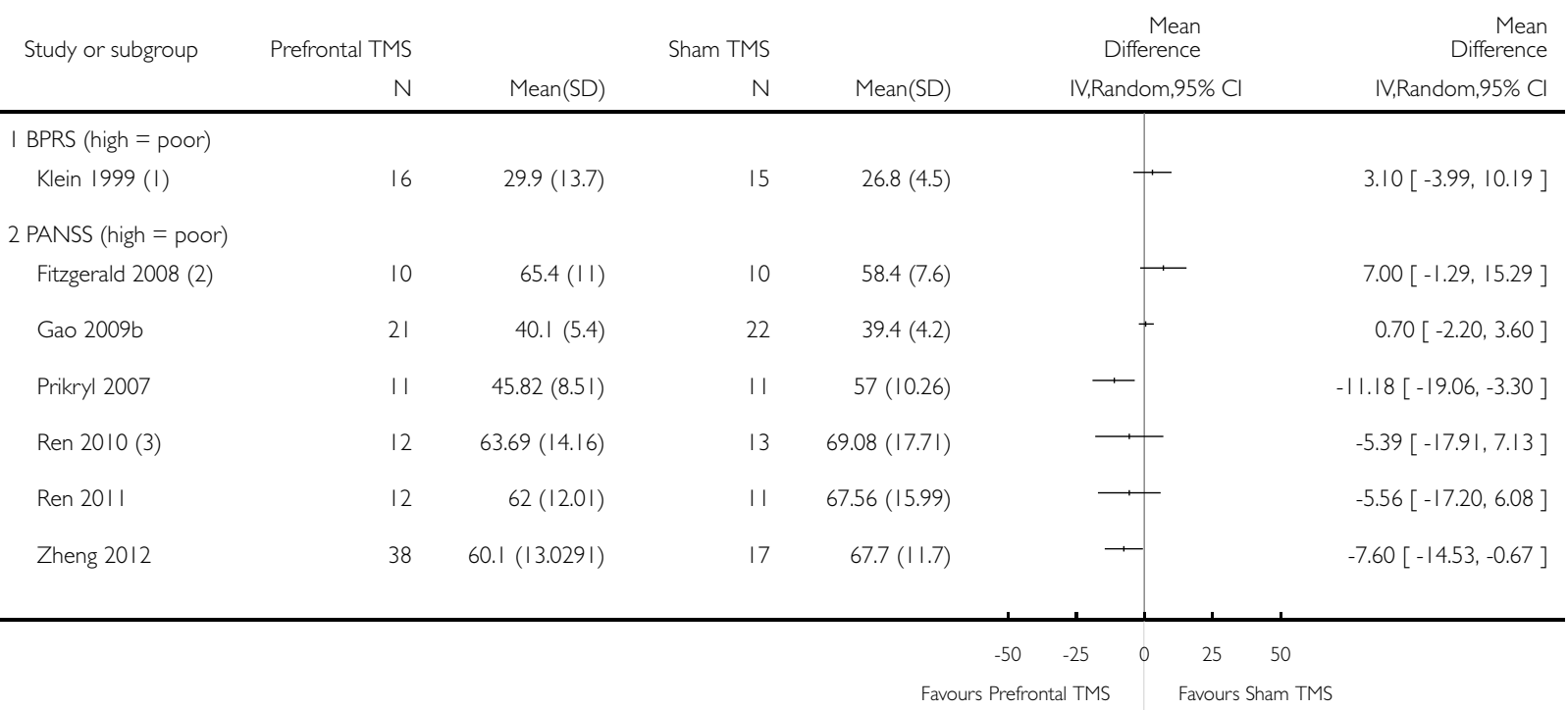

( I) Right prefrontal, low frequency $(\mathrm{IHz})$

(2) LOCF

(3) Low frequency $(\mathrm{I} \mathrm{Hz}$ 
Analysis 3.4. Comparison 3 PREFRONTAL TMS vs SHAM TMS, Outcome 4 Mental state: I. General: c. Average general psychopathology score (PANSS, high = poor).

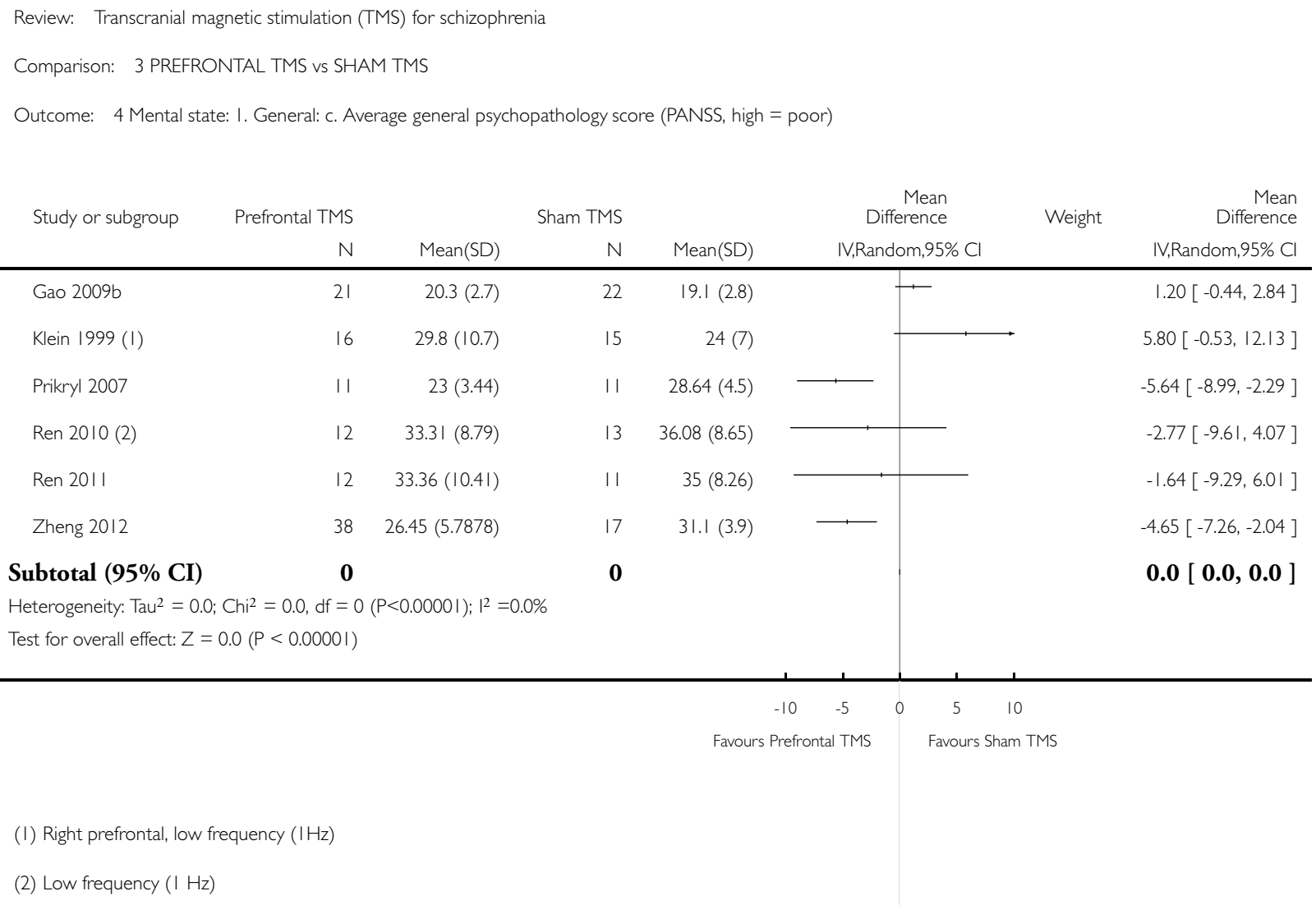


Analysis 3.5. Comparison 3 PREFRONTAL TMS vs SHAM TMS, Outcome 5 Mental state: 2. Specific: a. Average depression score (various scales).

Review: Transcranial magnetic stimulation (TMS) for schizophrenia

Comparison: 3 PREFRONTAL TMS vs SHAM TMS

Outcome: 5 Mental state: 2. Specific: a. Average depression score (various scales)

Study or subgroup Prefrontal TMS Sham TMS Mean Mean

N Mean(SD) N $\quad$ N $\quad$ Mean(SD) IV,Fixed,95\% Cl $\quad$ IV,Fixed,95\% Cl

I HAMD- 17 (high = poor)

Gao 2009b $\quad 21 \quad 11.7(2.1) \quad 22 \quad 14.1(2.8)$

Subtotal (95\% CI)

21

$22-|4|.(2.8)$

Heterogeneity: not applicable

22

$100.0 \%$

$-2.40[-3.88,-0.92]$

Test for overall effect: $Z=3.19(P=0.0014)$

2 HDRS (high = poor)

$$
\text { Klein } 1999 \text { (1) }
$$

$16 \quad 8.6(3.5)$

15

$6.9(4)$

Subtotal (95\% CI)

16

15

Heterogeneity: not applicable

Test for overall effect: $Z=1.26(P=0.21)$

3 MADRS (high = poor)

$$
\text { Prikryl } 2007
$$

II $4.64(3.61)$

| I

9 (2.76)

Subtotal (95\% CI)

11

11

$-4.36[-7.05,-1.67]$

Heterogeneity: not applicable

Test for overall effect: $Z=3.18(P=0.0015)$

4 SCL-90 DEP (high = poor)

$$
\text { Holi } 2004
$$

II $0.83(0.69)$

I $\quad 0.82(0.79)$

11

11

Subtotal (95\% CI)

Heterogeneity: not applicable

Test for overall effect: $Z=0.03(P=0.97)$

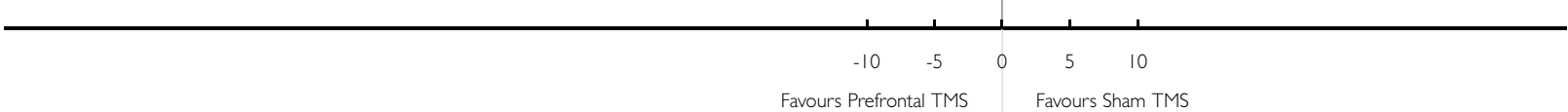

(I) Right prefrontal, low frequency $(\mathrm{IHz})$ 
Analysis 3.6. Comparison 3 PREFRONTAL TMS vs SHAM TMS, Outcome 6 Mental state: 2. Specific: b. Average hallucinations score (PANSS, high = poor).

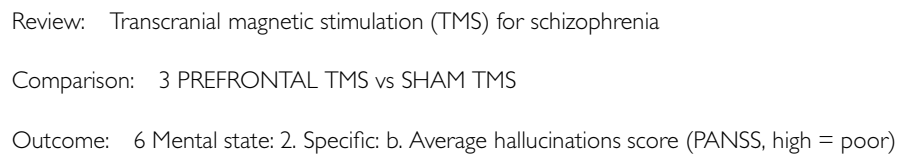

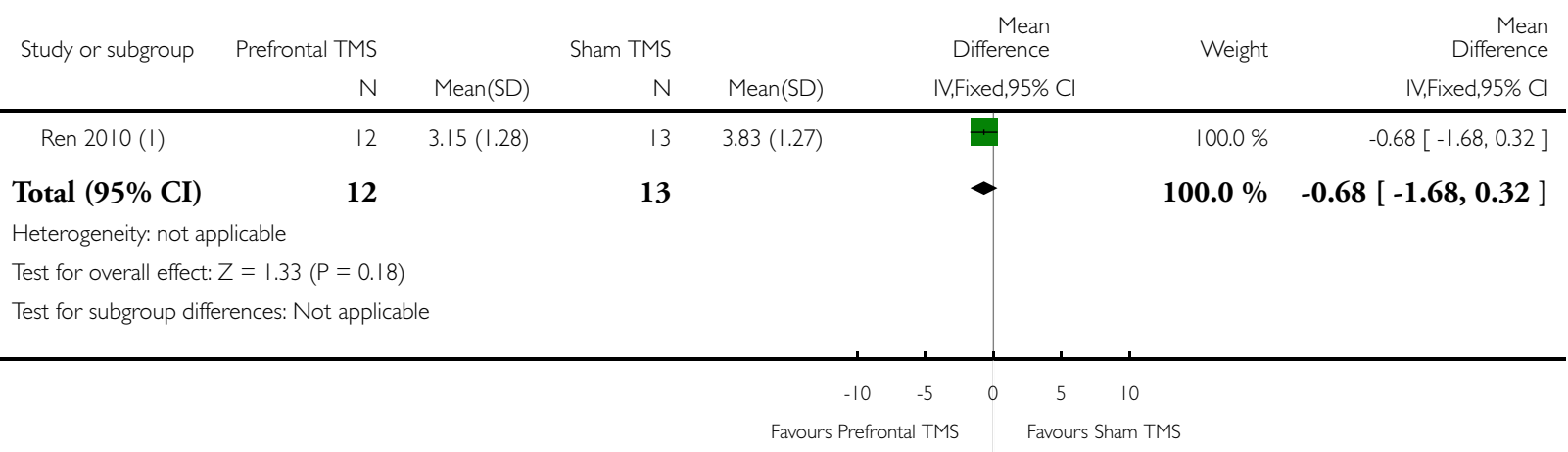

( I) Low frequency $(\mathrm{I} \mathrm{Hz})$

Analysis 3.7. Comparison 3 PREFRONTAL TMS vs SHAM TMS, Outcome 7 Mental state: 2 . Specific: c. i. Negative symptoms - clinical improvement (> 20\% decrease in PANSS negative).

\begin{tabular}{|c|c|c|c|c|c|}
\hline \multicolumn{6}{|c|}{ Comparison: 3 PREFRONTAL TMS vs SHAM TMS } \\
\hline \multicolumn{6}{|c|}{ Outcome: 7 Mental state: 2. Specific: c. i. Negative symptoms - clinical improvement (> 20\% decrease in PANSS negative) } \\
\hline \multirow[t]{2}{*}{ Study or subgroup } & Prefrontal TMS & Sham TMS & Risk Ratio & Weight & Risk Ratio \\
\hline & $\mathrm{n} / \mathrm{N}$ & $\mathrm{n} / \mathrm{N}$ & M-H,Fixed,95\% Cl & & M-H,Fixed,95\% Cl \\
\hline Novak 2006 (I) & $1 / 8$ & $4 / 8$ & 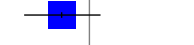 & $100.0 \%$ & $0.25[0.04,1.77]$ \\
\hline Total $(95 \% \mathrm{CI})$ & 8 & 8 & & $100.0 \%$ & $0.25[0.04,1.77]$ \\
\hline \multicolumn{6}{|c|}{ Total events: I (Prefrontal TMS), 4 (Sham TMS) } \\
\hline \multicolumn{6}{|c|}{ Heterogeneity: not applicable } \\
\hline \multicolumn{6}{|c|}{ Test for overall effect: $Z=1.39(P=0.17)$} \\
\hline \multicolumn{6}{|c|}{ Test for subgroup differences: Not applicable } \\
\hline
\end{tabular}

(I) Response criteria provided by the study 
Analysis 3.8. Comparison 3 PREFRONTAL TMS vs SHAM TMS, Outcome 8 Mental state: 2. Specific: c. ii. Average negative symptom score (various scales).

Review: Transcranial magnetic stimulation (TMS) for schizophrenia

Comparison: 3 PREFRONTAL TMS vs SHAM TMS

Outcome: 8 Mental state: 2. Specific: c. ii. Average negative symptom score (various scales)

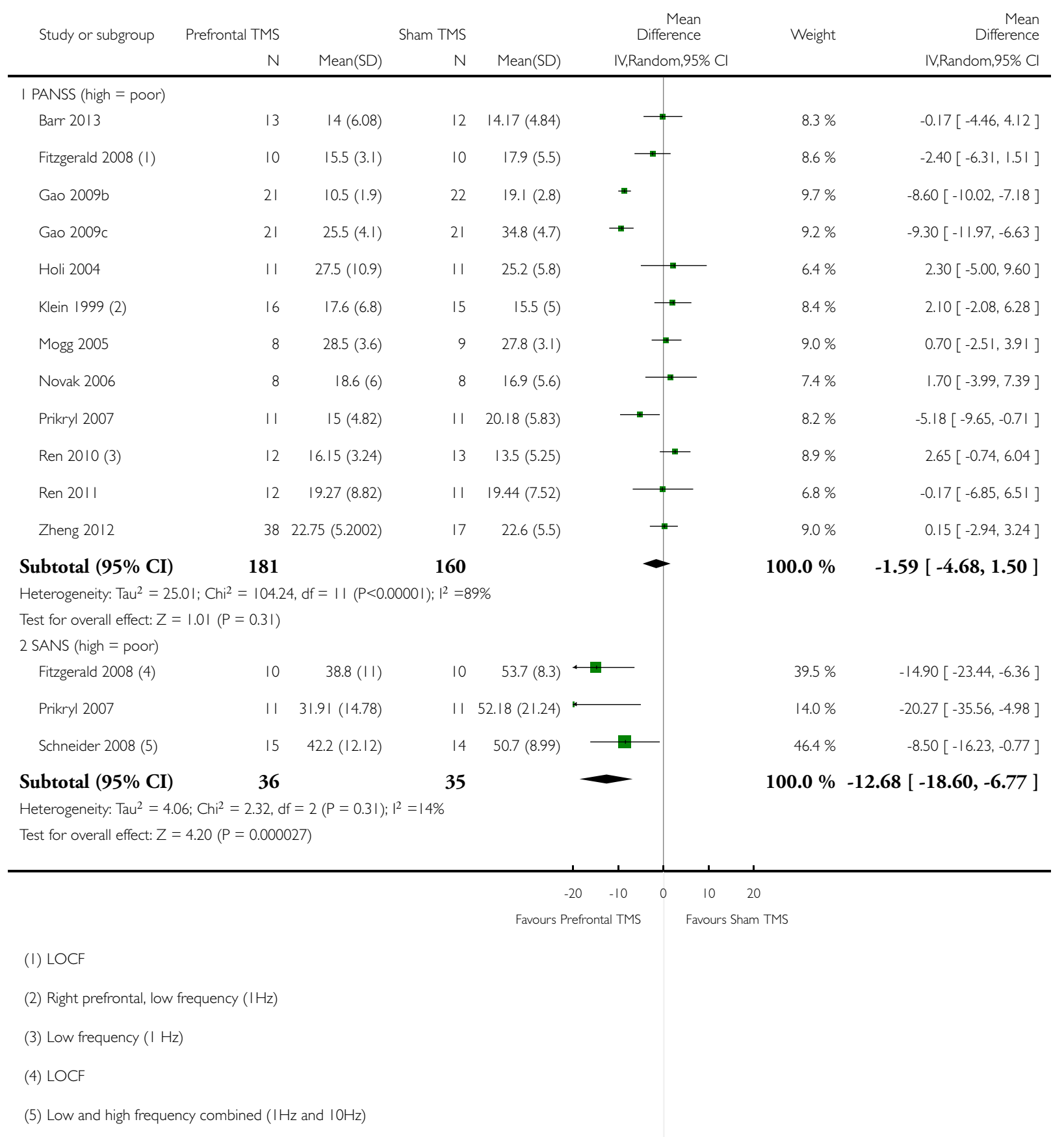

Transcranial magnetic stimulation (TMS) for schizophrenia (Review) 
Analysis 3.9. Comparison 3 PREFRONTAL TMS vs SHAM TMS, Outcome 9 Mental state: 2. Specific: d. Average positive symptom score (various scales).

Review: Transcranial magnetic stimulation (TMS) for schizophrenia

Comparison: 3 PREFRONTAL TMS vs SHAM TMS

Outcome: 9 Mental state: 2. Specific: d. Average positive symptom score (various scales)

\begin{tabular}{|c|c|c|c|c|c|c|c|}
\hline \multirow[t]{2}{*}{ Study or subgroup } & \multirow{2}{*}{$\begin{array}{r}\text { Prefrontal TMS } \\
\mathrm{N}\end{array}$} & \multicolumn{3}{|c|}{ Sham TMS } & \multirow{2}{*}{$\begin{array}{c}\text { Mean } \\
\text { Difference } \\
\text { IV,Fixed,95\% Cl }\end{array}$} & \multirow[t]{2}{*}{ Weight } & \multirow{2}{*}{$\begin{array}{r}\text { Mean } \\
\text { Difference } \\
\text { IV,Fixed,95\% C }\end{array}$} \\
\hline & & Mean(SD) & N & Mean(SD) & & & \\
\hline \multicolumn{8}{|l|}{ I PANSS (high = poor) } \\
\hline Barr 2013 & 13 & $13(4.26)$ & 12 & $13.22(4.21)$ & & $3.9 \%$ & $-0.22[-3.54,3.10]$ \\
\hline Gao 2009b & 21 & $9.3(1.3)$ & 22 & $9.4(1.9)$ & & $46.3 \%$ & $-0.10[-1.07,0.87]$ \\
\hline Holi 2004 & 11 & $20(9.1)$ & 11 & $19.1(7.4)$ & & $0.9 \%$ & $0.90[-6.03,7.83]$ \\
\hline Klein $1999(\mathrm{I})$ & 16 & $12.4(5.5)$ & 15 & $10.9(5.4)$ & & $3.0 \%$ & $1.50[-2.34,5.34]$ \\
\hline Mogg 2005 & 8 & $20.9(3.7)$ & 9 & $20(2.5)$ & - & $4.7 \%$ & $0.90[-2.14,3.94]$ \\
\hline Novak 2006 & 8 & I3.5 (4.7) & 8 & $10.1(3)$ & & $2.9 \%$ & $3.40[-0.46,7.26]$ \\
\hline Prikryl 2007 & || & $7.82(1.33)$ & 11 & $8.36(1.75)$ & 卉 & $25.8 \%$ & $-0.54[-1.84,0.76]$ \\
\hline Ren 2010 (2) & 12 & $13.69(4.5)$ & 13 & $17.08(4.56)$ & & $3.4 \%$ & $-3.39[-6.94,0.16]$ \\
\hline Ren 2011 & 12 & $9.91(3.51)$ & II & |3.1| (5.42) & & $3.1 \%$ & $-3.20[-6.97,0.57]$ \\
\hline Zheng 2012 & 38 & $10.9(4.2143)$ & 17 & $12.8(4.9)$ & - & $6.0 \%$ & $-1.90[-4.59,0.79]$ \\
\hline Subtotal (95\% CI) & 150 & & 129 & & & $100.0 \%$ & $-0.33[-0.99,0.33]$ \\
\hline \multicolumn{8}{|c|}{ Heterogeneity: $\mathrm{Chi}^{2}=|1.91, \mathrm{df}=9(P=0.22) ;|^{2}=24 \%$} \\
\hline \multicolumn{8}{|c|}{ Test for overall effect: $Z=0.98(P=0.33)$} \\
\hline \multicolumn{8}{|c|}{2 SAPS (high $=$ poor) } \\
\hline Prikryl 2007 & 11 & $1.73(2.87)$ & II & $2(2.72)$ & & $100.0 \%$ & $-0.27[-2.61,2.07]$ \\
\hline Subtotal (95\% CI) & 11 & & 11 & & & $100.0 \%$ & $-0.27[-2.61,2.07]$ \\
\hline \multicolumn{8}{|c|}{ Heterogeneity: not applicable } \\
\hline \multicolumn{8}{|c|}{ Test for overall effect: $Z=0.23(P=0.82)$} \\
\hline & & & & -10 & -5 & 10 & \\
\hline & & & & Favours Prefr & al TMS & nam TMS & \\
\hline
\end{tabular}

(I) Right prefrontal, low frequency $(\mathrm{IHz})$

(2) Low frequency $(\mathrm{I} \mathrm{Hz})$ 
Analysis 3.10. Comparison 3 PREFRONTAL TMS vs SHAM TMS, Outcome 10 Mental state: 2 . Specific: e. Average psychotism score (SCL-90 PSY, high = poor).

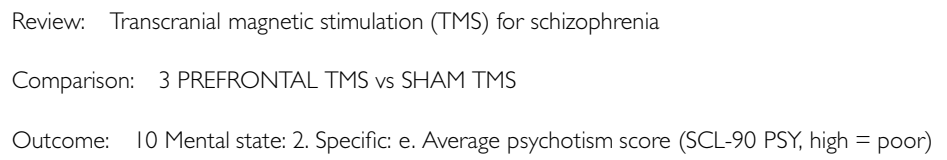

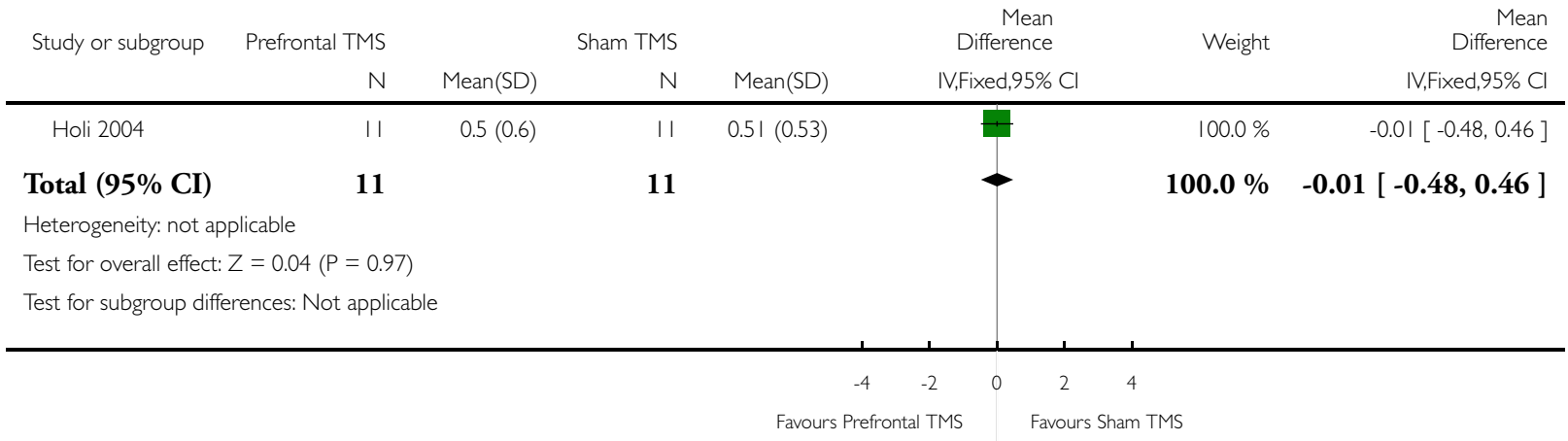

Analysis 3.I I. Comparison 3 PREFRONTAL TMS vs SHAM TMS, Outcome I I Adverse effects: I. General: a. Adverse events (UKU).

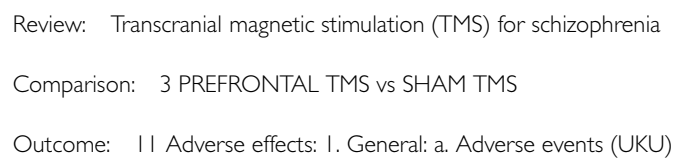

\begin{tabular}{ccccc} 
Study or subgroup & Prefrontal TMS & Sham TMS & Risk Ratio & Risk Ratio \\
& $\mathrm{n} / \mathrm{N}$ & $\mathrm{n} / \mathrm{N}$ & $\mathrm{M}-\mathrm{H}$, Fixed,95\% Cl & Weight \\
\hline Cordes $2010(\mathrm{I})$ & $0 / 20$ & $0 / 15$ & Not estimable
\end{tabular}

Total (95\% CI) 20

Total events: 0 (Prefrontal TMS), 0 (Sham TMS)

Heterogeneity: not applicable

Test for overall effect: not applicable

Test for subgroup differences: Not applicable

\section{$\begin{array}{lllll}0.01 & 0.1 & 1 & 10 & 100\end{array}$ \\ Favours Prefrontal TMS Favours Sham TMS}

( I) No adverse events other than mild headaches 
Analysis 3.12. Comparison 3 PREFRONTAL TMS vs SHAM TMS, Outcome 12 Adverse effects: I. General: b. Leaving the study early.

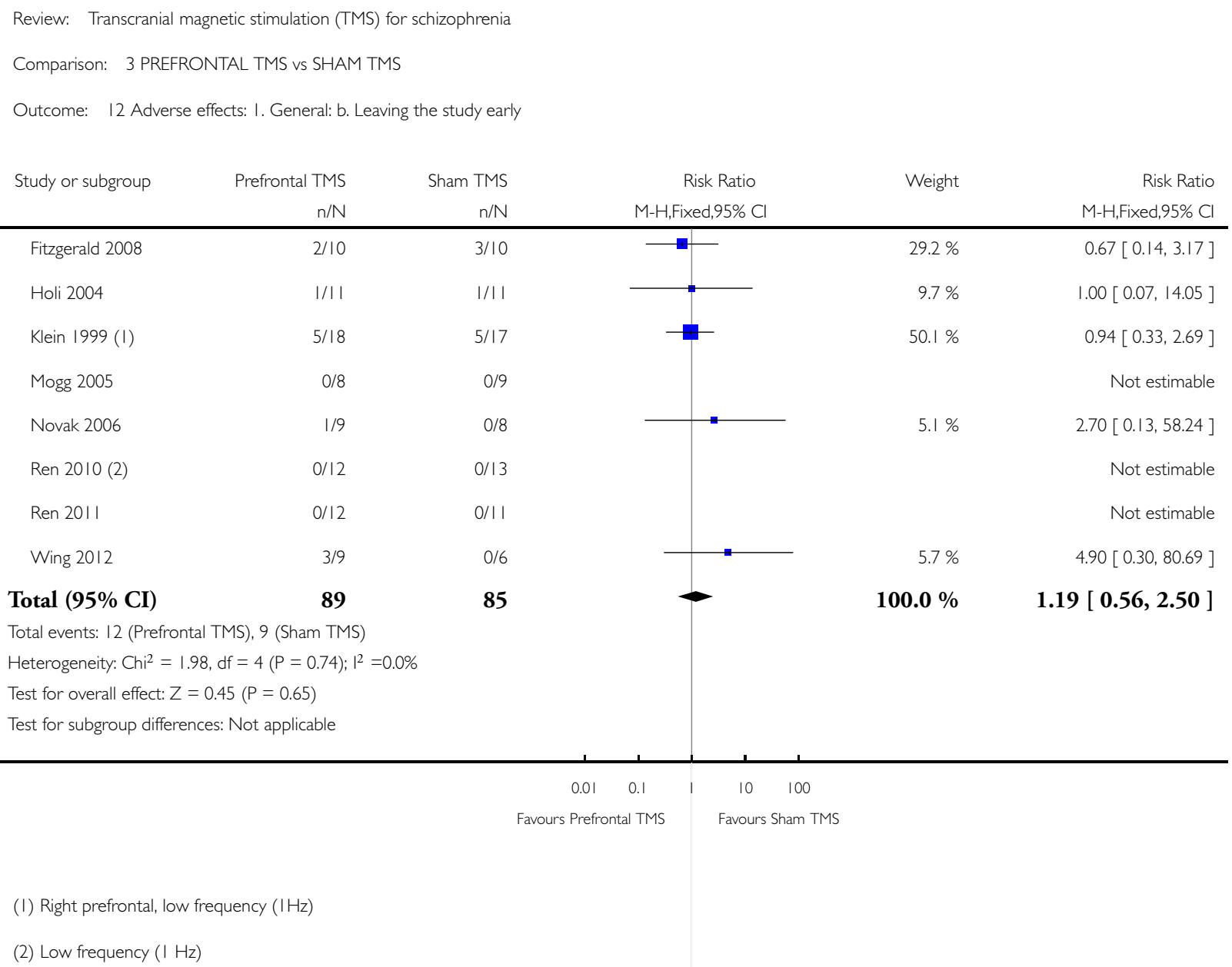


Analysis 3.13. Comparison 3 PREFRONTAL TMS vs SHAM TMS, Outcome 13 Adverse effects: 2 . Specific: a. Various.

Review: Transcranial magnetic stimulation (TMS) for schizophrenia

Comparison: 3 PREFRONTAL TMS vs SHAM TMS

Outcome: 13 Adverse effects: 2. Specific: a. Various

Study or subgroup $\quad$ Prefrontal TMS Sham TMS

$n / N \quad n / N$

Risk Ratio

Weight

Risk Ratio

$n / N$

M-H,Fixed,95\% Cl

$\mathrm{M}-\mathrm{H}, \mathrm{Fixed}, 95 \% \mathrm{Cl}$

I cognition - cognitive difficulties

Klein 1999 ( I)

$0 / 16$

$0 / 15$

Subtotal $(95 \%$ CI $)$

16

Total events: 0 (Prefrontal TMS), 0 (Sham TMS)

Heterogeneity: not applicable

Test for overall effect: not applicable

2 movement disorder - facial twitching

$$
\text { Klein } 1999 \text { (2) }
$$

Total events: 3 (Prefrontal TMS), 0 (Sham TMS)

Heterogeneity: not applicable

Test for overall effect: $Z=1.28(P=0.20)$

3 movement disorder - worsening of pre-existing akathesia

$$
\text { Klein } 1999 \text { (3) }
$$$$
\text { 2/16 }
$$

$0 / 15$

Subtotal (95\% CI)

16

Total events: 2 (Prefrontal TMS), 0 (Sham TMS)

Heterogeneity: not applicable

Test for overall effect: $Z=1.03(P=0.30)$

4 psychiatric - worsening of pre-existing $O C D$

$$
\text { Klein } 1999 \text { (4) }
$$

Subtotal (95\% CI)

Total events: 2 (Prefrontal TMS), 0 (Sham TMS)

Heterogeneity: not applicable

Test for overall effect: $Z=1.03(P=0.30)$

5 other - headache

Fitzgerald 2008

Gao 2009b

$0 / 10$

Holi 2004

$7 / 21$

Klein 1999 (5)

Ren 2010 (6)

Ren 2011

$1 / 10$

2/22

$0 / 11$

$0 / 15$

$2 / 13$

$0 / 11$
15

15

15

Not estimable

Not estimable

$6.59[0.37,117.77]$

$100.0 \%$

$6.59[0.37,117.77]$

$100.0 \%$

$100.0 \%$

$4.71[0.24,90.69]$

$4.71[0.24,90.69$ ]

$100.0 \%$

$4.71[0.24,90.69]$

$100.0 \%$

$4.71[0.24,90.69$ ]

15

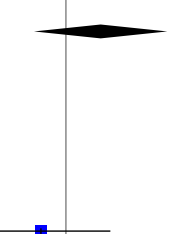

$21.7 \%$

$0.33[0.02,7.32]$

$28.3 \%$

$3.67[0.86,15.68]$

$7.2 \%$

$7.00[0.40,121.39]$

$7.5 \%$

$27.8 \%$

$7.5 \%$

$4.71[0.24,90.69]$

$1.63[0.33,8.11]$

$4.62[0.25,86.72]$

Favours Prefrontal TMS Favours Sham TMS

(Continued ... )

Transcranial magnetic stimulation (TMS) for schizophrenia (Review)

Copyright @ 2015 The Cochrane Collaboration. Published by John Wiley \& Sons, Ltd. 


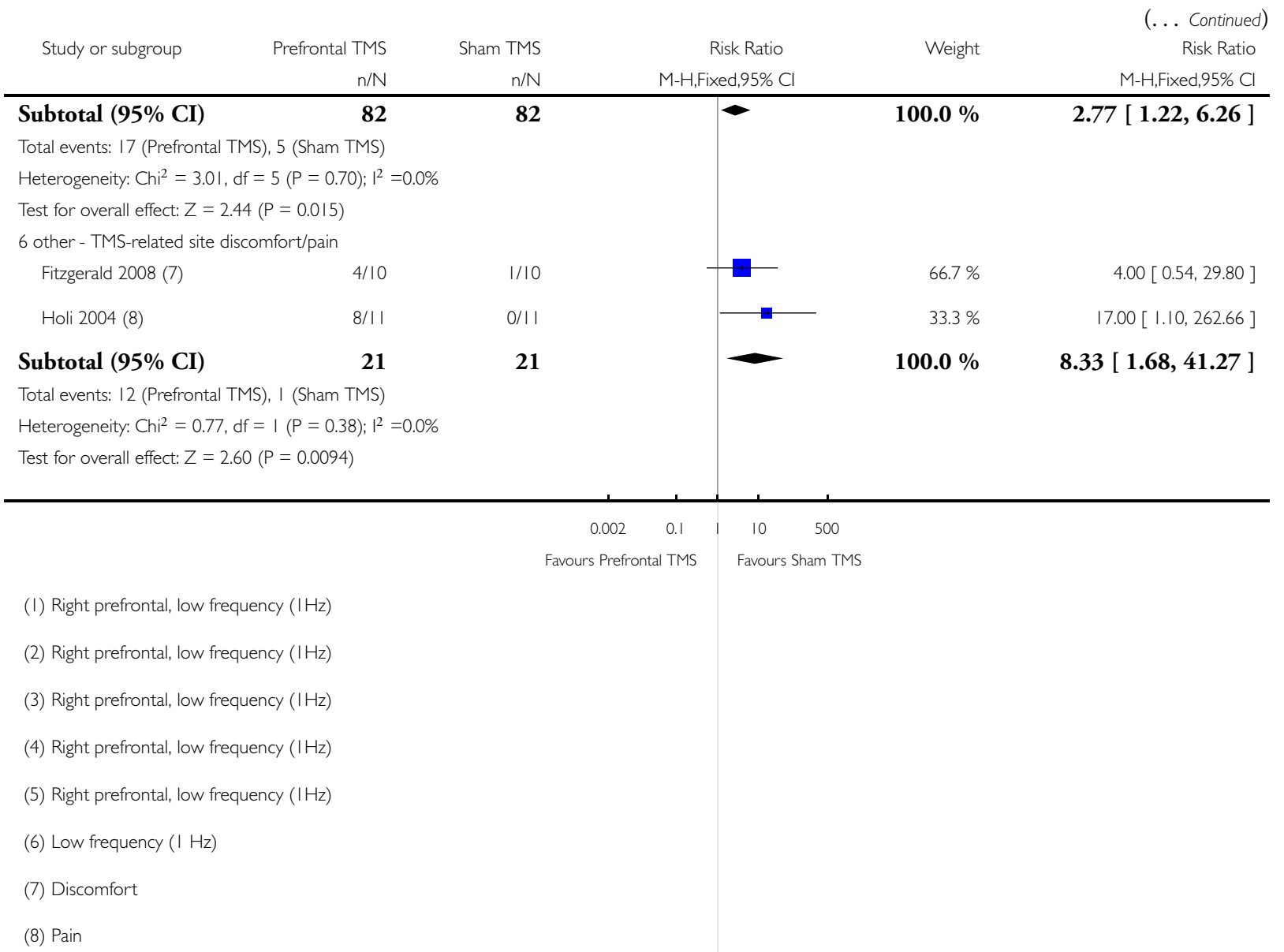


Analysis 3.14. Comparison 3 PREFRONTAL TMS vs SHAM TMS, Outcome I4 Adverse effects: 2 . Specific: b. Average score (CSSES, high = poor).

Review: Transcranial magnetic stimulation (TMS) for schizophrenia

Comparison: 3 PREFRONTAL TMS vs SHAM TMS

Outcome: 14 Adverse effects: 2. Specific: b. Average score (CSSES, high = poor)

\begin{tabular}{|c|c|c|c|c|c|c|c|}
\hline \multirow[t]{2}{*}{ Study or subgroup } & Prefrontal TMS & \multicolumn{2}{|r|}{ Sham TMS } & \multicolumn{2}{|r|}{$\begin{array}{r}\text { Mean } \\
\text { Difference }\end{array}$} & \multirow[t]{2}{*}{ Weight } & \multirow{2}{*}{$\begin{array}{r}\text { Mean } \\
\text { Difference } \\
\text { IV,Fixed,95\% Cl }\end{array}$} \\
\hline & $N$ & Mean(SD) & N & Mean(SD) & IV,Fixed,95\% Cl & & \\
\hline \multicolumn{8}{|l|}{ I cognitive complaints } \\
\hline Mogg 2005 & 8 & $1.8(2.1)$ & 9 & $2.4(2.3)$ & & $100.0 \%$ & $-0.60[-2.69,1.49]$ \\
\hline Subtotal (95\% CI) & 8 & & 9 & & ' & $100.0 \%$ & $-0.60[-2.69,1.49]$ \\
\hline \multicolumn{8}{|c|}{ Heterogeneity: not applicable } \\
\hline \multicolumn{8}{|c|}{ Test for overall effect: $Z=0.56(P=0.57)$} \\
\hline \multicolumn{8}{|l|}{2 subjective side effects } \\
\hline Mogg 2005 & 8 & $7.5(9.2)$ & 9 & $9.4(8.4)$ & & $100.0 \%$ & $-1.90[-|0.3|, 6.5 \mid]$ \\
\hline Subtotal (95\% CI) & 8 & & 9 & & 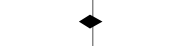 & $100.0 \%$ & $-1.90[-10.31,6.51]$ \\
\hline \multicolumn{8}{|c|}{ Heterogeneity: not applicable } \\
\hline \multicolumn{8}{|c|}{ Test for overall effect: $Z=0.44(P=0.66)$} \\
\hline & & & & -100 & -50 & 100 & \\
\hline & & & & Favours Prefro & al TMS & ham TMS & \\
\hline
\end{tabular}




\section{Analysis 4.I. Comparison 4 PREFRONTAL THETA BURST STIMULATION TMS vs SHAM TMS, Outcome I Global state: Clinical improvement.}

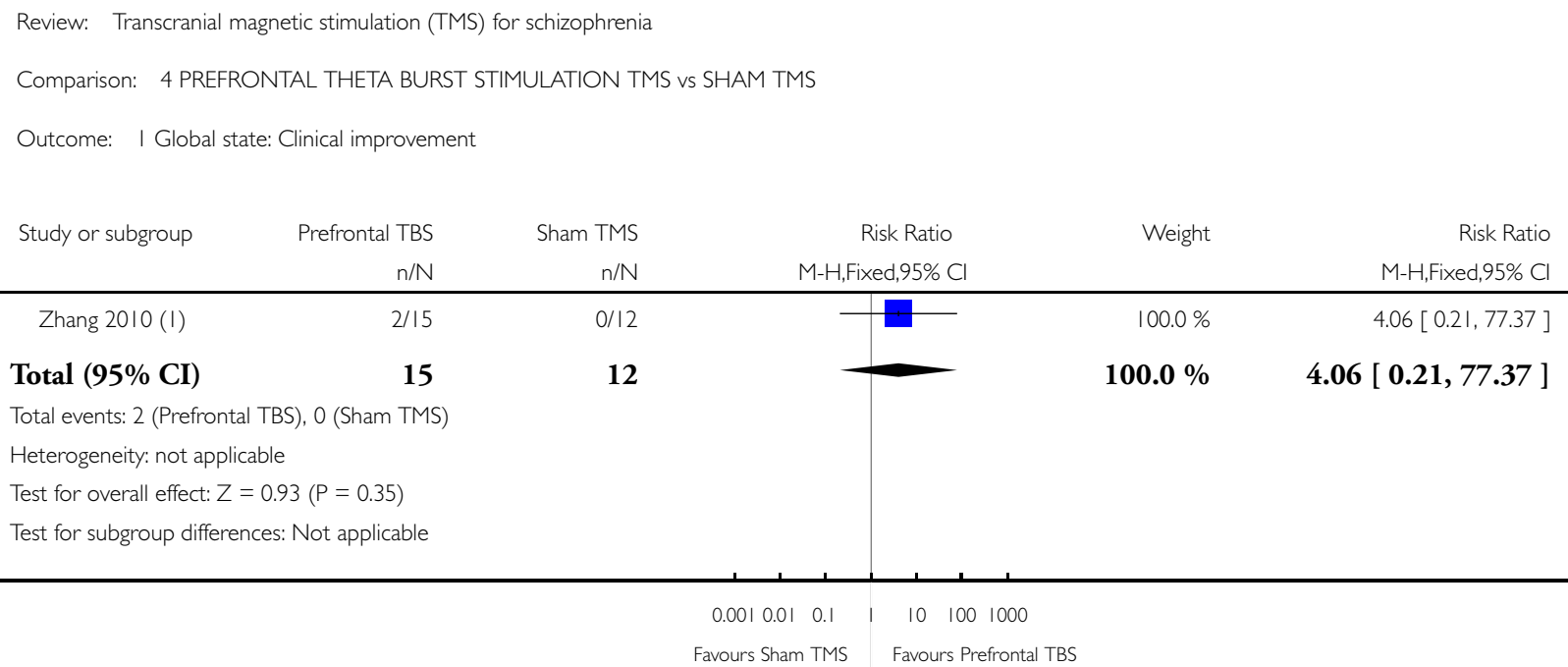

( I) TBS $(50 \mathrm{~Hz})$

Analysis 4.2. Comparison 4 PREFRONTAL THETA BURST STIMULATION TMS vs SHAM TMS, Outcome 2 Mental state: I. General: a. Average overall mental state score (PANSS total, high = poor).

Review: Transcranial magnetic stimulation (TMS) for schizophrenia

Comparison: 4 PREFRONTAL THETA BURST STIMULATION TMS vs SHAM TMS

Outcome: 2 Mental state: I. General: a. Average overall mental state score (PANSS total, high = poor)

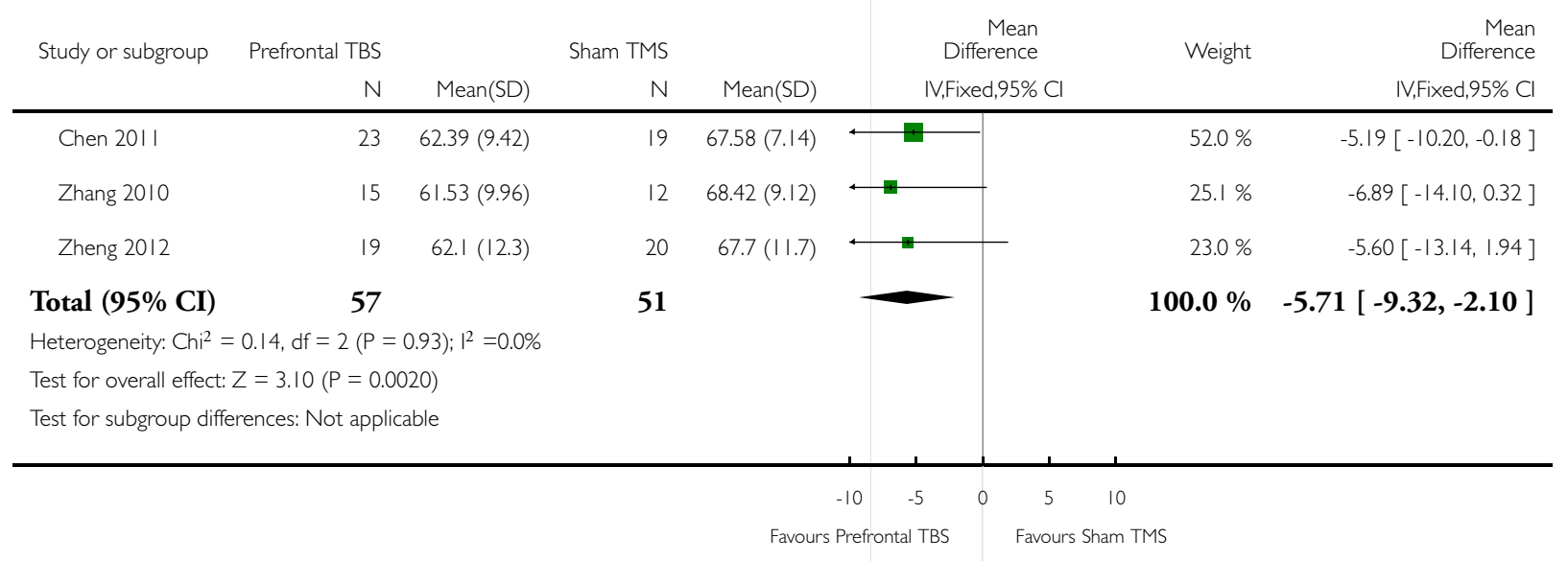

Transcranial magnetic stimulation (TMS) for schizophrenia (Review)

Copyright @ 2015 The Cochrane Collaboration. Published by John Wiley \& Sons, Ltd. 
Analysis 4.3. Comparison 4 PREFRONTAL THETA BURST STIMULATION TMS vs SHAM TMS, Outcome 3 Mental state: I. General: b. Average general psychopathology score (PANSS, high = poor).

Review: Transcranial magnetic stimulation (TMS) for schizophrenia

Comparison: 4 PREFRONTAL THETA BURST STIMULATION TMS vs SHAM TMS

Outcome: 3 Mental state: I. General: b. Average general psychopathology score (PANSS, high = poor)

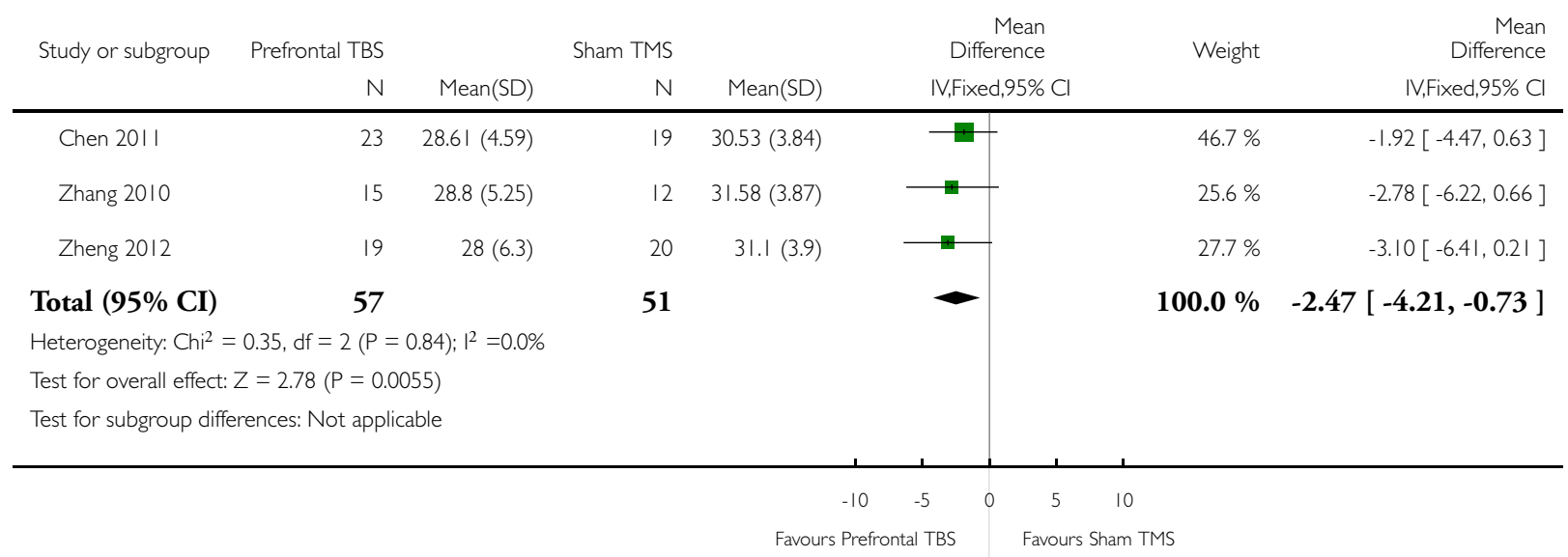


Analysis 4.4. Comparison 4 PREFRONTAL THETA BURST STIMULATION TMS vs SHAM TMS, Outcome 4 Mental state: 2 . Specific: a. Average negative symptom score (various scales).

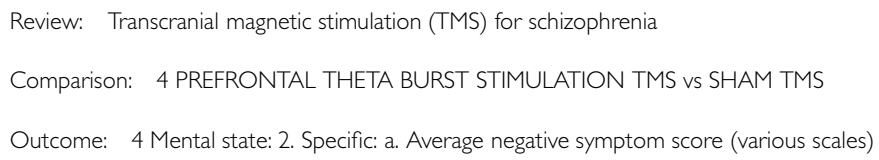

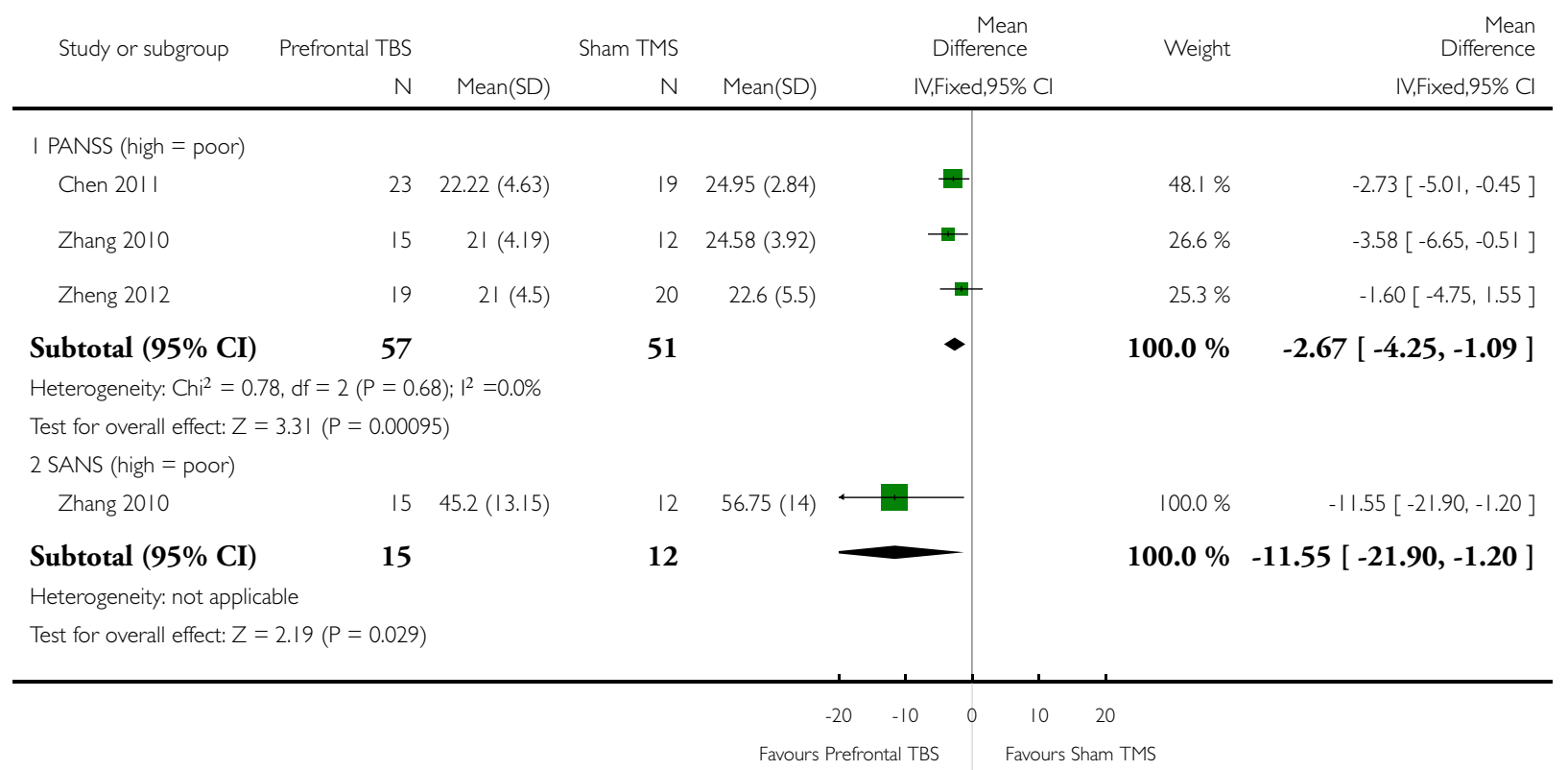


Analysis 4.5. Comparison 4 PREFRONTAL THETA BURST STIMULATION TMS vs SHAM TMS, Outcome 5 Mental state: 2. Specific: b. Average positive symptom score (PANSS, high = poor).

Review: Transcranial magnetic stimulation (TMS) for schizophrenia

Comparison: 4 PREFRONTAL THETA BURST STIMULATION TMS vs SHAM TMS

Outcome: 5 Mental state: 2. Specific: b. Average positive symptom score (PANSS, high = poor)

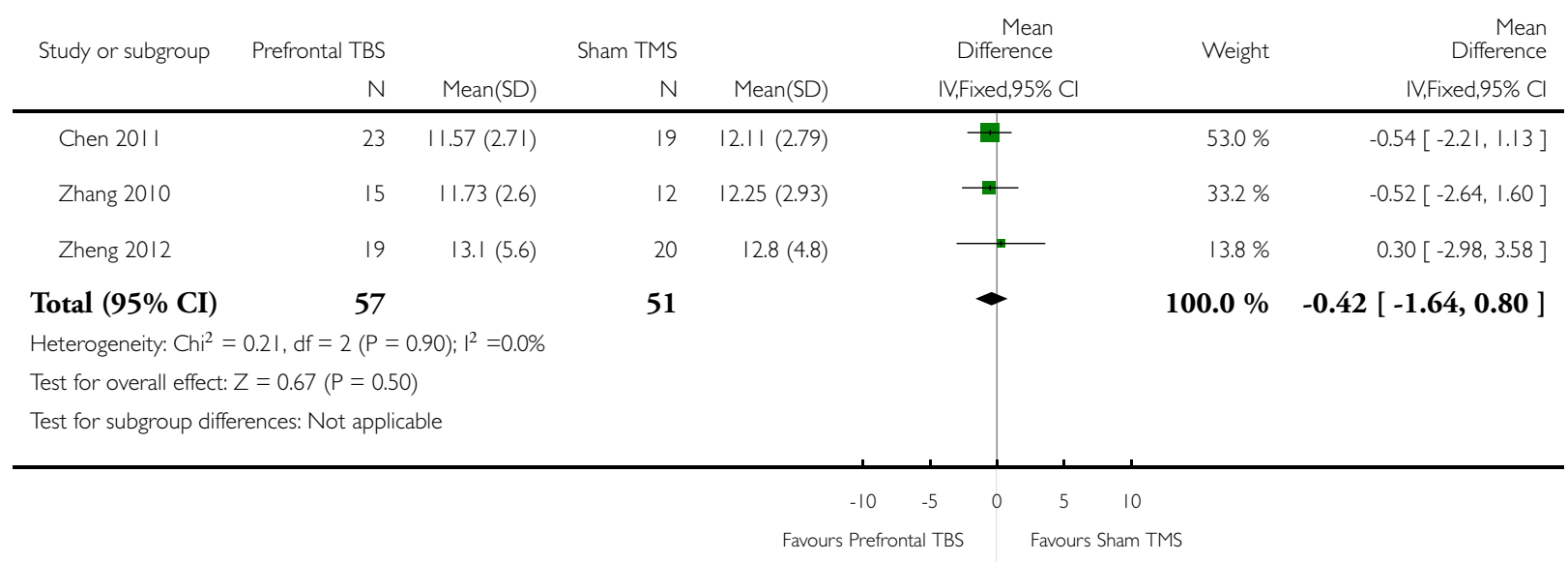


Analysis 4.6. Comparison 4 PREFRONTAL THETA BURST STIMULATION TMS vs SHAM TMS, Outcome 6 Cognitive state: Average score (various measures).

Review: Transcranial magnetic stimulation (TMS) for schizophrenia

Comparison: 4 PREFRONTAL THETA BURST STIMULATION TMS vs SHAM TMS

Outcome: 6 Cognitive state: Average score (various measures)

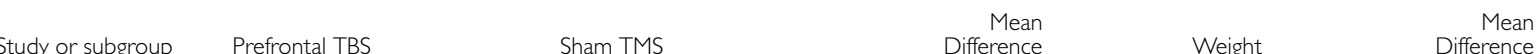

$\begin{array}{lllll}\mathrm{N} & \mathrm{N} \quad \text { Mean(SD) } & \text { Mean(SD) } & \text { IV,Fixed,95\% }, 95 \% \mathrm{Cl}\end{array}$

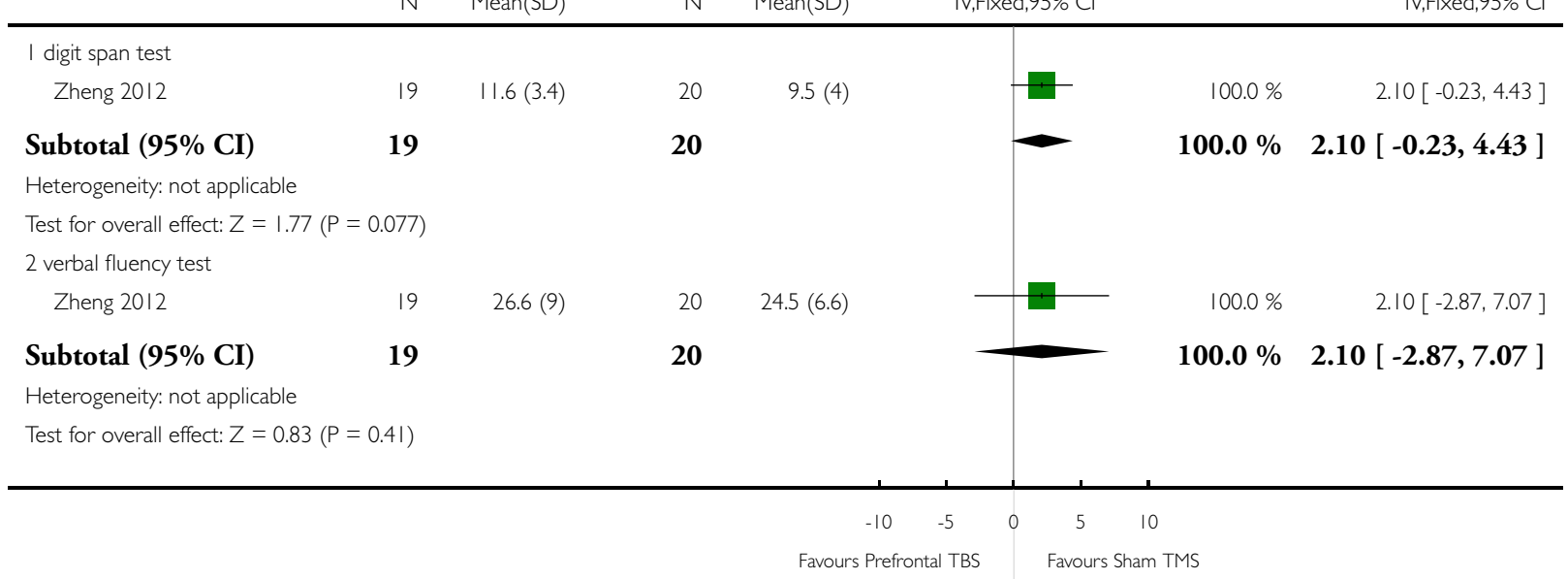




\section{Analysis 4.7. Comparison 4 PREFRONTAL THETA BURST STIMULATION TMS vs SHAM TMS, Outcome}

7 Adverse effects: I. Leaving the study early.

Review: Transcranial magnetic stimulation (TMS) for schizophrenia

Comparison: 4 PREFRONTAL THETA BURST STIMULATION TMS vs SHAM TMS

Outcome: 7 Adverse effects: I. Leaving the study early

\begin{tabular}{|c|c|c|c|c|c|}
\hline \multirow[t]{2}{*}{ Study or subgroup } & Prefrontal TBS & Sham TMS & Risk Ratio & Weight & Risk Ratio \\
\hline & $\mathrm{n} / \mathrm{N}$ & $\mathrm{n} / \mathrm{N}$ & M-H,Fixed,95\% Cl & & M-H,Fixed,95\% Cl \\
\hline Chen 2011 & $1 / 24$ & $3 / 22$ & \begin{tabular}{l|l}
$+1-$ &
\end{tabular} & $59.5 \%$ & $0.31[0.03,2.72]$ \\
\hline Zhang 2010 & $1 / 16$ & $2 / 14$ & \begin{tabular}{l|l}
$\mathbf{1}$ & \\
\end{tabular} & $40.5 \%$ & $0.44[0.04,4.32]$ \\
\hline
\end{tabular}

Total $(95 \%$ CI $)$

40

36

$100.0 \%$

$0.36[0.07,1.74]$

Total events: 2 (Prefrontal TBS), 5 (Sham TMS)

Heterogeneity: $\mathrm{Chi}^{2}=0.05, \mathrm{df}=\mathrm{I}(\mathrm{P}=0.82) ; \mathrm{I}^{2}=0.0 \%$

Test for overall effect: $Z=1.27(P=0.20)$

Test for subgroup differences: Not applicable 
Analysis 4.8. Comparison 4 PREFRONTAL THETA BURST STIMULATION TMS vs SHAM TMS, Outcome 8 Adverse effects: 2. Specific.

\begin{tabular}{|c|c|c|c|c|c|}
\hline \multicolumn{6}{|c|}{ Comparison: 4 PREFRONTAL THETA BURST STIMULATION TMS vs SHAM TMS } \\
\hline \multicolumn{6}{|c|}{ Outcome: 8 Adverse effects: 2 . Specific } \\
\hline \multirow[t]{2}{*}{ Study or subgroup } & Prefrontal TBS & Sham TMS & Risk Ratio & Weight & Risk Ratio \\
\hline & $\mathrm{n} / \mathrm{N}$ & $\mathrm{n} / \mathrm{N}$ & M-H,Fixed,95\% Cl & & $\mathrm{M}-\mathrm{H}$, Fixed,95\% Cl \\
\hline \multicolumn{6}{|l|}{ I headache } \\
\hline Zhang 2010 & $2 / 15$ & $3 / 12$ & & $100.0 \%$ & $0.53[0.11,2.70]$ \\
\hline Subtotal $(95 \% \mathrm{CI})$ & 15 & 12 & & $100.0 \%$ & $0.53[0.11,2.70]$ \\
\hline \multicolumn{6}{|c|}{ Total events: 2 (Prefrontal TBS), 3 (Sham TMS) } \\
\hline \multicolumn{6}{|c|}{ Heterogeneity: not applicable } \\
\hline \multicolumn{6}{|c|}{ Test for overall effect: $Z=0.76(P=0.45)$} \\
\hline \multicolumn{6}{|c|}{2 sleep disorder } \\
\hline Zhang 2010 & $0 / 15$ & $1 / 12$ & & $100.0 \%$ & $0.27[0.01,6.11]$ \\
\hline Subtotal $(95 \% \mathrm{CI})$ & 15 & 12 & & $100.0 \%$ & $0.27[0.01,6.11]$ \\
\hline \multicolumn{6}{|c|}{ Total events: 0 (Prefrontal TBS), I (Sham TMS) } \\
\hline \multicolumn{6}{|c|}{ Heterogeneity: not applicable } \\
\hline Test for overall effect: $Z=$ & $P=0.41)$ & & & & \\
\hline
\end{tabular}




\title{
Analysis 5.I. Comparison 5 SENSITIVITY ANALYSIS: PREFRONTAL THETA BURST STIMULATION TMS vs SHAM TMS, Outcome I Global state: Clinical improvement.
}

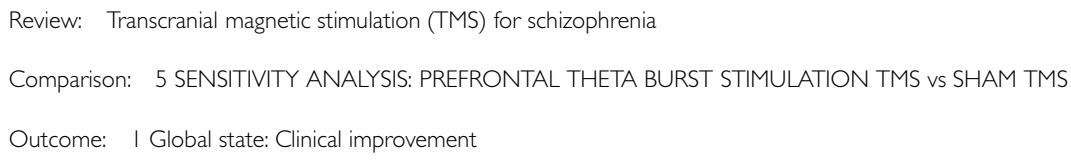

\begin{tabular}{|c|c|c|c|c|c|}
\hline \multirow[t]{2}{*}{ Study or subgroup } & Prefrontal TBS & Sham TMS & Risk Ratio & Weight & Risk Ratio \\
\hline & $\mathrm{n} / \mathrm{N}$ & $\mathrm{n} / \mathrm{N}$ & M-H,Fixed,95\% Cl & & M-H,Fixed,95\% Cl \\
\hline \multicolumn{6}{|c|}{ I including only people who completed the studies } \\
\hline Zhang $2010(1)$ & $2 / 15$ & $0 / 12$ & & $100.0 \%$ & $4.06[0.21,77.37]$ \\
\hline Subtotal (95\% CI) & 15 & 12 & & $100.0 \%$ & $4.06[0.21,77.37]$ \\
\hline \multicolumn{6}{|c|}{ Total events: 2 (Prefrontal TBS), 0 (Sham TMS) } \\
\hline \multicolumn{6}{|c|}{ Heterogeneity: not applicable } \\
\hline \multicolumn{6}{|c|}{ Test for overall effect: $Z=0.93(P=0.35)$} \\
\hline \multicolumn{6}{|c|}{2 Intention-to-treat analysis } \\
\hline Zhang 2010 (2) & $2 / 16$ & $0 / 14$ & & $100.0 \%$ & $4.41[0.23,84.79]$ \\
\hline Subtotal (95\% CI) & 16 & 14 & & $100.0 \%$ & $4.41[0.23,84.79]$ \\
\hline \multicolumn{6}{|c|}{ Total events: 2 (Prefrontal TBS), 0 (Sham TMS) } \\
\hline \multicolumn{6}{|c|}{ Heterogeneity: not applicable } \\
\hline \multicolumn{6}{|c|}{ Test for overall effect: $Z=0.98(P=0.33)$} \\
\hline \multicolumn{6}{|c|}{ Test for subgroup differences: $\mathrm{Chi}^{2}=0.00, \mathrm{df}=\mathrm{I}(\mathrm{P}=0.97), \mathrm{I}^{2}=0.0 \%$} \\
\hline
\end{tabular}
( I) TBS $(50 \mathrm{~Hz})$
(2) $\operatorname{TBS}(50 \mathrm{~Hz})$

\section{ADDITIONAL TABLES}

Table 1. Magstim Company Limited

\author{
Contact details \\ Mr John H Starzewski \\ Managing Director \\ Magstim Limited \\ Spring Gardens \\ Whitland SA34 0HR \\ UK \\ Telephone: +44 1994241093 \\ URL: http://www.magstim.com/index.html
}


Table 2. Skewed data - Temporoparietal TMS vs Sham TMS

\begin{tabular}{|c|c|c|c|c|c|c|c|}
\hline Study & Outcome & TMS Mean & TMS SD & TMS N & Sham TMS Mean & Sham TMS SD & Sham TMS N \\
\hline \multirow[t]{2}{*}{ De Jesus 2011} & $\begin{array}{l}\text { Mental } \\
\text { state: specific } \\
\text { - BPRS de- } \\
\text { pressive factor } \\
\text { (high = poor) }\end{array}$ & 2.25 & 2.18 & 8 & 3.56 & 3.24 & 9 \\
\hline & $\begin{array}{l}\text { Men- } \\
\text { tal state: spe- } \\
\text { cific - BPRS } \\
\text { excitement } \\
\text { factor (high = } \\
\text { poor) }\end{array}$ & 1.25 & 1.28 & 8 & 3.89 & 4.79 & 9 \\
\hline \multirow[t]{2}{*}{ Poulet 2005} & $\begin{array}{l}\text { Mental state: } \\
\text { Specific-posi- } \\
\text { tive symptoms } \\
\text { (SAPS, high = } \\
\text { poor) }\end{array}$ & 51.2 & 13.5 & 5 & 47.8 & 25.2 & 5 \\
\hline & $\begin{array}{l}\text { Mental state: } \\
\text { Specific - hal- } \\
\text { lucina- } \\
\text { tions (AHRS, } \\
\text { high = poor) }\end{array}$ & 14.6 & 12.1 & 5 & 20.8 & 3.4 & 5 \\
\hline \multirow[t]{2}{*}{$\begin{array}{l}\text { Rosenberg } \\
2012\end{array}$} & $\begin{array}{l}\text { Mental state: } \\
\text { Specific- posi- } \\
\text { tive symptoms } \\
\text { (SAPS, high = } \\
\text { poor) }\end{array}$ & 26 & 20 & 10 & 37 & 16 & 10 \\
\hline & $\begin{array}{l}\text { Men- } \\
\text { tal state: Spe- } \\
\text { cific - nega- } \\
\text { tive symptoms } \\
\text { (SANS, high = } \\
\text { poor) }\end{array}$ & 32 & 27 & 10 & 39 & 23 & 10 \\
\hline \multirow[t]{2}{*}{ Xu 2011} & $\begin{array}{l}\text { Cogni- } \\
\text { tive state: CPT } \\
\text { false items }\end{array}$ & 1.94 & 2.04 & 18 & 1.41 & 2.12 & 17 \\
\hline & $\begin{array}{l}\text { Cogni- } \\
\text { tive state: CPT } \\
\text { missed items }\end{array}$ & 6.28 & 4.5 & 18 & 7.59 & 6.68 & 17 \\
\hline
\end{tabular}

AHRS - Auditory Hallucination Rating Scale

BPRS - Brief Psychiatric Rating Scale

Transcranial magnetic stimulation (TMS) for schizophrenia (Review)

Copyright @ 2015 The Cochrane Collaboration. Published by John Wiley \& Sons, Ltd. 
CPT - Continuous Performance Test

SANS - Scale for Assessment of Negative Symptoms

SAPS - Scale for the Assessment of Positive Symptoms

Table 3. Cognitive outcomes - Temporoparietal TMS vs Sham TMS

\begin{tabular}{|c|c|c|c|c|c|c|c|c|c|}
\hline \multirow[t]{2}{*}{ Outcome } & \multirow{2}{*}{$\begin{array}{l}\text { Change } \\
\text { / endpoint } \\
\text { data }\end{array}$} & \multirow[t]{2}{*}{ Study } & \multicolumn{3}{|l|}{ TMS } & \multicolumn{3}{|c|}{ Sham TMS } & \multirow[t]{2}{*}{ Mean difference $[95 \% \mathrm{CI}]$} \\
\hline & & & Mean & SD & $\mathbf{N}$ & Mean & SD & $\mathbf{N}$ & \\
\hline $\begin{array}{l}\text { Animal } \\
\text { naming }\end{array}$ & Change & $\begin{array}{l}\text { Hoffman } \\
2005\end{array}$ & -0.77 & 4.41 & 26 & 0.9 & 4.17 & 21 & $-1.67[-4.13$ to 0.79$]$ \\
\hline $\begin{array}{l}\mathrm{CPT} \text { re- } \\
\text { action time } \\
(\mathrm{ms})\end{array}$ & Endpoint & Xu 2011 & 926.22 & 126.2 & 18 & 959 & 109.35 & 17 & $-32.78[-110.89$ to 45.33$]$ \\
\hline $\begin{array}{l}\text { Con- } \\
\text { trolled oral } \\
\text { word asso- } \\
\text { ciation }\end{array}$ & Change & $\begin{array}{l}\text { Hoffman } \\
2005\end{array}$ & 2.57 & 7.07 & 26 & 2.53 & 0.91 & 21 & $0.04[-2.71$ to 2.79$]$ \\
\hline $\begin{array}{l}\text { CVLT } 1 \\
\text { score }\end{array}$ & Change & $\begin{array}{l}\text { Hoffman } \\
2005\end{array}$ & 0.88 & 6.61 & 26 & -0.19 & 1.69 & 21 & $1.07[-1.57$ to 3.71$]$ \\
\hline $\begin{array}{l}\text { CVLT B } \\
\text { score }\end{array}$ & Change & $\begin{array}{l}\text { Hoffman } \\
2005\end{array}$ & 0.15 & 1.76 & 26 & 0.48 & 3.1 & 21 & $-0.33[-1.82$ to 1.16$]$ \\
\hline $\begin{array}{l}\text { CVLT } \\
\text { Long-de- } \\
\text { lay free re- } \\
\text { call }\end{array}$ & Change & $\begin{array}{l}\text { Hoffman } \\
2005\end{array}$ & -1.69 & 2.28 & 26 & -1.48 & 3.1 & 21 & $-0.21[-1.80$ to 1.38$]$ \\
\hline $\begin{array}{l}\text { CVLT } \\
\text { Recog- } \\
\text { nition dis- } \\
\text { crimina- } \\
\text { tive ability }\end{array}$ & Change & $\begin{array}{l}\text { Hoffman } \\
2005\end{array}$ & -0.007 & 0.08 & 26 & -0.014 & 0.088 & 21 & $0.01[-0.04$ to 0.06$]$ \\
\hline $\begin{array}{l}\text { CVLT } \\
\text { Short-de- } \\
\text { lay free re- } \\
\text { call }\end{array}$ & Change & $\begin{array}{l}\text { Hoffman } \\
2005\end{array}$ & -0.92 & 2.15 & 26 & -0.71 & 3 & 21 & $-0.21[-1.74$ to 1.32$]$ \\
\hline $\begin{array}{l}\text { CVLT1-5 } \\
\text { Total score }\end{array}$ & Change & $\begin{array}{l}\text { Hoffman } \\
2005\end{array}$ & -3.42 & 7.08 & 26 & -3.14 & 8.21 & 21 & $-0.28[-4.72$ to 4.16$]$ \\
\hline $\begin{array}{l}\text { Digit recall } \\
\text { (distrac- } \\
\text { tion) }\end{array}$ & Change & $\begin{array}{l}\text { Hoffman } \\
2005\end{array}$ & 0.61 & 3.93 & 26 & -0.9 & 4.77 & 21 & $1.51[-1.03$ to 4.05$]$ \\
\hline
\end{tabular}

Transcranial magnetic stimulation (TMS) for schizophrenia (Review) 
Table 3. Cognitive outcomes - Temporoparietal TMS vs Sham TMS

(Continued)

\begin{tabular}{|c|c|c|c|c|c|c|c|c|c|}
\hline $\begin{array}{l}\text { Digit recall } \\
\text { (non-dis- } \\
\text { traction) }\end{array}$ & Change & $\begin{array}{l}\text { Hoffman } \\
2005\end{array}$ & -0.12 & 4.66 & 26 & 1.19 & 4.08 & 21 & $-1.31[-3.81$ to 1.19$]$ \\
\hline $\begin{array}{l}\text { Digit sym- } \\
\text { bol }\end{array}$ & Change & $\begin{array}{l}\text { Hoffman } \\
2005\end{array}$ & 3.15 & 7.76 & 26 & 2.95 & 7.72 & 21 & $0.20[-4.25$ to 4.65$]$ \\
\hline $\begin{array}{l}\text { Grooved } \\
\text { pegboard, } \\
\text { dominant }\end{array}$ & Change & $\begin{array}{l}\text { Hoffman } \\
2005\end{array}$ & 4.65 & 15.1 & 26 & 5.57 & 48.8 & 21 & $-0.92[-22.58$ to 20.74$]$ \\
\hline $\begin{array}{l}\text { Grooved } \\
\text { pegboard, } \\
\text { nondomi- } \\
\text { nant }\end{array}$ & Change & $\begin{array}{l}\text { Hoffman } \\
2005\end{array}$ & 6.46 & 15.5 & 26 & 12 & 31.5 & 21 & $-5.54[-20.27$ to 9.19$]$ \\
\hline $\begin{array}{l}\text { Tempo- } \\
\text { ral orienta- } \\
\text { tion }\end{array}$ & Change & $\begin{array}{l}\text { Hoffman } \\
2005\end{array}$ & -0.154 & 1.82 & 26 & -0.35 & 2.39 & 21 & $0.20[-1.04$ to 1.43$]$ \\
\hline $\begin{array}{l}\text { Trail Mak- } \\
\text { ing A }\end{array}$ & Change & $\begin{array}{l}\text { Hoffman } \\
2005\end{array}$ & 2.58 & 12.6 & 26 & -0.42 & 8.23 & 21 & $3.00[-2.99$ to 8.99$]$ \\
\hline $\begin{array}{l}\text { Trail Mak- } \\
\text { ing B }\end{array}$ & Change & $\begin{array}{l}\text { Hoffman } \\
2005\end{array}$ & 19.5 & 48.3 & 26 & 25.3 & 50.4 & 21 & $-5.80[-34.25$ to 22.65$]$ \\
\hline $\begin{array}{l}\text { WCST } \\
\text { completed } \\
\text { categories }\end{array}$ & Endpoint & Xu 2011 & 2.17 & 2.23 & 18 & 2.82 & 2.32 & 17 & $-0.65[-2.16$ to 0.86$]$ \\
\hline $\begin{array}{l}\text { WCST } \\
\text { completed } \\
\text { categories }\end{array}$ & Endpoint & Liu 2008 & 5.3 & 1 & 11 & 4.5 & 1.4 & 10 & $0.80[-0.25$ to 1.85$]$ \\
\hline $\begin{array}{l}\text { WCST } \\
\text { conceptu- } \\
\text { alisation } \\
\text { level }\end{array}$ & Endpoint & Xu 2011 & 61 & 24.13 & 18 & 64.12 & 24.93 & 17 & $-3.12[-19.39$ to 13.15$]$ \\
\hline WCST CR & Endpoint & Liu 2008 & 54 & 9 & 11 & 49 & 11 & 10 & $5.00[-3.65$ to 13.65$]$ \\
\hline $\begin{array}{l}\text { WCST } \\
\text { FM }\end{array}$ & Endpoint & Liu 2008 & 13.6 & 7.3 & 11 & 9.8 & 11.2 & 10 & $3.80[-4.37$ to 11.97$]$ \\
\hline $\begin{array}{l}\text { WCST } \\
\text { NPE }\end{array}$ & Endpoint & Liu 2008 & 17.2 & 7.6 & 11 & 20.9 & 5.6 & 10 & $-3.70[-9.38$ to 1.98$]$ \\
\hline $\begin{array}{l}\text { WCST } \\
\text { PCLR }\end{array}$ & Endpoint & Liu 2008 & 60.5 & 19.2 & 11 & 45.9 & 18.6 & 10 & $14.60[-1.58$ to 30.78$]$ \\
\hline
\end{tabular}


Table 3. Cognitive outcomes - Temporoparietal TMS vs Sham TMS (Continued)

\begin{tabular}{|c|c|c|c|c|c|c|c|c|c|}
\hline WCST PE & Endpoint & Liu 2008 & 45.3 & 23.6 & 11 & 50.8 & 22.3 & 10 & $-5.50[-25.14$ to 14.14$]$ \\
\hline $\begin{array}{l}\text { WCST } \\
\text { PNPE }\end{array}$ & Endpoint & Liu 2008 & 31.3 & 13.8 & 11 & 32.4 & 14.5 & 10 & $-1.10[-13.24$ to 11.04$]$ \\
\hline $\begin{array}{l}\text { WCST } \\
\text { PPE }\end{array}$ & Endpoint & Liu 2008 & 68.7 & 13.8 & 11 & 67.6 & 14.6 & 10 & $1.10[-11.08$ to 13.28$]$ \\
\hline WCST PR & Endpoint & Liu 2008 & 41 & 13.3 & 11 & 34.2 & 15 & 10 & $6.80[-5.37$ to 18.97$]$ \\
\hline WCST Ra & Endpoint & Xu 2011 & 122.67 & 15.18 & 18 & 126.06 & 5.02 & 17 & $-3.39[-10.80$ to 4.02$]$ \\
\hline WCST Re & Endpoint & Xu 2011 & 56.11 & 22.99 & 18 & 53.88 & 16.14 & 17 & $2.23[-10.87$ to 15.33$]$ \\
\hline WCST Rp & Endpoint & Xu 2011 & 45.72 & 20.18 & 18 & 60.12 & 19.23 & 17 & $-14.40[-27.46$ to -1.34$]$ \\
\hline WCST TA & Endpoint & Liu 2008 & 117 & 18 & 11 & 121 & 10 & 10 & $-4.00[-16.31$ to 8.31$]$ \\
\hline $\begin{array}{l}\text { WCST } \\
\text { TCFC }\end{array}$ & Endpoint & Liu 2008 & 21.7 & 14 & 11 & 29.0 & 13.4 & 10 & $-7.30[-19.02$ to 4.42$]$ \\
\hline WCST TE & Endpoint & Liu 2008 & 63 & 24 & 11 & 72 & 20 & 10 & $-9.00[-27.84$ to 9.84$]$ \\
\hline $\begin{array}{l}\text { WCST } \\
\text { time (sec) }\end{array}$ & Endpoint & Liu 2008 & 405 & 174 & 11 & 411 & 177 & 10 & $-6.00[-156.36$ to 144.36$]$ \\
\hline $\begin{array}{l}\text { WCST se- } \\
\text { lective er- } \\
\text { ror rate } \\
(\%)\end{array}$ & Endpoint & Liu 2008 & 51.6 & 15.3 & 11 & 58.4 & 12.3 & 10 & $-6.80[-18.63$ to 5.03$]$ \\
\hline $\begin{array}{l}\text { WCST } \\
\text { correct } \\
\text { thinking } \\
\text { time (sec) }\end{array}$ & Endpoint & Liu 2008 & 172 & 67 & 11 & 160 & 96 & 10 & $12.00[-59.47$ to 83.47$]$ \\
\hline $\begin{array}{l}\text { WCST er- } \\
\text { ror think- } \\
\text { ing time } \\
(\mathrm{sec})\end{array}$ & Endpoint & Liu 2008 & 233 & 128 & 11 & 251 & 100 & 10 & $-18.00[-115.79$ to 79.79$]$ \\
\hline WRAT-R & Change & $\begin{array}{l}\text { Hoffman } \\
2005\end{array}$ & 0.19 & 2.54 & 26 & 0.33 & 2.81 & 21 & $6.80[-5.37$ to 18.97$]$ \\
\hline
\end{tabular}

CPT - Continuous performance test

CVLT - California verbal learning test

WCST - Wisconsin card sorting test

WRAT-R - wide range achievement test - reading 
Table 4. Skewed data - Temporoparietal TMS vs standard treatment

\begin{tabular}{|c|c|c|c|c|c|c|c|}
\hline Study & Outcome & TMS Mean & TMS SD & TMS N & Sham TMS Mean & Sham TMS SD & Sham TMS N \\
\hline Bagati 2009 & $\begin{array}{l}\text { Mental state: } \\
\text { Specific - hal- } \\
\text { lucinations } \\
\text { (AHRS, high = } \\
\text { poor) }\end{array}$ & 6.7 & 8.64 & 20 & 27.95 & 7.51 & 20 \\
\hline
\end{tabular}

AHRS - Auditory Hallucination Rating Scale

Table 5. Skewed data - Prefrontal TMS vs Sham TMS

\begin{tabular}{|c|c|c|c|c|c|c|c|}
\hline Study & Outcome & TMS Mean & TMS SD & TMS N & Sham TMS Mean & Sham TMS SD & Sham TMS N \\
\hline \multirow[t]{2}{*}{ Barr 2013} & $\begin{array}{l}\text { Men- } \\
\text { tal state: Spe- } \\
\text { cific - nega- } \\
\text { tive symptoms } \\
\text { (PANSS, high } \\
\text { = poor) }\end{array}$ & 26.15 & 13.45 & 13 & 31.42 & 13.19 & 12 \\
\hline & $\begin{array}{l}\text { Men- } \\
\text { tal state: Spe- } \\
\text { cific - depres- } \\
\text { sive symptoms } \\
\text { (CDS, high = } \\
\text { poor ) }\end{array}$ & 2.38 & 2.06 & 13 & 1.67 & 1.92 & 12 \\
\hline \multirow[t]{2}{*}{$\begin{array}{l}\text { Fitzgerald } \\
2008\end{array}$} & $\begin{array}{l}\text { Mental } \\
\text { state: Specific- } \\
\text { positive symp- } \\
\text { toms (PANSS, } \\
\text { high = poor) } \\
\text { (LOCF) }\end{array}$ & 10.8 & 7.0 & 10 & 7.3 & 2.9 & 10 \\
\hline & $\begin{array}{l}\text { Mental } \\
\text { state: Depres- } \\
\text { sion (CDRS, } \\
\text { high = poor) } \\
\text { (LOCF) }\end{array}$ & 7.2 & 5.9 & 10 & 3.5 & 3.8 & 10 \\
\hline
\end{tabular}

CDRS - Calgary depression rating scale

CDS - Calgary depression scale

PANSS - positive and negative symptoms scale

LOCF - last observation carried forward 
Table 6. Cognitive outcomes - Prefrontal TMS vs Sham TMS

\begin{tabular}{|c|c|c|c|c|c|c|c|c|c|}
\hline \multirow[t]{2}{*}{ Outcome } & \multirow{2}{*}{$\begin{array}{l}\text { Change / } \\
\text { endpoint }\end{array}$} & \multirow[t]{2}{*}{ Study } & \multicolumn{3}{|l|}{ TMS } & \multicolumn{3}{|c|}{ Sham TMS } & \multirow[t]{2}{*}{ Mean difference $[95 \% \mathrm{CI}]$} \\
\hline & & & Mean & SD & $\mathbf{N}$ & Mean & SD & $\mathbf{N}$ & \\
\hline $\begin{array}{l}\text { AVLT (low } \\
=\text { poor) }\end{array}$ & Endpoint & $\begin{array}{l}\text { Novak } \\
2006\end{array}$ & 45.6 & 6.8 & 8 & 44.9 & 8 & 8 & $0.70[-6.58$ to 7.98$]$ \\
\hline $\begin{array}{l}\text { COWAT } \\
\text { (within } \\
24 \text { hours of } \\
\text { TMS) }\end{array}$ & Endpoint & $\begin{array}{l}\text { Mogg } \\
2005\end{array}$ & 11.6 & 5.3 & 8 & 10.9 & 5.0 & 9 & $0.70[-4.22$ to 5.62$]$ \\
\hline $\begin{array}{l}\text { COWAT } \\
(2 \\
\text { weeks after } \\
\text { TMS) }\end{array}$ & Endpoint & $\begin{array}{l}\text { Mogg } \\
2005\end{array}$ & 14.2 & 5.7 & 8 & 9.1 & 2.7 & 9 & $5.10[0.77$ to 9.43$]$ \\
\hline $\begin{array}{l}\text { Digit span } \\
\text { test }\end{array}$ & Endpoint & $\begin{array}{l}\text { Zheng } \\
2012\end{array}$ & 10.5 & 3.5763 & 38 & 9.5 & 4 & 17 & $1.00[-15.70$ to 17.70$]$ \\
\hline $\begin{array}{l}\text { Grooved } \\
\text { pegboard } \\
\text { (seconds } \\
\text { to comple- } \\
\text { tion) } \\
\text { (within } \\
24 \text { hours of } \\
\text { TMS) }\end{array}$ & Endpoint & $\begin{array}{l}\text { Mogg } \\
2005\end{array}$ & 117.1 & 32.0 & 8 & 108.6 & 41.2 & 9 & $8.50[-26.37$ to 43.37$]$ \\
\hline $\begin{array}{l}\text { Grooved } \\
\text { pegboard } \\
\text { (seconds to } \\
\text { com- } \\
\text { pletion) (2 } \\
\text { weeks after } \\
\text { TMS) }\end{array}$ & Endpoint & $\begin{array}{l}\text { Mogg } \\
2005\end{array}$ & 109 & 29.5 & 8 & 98.5 & 16 & 9 & $10.50[-12.46$ to 33.46$]$ \\
\hline $\begin{array}{l}\text { HVLT- } \\
\text { de- } \\
\text { layed recall } \\
\text { (within } \\
24 \text { hours of } \\
\text { TMS) }\end{array}$ & Endpoint & $\begin{array}{l}\text { Mogg } \\
2005\end{array}$ & 4.4 & 2.3 & 8 & 4.4 & 1.1 & 9 & $0.00[-1.75$ to 1.75$]$ \\
\hline $\begin{array}{l}\text { HVLT- } \\
\text { delayed re- } \\
\text { call }(2 \\
\text { weeks after } \\
\text { TMS) }\end{array}$ & Endpoint & $\begin{array}{l}\text { Mogg } \\
2005\end{array}$ & 5.4 & 2.7 & 8 & 3.3 & 1.0 & 9 & $2.10[0.12$ to 4.08$]$ \\
\hline
\end{tabular}


Table 6. Cognitive outcomes - Prefrontal TMS vs Sham TMS (Continued)

\begin{tabular}{|c|c|c|c|c|c|c|c|c|c|}
\hline $\begin{array}{l}\text { HVLT- } \\
\text { imme- } \\
\text { diate recall } \\
\text { (within } \\
24 \text { hours of } \\
\text { TMS) }\end{array}$ & Endpoint & $\begin{array}{l}\text { Mogg } \\
2005\end{array}$ & 6.3 & 2.0 & 8 & 5.6 & 1.1 & 9 & $0.70[-0.86$ to 2.26$]$ \\
\hline $\begin{array}{l}\text { HVLT- } \\
\text { immedi- } \\
\text { ate recall ( } 2 \\
\text { weeks after } \\
\text { TMS) }\end{array}$ & Endpoint & $\begin{array}{l}\text { Mogg } \\
2005\end{array}$ & 7.4 & 2.8 & 8 & 5 & 0.8 & 9 & $2.40[0.39$ to 4.41$]$ \\
\hline $\begin{array}{l}\text { Stroop test } \\
\text { (within } \\
24 \text { hours of } \\
\text { TMS) }\end{array}$ & Endpoint & $\begin{array}{l}\text { Mogg } \\
2005\end{array}$ & 77.4 & 20.3 & 8 & 51.4 & 14.9 & 9 & $26.00[8.89$ to 43.11$]$ \\
\hline $\begin{array}{l}\text { Stroop test } \\
(2 \\
\text { weeks after } \\
\text { TMS) }\end{array}$ & Endpoint & $\begin{array}{l}\text { Mogg } \\
2005\end{array}$ & 88.2 & 12.3 & 8 & 60.8 & 6.4 & 9 & 27.40 [17.91 to 36.89$]$ \\
\hline $\begin{array}{l}\text { Trail mak- } \\
\text { ing test } A\end{array}$ & Change & Guse 2013 & 0.64 & 15.08 & 14 & -11.92 & 29.27 & 12 & $12.56[-5.79$ to 30.91$]$ \\
\hline $\begin{array}{l}\text { Trail mak- } \\
\text { ing test } B\end{array}$ & Change & Guse 2013 & -0.54 & 28.41 & 13 & -5.64 & 20.31 & 11 & $5.10[-14.46$ to 24.66$]$ \\
\hline $\begin{array}{l}\text { Ver- } \\
\text { bal fluency } \\
\text { test (high = } \\
\text { poor) }\end{array}$ & Endpoint & $\begin{array}{l}\text { Zheng } \\
2012\end{array}$ & 24.2 & 9.2542 & 38 & 24.5 & 6.6 & 17 & $-0.30[-4.60$ to 4.00$]$ \\
\hline $\begin{array}{l}\text { WCST } \\
\text { categories }\end{array}$ & Change & Guse 2013 & 1.58 & 22.2 & 12 & -0.27 & 1.95 & 11 & $1.85[-10.76$ to 14.46$]$ \\
\hline $\begin{array}{l}\text { WCST } \\
\text { categories } \\
\text { for partici- } \\
\text { pants with } \\
\text { WCST } \\
\text { categories } \\
\text { pre < me- } \\
\text { dian }(=4)\end{array}$ & Change & Guse 2013 & 3.33 & 2.58 & 6 & 0.4 & 2.07 & 5 & $2.93[0.18$ to 5.68$]$ \\
\hline $\begin{array}{l}\text { WCST } \\
\text { persevera- }\end{array}$ & Change & Guse 2013 & -9 & 11.65 & 12 & -19.18 & 27.76 & 11 & $10.18[-7.50$ to 27.86$]$ \\
\hline
\end{tabular}

Transcranial magnetic stimulation (TMS) for schizophrenia (Review)

Copyright () 2015 The Cochrane Collaboration. Published by John Wiley \& Sons, Ltd. 
Table 6. Cognitive outcomes - Prefrontal TMS vs Sham TMS (Continued)

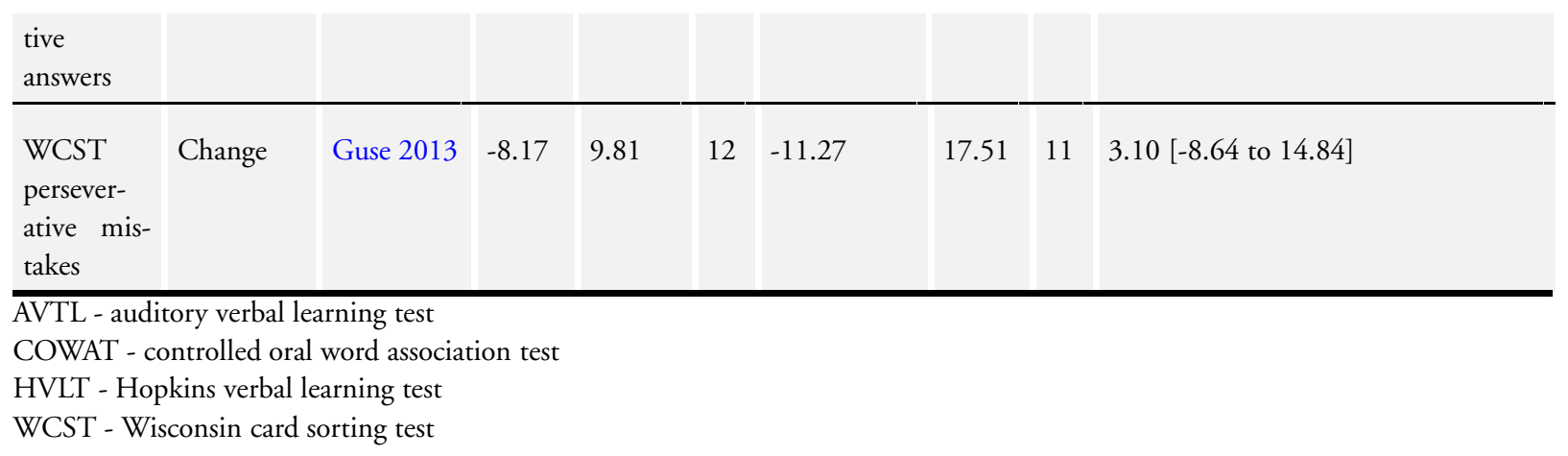

\section{A P P E N D I C E S}

\section{Appendix I. Outcome scales}

\section{Global functioning}

1.1 Clinical Global Impression Scale - CGI (Guy 1976), in De Jesus 2011; Gao 2009a; Guse 2013; Hoffman 2005; Klein 1999; Lee 2005; Liu 2011; NCT00308997; Rosenberg 2012; Saba 2006a. A rating scale which measures severity of illness and clinical improvement based on a seven-point scoring system. A low score indicates overall improvement and reduced illness severity. 1.2 Global Assessment of Functioning - GAF (APA 1987) in Guse 2013.

This scale measures the level of psychological, social, and occupational functioning of psychiatric patients. Possible scores range from 1 to 90 . High scores indicate better functioning.

\section{Mental State}

2.1 Positive and Negative Syndrome Scale - PANSS (Kay 1986), in most (27) of the studies.

A measure of schizophrenia with three subscales, which include severity of general psychopathology, positive symptoms, and negative symptoms. The scale is scored from 30 to 210 , with each item rated on a seven-point scale ranging from absent (1) to severe (7). Higher scores indicate more severe symptoms.

2.2 Auditory Hallucinations Rating Scale - AHRS (Hoffman 2005), in Blumberger 2012; Brunelin 2006; De Jesus 2011; Gao 2009a; Hoffman 2005; Klirova 2010; NCT00308997; Poulet 2005; Rosenberg 2012; Slotema 2011; Vercammen 2009a.

A descriptive measure of the specific characteristics of auditory hallucinations. The scale consists of seven items, which include frequency, reality, loudness, number of voices, length, attentional salience, and distress level. Higher scores indicate more severe symptoms.

2.3 Scale for Assessment of Negative Symptoms - SANS (Andreasen 1983), in Fitzgerald 2008; Hao 2008; Prikryl 2007; Schneider 2008; Zhang 2010.

An instrument to measure change of clinical outcomes in the negative symptoms of schizophrenia. A six-point rating system is used, ranging from absent (0) to severe (5) on measures of alogia, affective blunting, avolition apathy, anhedonia-associality, and attention impairment. Higher scores indicate greater severity of symptoms.

2.4 Scale for Assessment of Positive Symptoms - SAPS (Andreasen 1984), in Brunelin 2006; Hao 2008; Prikryl 2007.

A rating tool designed to measure change of clinical outcomes in the positive symptoms of schizophrenia. Severity is rated from questionable (0) to severe (5). Symptoms are divided into four main categories of hallucinations, delusions, bizarre behaviour and positive formal thought disorder. Higher scores indicate greater severity of symptoms.

Transcranial magnetic stimulation (TMS) for schizophrenia (Review)

Copyright $\odot 2015$ The Cochrane Collaboration. Published by John Wiley \& Sons, Ltd. 
2.5 Brief Psychiatric Rating Scale - BPRS (Overall 1962), in De Jesus 2011; Klein 1999.

A clinical instrument which is used to quantify the severity of various psychiatric symptoms. The scale consists of 18 items, each of which is rated on a seven-point scale from not present (1) to extremely severe (7). Scores range from 18 to 126 , with higher scores indicating greater severity.

2.6 Hamilton Rating Scale for Depression - HDRS/HAMD (Hamilton 1967), in Gao 2009b; Hao 2008; Klein 1999.

A depression rating scale for use in people who have already been diagnosed with a depressive disorder. Scores are based on the interviewer's assessment of 17 items which include depressed mood, suicide, work, loss of interest, agitation, general somatic symptoms, and loss of insight. Higher scores indicate greater severity of depression.

2.7 Psychotic Symptoms Rating Scale - PSYRATS (Haddock 1999), in Blumberger 2012; Slotema 2011.

This consists of two scales, which assess delusional beliefs and auditory hallucinations. There are 11 items in the auditory hallucinations scale, including frequency, duration, level of distress, controllability, loudness, location and beliefs about origin of voices. The delusional beliefs scale has six items, including preoccupation, intensity of distress, conviction and disruption. Each item is rated on a ve-point scale with higher scores indicating greater severity.

2.8 Hallucination Change Scale - HCS (Hoffman 1999) in Blumberger 2012; Fitzgerald 2005; Hoffman 2005; NCT00308997.

This scale consists of a single rating from 0 (no voices) to 20 (greatest severity) of hallucination severity. At baseline, the rating is set to 10 with each patient providing an individual description of the severity of his/her voices.

2.9 Self-rating Depression Scale - SDS (Zung 1965) in Hao 2008.

This is a short self-administered survey to quantify the depressed status of a patient. There are 20 items on the scale that rate the four common characteristics of depression: the pervasive effect, the physiological equivalents, other disturbances, and psychomotor activities. A higher score indicates more severe depression.

2.10 Symptom Checklist - SCL-90 (Derogatis 1973) in Holi 2004.

This self-report questionnaire helps evaluate a broad range of psychological problems and symptoms of psychopathology. The test helps measure nine primary symptom dimensions (somatisation, obsessive-compulsive, interpersonal sensitivity, depression, anxiety, hostility, phobic anxiety, paranoid ideation, psychoticism and a category of "additional items") and is designed to provide an overview of a patient's symptoms and their intensity at a specific point in time. The Global Severity Index (GSI) can be used as a summary of the test and is designed to measure overall psychological distress. High scores indicate more severe symptoms.

2.11 Montgomery-Asberg Depression Rating Scale - MADRS (Montgomery 1979) in Prikryl 2007.

This scale was developed using a 65-item psychopathology scale to identify the 17 most commonly occurring symptoms in primary depressive illness. The maximum score is 30 , and a higher score indicates more severe psychopathology.

\section{Cognitive State}

3.1 Auditory Verbal Learning Test - AVLT (Rey 1964, Rosenberg 1984, Geffen 1994) in Novak 2006.

A tool used to assess competence in various memory domains, which include immediate memory span, recognition, retroactive and proactive interference. The test involves the verbal presentation of 15 words which must be remembered in subsequent consecutive learning trials. Higher scores indicate better memory performance.

\section{Adverse effects}

4.1 Columbia ECT Subjective Side Effects Schedule - CSSES (Sackeim 1987) in Mogg 2005.

A 32-item schedule administered after electroconvulsive therapy to assess subjective side effects reflecting physical complaints, perceived cognitive impairment, and mood-related side effects. A high score indicates more severe side effects.

4.2 Udvalg for Kliniske Undersøgelser Side Effect Rating Scale - UKU (Lingjaerde 1987) in Cordes 2010.

A comprehensive, clinician-rated scale, designed to assess the side effects in people treated with psychotropic medications. The UKU consists of 48 questions. Zero indicates normal; one indicates mild symptoms; two indicates moderate symptoms; and three indicates severe symptoms.

\section{Quality of Life}

5.1 Q-LES-Q (Endicott 1993) in Rosenberg 2012.

This is a self-report measure designed to enable investigators to easily obtain sensitive measures of the degree of enjoyment and satisfaction experienced by subjects in various areas of daily functioning. A low score indicates poor satisfaction.

Transcranial magnetic stimulation (TMS) for schizophrenia (Review)

Copyright @ 2015 The Cochrane Collaboration. Published by John Wiley \& Sons, Ltd. 


\section{CONTRIBUTIONSOFAUTHORS}

Nadine Dougall - read abstracts, study selection, quality assessment for studies from the 2006 and 2008 searches, wrote to authors with missing data queries, data extraction, data entry into RevMan, wrote the protocol, edited and updated the review to Version 5 of RevMan, and edited the final review to incorporate peer-reviewer comments.

Lisa McDermott - converted the protocol to RevMan 5, conducted additional data entry, updated the quality assessments, and helped write the review.

Karla Soares-Weiser and Nicola Maayan - screened studies, quality assessment, data extraction and results for studies included from the 2013 search, 'Summary of findings' tables, and edited the review to incorporate the findings from the 2013 search.

Andrew McIntosh - read abstracts, study selection, quality assessment for studies from 2006 and 2008 searches, wrote to authors with missing data queries, data extraction, data entry into RevMan, and co-wrote the protocol.

\section{DECLARATIONSOF INTEREST}

Nadine Dougall - no conflict of interest to declare.

Lisa McDermott - no conflict of interest to declare.

Karla Soares-Weiser - currently works for Enhance Reviews Ltd, a company that carries out systematic reviews mostly for the public sector. It currently does not provide services for the pharmaceutical industry.

Nicola Maayan - currently works for Enhance Reviews Ltd, a company that carries out systematic reviews mostly for the public sector. It currently does not provide services for the pharmaceutical industry.

Andrew McIntosh - has received research support from Pfizer, Eli Lilly and Janssen, however he has no conflicts of interest to declare in relation to the subject of this review.

\section{SOURCES OF SUPPORT}

\section{Internal sources}

- No sources of support supplied

\section{External sources}

- Gordon Small Charitable Trust for Research in Old Age Psychiatry, UK.

\section{DIFFERENCES BETWEEN PROTOCOLANDREVIEW}

Three new review authors were added to the review (LM, NM, KSW) and one (KPE) was withdrawn.

The protocol was prepared in RevMan 4 with the review converted to RevMan 5 format. There is no substantive difference in the text itself between the protocol and review. However the text was reconfigured to fit under the RevMan 5 sub-headings.

We have updated the sections on Selection of studies, Contributions of authors and Acknowledgements.

'Risk of bias' tables and 'Summary of findings' tables: These were introduced as standard for Cochrane reviews after this protocol was published, see Data extraction and management and Assessment of risk of bias in included studies for the methods used.

Types of outcome measures: The outcome measures published in the protocol were classified into seven categories and made no distinction between primary and secondary outcome measures; primary outcomes were determined by measures of Global state and all other categories were designated secondary outcomes.

Transcranial magnetic stimulation (TMS) for schizophrenia (Review)

Copyright @ 2015 The Cochrane Collaboration. Published by John Wiley \& Sons, Ltd. 
We have added 'Quality of life' as an outcome.

We had planned in the protocol to divide outcomes into immediate (within two hours), short-term (greater than two hours and up to 24 hours) and medium-term (greater than 24 hours and up to two weeks). However, the majority of studies reported only that outcomes were measured after treatment and did not specify exactly how long after treatment, and so we did not classify the data this way.

Measures of treatment effect: For statistically significant results we had planned to calculate the number needed to treat for an additional beneficial outcome/harmful outcome statistic (NNTB/H), and its 95\% confidence interval (CI) using Visual Rx (www.nntonline.net/), taking account of the event rate in the control group. This, however, has been superseded by the 'Summary of findings' tables and calculations therein, and hence we did not estimate this statistic.

Had there been cluster-randomised trials in which clustering was not accounted for in primary studies, we would have presented data in a table, with a $\left(^{*}\right)$ symbol to indicate the presence of a probable unit of analysis error. In subsequent versions of this review we will seek to contact first authors of studies to obtain intra-class correlation coefficients (ICCs) for their clustered data and to adjust for this by using accepted methods (Gulliford 1999). Where clustering had been incorporated into the analysis of primary studies, we would have presented these data as if from a non-cluster randomised study, but adjusted for the clustering effect.

We have sought statistical advice and have been advised that the binary data as presented in a report should be divided by a 'design effect'. This is calculated using the mean number of participants per cluster $(\mathrm{m})$ and the intra-class correlation coefficient [Design effect $=1+(\mathrm{m}-1) *$ ICC] (Donner 2002). If the ICC is not reported we will assume it to be 0.1 (Ukoumunne 1999).

If cluster studies had appropriately analysed their data, taking into account ICCs and relevant data documented in the report, synthesis with other studies would have been possible using the generic inverse variance technique.

Standard deviations: Where there are missing measures of variance for continuous data but an exact standard error (SE) and confidence interval are available for group means, and either the $\mathrm{P}$ value or $\mathrm{t}$ value are available for differences in means, we will calculate them according to the rules described in the Cochrane Handbook (Higgins 2011). When only the standard error is reported, standard deviations (SDs) can be calculated by the formula $\mathrm{SD}=\mathrm{SE}^{*} \sqrt{ }(\mathrm{n})$. Chapters 7.7.3 and 16.1.3 of the Cochrane Handbook (Higgins $2011 b)$ present detailed formulae for estimating SDs from $P$ values, $t$ or F values, confidence intervals, and ranges or other statistics. If these formulae do not apply, we will calculate SDs according to a validated imputation method which is based on the SDs of the other included studies (Furukawa 2006). Some of these imputation strategies can introduce error. The alternative would be to exclude a given study's outcome and thus to lose information. We will nevertheless examine the validity of the imputations in a sensitivity analysis excluding imputed values.

Transcranial magnetic stimulation (TMS) for schizophrenia (Review) 